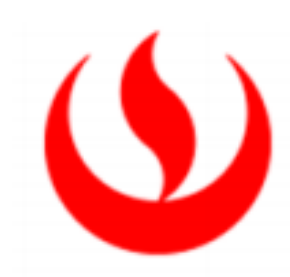

UNIVERSIDAD PERUANA DE CIENCIAS APLICADAS

FACULTAD DE INGENIERÍA

PROGRAMA ACADÉMICO DE INGENIERÍA CIVIL

\title{
USO DE VIGUETAS PRETENSADAS PARA \\ OPTIMIZAR TIEMPO, CALIDAD Y COSTOS EN \\ LA AUTOCONSTRUCCIÓN DE LOSAS \\ ALIGERADAS DE LOS SECTORES C Y D DE \\ LIMA
}

Tesis

Para optar título profesional de Ingeniero civil

AUTOR:

PUICÓN CAMPOS, LIZBETH (0000-0003-3291-5216)

VÁSQUEZ CHÁVEZ, OSCAR (0000-0003-0042-0251)

ASESORA:

ING. ANA TORRE CARRILLO (ㅁ000-0002-4531-4033)

Lima, 29 de noviembre del 2018 


\section{DEDICATORIA}

A nuestros padres y hermanos por ser un pilar fundamental en nuestras vidas, por su incondicional apoyo en todo este tiempo. A nuestros amigos y maestros por su motivación y asesoría constante.

Todo este trabajo ha sido posible gracias a ellos 


\section{AGRADECIMIENTOS}

Queremos agradecer a nuestros padres y hermanos por todo el cariño que nos brindan en cada momento de nuestras vidas. Gracias por todo el sacrificio y apoyo para poder realizar y culminar nuestros estudios.

Gracias a la ingeniera Ana Torre Carrillo y a los ingenieros Máx Torres Rojas y Ennio Morán Nuñez por sus consejos, asesorías y recomendaciones profesionales brindadas durante la realización de nuestra tesis.

Gracias a la empresa VIPRET por brindarnos su apoyo durante la búsqueda de información sobre la vigueta pretensada, gracias a esto pudimos mejorar nuestra investigación.

Gracias a todos los maestros de obra que nos brindaron su apoyo durante nuestra investigación, gracias a sus comentarios pudimos conocer mejor la realidad de la autoconstrucción en Lima y con esto plantear soluciones que se adapten mejor a sus necesidades.

Finalmente, gracias a todas las personas, que de una manera u otra, han sido claves en nuestra vida profesional y personal. 


\section{RESUMEN}

En la presente investigación se realizó un estudio sobre la losa aligerada en la autoconstrucción de los sectores C y D de Lima con la finalidad de identificar el mejor sistema constructivo de losa aligerada para aplicarse en la autoconstrucción de viviendas unifamiliares. Esto tiene su origen a partir de una problemática actual que se tiene en la autoconstrucción de viviendas unifamiliares de Lima, especialmente en la losa, la cual no tiene una adecuada asesoría lo que genera deficiencias estructurales, de calidad y de costo.

Esta investigación desarrolla los tres sistemas de losa aligera con más demanda en la actualidad: el sistema convencional, el sistema de vigueta pretensada y el sistema de vigueta tralicho. Posteriormente, se realizó una evaluación técnica y una evaluación económica de cada sistema en viviendas de los distritos de los Olivos y San Martin de Porres. En la evaluación económica se elaboró un presupuesto para cada sistema con precios actualizados y se tomó en cuenta todas las partidas que intervenían en cada sistema.

Al comparar los tres sistemas se concluyó que la mejor alternativa de losa aligerada es

el sistema de vigueta pretensada, ya que este representa un ahorro de costo directo de $12 \%$ frente a los otros sistemas, $33 \%$ de ahorro en tiempos de ejecución, mejor calidad en el acabado del fondo de losa y una mejor resistencia del concreto $(350 \mathrm{~kg} / \mathrm{cm} 2)$. Como recomendación principal es importante empezar a utilizar sistemas constructivos innovadores que generen beneficios económicos, pero que sobretodo garanticen viviendas seguras.

Palabras clave: Autoconstrucción, pretensado, prefabricado, losa aligerada, viviendas unifamiliares 


\begin{abstract}
In the present investigation a study was made on the lightened slab in the selfconstruction of sectors $\mathrm{C}$ and D of Lima with the purpose of identifying the best construction system of lightened slab to be applied in the self-construction of singlefamily homes. This has its origin from a current problem that is in the self-construction of single-family homes in Lima, especially in the slab, which does not have adequate advice which generates structural deficiencies, quality and cost.
\end{abstract}

This research develops the three slab systems lightens with more demand at present: the conventional system, the prestressed joist system and the tralicho joist system. Subsequently, a technical evaluation and an economic evaluation of each system were carried out in dwellings in the districts of Los Olivos and San Martin de Porres. In the economic evaluation a budget was elaborated for each system with updated prices and all the items that intervened in each system were taken into account.

When comparing the three systems, it was concluded that the best lightened slab alternative is the prestressed joist system, since this represents a direct cost saving of $12 \%$ compared to other systems, $33 \%$ savings in execution times, better quality in the finish of the slab bottom and better concrete strength $(350 \mathrm{~kg} / \mathrm{cm} 2)$. As a main recommendation, it is important to start using innovative construction systems that generate economic benefits, but above all guarantee safe housing.

Keywords: Self-construction, pre-stressed, prefabricated, lightweight slab, singlefamily homes 


\section{INDICE DE CONTENIDO}

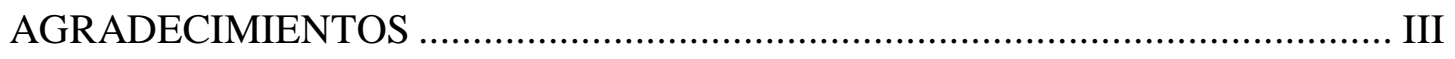

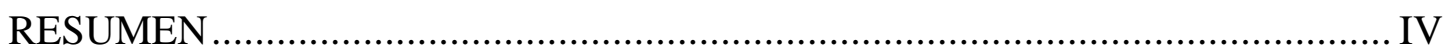

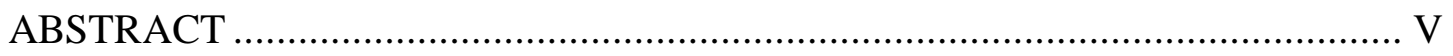

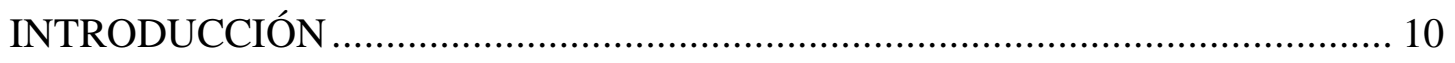

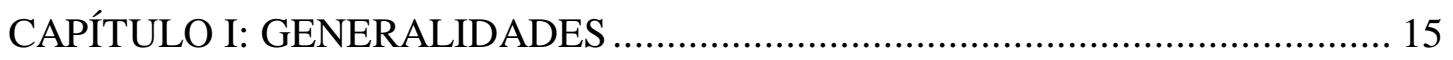

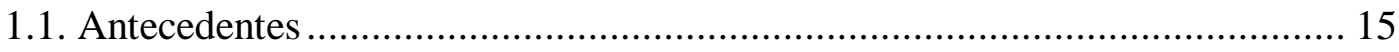

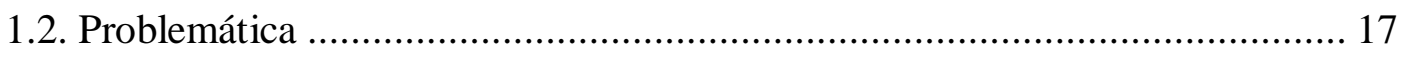

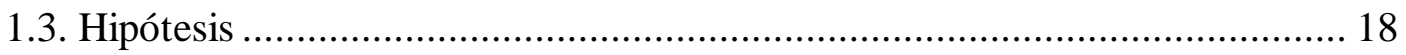

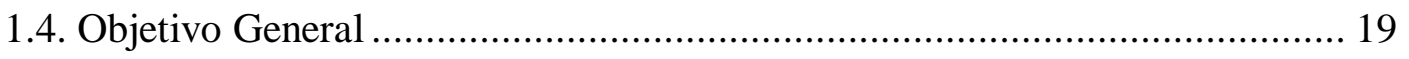

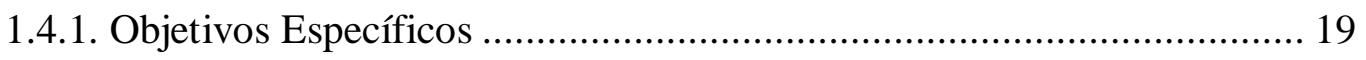

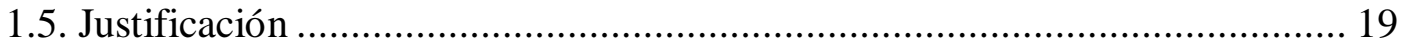

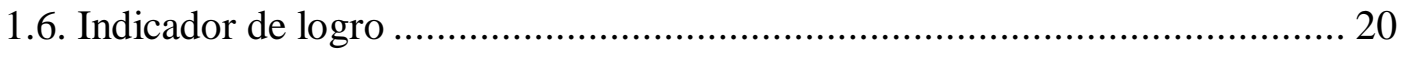

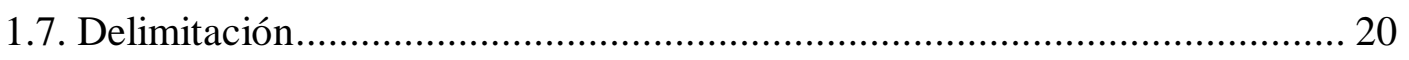

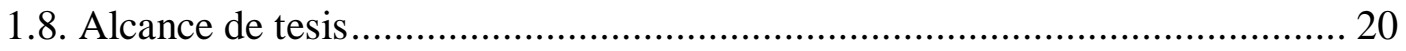

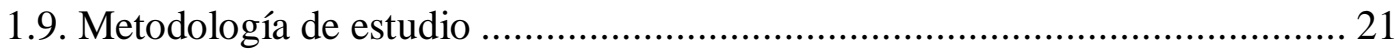

CAPÍTULO II: AUTOCONSTRUCCIÓN EN EL PERÚ Y LIMA

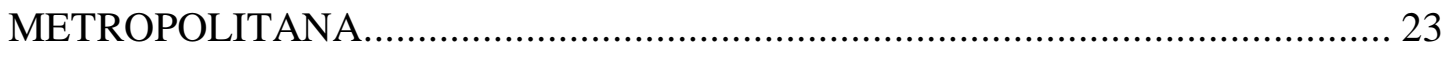

2.1. Situación de la construcción en el Perú y Lima Metropolitana ....................... 23

2.2. Autoconstrucción de viviendas unifamiliares en Lima Metropolitana ........... 27

2.2.1. Malas prácticas en la autoconstrucción ................................................... 28

2.3. Autoconstrucción de losa aligerada de una vivienda unifamiliar ................... 32

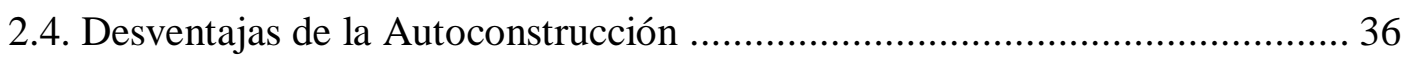

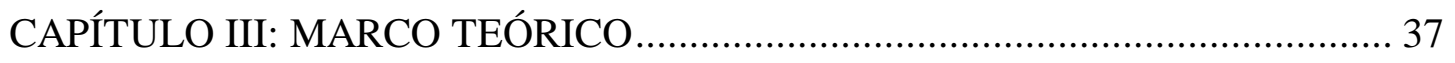

3.1. Industrialización en la Construcción ............................................................... 37

3.2. Prefabricados en la construcción actual ........................................................ 39

3.2.1. Definición de Prefabricado ................................................................. 39 
3.2.2. Tipos de Prefabricados en edificaciones inmobiliarias

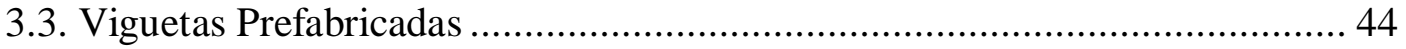

3.3.1. Proceso de Fabricación para la Vigueta Pretensada ............................. 44

3.3.2. Ventajas del uso de viguetas prefabricadas ..................................... 53

CAPÍTULO IV: EVALUACIÓN TÉCNICA DEL SISTEMA DE LOSAS ALIGERADAS CON VIGUETAS PREFABRICADAS Y DEL SISTEMA DE LOSAS ALIGERADAS CONVENCIONALES ............................................ 55

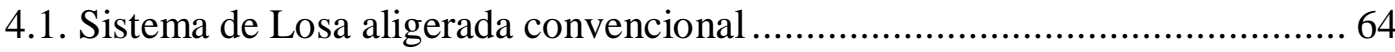

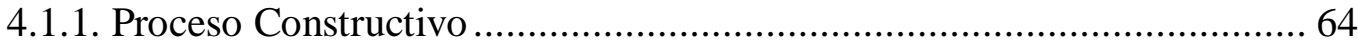

4.1.2. Evaluación Técnica por tiempo de ejecución ....................................... 72

4.1.3. Análisis Técnico por Calidad de Acabado ........................................ 74

4.1.4. Análisis Técnico por Calidad del Concreto ....................................... 75

4.2. Sistema de Losa aligerada con Vigueta Pretensada ................................... 77

4.2.1. Proceso constructivo: .................................................................... 77

4.2.2. Evaluación Técnica por tiempo de ejecución ..................................... 85

4.2.3. Análisis Técnico por Calidad de acabo .............................................. 87

4.2.4. Evaluación Técnica por Calidad del Concreto...................................... 88

4.3. Sistema de Losa aligerada con Vigueta TRALICHO ............................... 92

4.3.1. Proceso Constructivo:................................................................. 93

4.3.2. Análisis Técnico por tiempo de ejecución .......................................... 96

4.3.3. Análisis Técnico por Calidad de acabo ............................................. 97

4.3.4. Evaluación Técnica por Calidad del Concreto...................................... 98

4.4. Comparación Técnica de los 3 Sistemas de Losa ................................... 99

4.4.1. Comparación Técnica por tiempo de Ejecución .................................... 99

4.4.2. Comparación Técnica por Calidad de acabado ................................... 100

4.4.3. Comparación Técnica por Calidad del Concreto .................................. 101

CAPÍTULO V: EVALUACIÓN ECONÓMICA DE LOS SISTEMAS DE LOSAS ALIGERADA: CONVENCIONAL, CON VIGUETA PREFABRICADA VIPRET Y CON VIGUETA PREFABRICADA TRALICHO ......................................... 103

5.1. Sistema de Losa aligerada convencional ........................................... 106

5.2. Sistema de Losa aligerada con Vigueta VIPRET ................................... 116 
5.3. Sistema de Losa aligerada con Vigueta Tralicho ................................. 123

5.4. Comparación Económica de los sistemas evaluados ............................... 128

CAPÍTULO VI: GUIA PRÁCTICA PARA LA CORRECTA APLICACIÓN DE LA VIGUETA PRETENSADA EN UNA VIVIENDA UNIFAMILIAR Y DIFUSIÓN DE UN MANUAL PARA MAESTROS DE OBRA ….......................................... 131

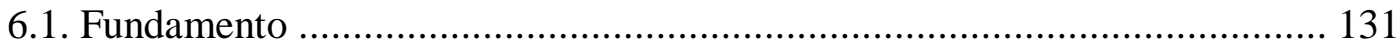

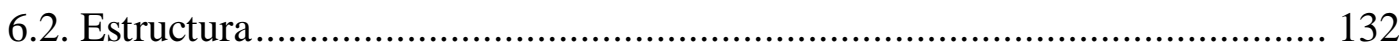

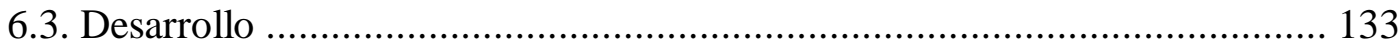

CAPÍTULO VII: CONCLUSIONES............................................................. 140

CAPÍTULO VIII: RECOMENDACIONES ................................................. 141

CAPÍTULO IX: BIBLIOGRAFÍA ............................................................ 142 


\section{INDICE DE TABLAS}

Figura 1: Déficit Habitacional en el Perú 2016 ..................................................... 11

Figura 2: Distribución de hogares según NSE 2017 - Lima Metropolitana ............... 12 Figura 3: Número de créditos del fondo MIVIVIENDA entregados y proyectados hasta

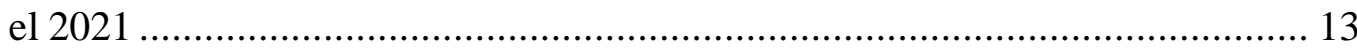

Figura 4: Losa con vigueta de hierro y bovedilla en forma de arco ........................... 16

Figura 5: Corte de techo aligerado con rieles de ferrocarril...................................... 16

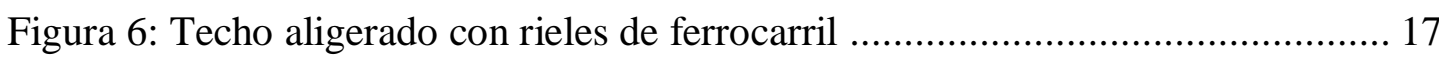

Figura 7: Distribución de Hogares según NSE 2017-Lima sin Callao........................ 18

Figura 8: Variación acumulada de la Producción del sector Construcción 2008-2017 .

Figura 9: Contribución a la variación de la Producción Nacional, según actividad

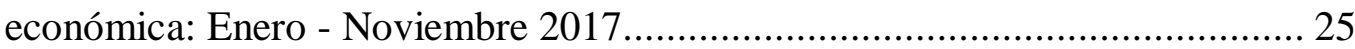

Figura 10: Población peruana estimada entre 2002 y 2017 ( $\mathrm{N}^{\circ}$ Habitantes) ............. 26

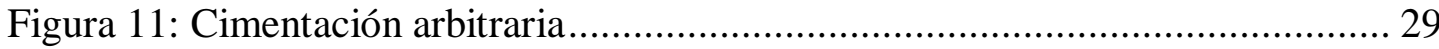

Figura 12: Muro de ladrillo pandereta …………………...................................... 30

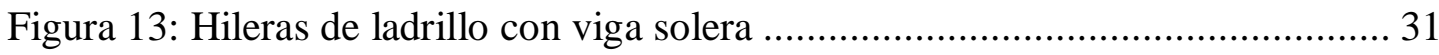

Figura 14: Deficiente calidad del ladrillo................................................................. 31

Figura 15: Encofrado de techo sin supervisión técnica ………………………….... 33

Figura 16: Corrosión de acero en el aligerado....................................................... 34

Figura 17: Caja octogonal ubicada en la vigueta....................................................... 34

Figura 18: Construcción de techo por etapas ........................................................... 35

Figura 19: Mechas de acero expuesto en vivienda. ………………………….......... 35

Figura 20: Fases del sistema industrializado............................................................ 38

Figura 21: Vigas prefabricadas de Viaducto Nicolás Ayllón........................................ 40

Figura 22: Columnas prefabricadas de Planta Cañete ……………………………... 41

Figura 23: Muros prefabricados como cercos perimétricos ....................................... 42

Figura 24: Sistema de vigueta pretensada con bovedilla ........................................... 43 
Figura 25: Sistema de vigueta tralicho con bovedilla ....................................... 43

Figura 26: Limpieza y preparación del molde...................................................... 44

Figura 27: Habilitado y corte de acero para vigueta pretensada ............................ 45

Figura 28: Colocación de acero en el molde ................................................... 46

Figura 29: Colocación de separadores en los moldes ........................................... 46

Figura 30: Colocación de barriletes y cuñas en el acero ..................................... 47

Figura 31: Tensado de acero previo al vaciado del concreto en el molde ................ 47

Figura 32: Distribución del concreto en el molde después del vaciado..................... 48

Figura 33: Vibrado del concreto en el molde .................................................... 49

Figura 34: Eliminación del exceso del concreto y acabados con regla..................... 50

Figura 35: Colocación de ganchos en la vigueta para facilitar su traslado ................ 50

Figura 36: Liberación del acero tensado ...................................................... 51

Figura 37: Desmolde manual del viguetas .................................................... 51

Figura 38: Viguetas recién desmoldadas....................................................... 52

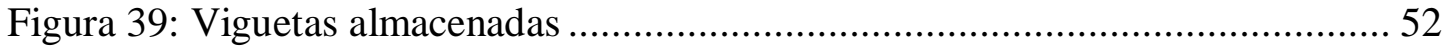

Figura 40: Geometría de una losa aligerada convencional de $1 \mathrm{~m} 2$....................... 56

Figura 41: Geometría de una losa aligerada con viguetas pretensadas de $1 \mathrm{~m} 2$....... 57

Figura 42: Geometría de una losa aligerada ..................................................... 59

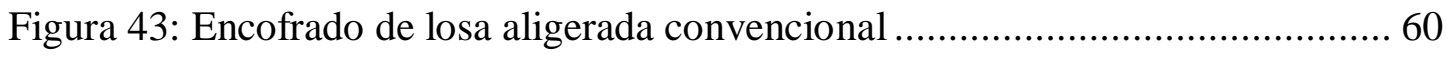

Figura 44: Distribución de encofrado para una losa con viguetas pretensadas .......... 61

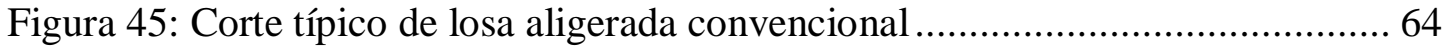

Figura 46: Proceso constructivo del sistema de losa aligerada convencional ............ 64

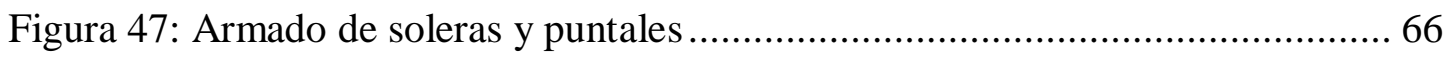

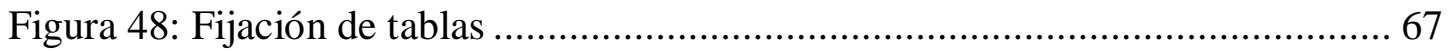

Figura 49: Fijación de tablas en el borde de la losa........................................... 68

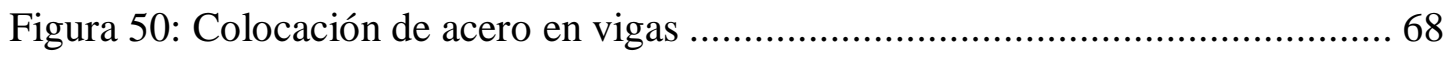

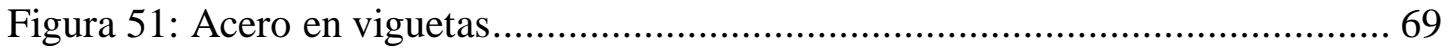

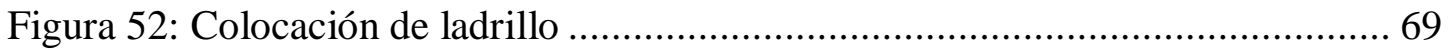

Figura 53: Instalaciones eléctricas en losas aligeradas ..................................... 70

Figura 54: Instalaciones sanitarias en losa aligerada ....................................... 70

Figura 55: Distribución del concreto en la capa a compresión ............................... 71 
Figura 56: Concreto colocado en capa de compresión ...................................... 71

Figura 57: Presencia de cangrejeras en las viguetas ......................................... 74

Figura 58: Desperdicio de madera en la vigueta .......................................... 75

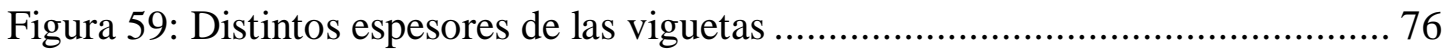

Figura 60: Proceso constructivo sistema de losa aligerada con vigueta pretensada... 77

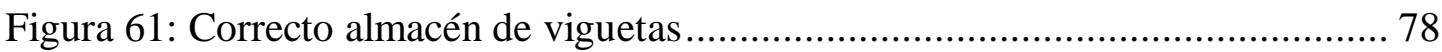

Figura 62: Colocación de soleras y puntales ................................................ 79

Figura 63: Montaje de vigueta pretensada ...................................................... 79

Figura 64: Conexión viga peraltada - vigueta .................................................. 80

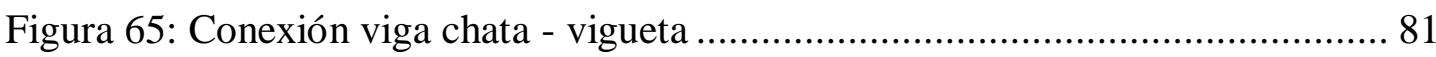

Figura 66: Colocación de bovedillas desde los extremos ................................... 81

Figura 67: Instalaciones eléctricas con viguetas pretensadas .............................. 82

Figura 68: Instalaciones sanitarias con viguetas pretensadas .............................. 83

Figura 69: Malla de temperatura en losa con viguetas pretensadas........................ 83

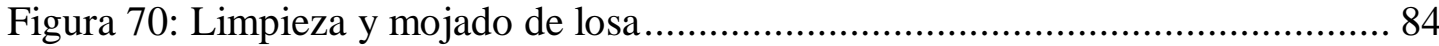

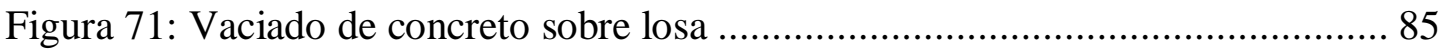

Figura 72: Fondo de losa luego del desencofrado - vigueta pretensada.................. 87

Figura 73: Fondo de losa con vigueta, columna y muro - vigueta prefabricada........ 88

Figura 74: Caso de carga $\mathrm{N}^{\circ} 1$ vigueta pretensada - 425kg/m2 + Peso propio .......... 89

Figura 75: Caso de carga $\mathrm{N}^{\circ} 2$ vigueta pretensada - 680kg/m2 + Peso propio.......... 90

Figura 76: Caso de carga $\mathrm{N}^{\circ} 1$ losa convencional - $680 \mathrm{~kg} / \mathrm{m} 2+$ Peso propio ......... 90

Figura 77: Caso de carga $\mathrm{N}^{\circ} 1$ losa convencional - 425kg/m2 + Peso propio .......... 91

Figura 78: Resultado de ensayo resistencia a la compresión para vigueta pretensada 92

Figura 79: Proceso constructivo sistema de losa aligerada con vigueta Tralicho ...... 93

Figura 80: Colocación de bovedilla ................................................................ 94

Figura 81: Colocado de Instalaciones en sistema Tralicho .................................. 95

Figura 82: Malla de temperatura en armado de losa con viguetas Tralicho ............. 95

Figura 83: Fondo de losa luego del desencofrado con vigueta Tralicho .................. 98

Figura 84: Duración en días por etapas para cada sistema de losa aligerada............ 99

Figura 85: Máxima resistencia del concreto (f’c) por sistema de losa aligerada ..... 101

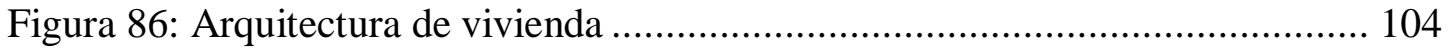


Figura 87: Encofrado de techo para la arquitectura planteada ............................ 105

Figura 88: Pasos para elaborar el presupuesto .............................................. 106

Figura 89: Distribución del acero por vigueta................................................ 107

Figura 90: Distribución del acero en vigas................................................ 109

Figura 91: Presupuesto final por sistema de losa aligerada ............................... 129

Figura 92: Edad de los maestros de obra encuestados ...................................... 134

Figura 93: Años de experiencia de los maestros de obra encuestados ................... 134

Figura 94: Razones por las que no usa el sistema de vigueta pretensada en la construcción de viviendas unifamiliares ..................................................... 136

Figura 95: Lugares donde compraría la vigueta pretensada.............................. 136

Figura 96: Lugares donde se informa sobre nuevos productos constructivos.......... 138

Figura 97: Portada y contenido del manual elaborado...................................... 139 


\section{INDICE DE TABLAS}

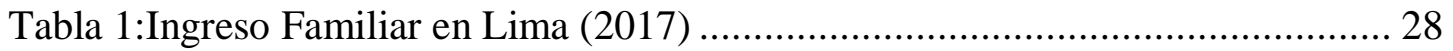

Tabla 2:Dosificación de materiales para edificaciones.............................................. 58

Tabla 3: Consumo de bolsas de cemento en diferentes metrados de losa aligerada de

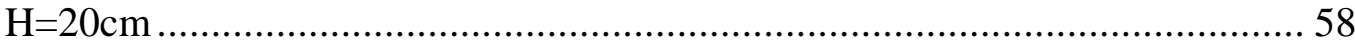

Tabla 4: Consumo de bolsas de cemento en diferentes metrados de losa aligerada de

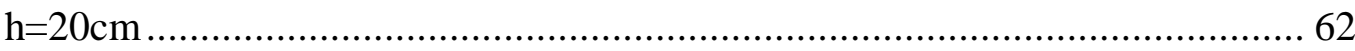

Tabla 5: Resistencia a la compresión de las muestras tomadas ................................ 76

Tabla 6: Comparación fotográfica del acabado de fondo de losa por sistema .......... 100

Tabla 7: Cálculo de la cantidad de acero por vigueta .............................................. 108

Tabla 8: Cálculo de acero longitudinal - Viga 1 ................................................... 110

Tabla 9: Cálculo de acero longitudinal - Viga 2 ……........................................... 111

Tabla 10: Consumo de encofrado por $\mathrm{m} 2$ para una losa convencional .................... 112

Tabla 11: APU de acero en losa - Sistema convencional......................................... 113

Tabla 12: APU de ladrillo de techo en losa - Sistema convencional ........................ 113

Tabla 13: APU de concreto en losa - Sistema convencional ..................................... 114

Tabla 14: APU de encofrado en losa - Sistema convencional................................. 114

Tabla 15: APU de acero en viga - Sistema convencional ...................................... 115

Tabla 16: APU de concreto en vigas - Sistema convencional .................................. 115

Tabla 17: APU de desencofrado en losa - Sistema convencional............................. 116

Tabla 18: Presupuesto final - Sistema convencional................................................ 116

Tabla 19: Cálculo de cantidad de acero por vigueta - Sistema VIPRET …….......... 117

Tabla 20: Consumo de encofrado por $\mathrm{m} 2$ para una losa con vigueta pretensada..... 119

Tabla 21: APU de apuntalamiento y desencofrado - Sistema Vigueta pretensada.. 121

Tabla 22: APU de viguetas pretensadas - Sistema VIPRET …………………….... 121

Tabla 23: APU de bovedilla - Sistema VIPRET ..................................................... 122

Tabla 24: APU de izaje de viguetas pretensadas - Sistema VIPRET ...................... 122

Tabla 25: Presupuesto final - Sistema VIPRET....................................................... 123 
Tabla 26: APU de apuntalamiento y desencofrado - Sistema TRALICHO ............ 126

Tabla 27: APU de vigueta - Sistema TRALICHO .......................................... 127

Tabla 28: APU de bovedilla - Sistema TRALICHO......................................... 127

Tabla 29: APU de izaje de viguetas - Sistema TRALICHO ............................. 127

Tabla 30: Presupuesto final - Sistema TRALICHO .......................................... 128 


\section{INTRODUCCIÓN}

La vivienda representa, de alguna u otra manera, uno de los más relevantes anhelos del ser humano, ya que hace posible satisfacer una necesidad básica de las familias en la sociedad.

En el Perú, el déficit de vivienda es alarmante, esto se debe a que la población se ha incrementado significativamente durante la última década, llegando a ser más de 32 millones de habitantes en el año 2018 (Ipsos, 2018). Del mismo modo, debido al desigual desarrollo del país, Lima Metropolitana representa el centro de privilegios como oportunidades de desarrollo, crecimiento de la actividad industrial, expansión del comercio y desarrollo profesional. Esto ha provocado un incremento sustancial de la población limeña, pues Lima concentra el 32\% de los habitantes peruanos, esto equivale casi 10 millones de habitantes. De esta manera, se agudiza aún más el problema de la falta de vivienda y queda evidenciado en el déficit habitacional para el 2016 que fue de 1.1 millones de viviendas y se detalla mejor en la Figura 1. 
Figura 1: Déficit Habitacional en el Perú 2016

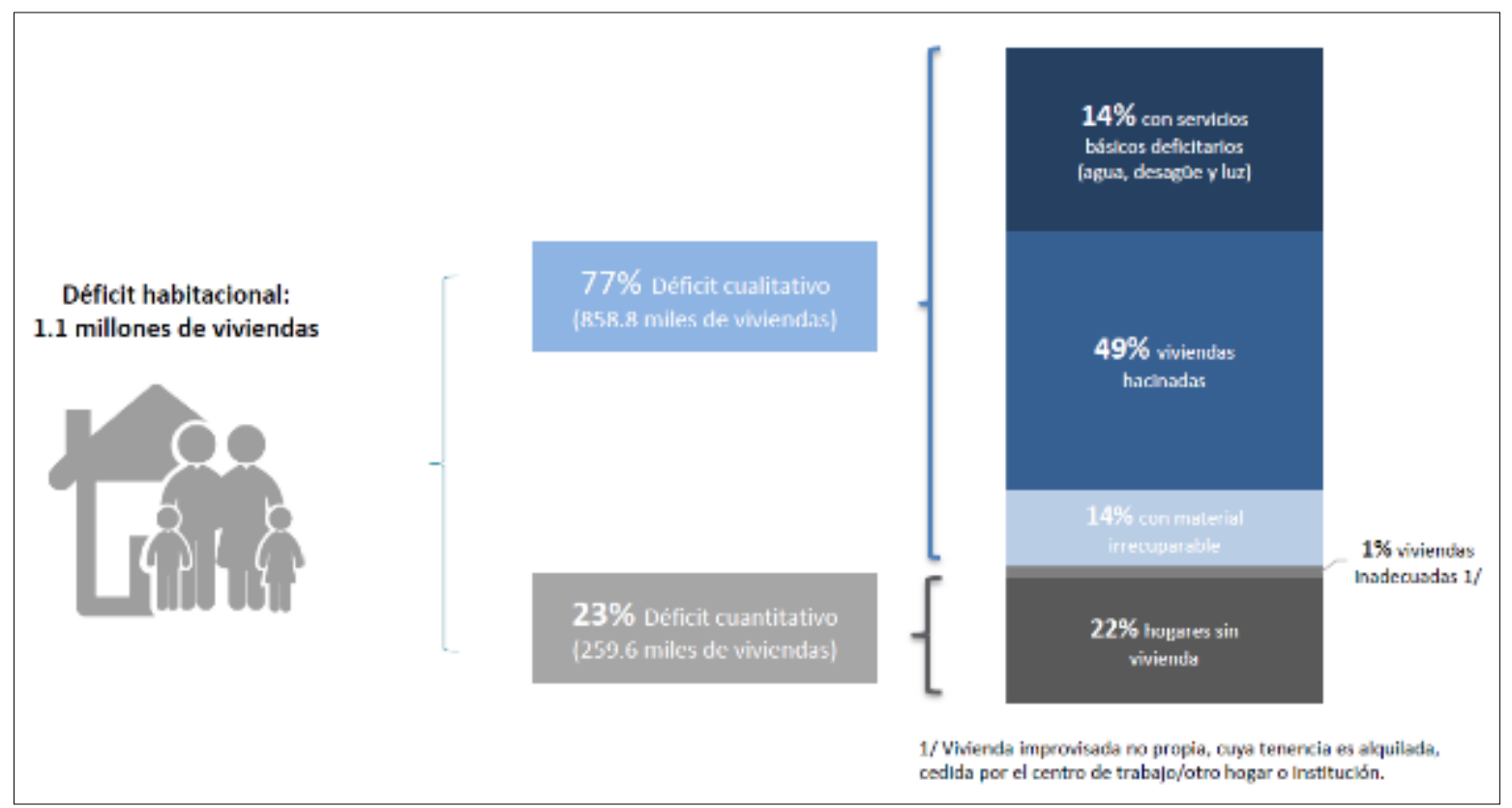

Adaptado de Ministerio de Vivienda, Construcción y Saneamiento (2017)

El déficit cuantitativo de $23 \%$ se refiere a la cantidad de viviendas que se necesitan construir, mientras que el $77 \%$ de déficit cualitativo hace referencia a las viviendas que no cumplen con las condiciones básicas para ser habitadas por deficiencia en materiales de construcción, hacinamiento y acceso a servicios de agua, desagüe y electricidad.

En la Figura 2 se muestra la distribución de hogares en Lima Metropolitana según el Nivel Socio Económico en el 2017. Se puede apreciar que los Niveles Socio Económicos (NSC) C y D representan el 64\% de hogares en Lima. 
Figura 2: Distribución de hogares según NSE 2017 - Lima Metropolitana

\begin{tabular}{|c|c|c|c|c|c|c|}
\hline \multicolumn{3}{|c|}{ № HOGARES 2'713,165 * } & NSE & Estrato & & \\
\hline \multirow[b]{2}{*}{ NSE A } & \multirow[b]{2}{*}{5.0} & & \multirow{2}{*}{ A } & $\mathrm{A} 1$ & 0.8 & \multirow{2}{*}{5.0} \\
\hline & & & & A2 & 4.2 & \\
\hline \multirow{2}{*}{ NSE B } & \multirow{2}{*}{24.4} & \multirow{2}{*}{$70.4 \%$} & \multirow{2}{*}{ B } & B1 & 9.0 & \multirow{2}{*}{24.4} \\
\hline & & & & B2 & 15.4 & \\
\hline \multirow{2}{*}{ NSE C } & \multirow{2}{*}{41.0} & & \multirow{2}{*}{ c } & $\mathrm{C} 1$ & 26.3 & \multirow{2}{*}{41.0} \\
\hline & & & & $\mathrm{C} 2$ & 14.7 & \\
\hline NSE D & 23.3 & & D & D & 23.3 & 23.3 \\
\hline NSE E & 6.3 & & E & $E$ & 6.3 & 6.3 \\
\hline \multicolumn{3}{|c|}{ APEIM 2017} & & & & \\
\hline
\end{tabular}

Adaptado de Asociación Peruana de Empresas de Investigación de Mercados (2017)

Los hogares que pertenecen a los NSE C y D cuentan con un ingreso familiar reducido (según IPSOS de 2000 a 4000 soles al mes), esto sumado al déficit de vivienda generan que la autoconstrucción o construcción informal represente la mejor alternativa para la construcción de la vivienda propia. La construcción sin asesoramiento técnico y/o profesional, llamada autoconstrucción, da lugar a sobrecostos, plazos de ejecución extensos, poca calidad de acabados y sobre todo viviendas inseguras, este es un problema alarmante si se tiene en cuenta que el Perú se sitúa en una zona altamente sísmica.

Actualmente, el estado mediante el Ministerio de Vivienda Construcción y Saneamiento (MVCS) ha intentado resolver el problema de la necesidad de vivienda de los sectores de NSE C y D ofreciendo Programas Sociales, los cuales consisten en créditos hipotecarios a través del Fondo Mi Vivienda, esto se puede apreciar en la Figura 3. Sin embargo, esta alternativa de solución solo es accesible para los hogares que pertenecen al NSE A y B, ya que son estos los que puede acceder a un crédito hipotecario. Además, esta alternativa no plantea una solución para la vivienda insegura; pues, si bien es cierto se cuenta con dinero destinado a la construcción de la vivienda, 
es probable que el poblador no sea asesorado por un técnico o profesional que garantice el adecuado proceso constructivo y calidad de los materiales de la vivienda.

Figura 3: Número de créditos del fondo MIVIVIENDA entregados y proyectados hasta el 2021

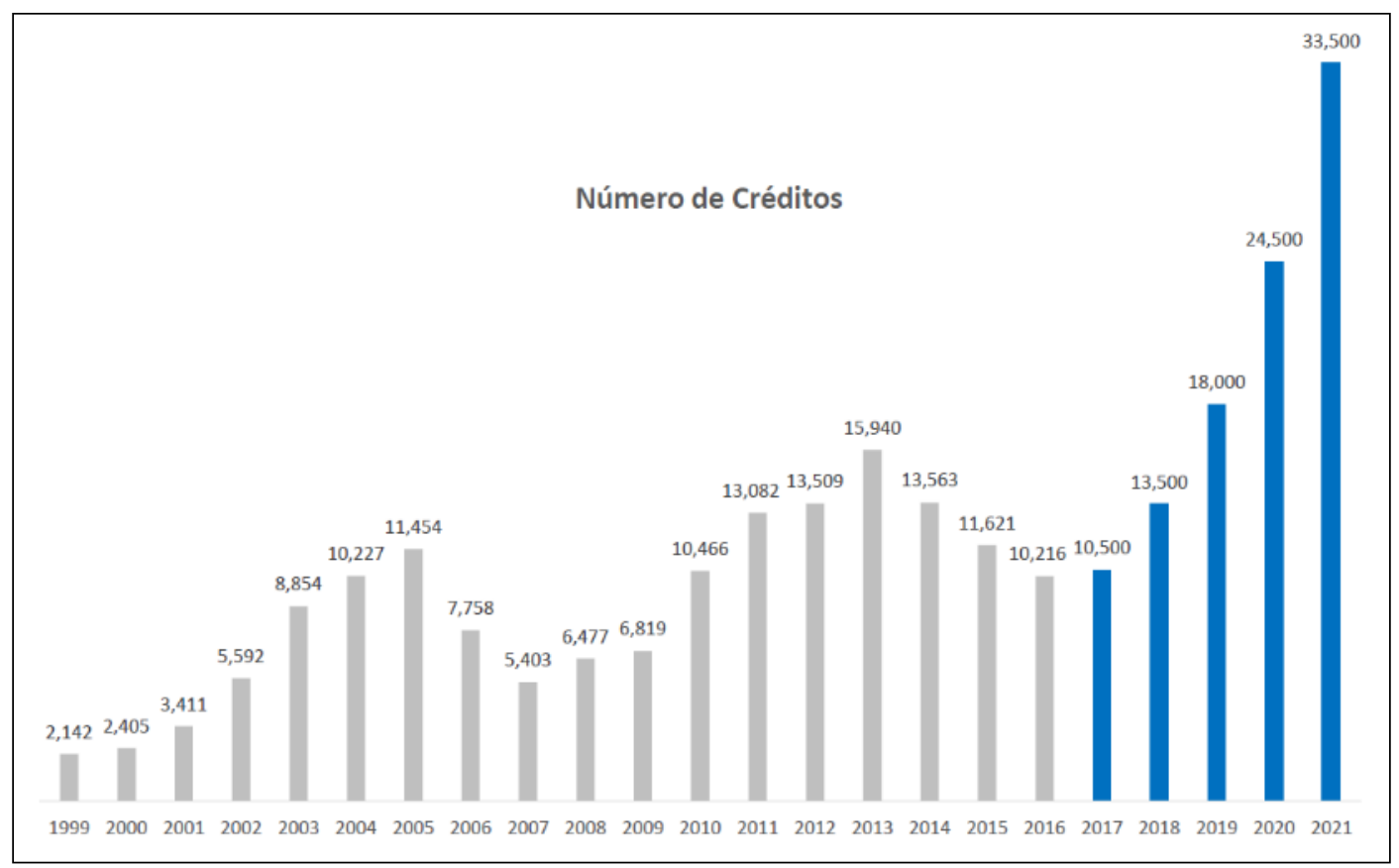

Adaptado de Ministerio de Vivienda, Construcción y Saneamiento (2017)

En los últimos años, las grandes empresas constructoras han desarrollado sistemas constructivos alternativos, se trata de procesos constructivos industrializados; los cuales generan beneficios como reducción de costos, disminución de tiempos de ejecución, mejora de calidad e incluso que protegen el medio ambiente. La mayoría de estos sistemas alternativos están dirigidos a proyectos de gran envergadura, tal es el caso de edificios multifamiliares, edificios de oficinas y centros comerciales; uno de los sistemas constructivos industrializados más utilizados es el sistema que hace uso de elementos prefabricados; es decir, utilizar para la construcción del casco de la estructura elementos como vigas, losas o muros que provienen de fábrica listos para su colocación. Entre estos sistemas ya mencionados se encuentra el sistema de losas aligeradas con viguetas prefabricadas, una alternativa más óptima para la construcción 
de losas o techos, pues permite la ejecución de estas de forma rápida, limpia, además de reducir costos, mejorar calidad en los acabados y garantiza una vivienda segura; esto significa que hacer uso de este sistema constructivo representa una ventaja significativa, en cuanto a ahorro de dinero y tiempo, tanto para el propietario como para el constructor; pues la losa representa el $68 \%$ del presupuesto en la construcción de la vivienda y cualquier ahorro en esta etapa es significativo.

Debido a lo expuesto anteriormente, la presente investigación tiene como objetivo proponer el uso adecuado de las viguetas prefabricadas en la autoconstrucción o construcción informal de losas aligeradas de las viviendas unifamiliares que pertenecen a los Niveles Socio Económicos C y D en Lima. Para conseguir este objetivo, básicamente, se identifica los problemas que se presentan en la autoconstrucción o construcción informal de losas aligeradas convencionales, con el objetivo de reducir las malas prácticas constructivas en la construcción informal; además, se realiza una evaluación técnica de consumo de concreto y encofrado entre estos sistemas, también se ha incluido una evaluación en cuanto a tiempos de ejecución, calidad de acabados y seguridad estructural de estos sistemas. Asimismo, se realiza una evaluación económica de costos unitarios, tanto para el sistema de losa convencional como para el sistema de vigueta pretensada y tralicho. 


\section{CAPÍTULO I: GENERALIDADES}

Este capítulo abarca los puntos generales de la investigación, los antecedentes y la problemática que se pretende solucionar, para esto también se detalla la justificación, indicadores de logro, alcance, metodología, entre otros, para llegar a los resultados esperados en la investigación.

\subsection{Antecedentes}

Según Gestión (2013) el 60\% de las viviendas, en todo el país, son autoconstruidas; es decir, se trata de una parte importante de la población que opta por construir su vivienda y lo más probable es que lo haga sin asesoramiento técnico y/o profesional. El presente estudio motiva la calidad en la construcción a través de procesos industrializados que conduzcan a disminuir la informalidad del sector construcción.

A nivel mundial Custodio (2014) detalla un ejemplo en la Factoría de Salford que fue construida en Manchester en el año 1801 como una de las primeras construcciones en utilizar un sistema de losa aligerada no convencional, en esta construcción se utilizó una vigueta de acero y el edificio representó, para su época, una de las primeras edificaciones de hierro en toda su estructura

Asimismo, uno de los primeros proyectos en los que se usaron viguetas y bovedillas fue en la construcción de la fábrica de hilados de algodón de Philips \& Lee, en donde se usó una viga de hierro en doble T, también se incluyó una especie de bovedilla en forma de arco y un relleno de concreto simple para nivelar la superficie, esto se aprecia mejor en la Figura 4. 
Figura 4: Losa con vigueta de hierro y bovedilla en forma de arco

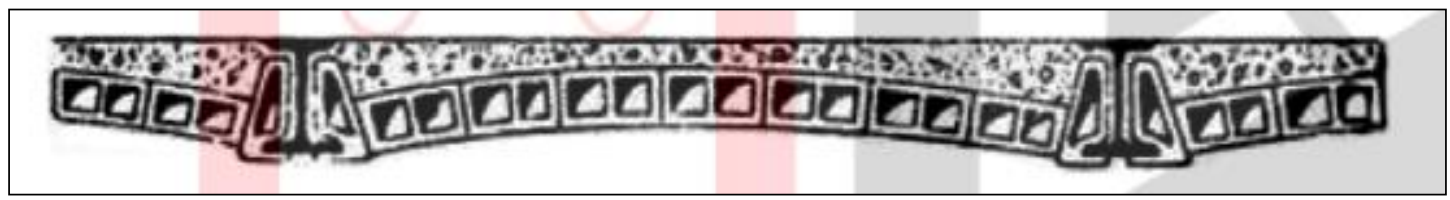

Adaptado de Custodio (2014)

En nuestro país, un proyecto realizado en Arequipa, luego del fuerte sismo del año 1911, contempló la reconstrucción de muchas edificaciones, en las cuales se hizo uso de viguetas de hierro en las losas o techos. Como se muestra en la Figura 5, los techos aligerados se realizaron con rieles de ferrocarril, separados a $80 \mathrm{~cm}$ entre sí, piedra sillar tallados, bovedillas o casetones, la parte superior tiene una mezcla de cal y arena, y por la parte inferior se enlucieron con cal. (Custodio, 2014)

Figura 5: Corte de techo aligerado con rieles de ferrocarril

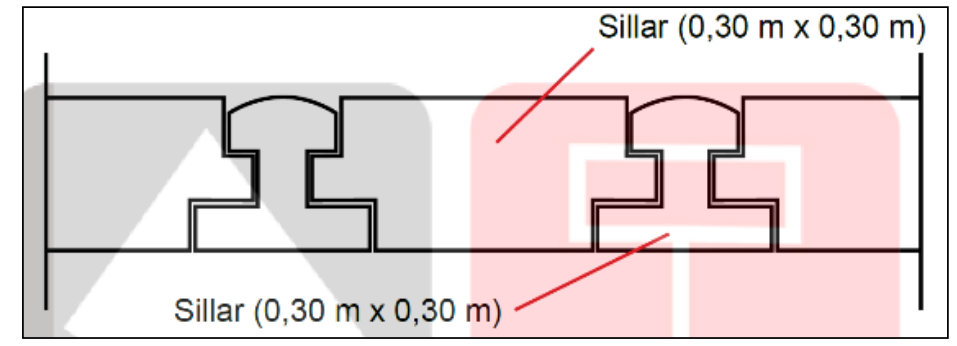

Adaptado de Custodio (2014)

Aún se puede observar estas edificaciones de uno, dos y tres pisos que, en su mayoría, son utilizadas como viviendas, locales comerciales, hoteles, entre otros. Según Custodio (2014) es importante mencionar que estas edificaciones no han sufrido daños, a pesar de los sismos ocurridos, como el de 1960 y 2001, que causaron daños al Centro Histórico de Arequipa, pero sin afectar estas edificaciones que hoy en día se pueden admirar. 
Figura 6: Techo aligerado con rieles de ferrocarril

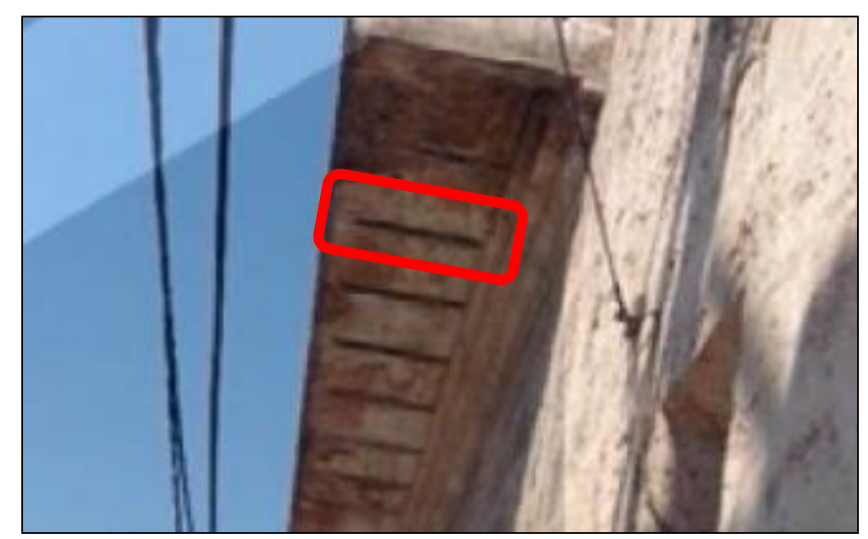

Adaptado de Custodio (2014)

En la Figura 6 se puede observar una de estas edificaciones que hasta hoy continúa de pie, pero que ha empezado a mostrar desgaste en la parte inferior de la losa por lo que el tarrajeo está permitiendo ver el riel de ferrocarril que se utilizó como vigueta en esta vivienda.

\subsection{Problemática}

Por un lado, según SENCICO, el 60\% de viviendas en el Perú son autoconstruidas, esto equivale a 3.6\% del PBI (Gestión, 2013); es decir, un sustancial mercado con un aporte significativo en la economía peruana, puesto que se trata de una actividad económica relacionada con diversas industrias capaces de crear puestos de trabajo para diferentes tipos de personal profesional y técnico.

Por otro lado, la desigualdad de desarrollo en el país, es decir, la falta de oportunidades de desarrollo en las provincias, ha provocado que la población, desde hace muchos años, se concentre en Lima (Compañía Peruana de Estudios de Mercados y Opinión Pública S.A.C., 2017), ya que esta ciudad es símbolo de desarrollo y oportunidades en diferentes ámbitos. Además, el 64\% de la población en Lima pertenece a los niveles socioeconómicos C y D (Asociación Peruana de Empresas de Investigación de Mercados, 2017), lo cual se muestra en la Figura 7. Asimismo, según un estudio de Arellano Marketing (2014), el 75\% de la población Limeña autoconstruye. 
Figura 7: Distribución de Hogares según NSE 2017-Lima sin Callao.

\begin{tabular}{|c|c|c|c|c|c|c|}
\hline \multicolumn{3}{|c|}{$\mathrm{N}^{\circ}$ HOGARES 2' $437,698^{*}$} & NSE & Estrato & & \\
\hline \multirow{2}{*}{ NSE A } & \multirow{2}{*}{5.4} & & \multirow{2}{*}{ A } & A1 & 0.9 & \multirow{2}{*}{5.4} \\
\hline & & & & A2 & 4.5 & \\
\hline \multirow{2}{*}{ NSE $B$} & \multirow{2}{*}{24.8} & \multirow{2}{*}{$-70.7 \%$} & \multirow{2}{*}{ B } & B1 & 9.5 & \multirow{2}{*}{24.8} \\
\hline & & & & B2 & 15.3 & \\
\hline \multirow{2}{*}{ NSE C } & \multirow{2}{*}{40.5} & & \multirow{2}{*}{ c } & C1 & 25.8 & \multirow{2}{*}{40.5} \\
\hline & & & & $\mathrm{C} 2$ & 14.7 & \\
\hline NSE D & 23.3 & & D & D & 23.3 & 23.3 \\
\hline NSE E & \multicolumn{2}{|l|}{6.0} & E & E & 6.0 & 6.0 \\
\hline \multicolumn{3}{|c|}{ APEIM 2017} & & & & \\
\hline
\end{tabular}

Adaptado de Asociación Peruana de Empresas de Investigación de Mercados (2017)

Los pobladores de los hogares pertenecientes a los Niveles Socio Económicos C y D no cuentan con los medios económicos necesarios; por ello, la necesidad de vivienda, en muchos casos, es cubierta de forma arbitraria y muchos pobladores se inclinan por una construcción informal, es decir, una construcción carente de dirección técnica y/o profesional que garantice la calidad y seguridad de la vivienda. A esto se le suma que la losa representa una suma considerable en el presupuesto de construcción de la vivienda, por ello muchas veces los pobladores optan por utilizar otros materiales como eternit o madera de forma provisional; esto genera muchos inconvenientes, ya que, en la mayoría de los casos la losa se hace por paños y esto genera diferentes problemas constructivos.

\subsection{Hipótesis}

Es posible, viable y confiable hacer uso de las viguetas pretensadas para la autoconstrucción de losas aligeradas de viviendas unifamiliares en los sectores socioeconómicos C y D de Lima Metropolitana. 


\subsection{Objetivo General}

Proponer el adecuado uso de viguetas pretensadas en la autoconstrucción o construcción informal de losas aligeradas de viviendas unifamiliares en los sectores socioeconómicos C y D de Lima Metropolitana.

\subsubsection{Objetivos Específicos}

Conocer la situación actual y el aporte económico del sector construcción en el Perú e identificar la situación de la autoconstrucción o construcción informal en Lima e identificar los problemas que se presentan en la autoconstrucción o construcción informal de una losa aligerada convencional de una vivienda unifamiliar.

Realizar una evaluación técnica en viviendas unifamiliares sobre el consumo de concreto y de encofrado por metro cuadrado entre el sistema de losa convencional el sistema de vigueta pretensada. También una comparación en cuanto tiempo de ejecución, calidad del acabado y seguridad estructural entre el sistema de losa aligerada convencional, sistema de vigueta pretensada y sistema de vigueta tralicho.

Realizar una evaluación económica de costos unitarios en viviendas unifamiliares con sistema de losas aligeradas convencional, sistema de losas aligeradas con viguetas pretensada y sistema de losa aligerada con vigueta tralicho.

Analizar los resultados obtenidos en los tres sistemas de losas aligeradas en viviendas unifamiliares para elegir el mejor a aplicarse en viviendas unifamiliares de los sectores C y D de Lima.

Elaborar un guía que ayude a la correcta aplicación del mejor sistema de losa aligerada en una vivienda unifamiliar de los sectores C y D de Lima.

\subsection{Justificación}

La vivienda define las condiciones en las que vive la población; por ello, resulta necesario implementar y generar nuevas tecnologías en la autoconstrucción de viviendas unifamiliares en Lima, específicamente de la losa. Es importante resaltar que 
es necesario empezar a reducir y suprimir las malas prácticas constructivas que ponen en riesgo a una parte importante de la población, ya que existe una cantidad importante de viviendas construidas de manera informal. Asimismo, debido a que la losa o techo representa una parte importante del presupuesto de la vivienda, es importante dar a conocer los nuevos sistemas de losas aligeradas empleados en países desarrollados en la construcción de viviendas unifamiliares, esto permite ingresar a la autoconstrucción o construcción informal en el autoconstrucción sostenible. Con ello es posible lograr mejorar calidad de trabajos hechos en una losa aligerada usando viguetas prefabricadas en el sistema constructivo frente al sistema de losa aligerada convencional. Del mismo modo, con estos nuevos sistemas constructivos es probable reducir costos al optimizar mano de obra, tiempos de ejecución, materiales utilizados en la construcción de una vivienda unifamiliar y generar puestos de trabajo de mano no obra no calificada.

\subsection{Indicador de logro}

Demostrar mediante una evaluación técnica y económica cuál de los sistemas de losas aligeradas, convencional o con viguetas prefabricadas, brinda mejores beneficios tanto económicos como técnicos en la construcción de viviendas unifamiliares de los sectores C y D de Lima.

\subsection{Delimitación}

Para la investigación se ha elegido evaluar las viviendas del cono norte de Lima, específicamente en Los Olivos y San Martín de Porres, distritos que están constituidos por un gran porcentaje de su población que se dedica a autoconstruir sus viviendas en la actualidad.

\subsection{Alcance de tesis}

El presente proyecto de tesis ha realizado una comparación técnica y económica de tres sistemas de losa aligerada aplicados a una vivienda unifamiliar de los sectores $\mathrm{C}$ y D de Lima con el fin de obtener resultados en este sector en específico y determinar cuál 
de estos tres sistemas es el más conveniente de aplicar, tanto en términos técnicos como económicos.

\subsection{Metodología de estudio}

La investigación parte de la necesidad de mejorar e innovar procesos constructivos en la ejecución de la losa aligerada de una vivienda unifamiliar, ya que un gran porcentaje de la población limeña autoconstruye su vivienda (60\%) sin asesoramiento técnico o profesional.

Debido a ello, el presente estudio tiene la finalidad de seleccionar las principales etapas de la construcción de una losa aligerada para describir cada parte de este proceso. El primer paso es comenzar una búsqueda bibliográfica que nos colocará en el contexto de la construccion actual de Lima, especificamente en los sectores $\mathrm{C}$ y D; de este modo conocer más a fondo el proceso de la autoconstrucción de una losa aligerada y las falencias que esta presenta en su ejecución.

Asimismo se considera importante conocer los sectores económicos que existen en Lima, con el objetivo de identificar cuáles son los sectores que optan por autoconstruir actualmente.

Luego se investigará las bases teóricas necesarias que permitan tener en cuenta todas las ventajas y desventajas que tienen los sistemas de prefabricados utilizados en la construcción actual con la finalidad de proponer uno de estos sistemas como solución ante las prácticas convencionales que tiene la autoconstrucción.

Para sustentar que el sistema propuesto es el adecuado se va a realizar una evaluación técnica y económica de la construcción convencional de una losa aligerada y la construcción de la misma con el uso de viguetas prefabricadas (Pretensada y Tralicho) en una vivienda unifamiliar.

Los resultados obtenidos servirán para elaborar un comparativo entre los tres sistemas utilizados con el objetivo de establecer las ventajas y desventajas que tiene un sistema 
frente al otro. Finalmente, se concluirá esta evaluación con un comentario sobre cuál de los sistemas es mejor tanto en la parte económica como técnica.

Para finalizar, se va a elaborar una guia dirigida a los maestros de obra y autoconstructores para la correcta aplicación del sistema de losa aligera propuesto para una vivienda unifamiliar de los sectores C y D de Lima. 


\section{CAPÍTULO II: AUTOCONSTRUCCIÓN EN EL PERÚ Y LIMA METROPOLITANA}

Este capítulo explica la situación del sector construcción en el Perú durante los últimos 10 años y cómo ha ido creciendo la autoconstrucción de viviendas por regiones y por Niveles Socio Económicos, especialmente en Lima. Se finaliza con una recopilación de las malas prácticas que se dan al momento de autoconstruir una vivienda y específicamente en la construcción de la losa aligerada de una vivienda.

\subsection{Situación de la construcción en el Perú y Lima Metropolitana}

El Perú ha experimentado un crecimiento económico sostenido. Asimismo, el sector construcción es considerado como uno de los sectores más importantes en la economía peruana debido a su efecto multiplicador, para Dominguez (2017) "por cada millón de dólares que se inviertan en la construcción se generan 90 empleos directos y 180 indirectos". Para el año 2017, en un reciente estudio del Instituto Nacional de Estadística e Informática (2018), el periodo enero-noviembre, se dio un aumento de $1.29 \%$ en el sector construcción respecto al año anterior, esto ante el avance físico de obras en 7.32\%, ya que se incrementó la inversión del Gobierno Local (12.56\%) y del Gobierno Nacional (7.09\%); por otro lado, en el Gobierno Regional fue de -6.76\%; esto se observa mejor en la Figura 8 que se muestra a continuación. 
Figura 8: Variación acumulada de la Producción del sector Construcción 2008-2017

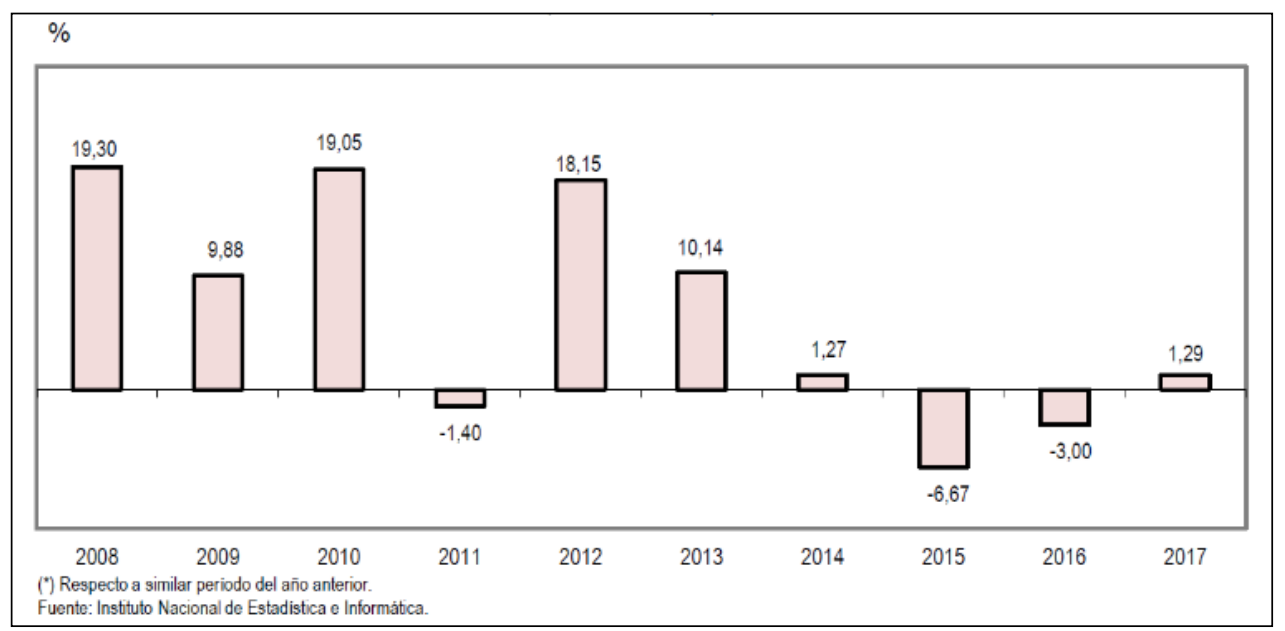

Adaptado de Instituto Nacional de Estadística e Informática (2018)

La figura anterior muestra una variación positiva de $1.29 \%$ en la producción del sector construcción en el 2017 respecto al año anterior, esto se debe a la inversión en Servicios Básicos en Piura, también al crecimiento de infraestructura vial en Lima con las obras de mejoramiento y ampliación en las principales avenidas (Instituto Nacional de Estadística e Informática, 2018)

En la Figura 9 se puede observar que para el periodo enero-noviembre del 2017 el sector construcción registró un aumento de $0.07 \%$ con respecto al año anterior, esto debido a los trabajos de reconstrucción en las regiones más afectadas por el fenómeno del niño, la inversión del Gobierno Nacional en obras de Prevención de Riesgos y con el incremento de obras en Ayacucho con el mejoramiento y ampliación de servicios educativos (Instituto Nacional de Estadística e Informática, 2018). 
Figura 9: Contribución a la variación de la Producción Nacional, según actividad económica: Enero - Noviembre 2017

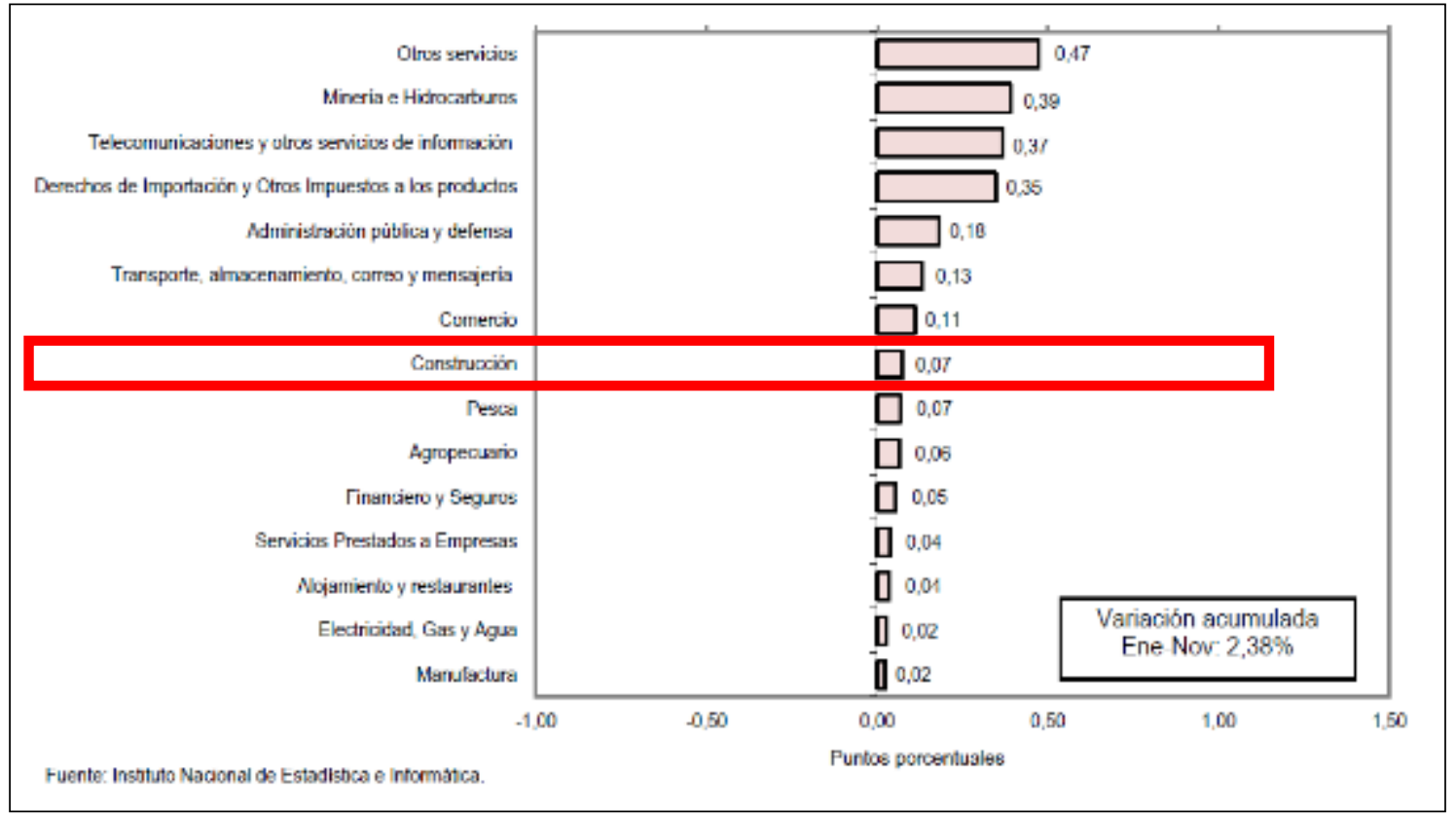

Adaptado de Instituto Nacional de Estadística e Informática (2018)

A pesar de que el consumo interno de cemento disminuyó en $-0.34 \%$ respecto al año anterior, la inversión en diferentes puntos del país han logrado que el sector construcción cierren en cifras positivas como ya se mencionó antes. En Pasco, se instalaron servicios de protección de áreas agrícolas del Rio Chontabamba, en Lambayeque las obras se servicios básicos aumentaron con la construcción de un sistema de agua potable y alcantarillado, al igual que en Piura que se mejoró el sistema de agua potable y en Lima, específicamente San Martín de Porres, la ampliación y mejoramiento del sistema de agua potable (Instituto Nacional de Estadística e Informática, 2018).

Sin embargo, el aumento poblacional y la centralización han acarreado muchos problemas de déficit de viviendas, sobre todo en Lima Metropolitana. En la Figura 10 se puede observar el aumento poblacional en todo el territorio peruano que cuenta actualmente con una población de más de 31 millones de habitantes. 
Figura 10: Población peruana estimada entre 2002 y 2017 ( $N^{\circ}$ Habitantes)

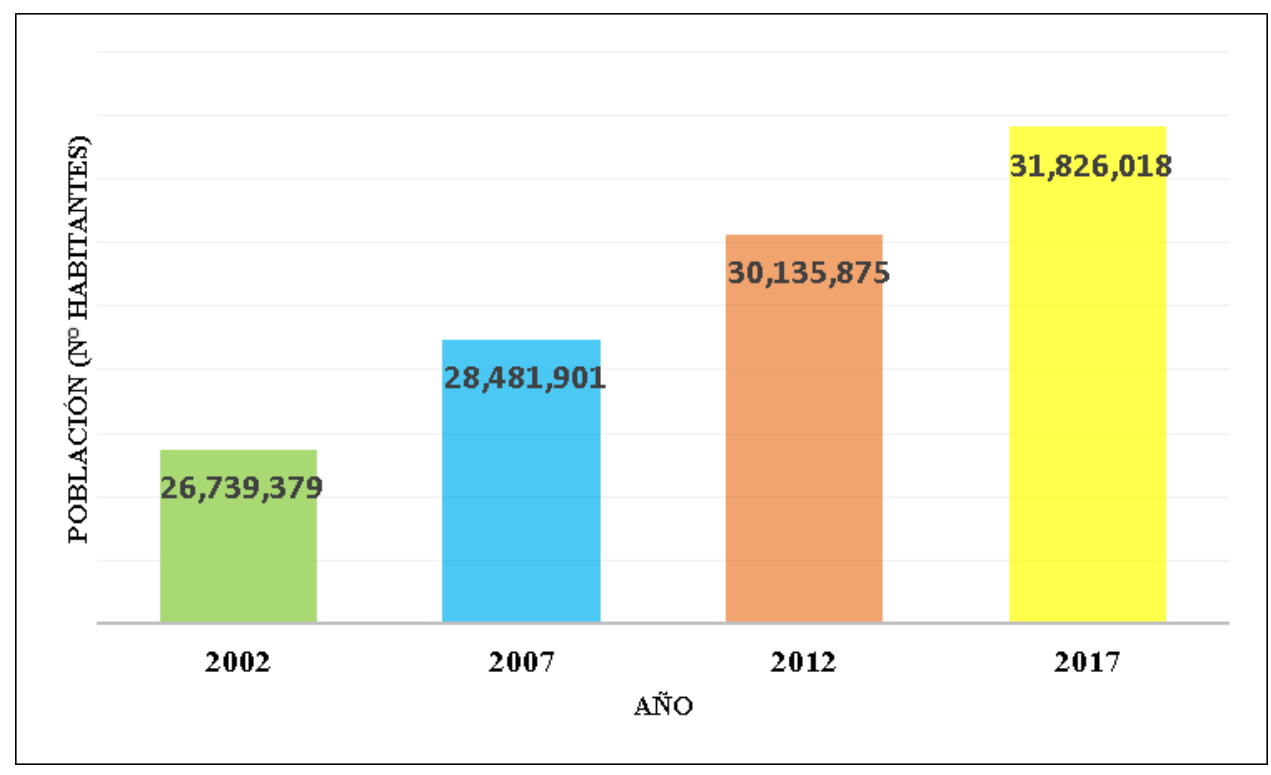

Adaptado de Instituto Nacional de Estadística e Informática (INEI) (s.f.)

De este modo, el déficit habitacional que tiene Lima es el más acentuado en todo el país, ya que se estima que el 32\% de la población total del Perú reside en Lima Metropolitana (Corcuera, 2009).

Este aumento poblacional es preocupante, ya que según el Instituto Nacional de Estadística e Informática (INEI) (s.f.), se estima que para el 2050 se tenga una población de más de 40 millones de habitantes en todo el Perú, quienes necesitarán una vivienda con los servicios básicos para un adecuado nivel de vida, sobretodo en Lima Metropolitana, ciudad que albergará el mayor porcentaje de esta población.

Según el Ministerio del Trabajo y Promoción del Empleo (MTPE) (2014), la construcción en Lima representa el $37.7 \%$ del VAB a nivel nacional, esto se debe principalmente a la creciente demanda de viviendas y a la mayor construcción de obras públicas. Es decir, es importante conocer y monitorear el sector construcción, pues aporta de manera considerable a la economía peruana. 


\subsection{Autoconstrucción de viviendas unifamiliares en Lima Metropolitana}

Se conoce por autoconstrucción al método que utilizan las familias para construir sus viviendas bajo supervisión o dirección propia; generalmente, esto se debe a la situación de escasez de recursos (Lozano, 2011). Desde el punto de vista del usuario, la autoconstrucción es un sistema abierto, permite adaptar la vivienda con su identidad y cultura, además, se puede construir por etapas según los recursos que posea el usuario, es decir no necesita una fuerte cantidad de dinero para empezar a construir. Según Lozano (2011), es indispensable cumplir normas técnicas, sin embargo, en la mayoría de los casos no se cuenta con un diseño definido; por lo tanto, no se utilizan planos; generalmente, se siguen modelos del entorno o en caso contrario poner un sello de

originalidad. Otro punto importante de resaltar en la autoconstrucción es que se ejecuta por un maestro de obra sin una supervisión técnica o profesional, esto se evidencia en la falta de medidas de seguridad en la obra, ya que en la mayoría de los casos no se usa ningún elemento de protección personal o colectiva que proteja a los trabajadores.

Desde el enfoque socioeconómico que tiene Lima se vuelve necesario identificar cuáles son los sectores económicos que optan por la autoconstrucción de sus viviendas. Según la Asociación Peruana de Empresas de Investigación de Mercado (APEIM), la población de Lima y Perú se clasifica en los siguientes estratos socioeconómicos:

Sector A Alto

Sector B Medio

Sector C Bajo Superior

Sector D Bajo Interior

Sector E Marginal

En la Tabla 1 se puede observar los ingresos que perciben las familias limeñas según el sector económico al que pertenecen. 
Tabla 1:Ingreso Familiar en Lima (2017)

\begin{tabular}{|c|c|c|c|}
\hline Niveles & \# de hogares & \% de hogares & $\begin{array}{l}\text { Ingreso Familiar } \\
\text { Promedio en soles }\end{array}$ \\
\hline A & $131 ' 635$ & $5.4 \%$ & $14^{\prime} 205$ \\
\hline B & $604 ’ 549$ & $24.80 \%$ & 7’297 \\
\hline $\mathrm{C}$ & $987^{\prime} 267$ & $40.50 \%$ & 4'193 \\
\hline $\mathrm{D}$ & $567^{\prime} 983$ & $23.30 \%$ & $2 ’ 851$ \\
\hline $\mathrm{E}$ & $146^{\prime} 262$ & $6.00 \%$ & 2’120 \\
\hline Total & 2’437'698 & $100 \%$ & \\
\hline
\end{tabular}

Nota: Adaptado de Asociación Peruana de Empresas de Investigación de Mercados (2017)

En el cuadro anterior se puede notar fácilmente la diferencia que existe entre cada sector socioeconómico respecto a los ingresos familiares. El sector C podrá pensar en adquirir una vivienda con mucho esfuerzo a través de un financiamiento de 25 años, ya que sus posibilidades de ahorro son nulas (Lozano, 2011) En esta misma línea, el sector D tiene una situación más precaria que el sector $\mathrm{C}$, es por esto que generalmente opta por autoconstruir su vivienda.

Si nos enfocados en estos dos sectores (C y D), se puede concluir que el $64 \%$ de la población limeña opta por la autoconstrucción para concretar su deseo de una vivienda propia. Es importante prestarles atención a estas cifras, sobre todo teniendo en cuenta los efectos negativos que acarrea autoconstruir una vivienda en la actualidad.

\subsubsection{Malas prácticas en la autoconstrucción}

Anteriormente se mencionó que la autoconstrucción es una opción por la que opta gran parte de la población limeña para construir su vivienda. Entonces, es importante conocer algunas de las malas prácticas que se dan en la autoconstrucción de viviendas unifamiliares en Lima.

Generalmente no se realiza la limpieza del terreno, esto puede ocasionar que material orgánico, piedras o material sintético como botellas de plástico se mezclen con el 
concreto de la cimentación. Esta actividad la puede realizar cualquier persona, pues no requiere de capacitación alguna, tampoco de herramientas costosas, a pesar de esto los autoconstructores no toman las medidas adecuadas en la construcción de sus viviendas.

Previo a hacer la cimentación, se realiza el trazo con ayuda de algún familiar o vecino, en la mayoría de los casos sin supervisión de mano de obra técnica o profesional, esto genera trazos torcidos, sin niveles que generan muros torcidos, columnas con sección variable, que finalmente terminarán necesitando de una capa de tarrajeo gruesa para nivelar el muro o columna.

Luego, como se muestra en la Figura 11, la profundidad de cimentación es arbitraria a elección del propietario autoconstructor con ayuda del mismo maestro de obra o de sus vecinos. Pese a la importancia que tiene esta etapa, el autoconstructor se deja guiar de la experiencia que tiene el maestro de obra, quien muchas veces sobredimensiona y genera gastos innecesarios para el propietario de la vivienda.

Figura 11: Cimentación arbitraria

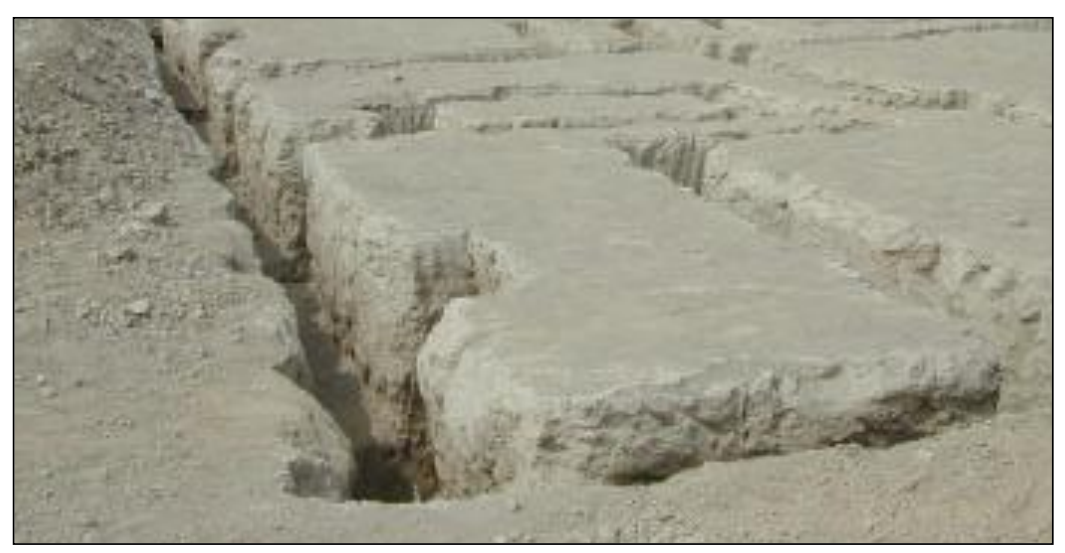

Adaptado de Flores (2002)

En la siguiente etapa, conformación de los muros, estos están constituidos por ladrillo pandereta en lugar de un ladrillo macizo o King-Kong 18 huecos que tienen mayor capacidad portante. En los muros construidos con ladrillo pandereta se presenta una falla frágil y repentina, provocando el colapso en un corto lapso de tiempo después de las primeras grietas producidas por el sismo (Mosqueira \& Tarque, 2005) 
En la Figura 12 se puede observar que el muro que porta la losa aligerada de una vivienda está compuesto por ladrillo pandereta, de este modo se compromete la vida de los ocupantes ante solicitaciones sísmicas.

Figura 12: Muro de ladrillo pandereta

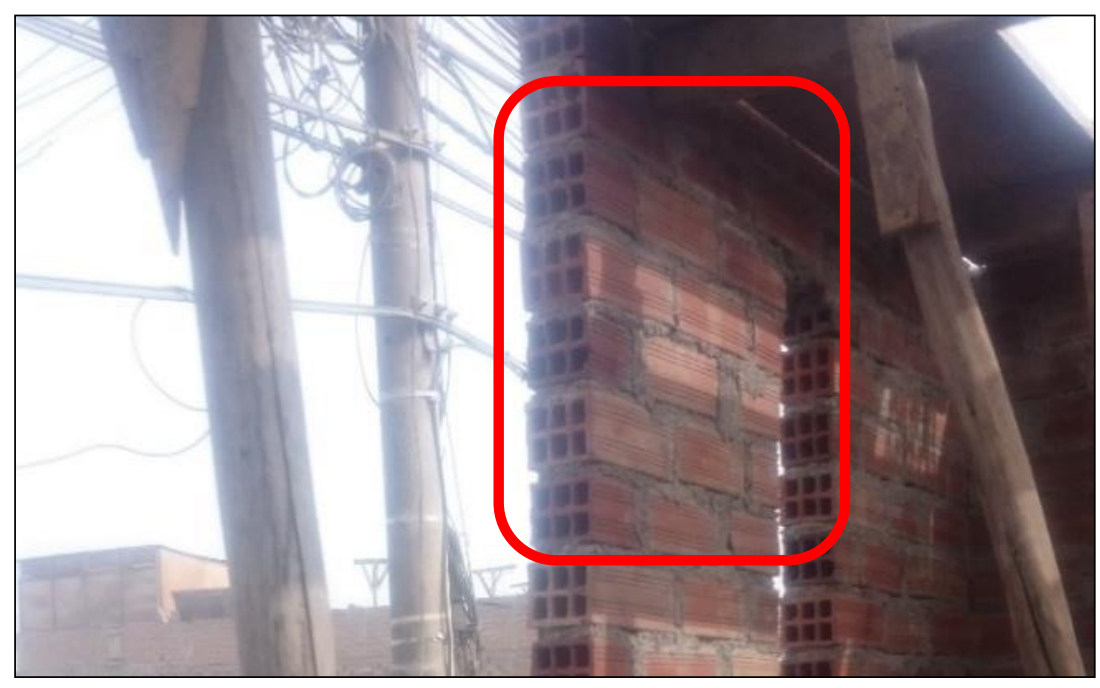

Adaptado de Propia (2016)

Además de este problema, no contar con una mano de obra capacitada en el adecuado asentado de ladrillo para muro puede reducir hasta un $40 \%$ la resistencia al corte que deben tener los muros (Mosqueira \& Tarque, 2005).

Una vez construidos los muros, se procede a continuar con las columnas de amarre que también van a soportar el techo de la vivienda. Según Laucata (2013), en esta etapa, es fácil encontrar al obrero multifacético que se encarga de terminar el asentado de ladrillo, preparar el encofrado y el acero de la columna, actividades que requieren mayor conocimiento técnico.

Antes del techado, algunas viviendas no cuentan con vigas de amarre en la parte superior de los muros, esto se puede observar en la Figura 13. La falta de vigas de amarre ocasiona que el techo y el muro trabajen independientes la una de la otra, lo que haría que las columnas sean sometidas a esfuerzos mayores de los que fueron diseñados (Mosqueira \& Tarque, 2005). 
Figura 13: Hileras de ladrillo con viga solera

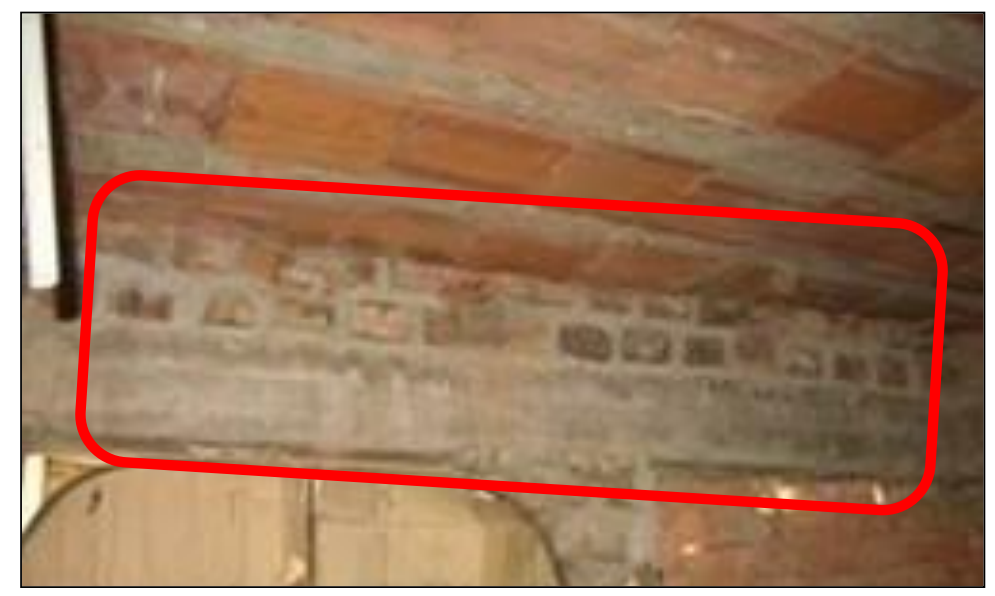

Adaptado de Mosqueira \& Tarque (2005)

Además se pueden mencionar algunas deficiencias en cuanto a los materiales empleados para la autoconstrucción. En la Figura 14 se puede observar el deterioro de ladrillos hechos artesanalmente, según Mosqueira \& Tarque (2005), estos ladrillos son fabricados con mano de obra no calificada y no tienen un proceso adecuado de quemado ni las dimensiones adecuadas.

Figura 14: Deficiente calidad del ladrillo

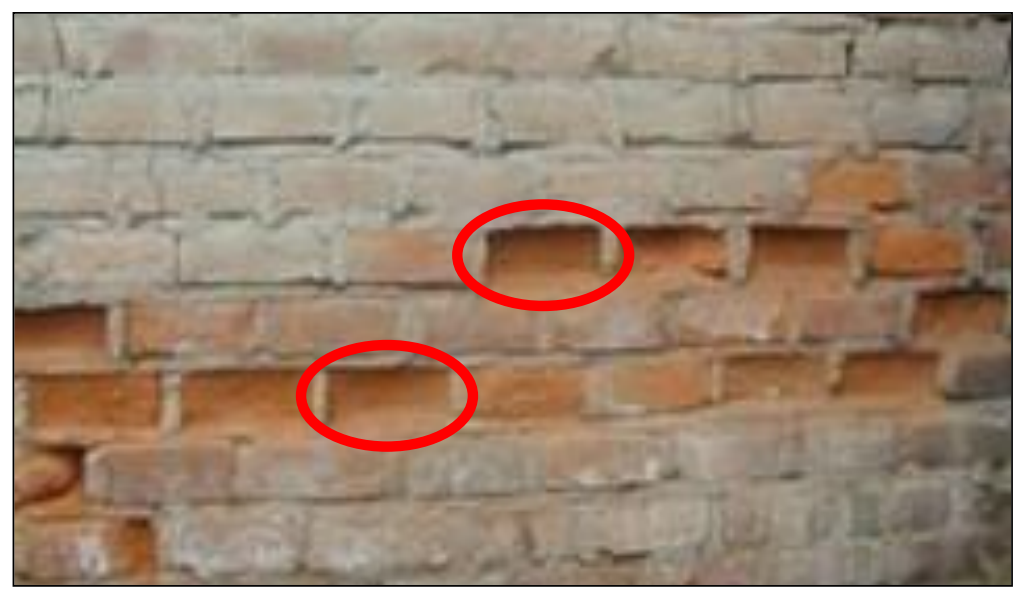

Adaptado de Mosqueira \& Tarque (2005)

Como se ha podido apreciar, dos actores importantes que influyen en el resultado final de una vivienda son la mano de obra y los materiales empleados. Las etapas que se han 
visto son anteriores a la ejecución de la losa aligerada, la cual será abordada con mayor profundidad en el subcapítulo 2.3.

\subsection{Autoconstrucción de losa aligerada de una vivienda unifamiliar}

La losa aligerada es un elemento estructural que se comporta como un diafragma rígido en una edificación, con lo que logra distribuir los cortantes sísmicos para ser absorbidos por los muros y columnas de la vivienda. Teniendo clara la importancia que tiene la losa aligerada, es necesario conocer cuál es el procedimiento que se sigue para su ejecución en la autoconstrucción de una vivienda unifamiliar.

Durante el proceso de autoconstrucción de una vivienda, esta etapa es la que requiere mayor inversión económica para su culminación, el poblador debe contar con el capital suficiente para adquirir los materiales y contratar la mano de obra para el vaciado o, comúnmente llamado, llenado del techo (Flores, 2002).

La mayoría de veces, la mano de obra está conformada por vecinos y algunos operarios que no cuentan con la capacitación necesaria para esta labor, a esto se suma la falta de supervisión de un profesional o técnico capacitado. En la Figura 15 se puede observar la falta de organización en el encofrado de una losa aligerada. 
Figura 15: Encofrado de techo sin supervisión técnica

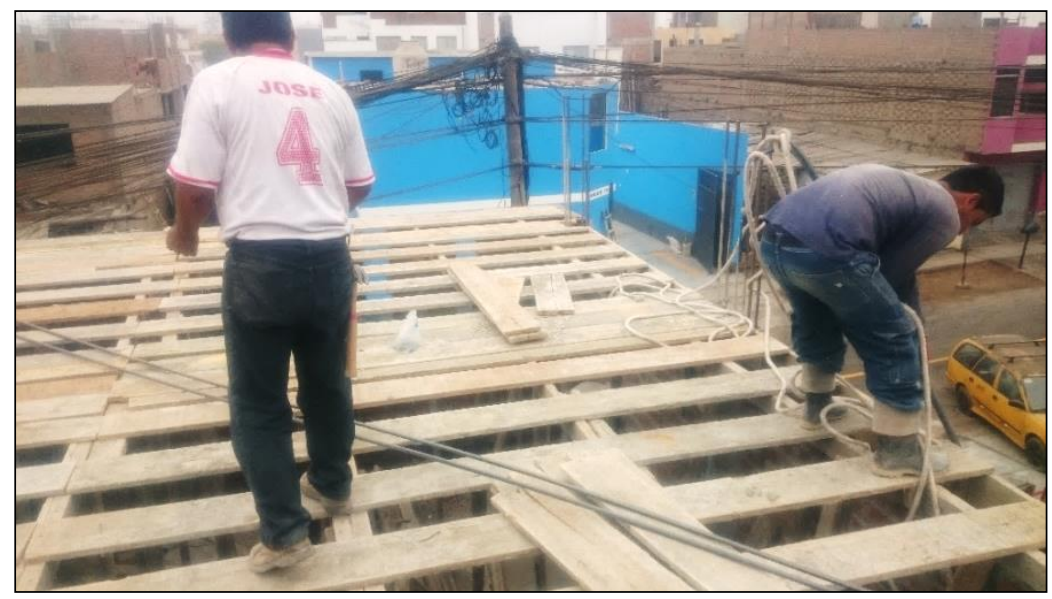

Fuente propia (2016)

Como se puede apreciar en la foto, los obreros no cuentan con los requerimientos mínimos de seguridad establecidos por la norma (Ministerio del Trabajo y Promoción del Empleo, 2010), esto evidencia lo que se definió en la página 27 de esta investigación. Por otro lado, la calidad del trabajo final va a depender de la experiencia y habilidad que tenga el obrero para realizar su labor.

Durante la etapa constructiva, es recomendable tener el falso piso o por lo menos contar con una superficie nivelada y apisonada que sirva para asegurar el encofrado del techo (Mosqueira \& Tarque, 2005). Esta práctica es poco vista en la autoconstrucción, debido a esto es común ver que se usen ladrillos para nivelar el piso donde estarán apoyados los pies derechos.

Otra práctica que reduce el tiempo de vida de la losa es no usar dados o separadores de concreto para garantizar el recubrimiento mínimo de $2 \mathrm{~cm}$ para losas, al no usar dados de concreto el acero longitudinal de las viguetas queda más expuesto a la humedad de la vivienda y presenta oxidación más rápido. En la Figura 16 la oxidació

$\mathrm{n}$ hizo que el tarrajeo del cielo raso se desprenda y que el acero quede expuesto. 
Figura 16: Corrosión de acero en el aligerado

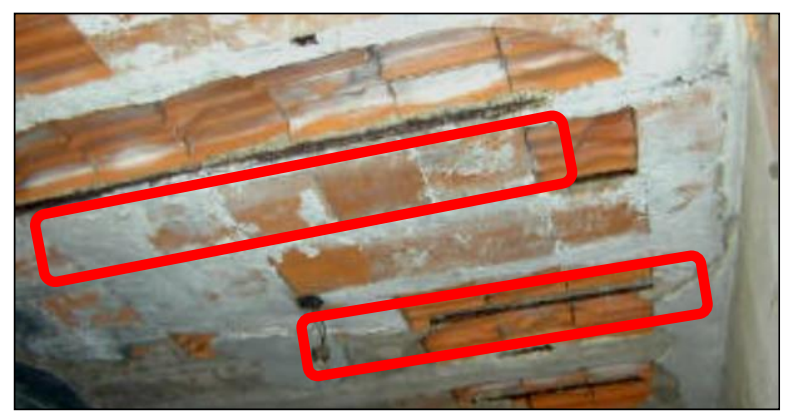

Adaptado de Flores (2002)

Respecto a las instalaciones, es común ver que las cajas octogonales se colocan en los centros de la vigueta, esta mala práctica interrumpe el paso libre del refuerzo de la vigueta (Mosqueira \& Tarque, 2005). En la Figura 17 se observa la salida de luz en el centro de la vigueta del aligerado.

Figura 17: Caja octogonal ubicada en la vigueta

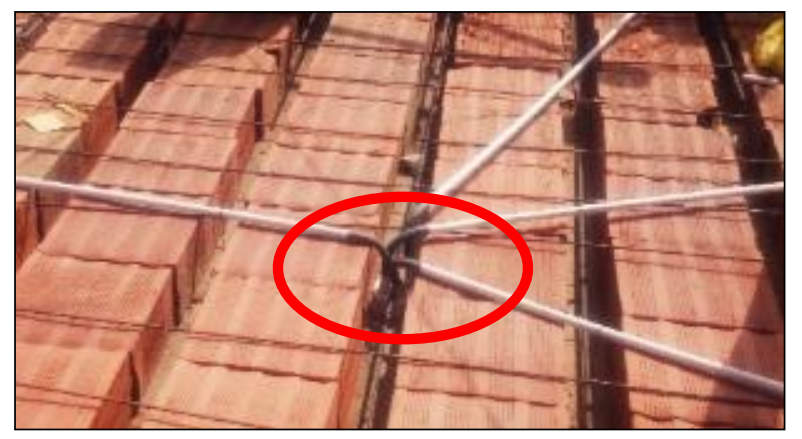

Fuente propia (2016)

Como se indicó al inicio, la construcción de una losa aligerada implica contar con una suma considerable de dinero, para solucionar este problema, se acostumbra hacer el techado por etapas, es decir, una vez hechos los muros se vacían las vigas principales para luego colocar alguna cobertura provisional (Flores, 2002) y después terminar el techo con una losa de concreto. En la Figura 18 se puede apreciar el caso mencionado. 
Figura 18: Construcción de techo por etapas

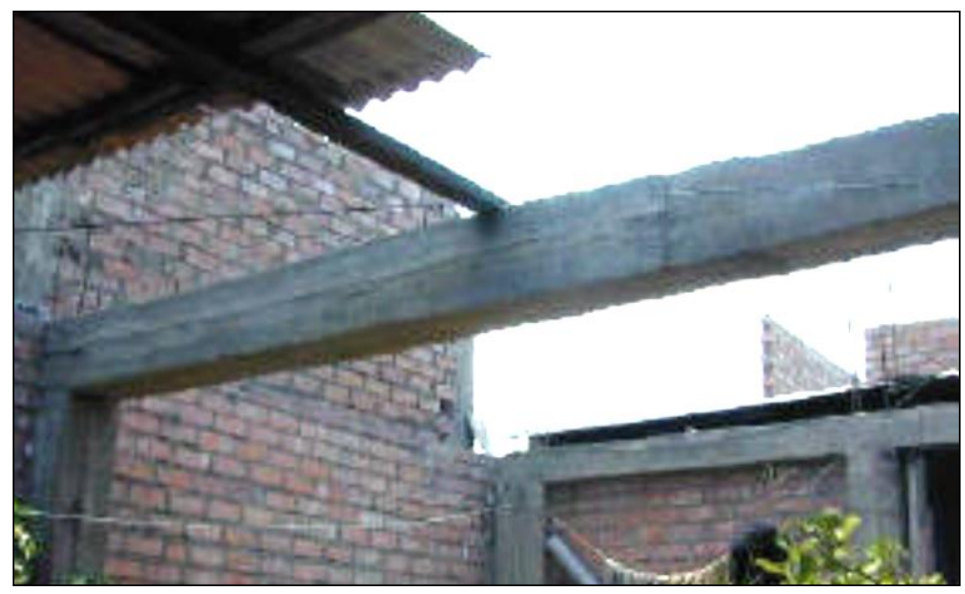

Adaptado de Flores (2002)

La figura anterior evidencia un problema para el futuro de este tipo de construcciones, cuando se quiera completar el techo aligerado, no se logrará que el comportamiento de toda la losa sea como de un solo elemento, sino que cada paño se comporte individualmente ante un posible sismo. En la Figura 19 se puede apreciar otra mala práctica, dejar las mechas de las vigas y columnas expuestas sin ninguna protección.

Figura 19: Mechas de acero expuesto en vivienda.

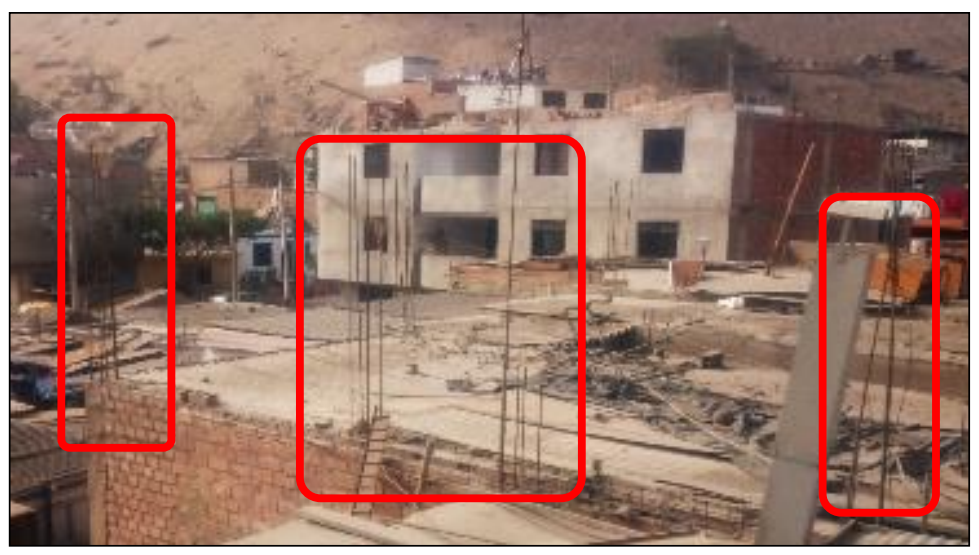

Fuente propia (2016)

Como ya se mencionó, la autoconstrucción de viviendas es un proceso que se da por etapas, por lo cual es común que se dejen expuestas mechas del acero de las columnas, 
las que serán el refuerzo para futuras ampliaciones de la vivienda (Flores, 2002). Como consecuencia de esto, las varillas de acero se oxidan, empiezan a corroerse y perder área transversal, lo que ocasiona mayores trabajos en el caso de que opte por limpiarlos antes de utilizarlos en la construcción de la ampliación de la vivienda.

\subsection{Desventajas de la Autoconstrucción}

\section{Sobrecostos:}

Debido a la mala calidad del encofrado utilizado para el fondo de la losa, el tarrajeo requiere mayores trabajos y materiales, además de ocasionar mayor desperdicio.

Se tiene que comprar mayor cantidad de materiales del que se va a utilizar ya que muchas veces los ladrillos de techo se rompen durante los trabajos, el acero en las losas está sobredimensionado y el concreto se pierde en los ladrillos rotos.

Viviendas inseguras:

Debido a que el techo se llena por tramos, puede que no haya la correcta adherencia entre un paño y otro (concreto viejo con concreto nuevo), el diafragma no actúa como una sola estructura ante evento sísmico.

No se respeta el recubrimiento del acero en las viguetas esto deja vulnerable el trabajo de la losa en futuras solicitaciones.

Mala calidad de acabados

Debido a la mala calidad del encofrado que se utiliza para las viguetas, las tablas presentan irregularidades que ocasionan desniveles en el fondo de losa que al final es difícil solucionar con el tarrajeo. 


\section{CAPÍTULO III: MARCO TEÓRICO}

Este capítulo detalla el marco teórico necesario de la investigación, en la cual se menciona el desarrollo de la construcción industrializada hasta llegar a los prefabricados, entre ellos los prefabricados de concreto para construcción de obras civiles y edificaciones. Finalmente se detalla el proceso de fabricación de una vigueta prefabrica.

\subsection{Industrialización en la Construcción}

La industrialización en la construcción empezó a inicios del siglo XVIII en Europa, la construcción de puentes exigía nuevas tecnologías para su ejecución, por lo que se optó por utilizar elementos prefabricados en su construcción como vigas y columnas prefabricadas (Chang, 2014). Luego de la segunda guerra mundial se impulsó más aun el uso de estos sistemas en la construcción de viviendas para la población que se quedó sin viviendas. A pesar de que utilizar módulos prefabricados ayudó a combatir el problema de la escasez de vivienda, el transporte de los módulos implicaba que estos tuvieran distribuciones de planta inadecuadas y que sus dimensiones sean limitadas. Con el pasar de los años, los sistemas de prefabricación se utilizaron para fabricar componentes de hormigón y acero para la construcción de grandes edificios, dejando la construcción de viviendas a los sistemas tradicionales.

El concepto de industrialización en la construcción de una vivienda está relacionado a procesos, mediante una planificación y presupuesto adecuado, que generan productos que se adaptan fácilmente a las necesidades, generando producción elevada en obra, mejor calidad de los trabajos y un mejor aprovechamiento de los recursos humanos y materiales. 
Según Chang (2014), la construcción industrializada consiste en transformar la construcción de una vivienda en una producción industrial o cadena de montaje, con lo que se busca obtener beneficios económicos y de calidad.

En la Figura 20 se observan las diferentes fases que intervienen para que un sistema industrializado pueda dar los resultados esperados.

Figura 20: Fases del sistema industrializado.

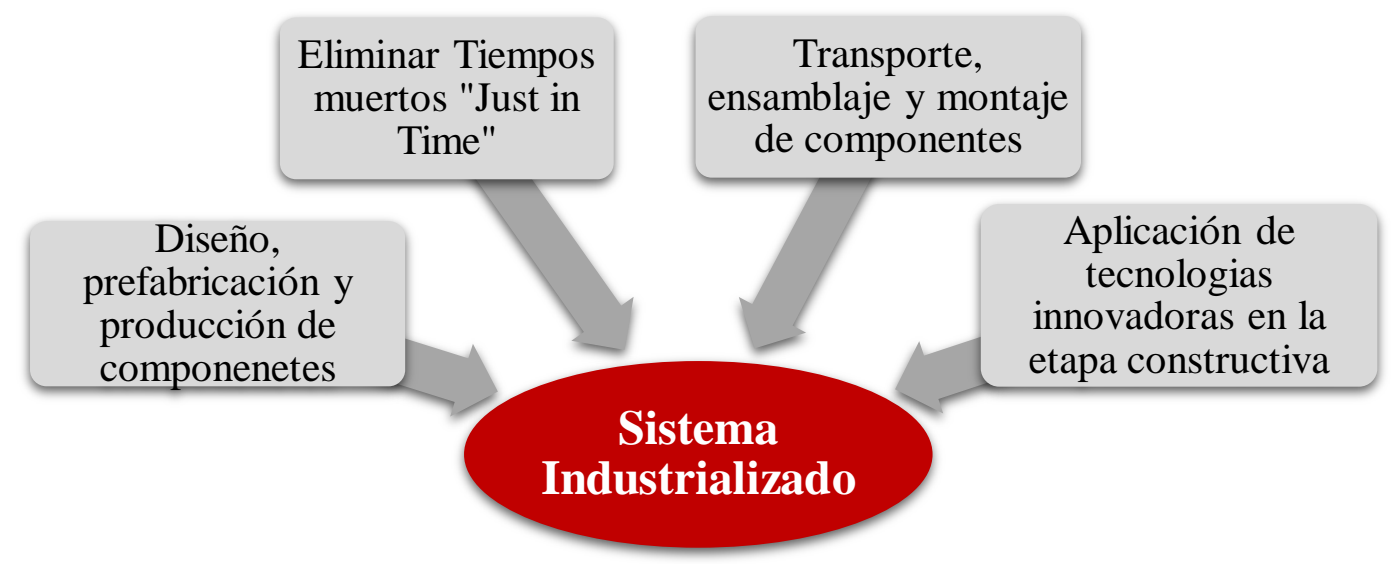

Adaptado de Chang (2014)

Como se aprecia, cada una de las fases de un sistema industrializado ayuda a que este tenga una mayor acogida dentro del sector donde se encuentra. Sin embargo, conseguir que cada una de estas fases se concrete adecuadamente también depende de participantes externos como el mercado, propietario y constructor que deben ser gestionados de manera correcta.

Los factores que ayudan a desarrollar adecuadamente este sistema son: innovación tecnológica, capital para invertir y un mercado que amortice la inversión inicial (Chang, 2014). Este enfoque hace ver que si no se pueden garantizar cualquiera de los factores mencionados el proceso general tiene grandes probabilidades de fracasar. Es por este motivo que se debe buscar el apoyo de entidades públicas y privadas que apoyen estas nuevas tecnologías que van a apareciendo con el fin de sacarle el mayor provecho posible. Con lo dicho en párrafos anteriores, ya se tiene una idea de lo que implica un sistema industrializado en la construcción de una vivienda, pero falta entender lo que 
no es un sistema industrializado. El grado de industrialización que tiene una obra no se define por la perfección de fabricación de sus elementos, sino que, es la forma de emplear estos materiales para obtener un producto lo que le da el carácter de industrializado (Vargas, 2007).

\subsection{Prefabricados en la construcción actual}

\subsubsection{Definición de Prefabricado}

El proceso de prefabricación se puede definir como "la fabricación industrial fuera de la obra de partes de la construcción aptas para ser utilizadas mediante distintas acciones de montaje". En este sentido, según Vargas (2007), se va a considerar que un elemento o sistema prefabricado es aquel que puede ejecutarse en obra (In Situ) o en una fábrica especializada y luego ser trasladada a obra (Producto Industrial).

\subsubsection{Tipos de Prefabricados en edificaciones inmobiliarias}

Esta investigación va a clasificar los prefabricados según la función que cumplen dentro de una edificación, es decir, se van a mencionar los elementos prefabricados de hormigón que se utilizan mayormente en la construcción actual tales como vigas, columnas, muros y elementos de losas prefabricados.

Estos tipos de prefabricados se detallan en la siguiente lista, así como también algunos proyectos en cuales se han utilizado dentro del país.

Vigas Prefabricadas:

La función principal de estos elementos es la de soportar y recibir las cargas de la losa para ser transmitida a las columnas, en el mercado actual se utilizan diferentes formas de viga, según la tarea específica que deba cumplir (Novas, 2010). Por las dimensiones que tienen estos elementos, deben ser transportados por grandes camiones que puedan soportar su peso y una vez en obra su izaje y colocación también tiene que ser con una maquinaria capaz de cargar grandes pesos como una grúa móvil. 
En la Figura 21 se aprecia una serie de vigas prefabricadas que se utilizaron en la construcción del Viaducto Nicolás Ayllón.

Figura 21: Vigas prefabricadas de Viaducto Nicolás Ayllón

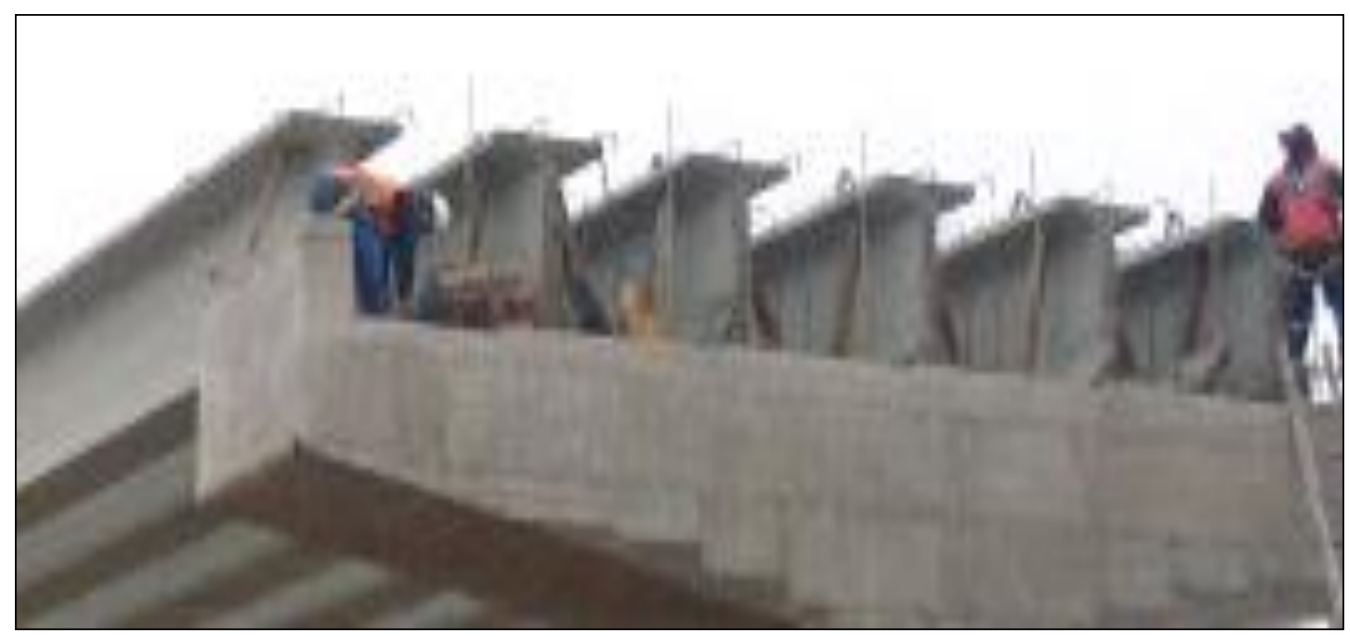

Adaptado de Preansa (s.f.)

Columnas Prefabricadas:

Son elementos estructurales que soportan las cargas desde las vigas en todos los niveles y las transmiten a la cimentación de la edificación. Este tipo de elementos se utilizan mayormente como pilotes. En la Figura 22 se observa un conjunto de columnas prefabricadas en las cuales van a ir apoyadas vigas prefabricadas del proyecto Planta Cañete Productos Tissue del Perú. 
Figura 22: Columnas prefabricadas de Planta Cañete

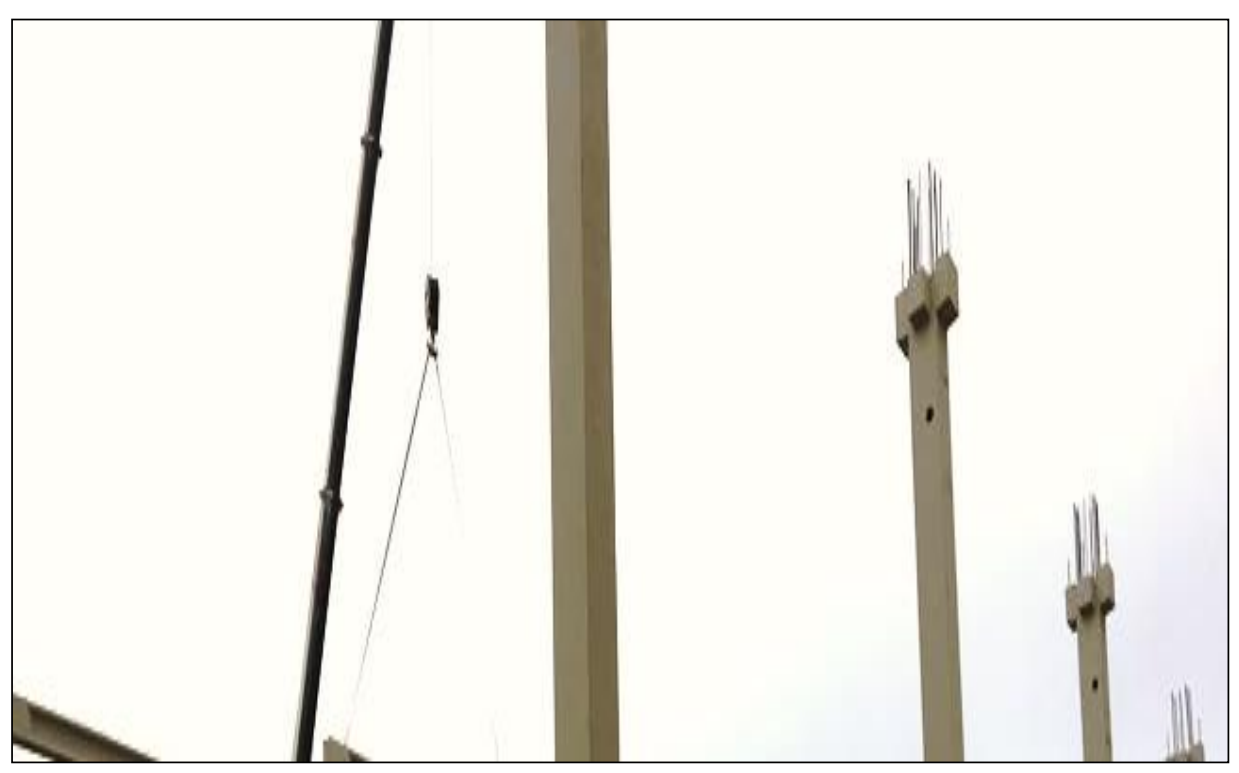

Adaptado de Preansa (s.f.)

Muros Prefabricados:

Generalmente, se utilizan como muros perimetrales para cercar lotes de un terreno. En nuestro país, son cada vez más las empresas que se suman a la producción de muros perimétricos, una de ellas, PRECOM, ofrece varios tipos de estos muros como se aprecia en la Figura 23. 
Figura 23: Muros prefabricados como cercos perimétricos

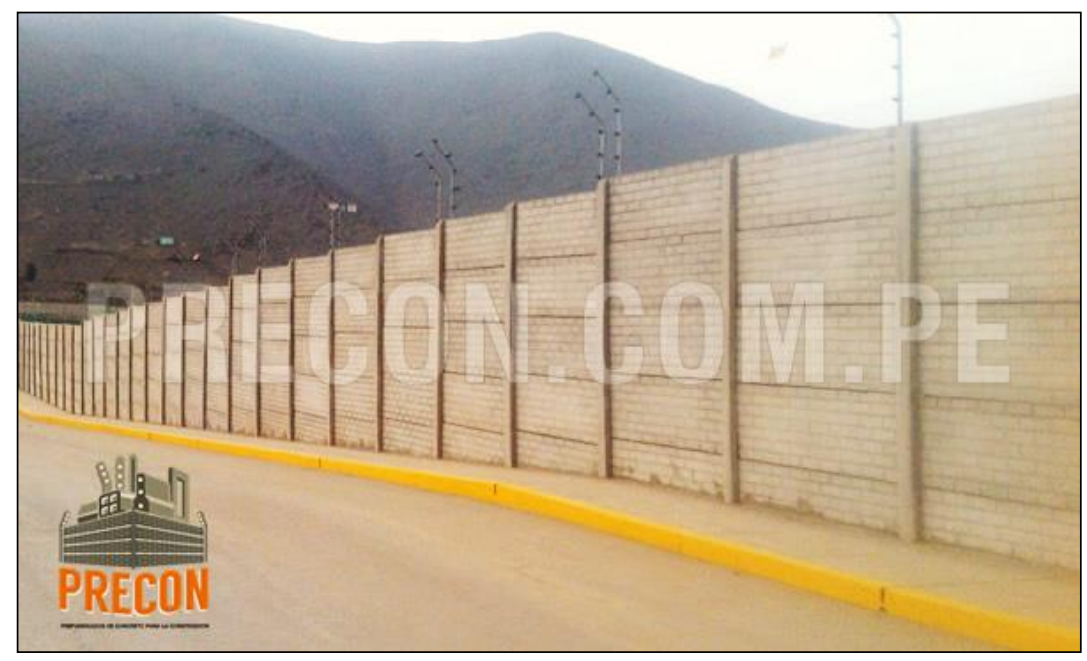

Adaptado de Prefabricados de Concreto para la Construcción (PRECON) (s.f.)

Elementos de Losa:

Para la ejecución de una losa aligerada, existen nuevas tecnologías que ayudan a que su ejecución permita reducir costos de materiales y de mano de obra. Dentro de los elementos que conforman una losa, son las viguetas prefabricadas y las prelosas los elementos con mayor incidencia en el mercado actual.

La primera empresa en comercializar estos elementos fue FIRTH, luego pasó a ser CONCREMAX y ahora pertenecen a UNICON, más adelante al referirnos a estas empresas se debe entender que nos referimos a ambas empresas. Otras empresas en la actualidad son VIPRET en Lima y SUPERMIX en Arequipa. La vigueta pretensada con bovedilla como se aprecia en la Figura 24 está conformado por una vigueta pretensada y un ladrillo tipo bovedilla que se utiliza mayormente en edificaciones de vivienda y oficinas y permite a las constructoras tener mayor productividad en los proyectos que ejecutan y un mejor acabado de la losa. 
Figura 24: Sistema de vigueta pretensada con bovedilla

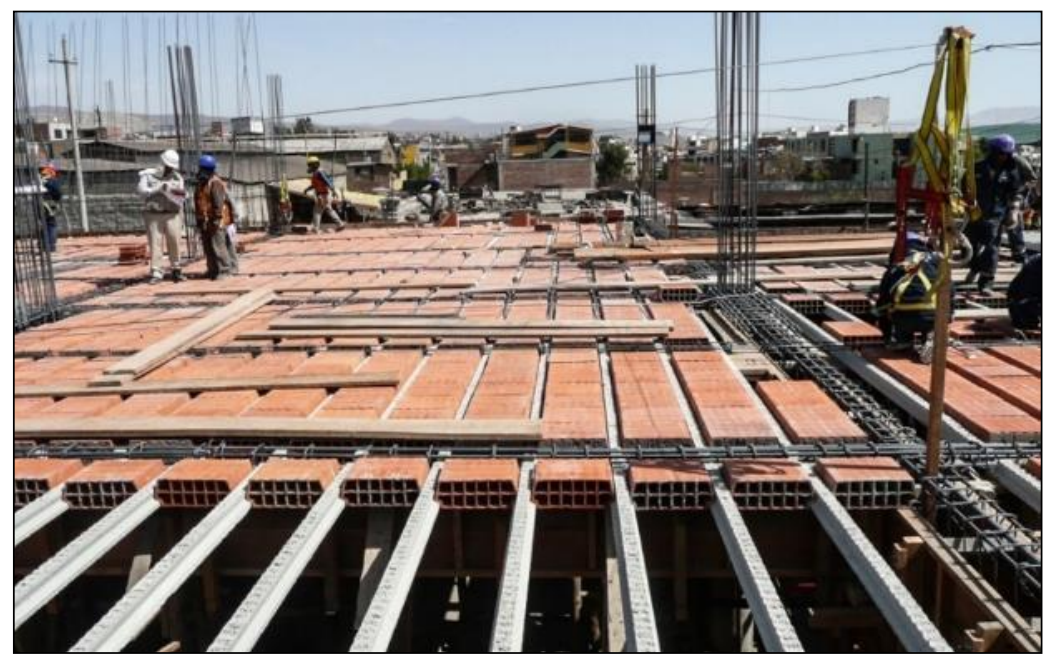

Adaptado de Supermix (s.f.)

En el mercado también existe el tipo de vigueta llamada "Tralicho", que es un tipo de vigueta prefabricada que se utiliza para losas aligeradas en una y dos direcciones. En la Figura 25 se observa la vigueta tralicho junto con las bovedillas en un techo aligerado, como se observa, las bovedillas se colocan empezando desde los extremos para asegurar la colocación del resto de bovedillas.

Figura 25: Sistema de vigueta tralicho con bovedilla

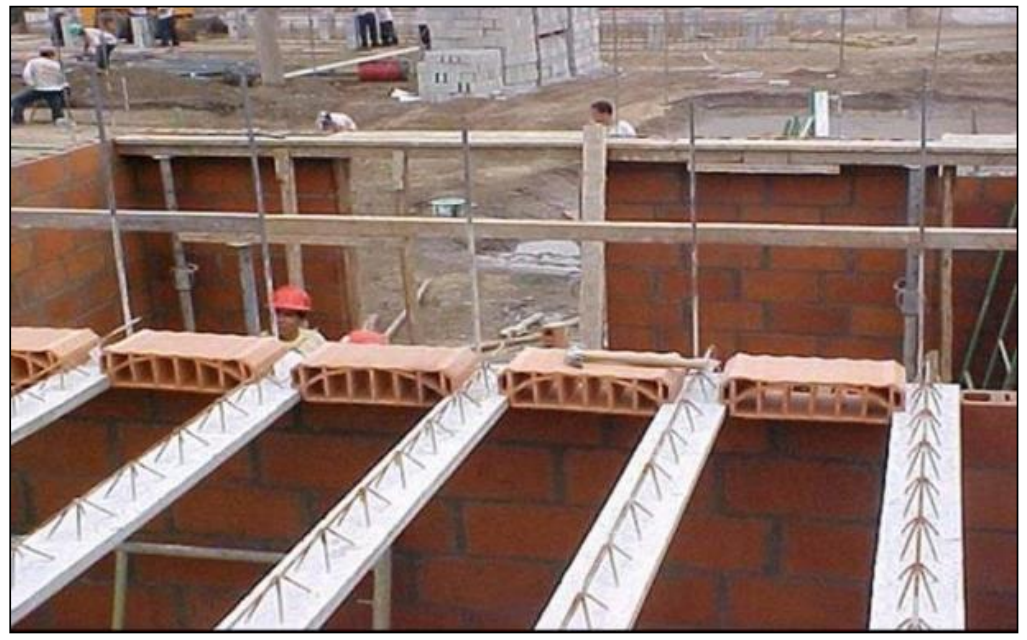

Adaptado de Italconcreto (s.f.) 


\subsection{Viguetas Prefabricadas}

\subsubsection{Proceso de Fabricación para la Vigueta Pretensada}

El proceso de fabricación de las viguetas pretensadas no es uniforme, ya que las fábricas emplean diferentes procesos y maquinarias, esto a su vez depende de la inversión y de la mano de obra con la que cuenta cada empresa. A continuación, se detalla el proceso de fabricación para la vigueta pretensada.

Limpieza y preparación del molde

Esta parte del proceso de fabricación consiste en limpiar el molde previo a la aplicación del desmoldante, ya que es necesario evitar que en el molde haya polvo, basura o algún objeto que pueda dañar el acabado de la vigueta. Es necesario mencionar que el desmoldante se prepara y aplica según lo que indique su ficha técnica. Generalmente, se aplica con un aspersor como se aprecia en la Figura 26.

Figura 26: Limpieza y preparación del molde

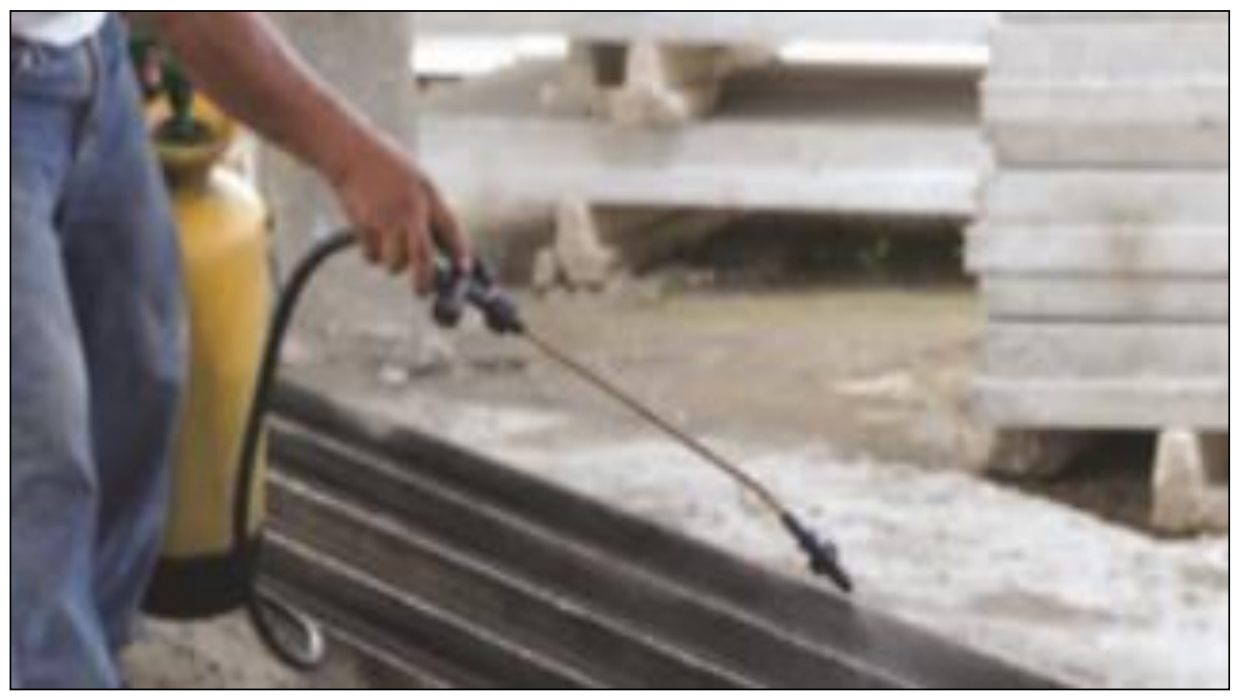

Adaptado de Rivera (2014)

Si bien es cierto este proceso tiene mayor control en el proceso de fabricación, en la figura se puede apreciar la falta de guantes en el operario que está realizando la limpieza 
del molde. Algunas de estas deficiencias en la seguridad de los trabajadores también se pueden ver en las siguientes figuras de todo este proceso.

Corte del acero longitudinal de la vigueta

En esta etapa se corta el acero según la longitud del largo de la mesa más las puntas adicionales en cada uno de los extremos para poder anclar y tensar el acero, esto se puede observar en la Figura 27. Las puntas adicionales van a ser de $1 \mathrm{~m}$.

Figura 27: Habilitado y corte de acero para vigueta pretensada

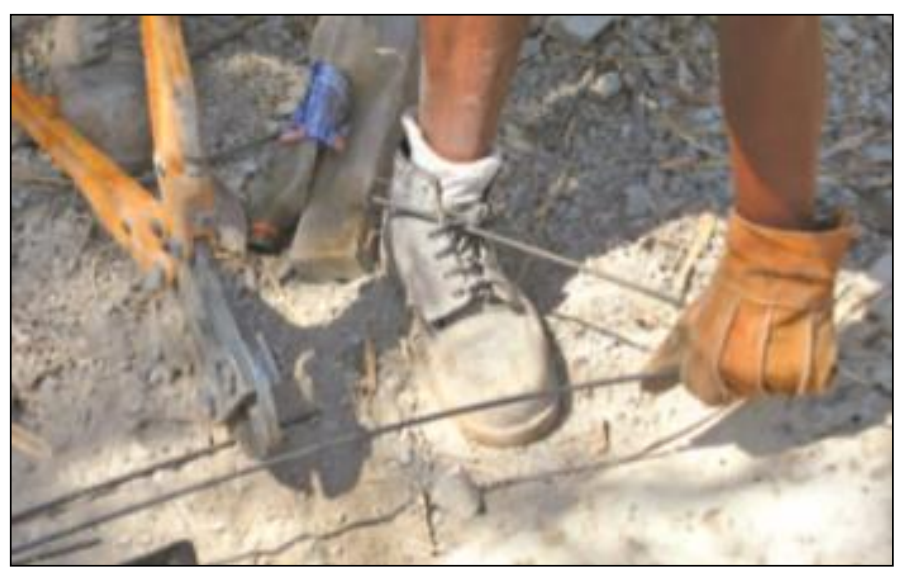

Adaptado de Rivera (2014)

Colocación del acero y separadores

Como se aprecia en la Figura 28, esta parte del proceso de fabricación consiste en colocar el acero en los moldes, luego el acero se pasa por los agujeros de los separadores y es colocado en cada línea de los moldes. Los separadores se distribuyen en pares a lo largo de la mesa de molde y la distancia de cada par será dependiendo de la longitud de cada vigueta. 
Figura 28: Colocación de acero en el molde

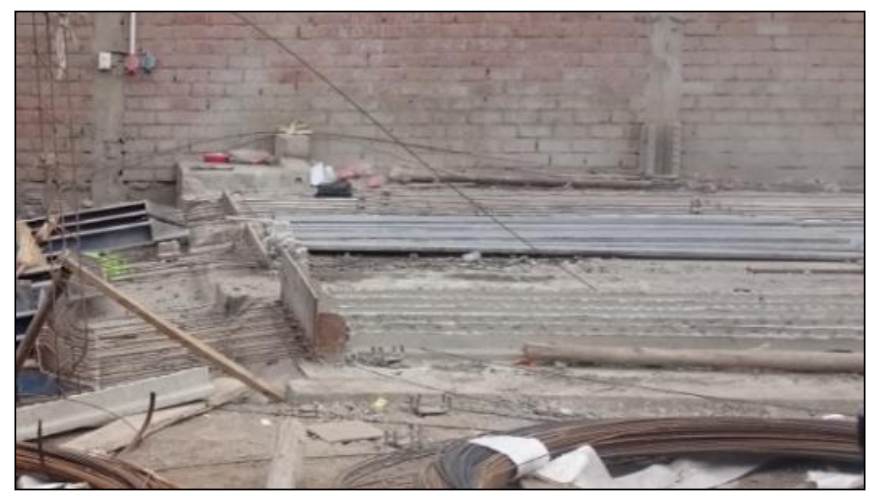

Fuente propia (2016)

En la Figura 29 se aprecian los separadores de las viguetas, entre separador y separador se coloca una tapa para evitar la entrada de concreto. En algunos casos, los separadores no son necesarios, ya que se corta la vigueta a la longitud deseada con un disco de corte o con maquinaria especializada.

Figura 29: Colocación de separadores en los moldes

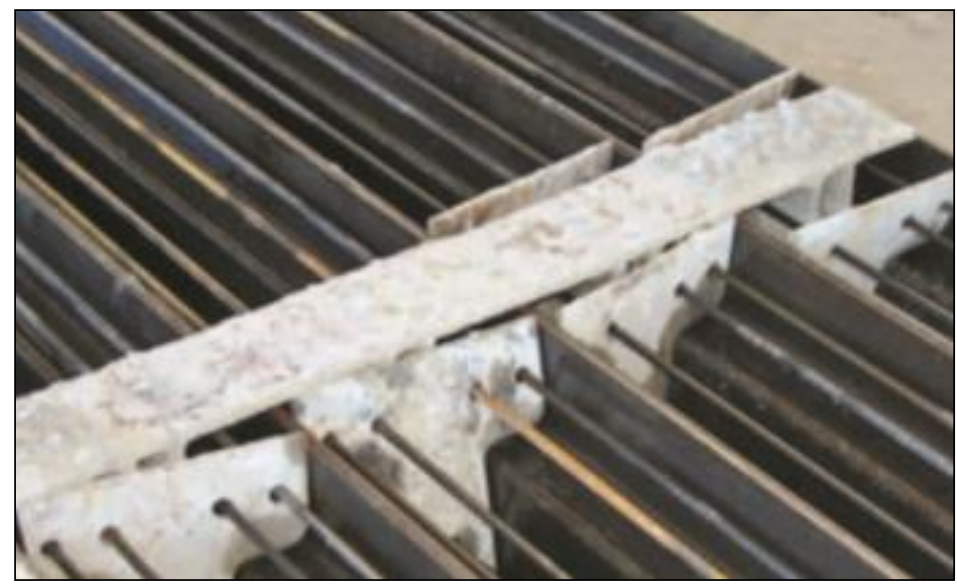

Adaptado de Rivera (2014)

Anclaje del alambre

Luego de colocado el acero en los separadores, se hace pasar por los agujeros de la placa de anclaje y se aseguran con cuñas y barriletes, esto se puede apreciar en la Figura 30. El objetivo de ello es fijar el acero para poder ser tensado sin problemas. 
Figura 30: Colocación de barriletes y cuñas en el acero

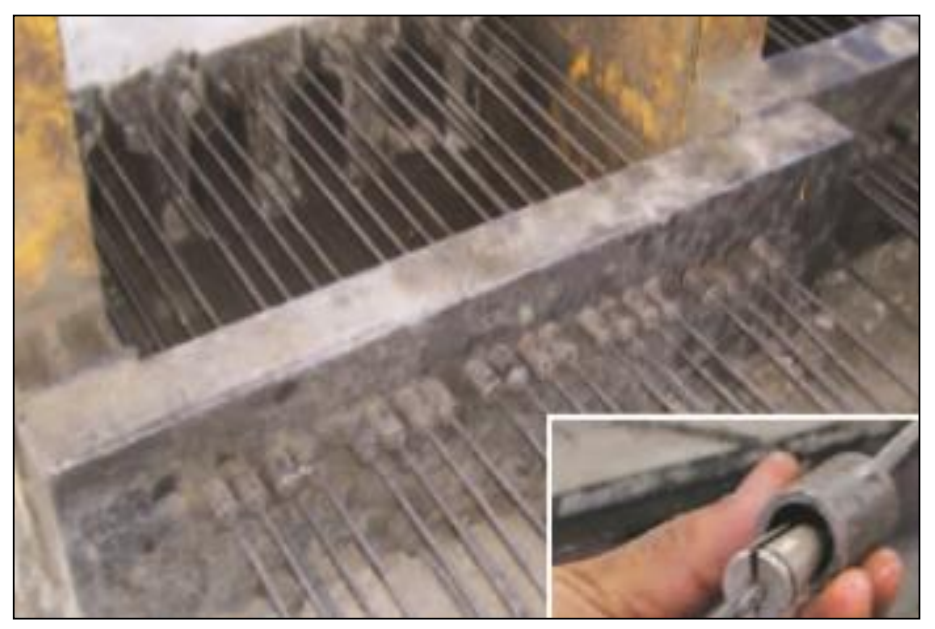

Adaptado de Rivera (2014)

Tensado del Acero

El acero es tensado con un equipo hidráulico, puede ser una gata hidráulica o una bomba, y el proceso puede ser manual o eléctrico. Cada alambre se tensa a la misma presión, definido previamente por el diseño de la vigueta; este proceso se aprecia en la Figura 31.

Figura 31: Tensado de acero previo al vaciado del concreto en el molde

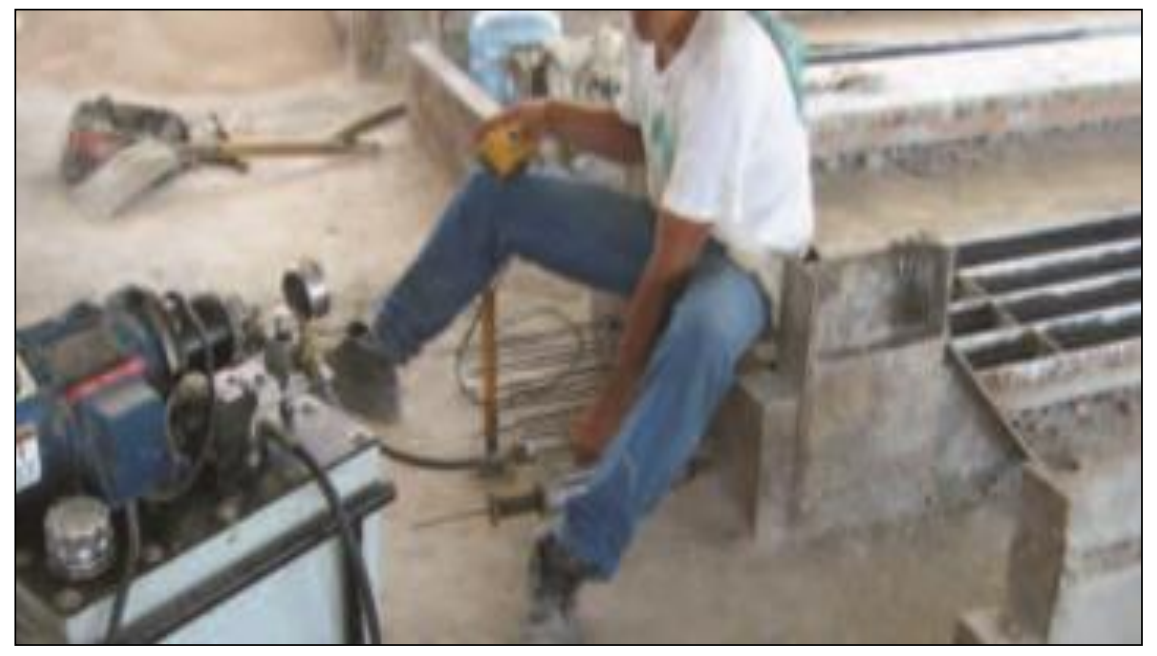

Adaptado de Rivera (2014) 
Concreto para la vigueta pretensada

En este caso, el concreto puede ser elaborado en planta. Para la vigueta de concreto se requiere una resistencia de f'c de $350 \mathrm{~kg} / \mathrm{cm}^{2}$ o mayor. La resistencia del concreto es indispensable para un adecuado comportamiento del elemento. Sin embargo, la resistencia puede variar en función a la calidad y tipo de agregado, siempre y cuando se respete la resistencia mínima de $280 \mathrm{~kg} / \mathrm{cm} 2$ establecida por la NTP 339.114. Será adecuado tomar muestras para la correspondiente medición de la resistencia en laboratorio.

Vaciado del concreto

El concreto debe ser distribuido a lo largo de la mesa del molde de forma uniforme, luego, como se aprecia en la Figura 32, es posible utilizar una pala para distribuir el concreto en las zonas en las que se haya acumulado.

Figura 32: Distribución del concreto en el molde después del vaciado

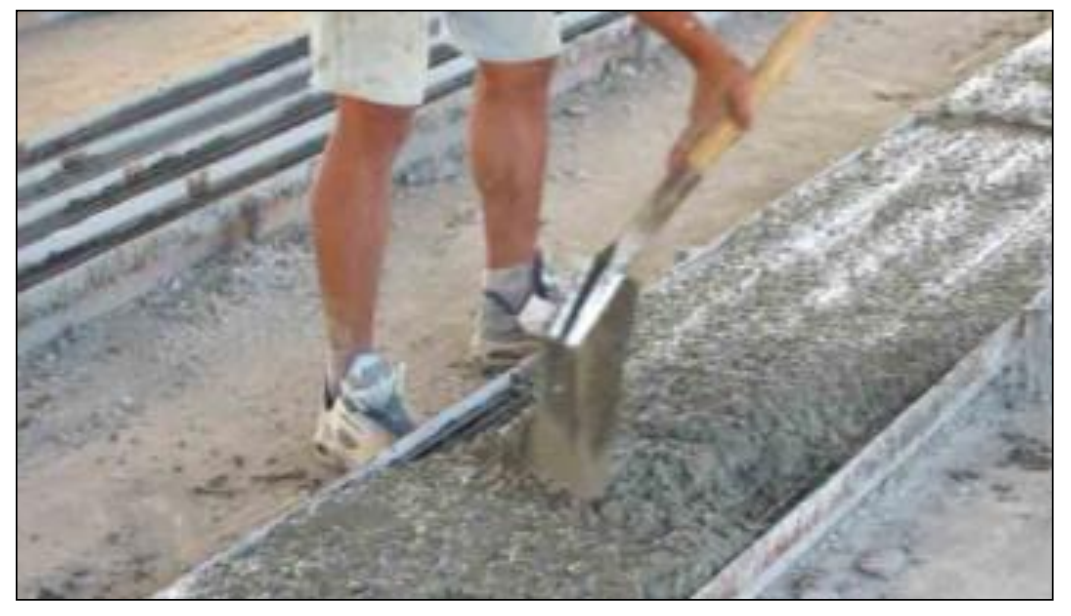

Adaptado de Rivera (2014)

En la figura anterior se observa que el trabajador no cuenta con un pantalón, lo cual no debería ser permitido para la labor que está realizando.

Vibrado del concreto, acabado y colocación de ganchos 
Esta parte del proceso de fabricación consiste en el vibrado del concreto. El procedimiento óptimo será colocar verticalmente el vibrador en el concreto, como se aprecia en la Figura 33, y retirarlo lentamente cuando aparece un flujo de agua en la superficie del concreto.

Figura 33: Vibrado del concreto en el molde

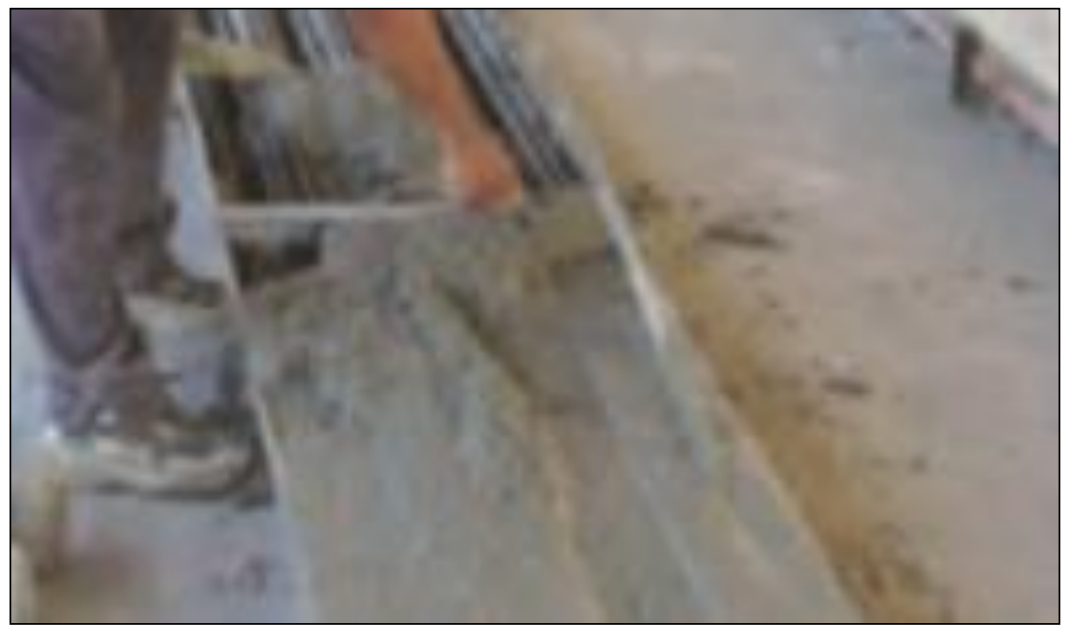

Adaptado de Rivera (2014)

El tamaño de la cabeza del vibrador debe ser lo suficiente para sumergirse en el fondo del molde. El vibrado juega un rol importante en la resistencia final del concreto y acabado de vigueta.

Luego, como se aprecia en la Figura 34, se procede a dar el acabado con una regla y eliminar los sobrantes del concreto. 
Figura 34: Eliminación del exceso del concreto y acabados con regla

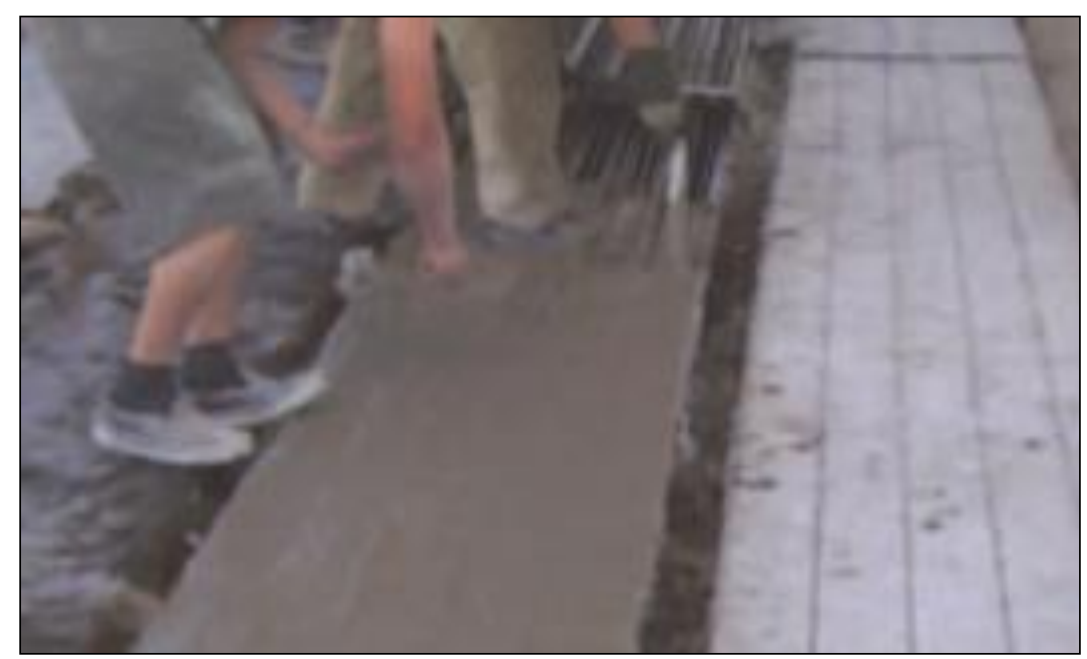

Adaptado de Rivera (2014)

Posteriormente se colocan manualmente los ganchos para el traslado de viguetas como se puede observar en la Figura 35

Figura 35: Colocación de ganchos en la vigueta para facilitar su traslado

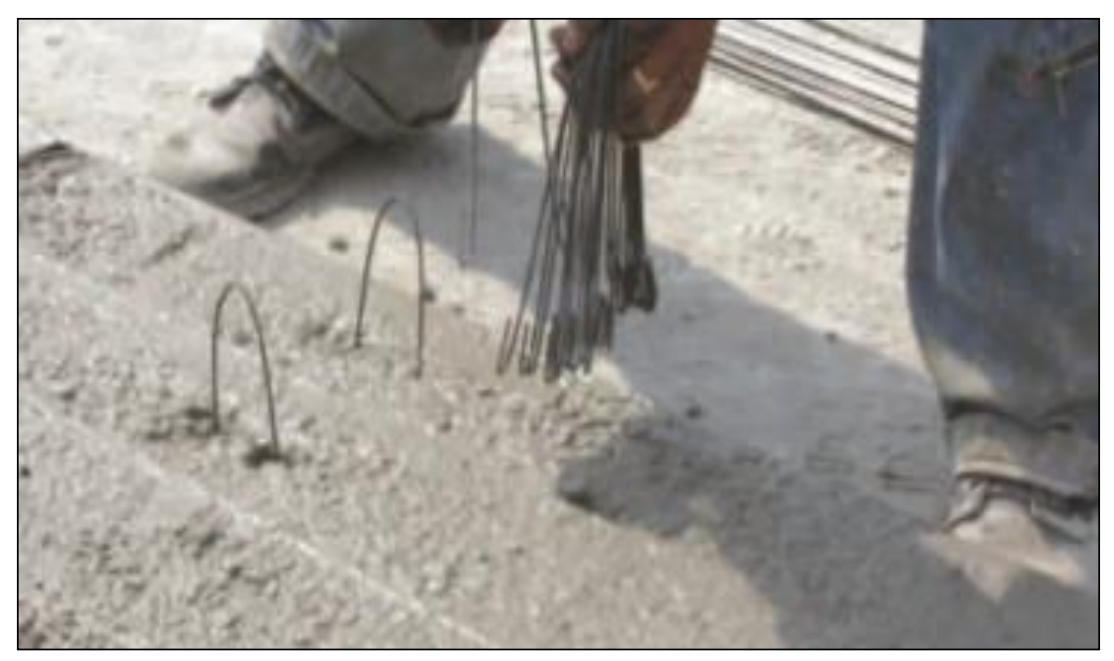

Adaptado de Rivera (2014)

Destensado del acero y cortes

Una vez que el concreto adquiere la resistencia del diseño f'c, se procede a la liberación del acero. Como se observa en la Figura 36, primero se afloja el acero de los extremos 
de la vigueta, posteriormente se corta el acero desde el centro de la mesa hacía los extremos.

Figura 36: Liberación del acero tensado

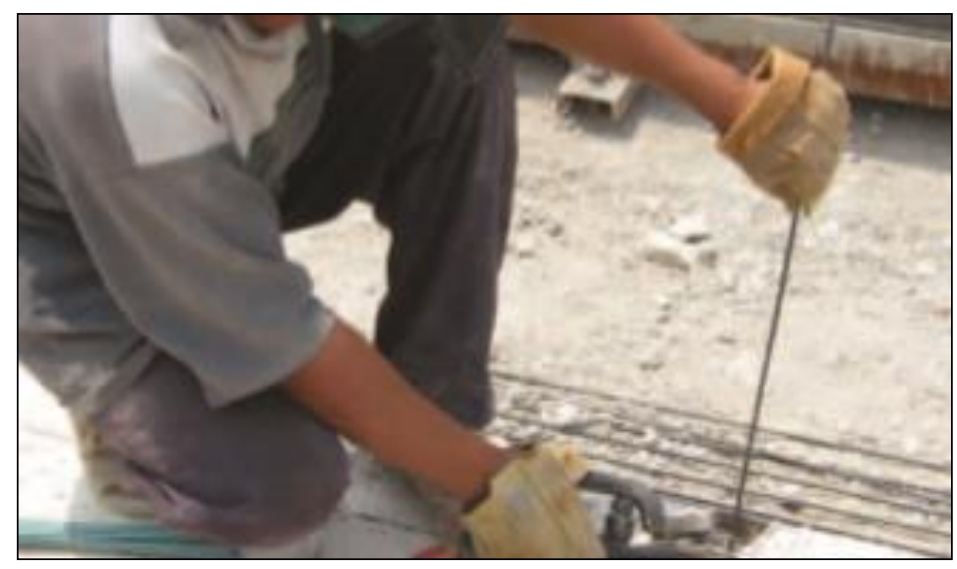

Adaptado de Rivera (2014)

Habilitación de viguetas

Después de cortar el acero tensado, como se aprecia en la Figura 37, con una barra de acero se genera un brazo de palanca para desmoldar la vigueta a través de los ganchos que fueron colocados en el proceso previo.

Figura 37: Desmolde manual del viguetas

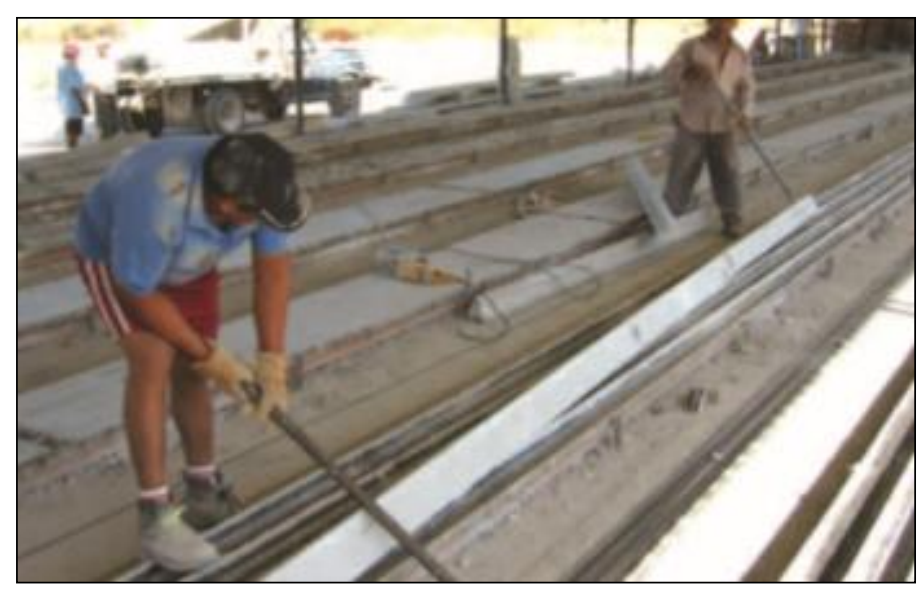

Adaptado de Rivera (2014) 
Acarreo y almacenaje

Finalmente, como se muestra en las Figura 38 y 39, las viguetas que cumplan con las longitudes, peraltes y resistencias requeridas son cargadas por operarios o con una grúa, para ser llevadas al patio de almacén para ser estibadas en paquetes de viguetas de la misma longitud.

Figura 38: Viguetas recién desmoldadas

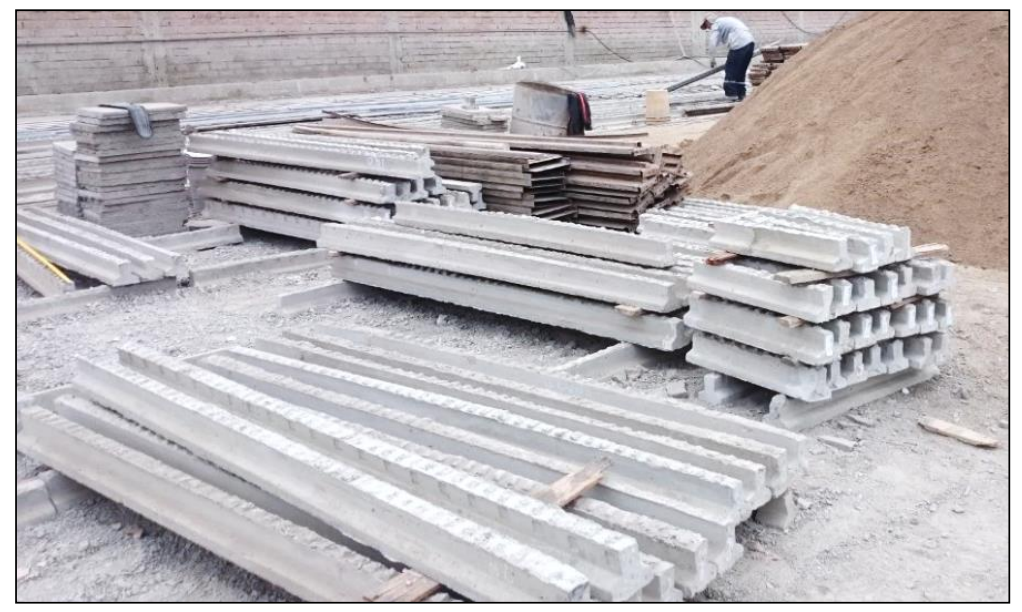

Fuente propia (2016)

Figura 39: Viguetas almacenadas

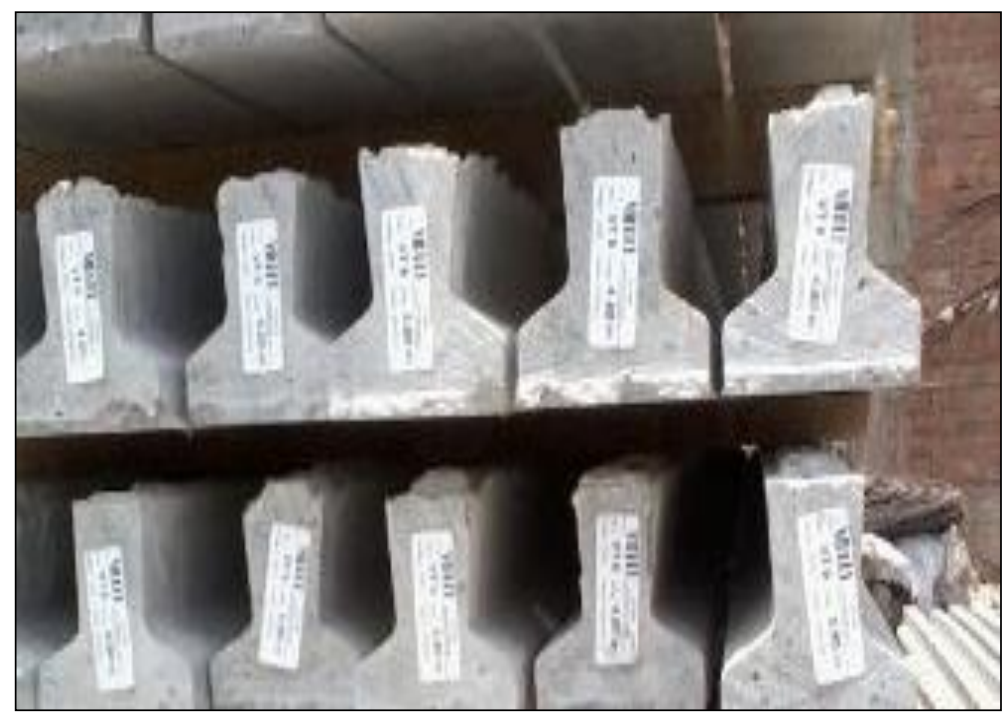

Fuente propia (2016) 


\subsubsection{Ventajas del uso de viguetas prefabricadas}

En obra:

Velocidad de trabajo

El mayor trabajo consiste en integrar las viguetas prefabricadas con los demás elementos como bovedillas, acero y concreto, ya no serán necesarios encontrados de tablas ya que se trata de integrar los elementos que no han sido prefabricados con los elementos in situ.

Optimización de los tiempos de construcción

Reducción de tiempos muertos. Reducción de tiempos y costos de construcción, pues se tiene menor cantidad de personal en obra y el trabajo se reduce con las partidas que se eliminan como el encofrado con tablas y el habilitado de todo el acero positivo.

Precisión dimensional

Debido a que las viguetas llegan pre dimensionadas de fábrica, se tiene precisión dimensional exacta como se indica en los planos y no será necesario realizar trabajos adicionales en obra.

Mejor calidad de acabados

Debido a que se trata de elementos realizados en fábrica cuentan con un control de calidad de acabados, incluso en algunos casos no se requiere de tarrajeo, ya que podría tener un acabado caravista.

Disminuye los desperdicios

No se generan desperdicios en la elaboración de las viguetas prefabricadas, debido a que las viguetas son realizadas en fábrica; del mismo modo, se requiere menor cantidad de encofrado, por ello no se generan desperdicios del encofrado en obra.

En Tiempo: 
Rapidez en habitar la vivienda

Debido a que no es necesario usar tablas en el encofrado y el control exhaustivo de fábrica se puede habitar la vivienda más rápido Además, es importante considerar el desencofrado de la losa, actividad que tarda 2 semanas aproximadamente con el sistema convencional, pero con el sistema de viguetas prefabricadas se reduce a 1 semana.

En Costos:

Presupuestos más precisos

Debido a que se tiene una cantidad determinada de viguetas y del material a utilizar el cálculo del presupuesto se vuelve más preciso.

Control de materiales

Al utilizar viguetas prefabricadas disminuye, considerablemente, la cantidad de desperdicios, de esta manera es más sencillo tener un control en obra, ya que se tiene una menor cantidad de materiales en la obra.

Mano de obra no especializada

El montaje de las viguetas prefabricadas es sencillo, por ello no será necesario de personal calificado, ya que solo serán necesarias charlas de capacitación. Asimismo, se requiere de menor cantidad de personal y maquinaria en obra, ya que se trata de elementos medianamente ligeros.

Anular los tiempos muertos

La velocidad de producción se incrementa, ya que los tiempos muertos se reducen sustancialmente. En efecto, se eliminan tiempos muertos por ineficiencia de la administración, como por ejemplo esperar materiales internos, esperar materiales externos, esperar por herramientas y espera de equipos. 


\section{CAPÍTULO IV: EVALUACIÓN TÉCNICA DEL SISTEMA DE LOSAS ALIGERADAS CON VIGUETAS PREFABRICADAS Y DEL SISTEMA DE LOSAS ALIGERADAS CONVENCIONALES}

Este capítulo desarrolla la evaluación técnica. Primero se realiza una comparación entre el sistema convencional y el sistema de vigueta pretensada en cuanto al consumo de concreto y encofrado por metro cuadrado, además de una comparación por tiempo de ejecución, calidad de acabado y del concreto para los tres sistemas evaluados.

Evaluación Técnica por consumo de concreto por m2 de Losa

Como ya se mencionó en el CAPITULO II, esta evaluación se realizará en viviendas de los sectores C y D de Lima. El propietario de la vivienda, asesorado por el maestro es quien se encarga de comprar todos los materiales para el techado de la losa. Con un menor consumo de concreto, el propietario incurrirá en menores gastos de bolsas de cemento, agregado fino y piedra chancada.

La evaluación se realizó para una losa con espesor de $20 \mathrm{~cm}$, espesor que se utiliza en la construcción de viviendas unifamiliares. Para el caso de la losa aligerada convencional se hizo el cálculo manual según la geometría que se aprecia en la Figura 40 para $1 \mathrm{~m}^{2}$ de losa aligerada, para calcular el volumen de concreto por área de losa $\left(\mathrm{m}^{3} / \mathrm{m}^{2}\right)$ se restó el volumen ocupado por los ladrillos huecos al volumen total de la losa, esto se aprecia en la Fórmula 1. 
Figura 40: Geometría de una losa aligerada convencional de $1 \mathrm{~m} 2$
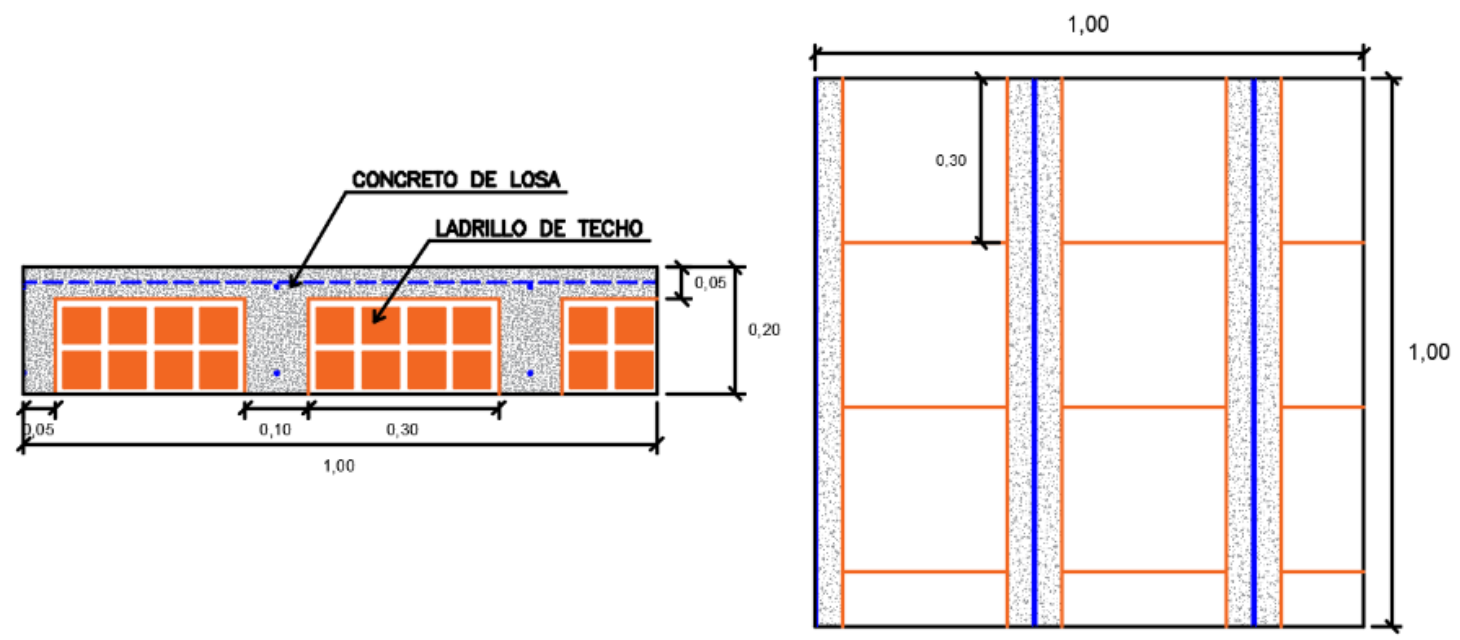

Fuente propia (2018)

Fórmula 1: Volumen de concreto losa aligerada convencional

Volumen Concreto $=$ Volumen $_{\text {Total }}-$ Volumen Ladrillo hueco

Fuente: Propia (2018)

Considerando 8.33 ladrillos $/ \mathrm{m}^{2}$ de losa aligerada, un ladrillo de techo de $15 \mathrm{~cm}$ de espesor y $30 \mathrm{~cm}$ en los lados, el volumen calculado seria:

$$
\begin{gathered}
\text { Volumen Concreto }=(1 \times 1 \times 0.20) \mathrm{m}^{3} / \mathrm{m}^{2}-(8.33 \times 0.15 \times 0.30 \times 0.30) \mathrm{m}^{3} / \mathrm{m}^{2} \\
\text { Volumen } \text { Concreto }^{2}=0.0875 \mathrm{~m}^{3} / \mathrm{m}^{2}
\end{gathered}
$$

Para obtener el consumo de concreto para el sistema de vigueta pretensada se utilizó un corte típico de esta losa como el que se aprecia en la Figura 41. 
Figura 41: Geometría de una losa aligerada con viguetas pretensadas de $1 \mathrm{~m} 2$
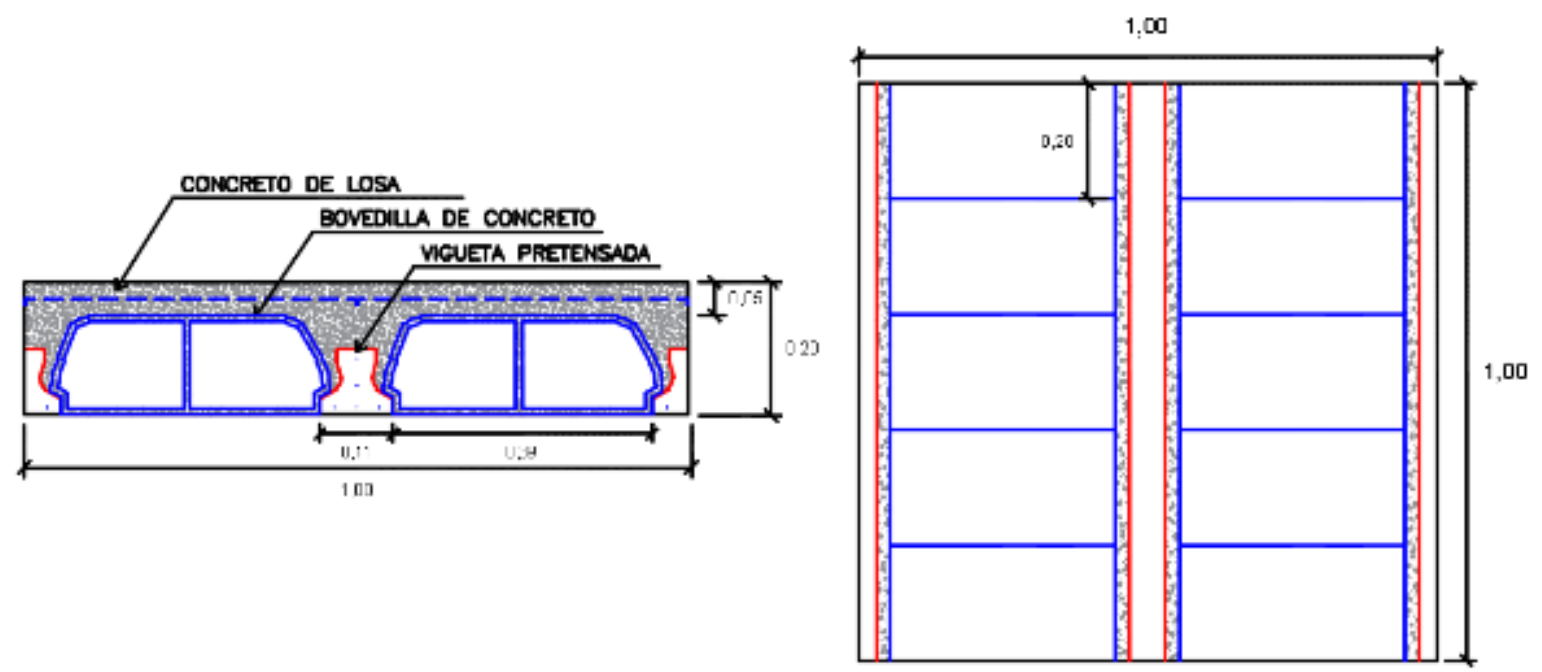

Fuente propia (2018)

Para este caso, el consumo de concreto por área de losa $(\mathrm{m} 3 / \mathrm{m} 2)$ se obtuvo al restar el volumen de la bovedilla y de la vigueta pretensada del volumen total de la losa. El cálculo que se va a realizar se muestra en la Fórmula 2.

Fórmula 2: Volumen de concreto losa aligerada con viguetas pretensadas Volumen Concreto $=$ Volumen Total - Volumen Ladrillo hueco - Volumen Vigueta Fuente: Propia (2018)

A partir de la sección mostrada en la figura anterior, una bovedilla presenta un volumen de $0.0117 \mathrm{~m} 3$ y son 10 bovedillas en la losa, la vigueta presenta un volumen de $0.0072 \mathrm{~m} 3$ y son 2 viguetas en la losa, con estos datos el volumen calculado sería:

Volumen Concreto $=(1 \times 1 \times 0.20) \mathrm{m}^{3} / \mathrm{m}^{2}-(10 \times 0.0117) \mathrm{m}^{3} / \mathrm{m}^{2}-(2 \times 0.0072) \mathrm{m}^{3} / \mathrm{m}^{2}$

$$
\text { Volumen Concreto }=0.0686 \mathrm{~m}^{3} / \mathrm{m}^{2}
$$

Para fines de esta investigación se utilizará un volumen de concreto de $0.0700 \mathrm{~m} 3 / \mathrm{m} 2$ para el caso de una losa aligerada con vigueta pretensada y bovedilla, ya que este valor es más conocido y reconocido por los constructores de este sistema. A partir de estos 
resultados, se puede calcular el consumo de bolsas de cemento por $\mathrm{m}^{2}$ de losa, ya que este resultado es más fácil de entender y de comparar. En la Tabla 2 se observan algunos ratios de consumo para un concreto típico utilizado en una losa aligerada.

Tabla 2:Dosificación de materiales para edificaciones

\begin{tabular}{ccccc}
\hline $\begin{array}{c}\mathrm{f}^{\prime} \mathrm{c} \\
\left(\mathrm{kg} / \mathrm{cm}^{2}\right)\end{array}$ & $\begin{array}{c}\text { Cemento } \\
(\mathrm{bls})\end{array}$ & $\begin{array}{c}\text { Arena } \\
\left(\mathrm{m}^{3}\right)\end{array}$ & $\begin{array}{c}\text { Piedra } \\
\text { chancada }\left(\mathrm{m}^{3}\right)\end{array}$ & $\begin{array}{c}\text { Agua } \\
\left(\mathrm{m}^{3}\right)\end{array}$ \\
\hline 210 & 9.73 & 0.52 & 0.53 & 0.186
\end{tabular}

Nota: Dosificación considerada para un concreto con asentamiento de 3", tamaño de agregado de 2" y módulo de fineza entre 2.40 y 3.00. Adaptado de Ramos (2017)

A partir de la tabla anterior y los resultados obtenidos por consumo de concreto se ha realizado la Tabla 3, en el cual se muestra los consumos de bolsa de cemento para ambos tipos de losa.

Tabla 3: Consumo de bolsas de cemento en diferentes metrados de losa aligerada de $\mathrm{H}=20 \mathrm{~cm}$

\begin{tabular}{|c|c|c|c|c|c|}
\hline & \multirow{2}{*}{$\begin{array}{c}\text { Consumo } \\
\text { concreto } \\
\left(\mathbf{m}^{3} / \mathbf{m}^{2}\right)\end{array}$} & \multirow{2}{*}{$\begin{array}{c}\text { Consumo } \\
\text { cemento } \\
\left(\mathrm{bls} / \mathbf{m}^{3}\right) \\
\end{array}$} & \multicolumn{3}{|c|}{ Área de Losa $\left(\mathrm{m}^{2}\right)$} \\
\hline & & & 60 & 80 & 120 \\
\hline $\begin{array}{c}\text { Losa } \\
\text { Convencional }\end{array}$ & 0.0875 & 9.73 & 51 & 69 & 103 \\
\hline $\begin{array}{c}\text { Losa con vigueta } \\
\text { pretensada }\end{array}$ & 0.0700 & 9.73 & 41 & 55 & 82 \\
\hline
\end{tabular}

Nota: Elaboración propia

Con el uso de un sistema de losa aligerada con vigueta pretensada se puede ahorrar un $20 \%$ en el consumo de bolsas de cemento ( 0.17 bolsas por cada $\mathrm{m} 2)$, lo cual se traduce en ahorro de dinero para el propietario, si a esto le sumamos el ahorro por agregado, los beneficios económicos se hacen cada vez más significativos.

Evaluación Técnica por consumo de encofrado por $\mathrm{m}^{2}$ de Losa

Esta evaluación pretende beneficiar al maestro de obra, quien se encarga de transportar la madera para el encofrado de la losa aligerada como son los puntales, tablones y 
soleras, es decir, el maestro debe buscar y pagar el transporte de este material. El objetivo de esta evaluación es concluir que el maestro de obra va a transportar menos encofrado con el uso del sistema de losa con viguetas prefabricadas y de este modo reducir sus gastos. Al usar menos encofrado, el maestro de obra puede ofertar los mismos precios por un menor trabajo durante el encofrado. Además, se reducen los desperdicios de encofrado, se elimina el uso de tablones que por el uso están en mal estado y perjudican la calidad de la losa.

Para entender mejor las diferencias entre ambos sistemas en cuanto al consumo de encofrado por área de losa $\left(\mathrm{m}^{2} / \mathrm{m}^{2}\right)$ se utilizará la geometría de una losa aligerada de $40 \mathrm{~m} 2$ que se muestra en la Figura 42.

Figura 42: Geometría de una losa aligerada

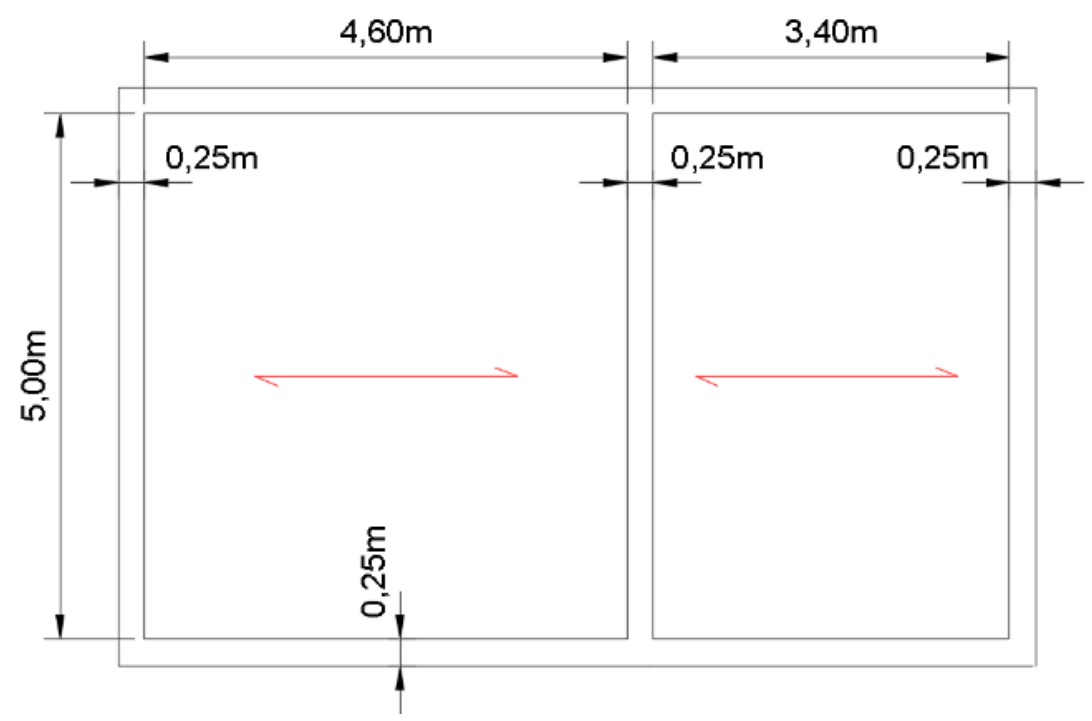

Fuente propia (2018)

En este caso se tiene una losa de $20 \mathrm{~cm}$ de espesor, con vigas en sus bordes y en la parte intermedia. El cálculo de consumo de encofrado para una losa aligerada convencional se hizo en base a algunos ratios vistos en clases de construcción y en el libro de Costos y Presupuestos de CAPECO (Ramos, 2017). 
Se ha considerado 2.5 tablas por cada metro que tenga la losa en el sentido transversal al de las viguetas, en este caso tenemos 5 metros en cada paño. Los espaciamientos entre puntales y soleras se aprecian mejor en la Figura 43.

Figura 43: Encofrado de losa aligerada convencional

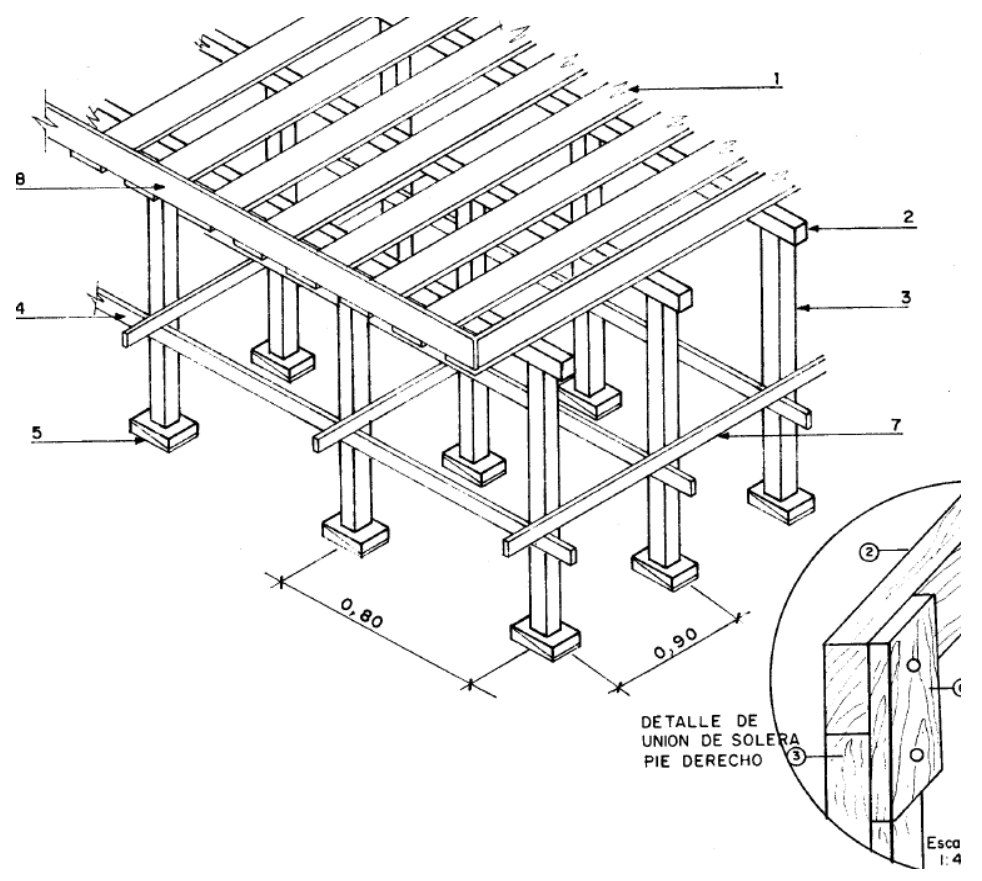

Adaptado de Ramos (2017)

Ayudados en esta figura se ha realizado el siguiente cálculo para obtener la cantidad de madera que se utiliza en este sistema.

2.50 tablas $/ \mathrm{m} \times 5 \mathrm{~m}=12.5$ tablas $=13$ tablas de $20 \mathrm{~cm}$ de espesor

13 tablas de $3 \mathrm{~m}=13$ tablas de 8 " $\times 1$ 1/2" x 10'

13 tablas de $1.60 \mathrm{~m}=7$ tablas de 8 " $11 / 2 " \times 12$ '

13 tablas de $3.40 \mathrm{~m}=13$ tablas de 8 " $11 / 2$ " x 12 '

Finalmente tendremos 13 tablas de 8" x 1 1/2" x 10' y 20 tablas de 8" x 1 1/2" x 12'

$$
N^{\circ} \text { de soleras }=\frac{4.60}{0.90}+1=7 \text { soleras en el primer } p a \tilde{n} o
$$




$$
N^{\circ} \text { de soleras }=\frac{3.40}{0.90}+1=5 \text { soleras en el segundo paño }
$$

En total se tiene 12 soleras para toda la losa aligerada. El número de puntales se ha calculado de la siguiente forma:

$$
\begin{gathered}
N^{\circ} \text { de puntales }=\frac{5.00}{0.80}+1=8 \text { puntales por cada solera } \\
N^{\circ} \text { de puntale }=8 \times 12=96 \text { puntales en toda la losa }
\end{gathered}
$$

Para el caso del sistema de losa aligerada con viguetas pretensadas se elimina el uso de tablas y solo se consideran puntales y soleras. En el caso de las soleras, este sistema nos permite colocarlas espaciadas a $1.50 \mathrm{~m}$ igual que los puntales. La distribución de estas soleras y puntales se observa mejor en la Figura 44.

Figura 44: Distribución de encofrado para una losa con viguetas pretensadas

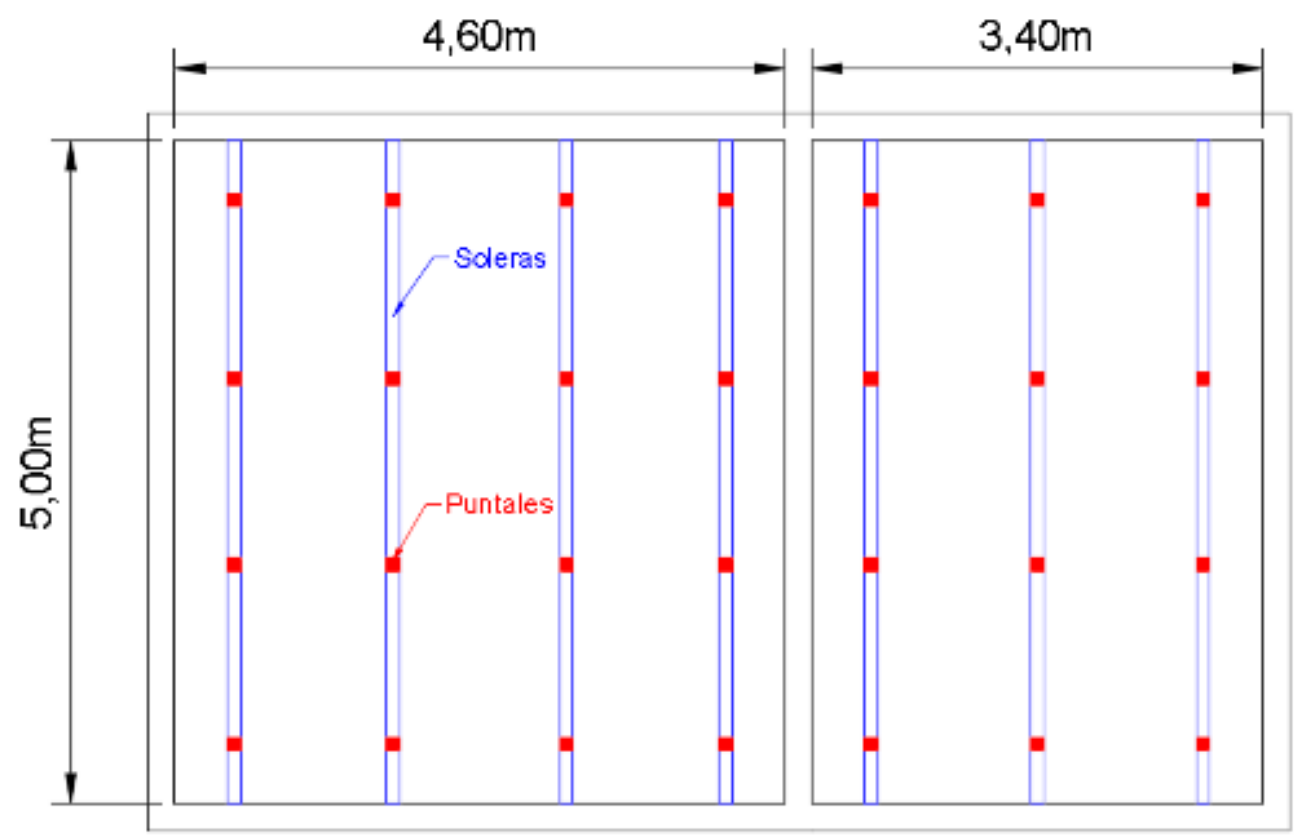

Fuente propia (2018)

$$
N^{\circ} \text { de soleras }=\frac{4.60}{1.50}+1=4 \text { soleras en el primer paño }
$$




$$
N^{\circ} \text { de soleras }=\frac{3.40}{1.50}+1=3 \text { soleras en el segundo paño }
$$

En total se tiene 7 soleras para toda la losa aligerada. El número de puntales se ha calculado de la siguiente forma:

$$
\begin{gathered}
N^{\circ} \text { de puntales }=\frac{5.00}{1.50}+1=4 \text { puntales por cada solera } \\
N^{\circ} \text { de puntale }=4 \times 7=28 \text { puntales en toda la losa }
\end{gathered}
$$

En la Tabla 4 se resumen estos resultados entre los dos sistemas de losa aligerada

\begin{tabular}{|c|c|c|}
\hline & Sistema convencional & $\begin{array}{c}\text { Sistema con vigueta } \\
\text { pretensada }\end{array}$ \\
\hline $\mathrm{N}^{\circ}$ de Tablas & $\begin{array}{l}13 \text { tablas de } 8 \text { " x } 1 \text { 1/2" x } 10^{\prime} \\
20 \text { tablas de } 8 \text { " x } 1 \text { 1/2" x } 12 \text {, }\end{array}$ & 0 tablas \\
\hline $\mathrm{N}^{\circ}$ de Soleras & 12 & 7 \\
\hline $\mathrm{N}^{\circ}$ de Puntales & 96 & 28 \\
\hline
\end{tabular}
evaluados:

Tabla 4: Consumo de bolsas de cemento en diferentes metrados de losa aligerada de

Nota: Fuente Propia (2018)

A partir del cuadro 4 se puede obtener un ratio de 0.30 soleras $/ \mathrm{m} 2$ y 2.40 puntales $/ \mathrm{m} 2$ para el sistema de losa aligerada convencional, por otro lado, para el sistema de losa aligerada con vigueta pretensada se tiene 0.175 soleras $/ \mathrm{m} 2$ y 0.70 puntales $/ \mathrm{m} 2$.

En el caso de las tablas se ha logrado ahorrar el $100 \%$ del material, para las soleras se tiene un ahorro de $40 \%$ y para puntales el ahorro es de hasta $70 \%$ en material. Este cálculo debe servir como una referencia, ya que en el siguiente capítulo se detalla mejor el consumo de encofrado dentro de los análisis de precio unitarios para cada sistema.

Asimismo, con el uso del sistema de viguetas prefabricadas el desencofrado podrá realizarse en la mitad de tiempo que con el sistema convencional, es decir, en una 
semana se podrá realizar el desapuntalamiento, ya que la vigueta prefabricada es autoportante.

A continuación se va a detallar el proceso constructivo de cada sistema de losa aligerada, dentro de cada proceso se van a realizar las siguientes evaluaciones:

- Evaluación Técnica por Tiempo de ejecución

- Evaluación Técnica por Calidad de acabado

- Evaluación Técnica por Seguridad estructural

Estas evaluaciones permitirán conocer, mejor, el comportamiento de cada sistema de losa aligerada, además de permitir identificar cuál de los tres sistemas ofrece los mejores beneficios para utilizarse en la autoconstrucción de una losa aligerada de vivienda unifamiliar en Lima.

En el proceso constructivo se va a detallar cada sub-proceso en la construcción de una losa aligerada para cada sistema evaluado. Con esto se podrá entender mejor las ventajas y desventajas constructivas que presenta cada sistema al ser ejecutado. La evaluación técnica por tiempo de ejecución pretende mostrar la duración total que lleva la construcción de una losa aligerada en tres etapas representativas: Armado de Losa, Vaciado de Losa, Desencofrado de Losa.

La evaluación técnica por calidad de acabado pretende evidenciar mediante fotografías reales de los proyectos visitados la calidad que tiene el fondo de losa luego del desencofrado.

Finalmente se concluirá el capítulo con una comparación técnica para los tres sistemas evaluados según los resultados que se obtengan de las tres evaluaciones que se han descrito en párrafos anteriores. 


\subsection{Sistema de Losa aligerada convencional}

\subsubsection{Proceso Constructivo}

La losa denominada "aligerada" está constituida por viguetas de concreto, losa de compresión y ladrillos huecos, estos últimos son de arcilla cocida y su altura varía entre $0.15,0.20$ y $0.25 \mathrm{~m}$, con lo que la altura o peralte de la losa varía entre $0.20,0.25$ y $0.30 \mathrm{~m}$. En la Figura 45 se aprecia mejor los componentes de este tipo de losa.

Figura 45: Corte típico de losa aligerada convencional

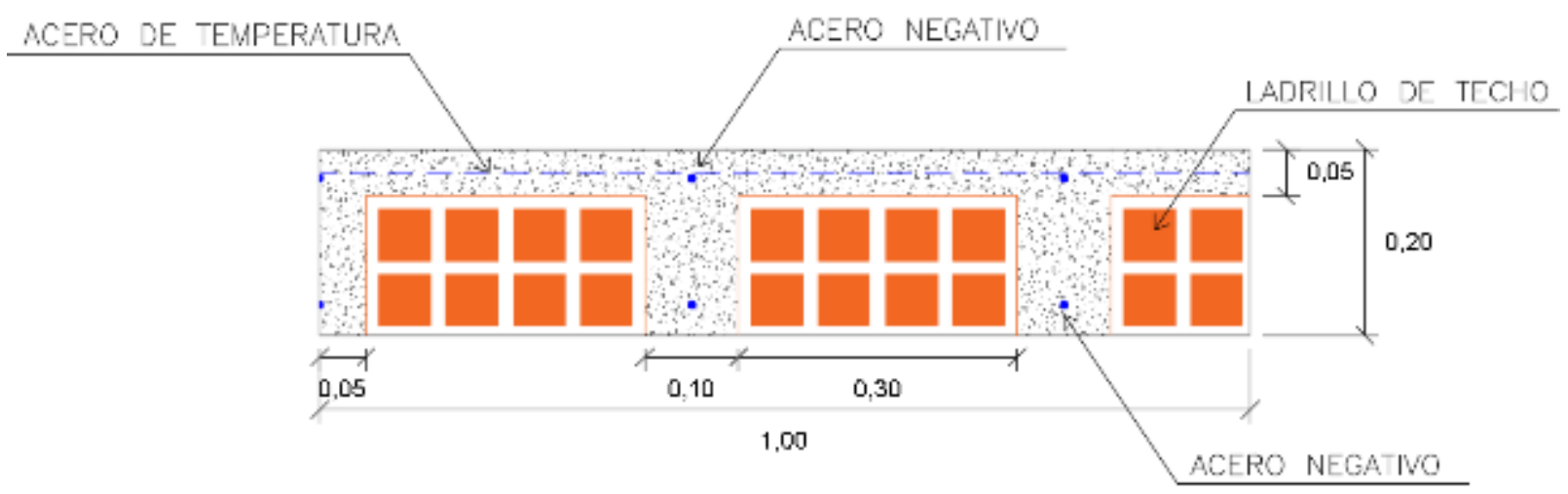

Fuente propia (2018)

Las etapas del proceso constructivo para este sistema están resumidos en la Figura 46.

Figura 46: Proceso constructivo del sistema de losa aligerada convencional

\section{- Encofrado}

- Colocación de acero, ladrillo e instalaciones

- Vaciado de concreto de Losa

- Curado de concreto

- Desencofrado

Fuente propia (2018) 
Encofrado y apuntalamiento

El encofrado es una estructura temporal que sirve para darle forma definitiva al concreto mientras alcanza la resistencia y fraguado necesarios. Ofrece al acero la posibilidad de colocarlo en el sitio correcto y servir de apoyo tanto al concreto y acero.

Como ya se vio en la Figura 43, página 56 de esta investigación, el encofrado está constituido por tablones, soleras, pies derechos, entre otros, además, existen una variedad de tipos de encofrado de distintos materiales y de diversas formas. Para determinar el tipo de encofrado se presentan muchos factores, desde factores económicos hasta del tipo de acabados. A continuación se enlista todos los elementos usados en el encofrado de una losa aligerada convencional según Ramos (2017).

- Tablones de $11 / 2^{\prime \prime}$ x 8"

- Soleras de 2" x 4"

- Pies derechos o puntales de 2" x 3"

- Arriostres de 1 1/2" x 4"

- Cuñas de 2" x 4"

- Unión solera - pie derecho de 1" x 3"

- Refuerzo lateral adicional de 1" x 3"

- Diagonales de 1" x 3"

- Alambre negro $\mathrm{N}^{\circ} 16$

- Clavos de $21 / 2$ " para losa y friso

Es necesario mencionar que el encofrado no se debe considerar como un simple molde, ya que son estructuras que están sujetas a diferentes cargas de diferentes magnitudes; en la mayoría de los casos, según el Servicio Nacional de Capacitación para la Industria de la Construcción (SENCICO) (2010) las fallas en el encofrado se deben a que no se considera la magnitud de la carga real a la que están sujetos los encofrados; además del uso de madera en mal estado y procedimientos constructivos inadecuados. 
Para conservar el encofrado se pueden seguir las siguientes indicaciones:

- El encofrado se debe limpiar retirando el concreto adherido inmediatamente después del desencofrado con agua a presión y cepillo de cerdas plásticas blandas. Además, se deben retirar todos los dispositivos flojos, clavos, tornillos, abrazaderas, alambres.

- No deben almacenarse a la intemperie al sol y al agua, porque se tuercen y se deteriora su superficie. Asimismo, no se debe abusar del uso de clavos y tornillos, ya que se debilita la madera.

Se debe garantizar la calidad de los puntales y las soleras. En los casos en que las soleras se encuentren ligeramente pandeadas, la parte pandeada será fijada hacia arriba (SENCICO, 2010). Estos elementos son los que se deben armar primero como se aprecia en la Figura 47.

Figura 47: Armado de soleras y puntales

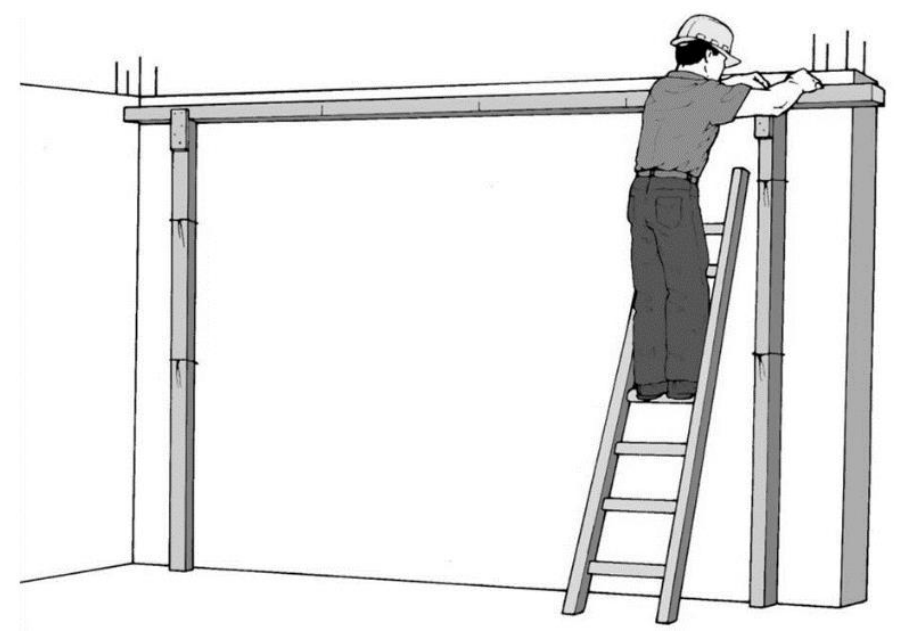

Adaptado de SENCICO (2010)

Luego se fija el fondo de las viguetas, se colocan tablas sobre las soleras, estas servirán de apoyo a los ladrillos huecos, armadura y concreto freso. Para ello, primero se marcará en los ejes de viguetas, a partir de uno de los extremos primero a $35 \mathrm{~cm}$ luego a $40 \mathrm{~cm}$, este proceso se repite hasta llegar a la viga opuesta (SENCICO, 2010). En la Figura 48 se aprecia el proceso de fijación de las tablas. 
Figura 48: Fijación de tablas

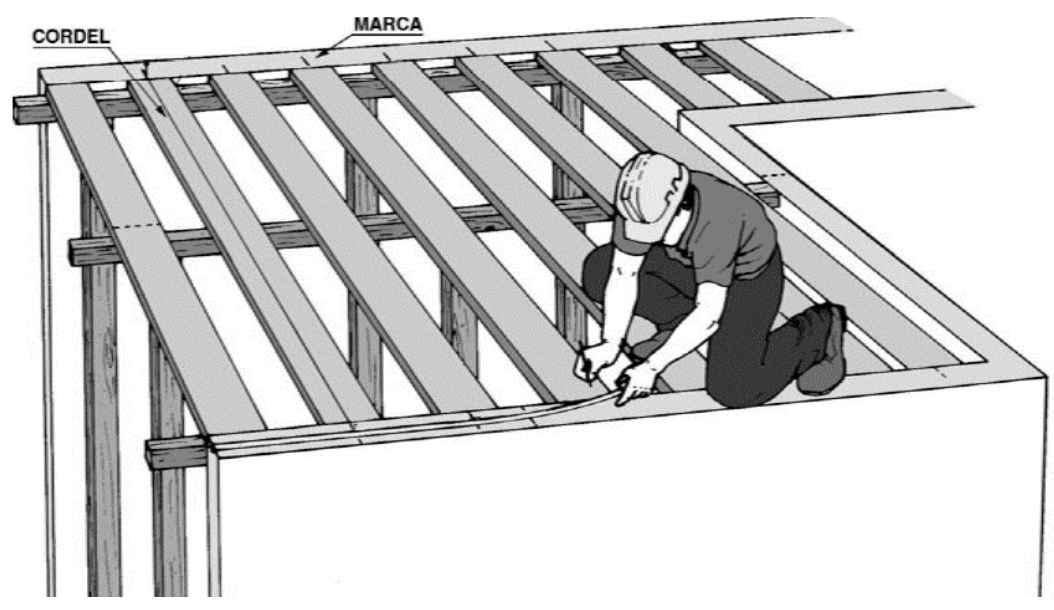

Adaptado de SENCICO (2010)

Dividiendo la tabla en dos partes iguales en ambos extremos y uniendo con una línea recta longitudinal se colocan las tablas sobre las soleras. Luego se ubica la altura de arriostre para arriostrar los pies derechos; se debe tener en cuenta la longitud del pie derecho y el peso que soportará, debiendo quedar aproximadamente en el tercio central. En seguida se clavan las tablas una seguida de la otra (SENCICO, 2010). Para culminar con el encofrado se aseguran los frisos en el perímetro de la losa como se aprecia en la Figura 49. 
Figura 49: Fijación de tablas en el borde de la losa

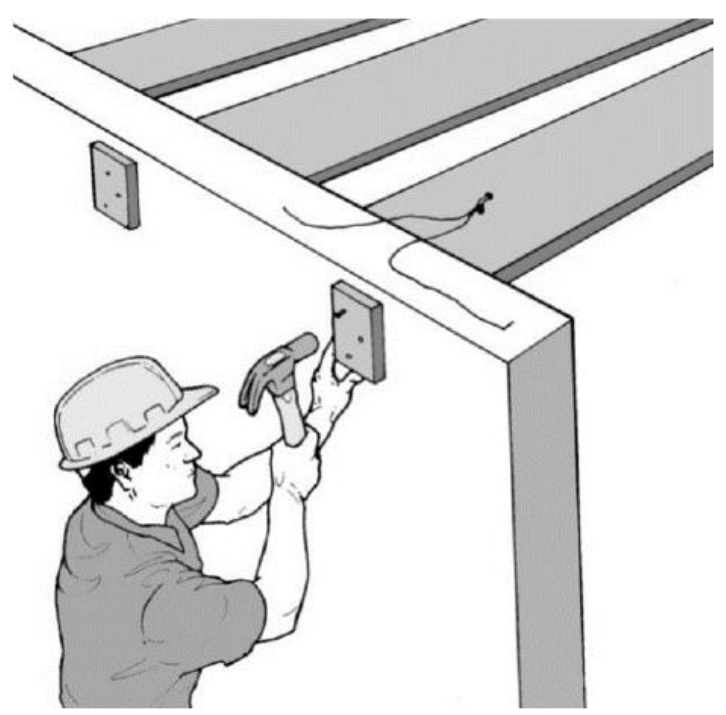

Adaptado de SENCICO (2010)

\section{Colocación del acero}

En esta etapa se arman y colocan las armaduras de las vigas principales y soleras como se aprecia en la Figura 50. Por otro lado, en la imagen se observa que a los lados de la viga chata tiene los ladrillos pegados, pero la recomendación es tener una vigueta para poder brindar mejor comportamiento ante solicitaciones sísmicas.

Figura 50: Colocación de acero en vigas

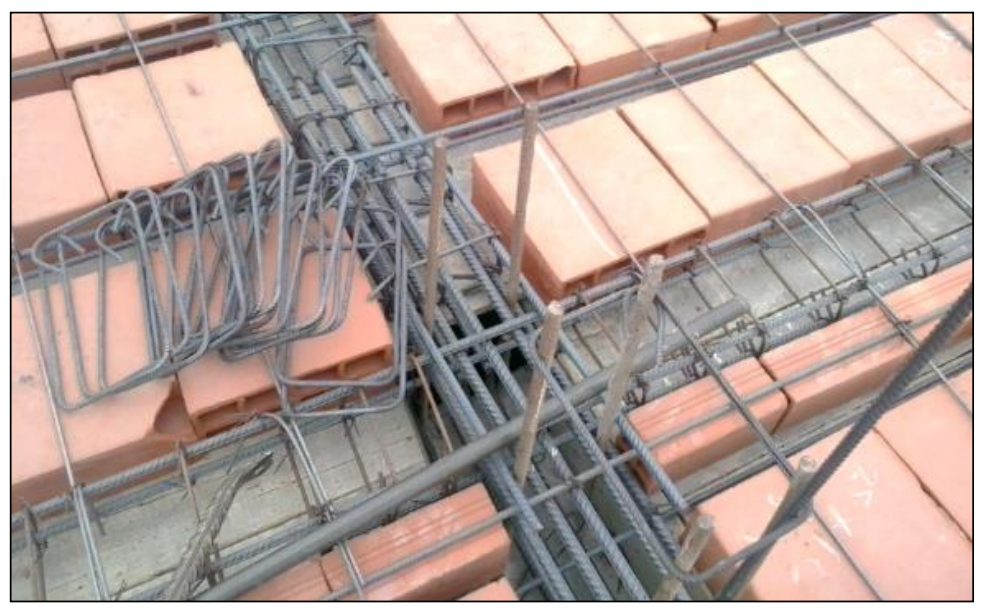

Fuente propia (2016) 
Los aceros de las viguetas también se colocan en esta etapa antes de colocar los ladrillos de techo, en la Foto 51 se aprecia mejor lo mencionado:

Figura 51: Acero en viguetas

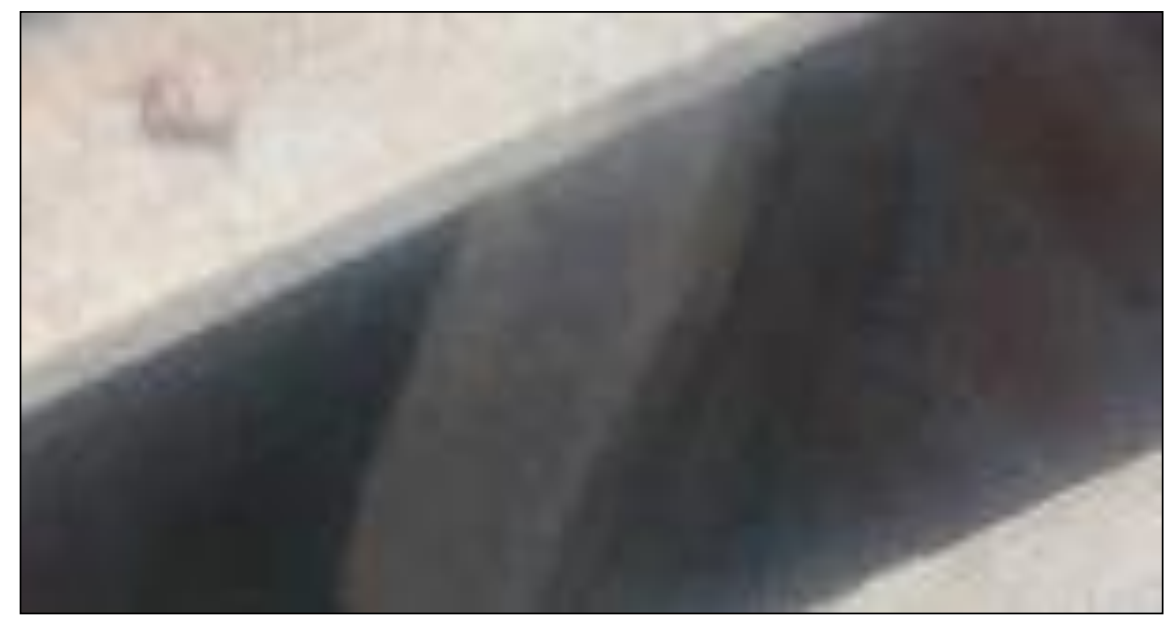

Fuente propia (2016)

Colocación de ladrillos

Con el encofrado asegurado y el acero colocado, se procede a colocar el ladrillo de techo junto con la malla de temperatura como se aprecia en la Figura 52.

Figura 52: Colocación de ladrillo

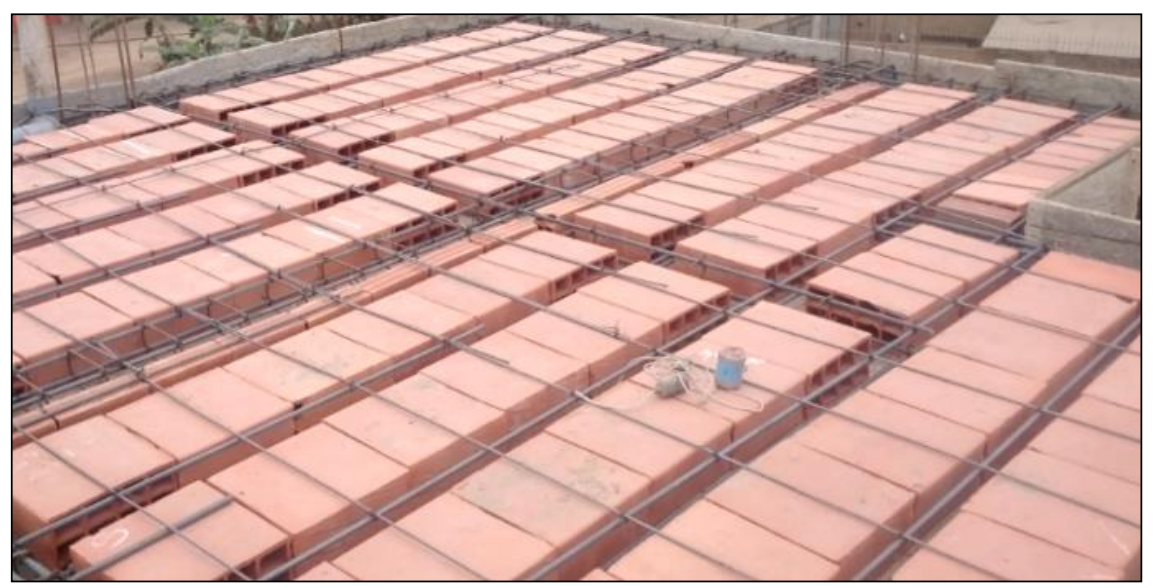

Fuente propia (2016) 


\section{Colocación de las tuberías}

En las instalaciones eléctricas no se tiene mucho problema por el tamaño de las tuberías; sin embargo, la ubicación de las cajas ortogonales son el primer defecto en esta etapa, ya que se ubica en las viguetas como se aprecia en la Figura 53.

Figura 53: Instalaciones eléctricas en losas aligeradas

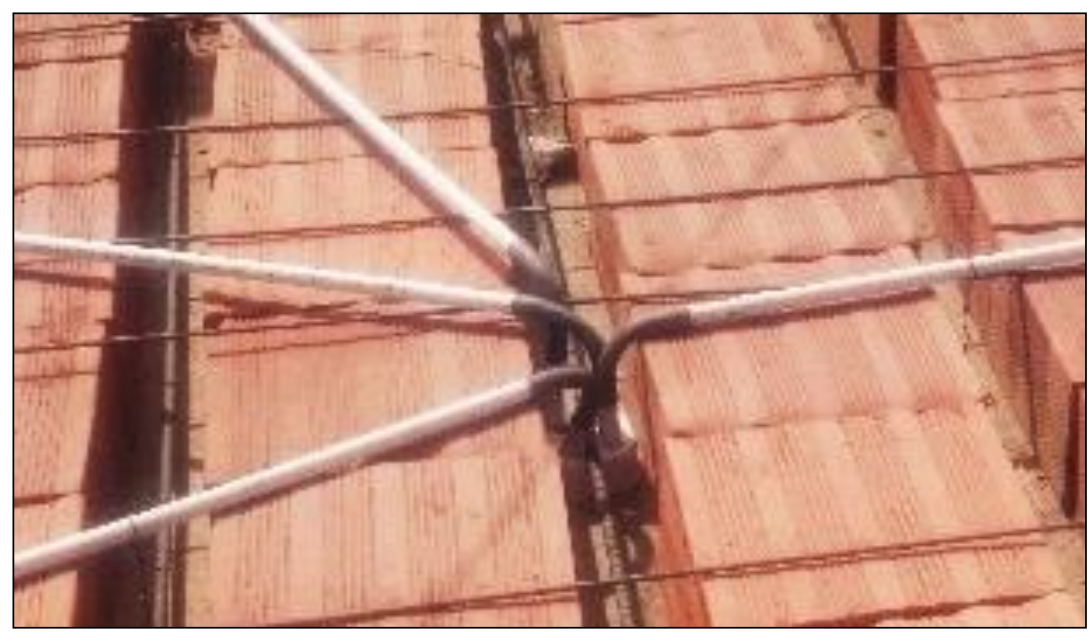

Fuente propia (2016)

En muchos casos se optan por soluciones rápidas para colocar las tuberías de desagüe rompiendo los ladrillos y creando más desperdicio de materiales, esto se aprecia mejor en la Figura 54.

Figura 54: Instalaciones sanitarias en losa aligerada

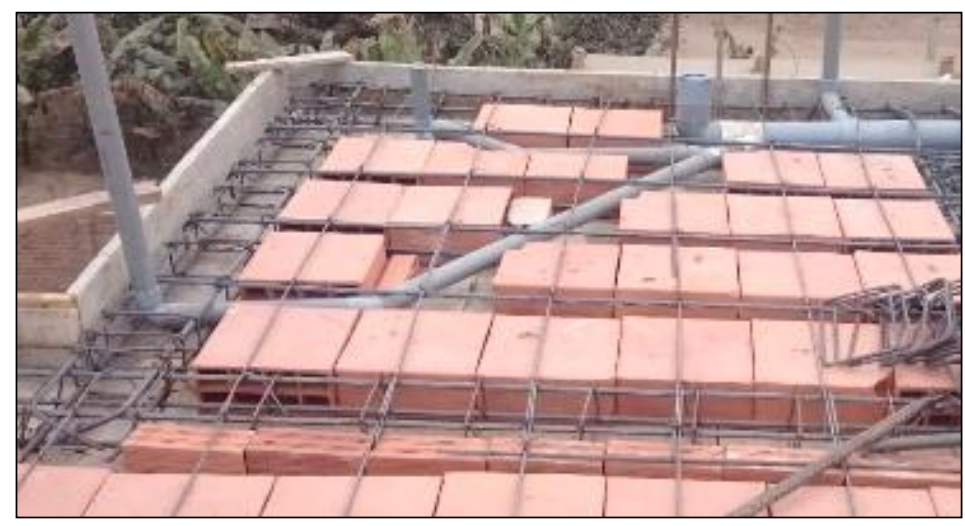

Fuente propia (2016) 
Vaciado de concreto de losa.

Una vez que se tiene la mezcla de concreto lista, esta se coloca en tres etapas, primero en las vigas, en segundo lugar, en las viguetas como se aprecia en la Figura 55.

Figura 55: Distribución del concreto en la capa a compresión

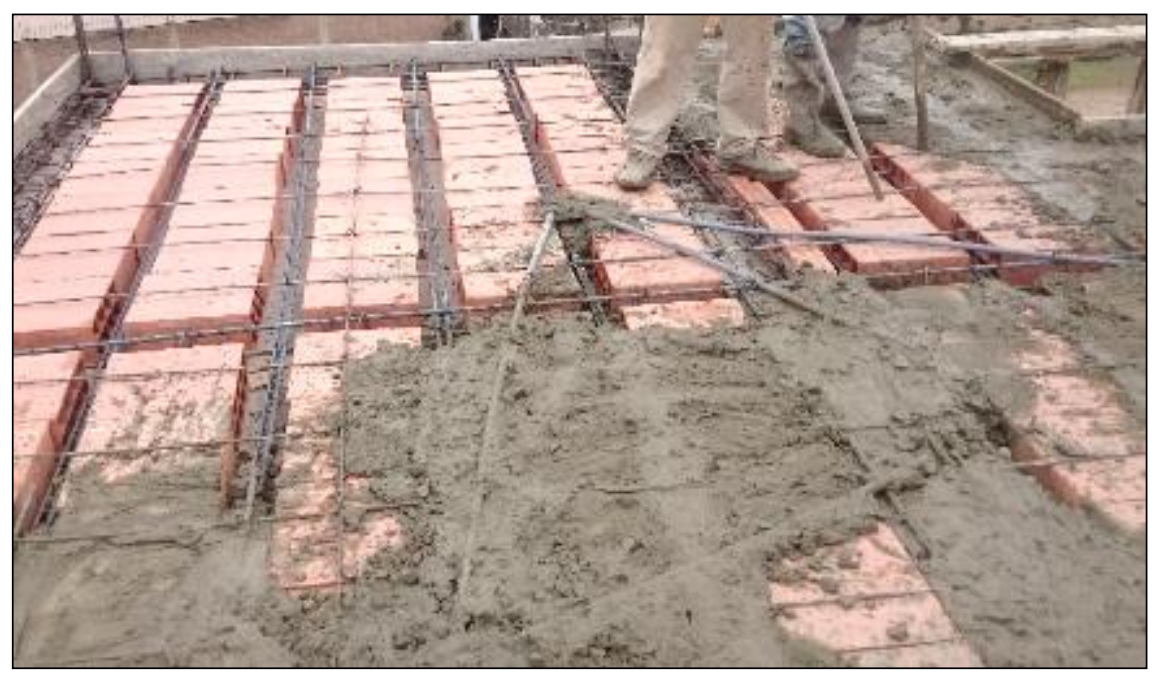

Fuente propia (2016)

En tercer lugar, se coloca el concreto en la capa de compresión de $5 \mathrm{~cm}$, para luego dar paso al acabado que va a tener la losa aligerada, esto se aprecia en la Figura 56.

Figura 56: Concreto colocado en capa de compresión

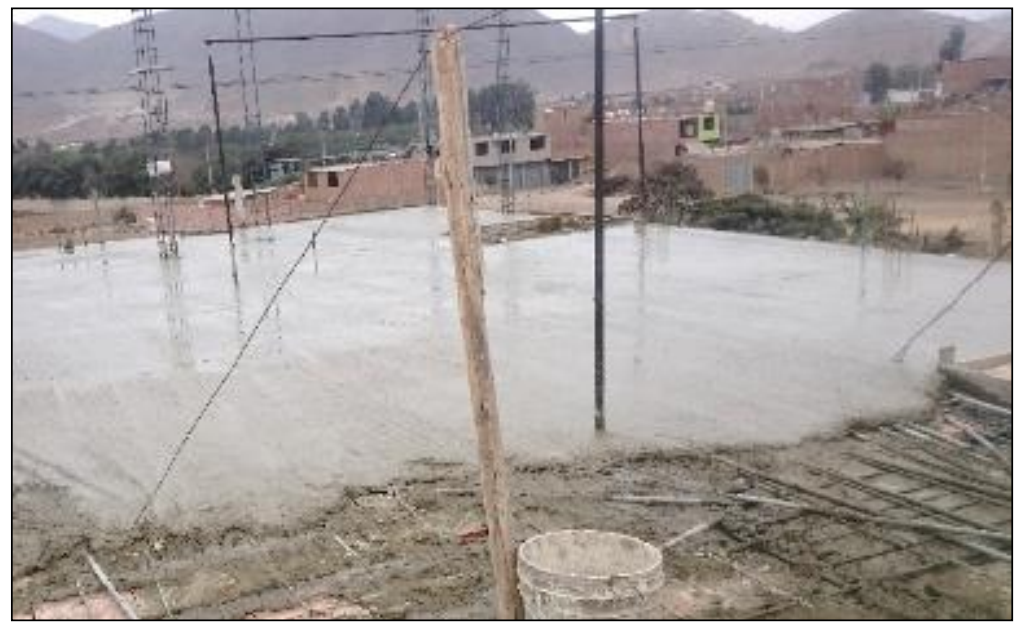

Fuente propia (2016) 
Curado del concreto

El objetivo principal del curado es el de evitar que se evapore el agua de la mezcla, lo que podría producir grietas de retracción debido a la pérdida de humedad y alteraciones en la relación agua/cemento de la mezcla, lo que incide directamente en su resistencia. Para obtener mejores resultados, se recomienda humedecer el concreto durante los primeros 7 días de vaciado.

Retiro de puntales y desencofrado

Una vez que el concreto haya alcanzado la resistencia suficiente $\left(150 \mathrm{~kg} / \mathrm{cm}^{2}\right)$ se pueden comenzar a retirar los encofrados laterales de la losa. Luego se pueden retirar algunos puntales; el retiro de puntales es de forma progresiva a medida que van pasando los días, hasta que, finalmente, se pueden retirar todos los puntales y el encofrado a los 28 días.

\subsubsection{Evaluación Técnica por tiempo de ejecución}

Para explicar esta evaluación se buscó un proyecto de losa aligerada convencional de $120 \mathrm{~m}^{2}$ Las características que tiene este proyecto son las siguientes:

$\begin{array}{ll}\text { Ubicación: } & \text { Av. Naranjal con Av. San Nicolás } \\ & \text { Urb. Chuquitanta-San Martín de Porres }\end{array}$

Nombre del maestro a cargo: Félix Peña

Área de losa: $\quad 120 \mathrm{~m}^{2}$

Dentro de todo el proceso constructivo que se tiene para la ejecución se han identificado

3 etapas principales que son: Armado de losa, Vaciado de concreto de losa y Desencofrado de losa. A continuación, se va a explicar el tiempo que ha llevado cada una de estas etapas con el sistema de viguetas convencionales.

Armado de la losa (12 días) 
Esta etapa comienza con el encofrado de las vigas principales y colocación de soleras, para esta primera etapa se ha contado con una cuadrilla de 2 carpinteros, 2 fierreros y un maestro de obra, teniendo un total de 5 personas en esta labor.

La primera actividad es el armado del encofrado de madera, esta actividad tiene una duración de 6 días. Luego se coloca el acero de las vigas y viguetas para luego seguir con la colocación de los ladrillos y el armado de la malla de temperatura, estas actividades duran 4 días más.

Después de terminar los trabajos de acero, se comienzan con los trabajos de instalaciones. En esta etapa, el sistema convencional presenta algunas desventajas para el colocado de las cajas ortogonales y las tuberías de desagüe como se vio antes. Estas actividades duran 2 días para terminar las instalaciones y cualquier trabajo previo al vaciado de la losa.

Vaciado de concreto de losa (1 días)

En esta etapa, la cuadrilla está conformada por 1 operador, 6 peones, y el maestro. En el caso del proyecto que se ha visitado, se utilizó un trompo para mezclar el concreto. Este día se realizaban correcciones antes del vaciado. Uno de los defectos que se apreció en esta etapa fue que el desperdicio de concreto debido al encofrado afectaba directamente la economía del propietario, ya que se debía utilizar más materiales para culminar con la losa.

Desencofrado de la losa (10 días)

Para esta tercera y última etapa se contó con una cuadrilla de 3 peones y el maestro a cargo para supervisar los trabajos. Para comenzar con el desencofrado de la losa el concreto debe haber adquirido una resistencia de por lo menos $150 \mathrm{~kg} / \mathrm{cm}^{2}$, en el caso del sistema convencional de losas aligeradas se debe esperar aproximadamente 10 días. Durante esta etapa es probable que se retiren algunos tablones de los bordes. 


\subsubsection{Análisis Técnico por Calidad de Acabado}

Esta etapa del análisis consiste en revisar la calidad del acabado que tiene el fondo de losa una vez que se retira el encofrado; es decir, se van a identificar todas las imperfecciones que puede tener la losa. Mostar mediante fotos el estado real del fondo de la losa.

Para este sistema se ha comprobado que al desencofrar las viguetas se encuentra segregación del concreto de las viguetas, esto debido a la calidad de los materiales empleados para la elaboración del concreto; otro factor puede ser a la falta de vibrado luego del vaciado del concreto de la losa, ya que el vibrado ayuda a eliminar los vacíos generados por burbujas de aire atrapados en el concreto y también contribuye a que los agregados se repartan mejor en la mezcla.

En la Figura 57 se puede apreciar la presencia de segregación en las viguetas de una losa aligerada recién techada de una vivienda unifamiliar que se visitó para esta investigación.

Figura 57: Presencia de cangrejeras en las viguetas

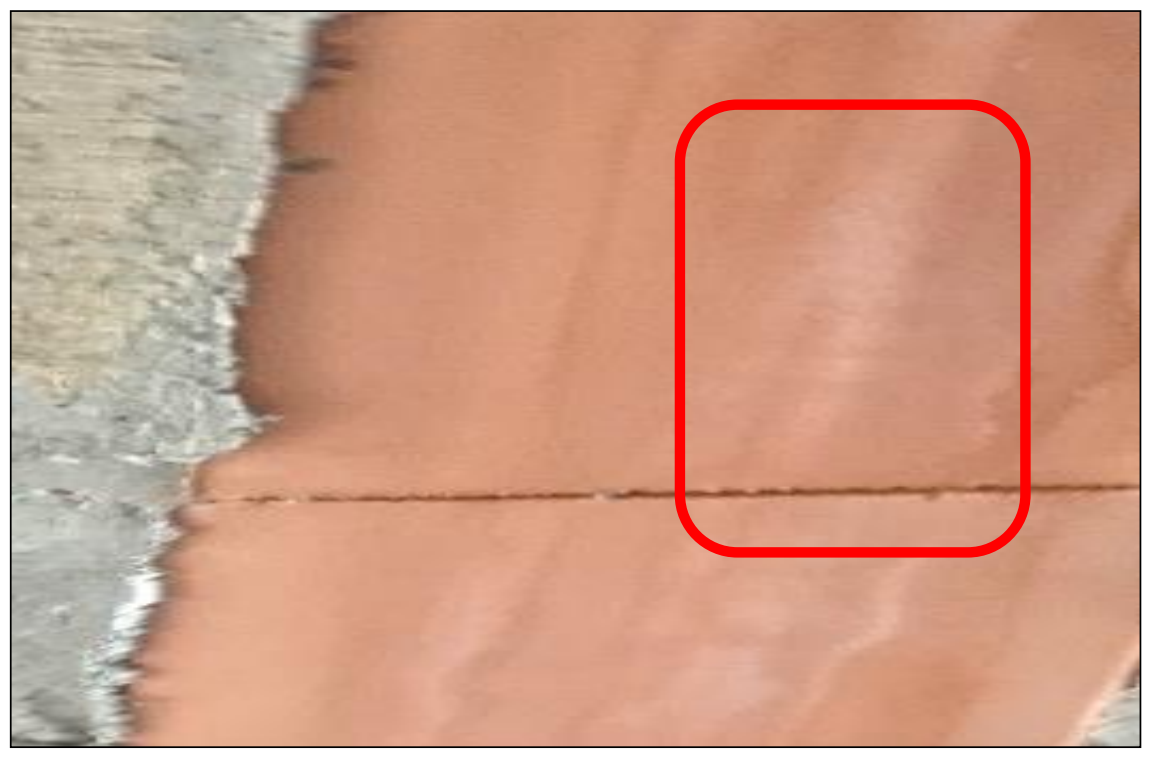

Fuente propia (2016) 
Es claro que el acabado del fondo de la vigueta no es el óptimo, pero a esto se le suma otro defecto que tiene el sistema convencional, ya que durante el encofrado no se utiliza ningún tipo de desmoldante y, como se parecía en la Figura 58, pedazos de madera se quedan pegados en las vigas o viguetas afectando más aun la calidad del fondo de losa y generando desperdicios mayores para la obra.

Figura 58: Desperdicio de madera en la vigueta

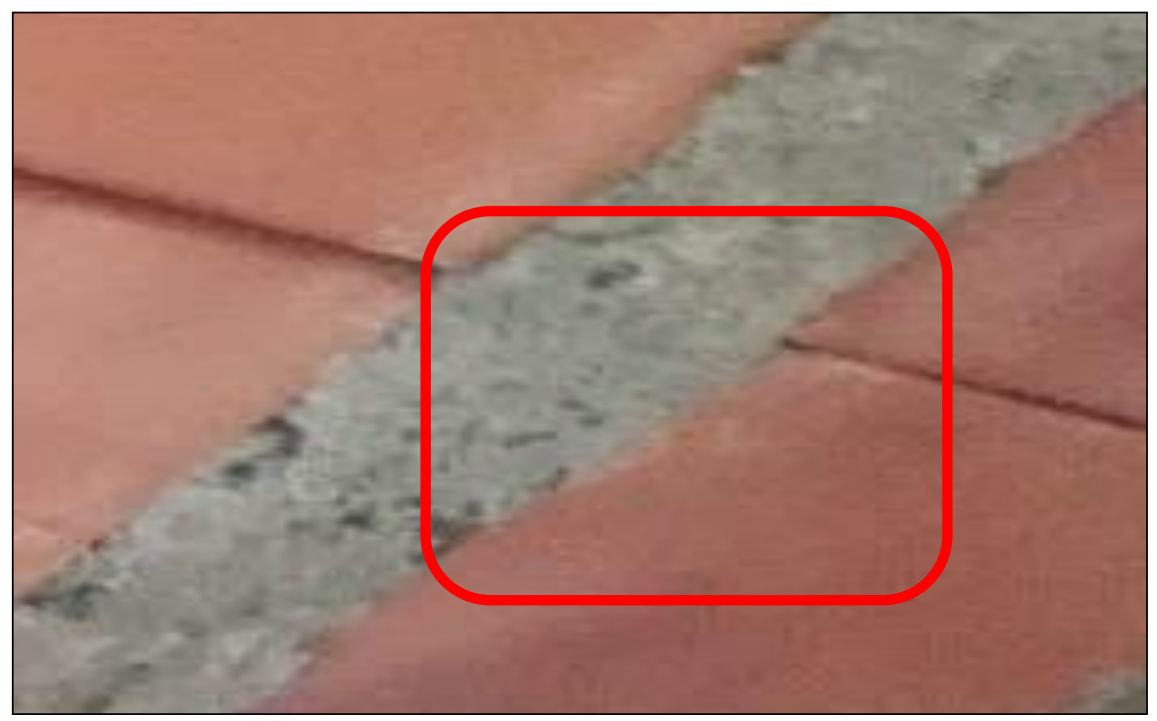

Fuente propia (2016)

\subsubsection{Análisis Técnico por Calidad del Concreto}

El objetivo de este subcapítulo es poner en evidencia los problemas que se presentan en el concreto en la autoconstrucción. Para esto se han obtenido 2 probetas de concreto para evidenciar 2 problemas específicos: el primero es que en la autoconstrucción se utilizan varios tipos de mezcla que ocasionan diferentes resistencias en la losa, eliminándose la homogeneidad estructural. El segundo es que la resistencia a la compresión del concreto utilizado en las viguetas no llega a la resistencia adecuada.

Para comprobar estas hipótesis las probetas han sido tratadas en el laboratorio Ingeniería Civil de la Universidad Peruana de Ciencias Aplicadas, las probetas han sido curadas cambiándose el agua cada semana hasta el día 28. Los resultados de estas probetas se muestran en la Tabla 5. 
Tabla 5: Resistencia a la compresión de las muestras tomadas

\begin{tabular}{ccc}
\hline & Muestra $\mathbf{N}^{\circ} \mathbf{1}$ & Muestra $\mathbf{N}^{\circ} \mathbf{2}$ \\
\hline Resistencia a la compresión a & $150 \mathrm{~kg} / \mathrm{cm}^{2}$ & $80 \mathrm{~kg} / \mathrm{cm}^{2}$ \\
los 28 días & & \\
\hline
\end{tabular}

Nota: Fuente propia (2017)

La Muestra $\mathrm{N}^{\circ} 1$ se obtuvo del concreto utilizado en las vigas principales y soleras; la Muestra $\mathrm{N}^{\circ} 2$ se obtuvo del concreto utilizado en las viguetas y la capa de compresión, con estos resultados se puede concluir las 2 hipótesis antes planteadas son ciertas, en primer lugar, no existe una homogeneidad estructural en la losa aligerada y en segundo lugar la resistencia de este concreto no llega a la resistencia mínima requerida para este tipo de elemento estructural.

Otra falencia que se identificó es la falta de homogeneidad en la geometría de la vigueta, ya que algunas se ven reducidas durante el proceso de armado perjudicando el comportamiento ante solicitaciones posteriores. La Figura 59 muestra estas falencias.

Figura 59: Distintos espesores de las viguetas

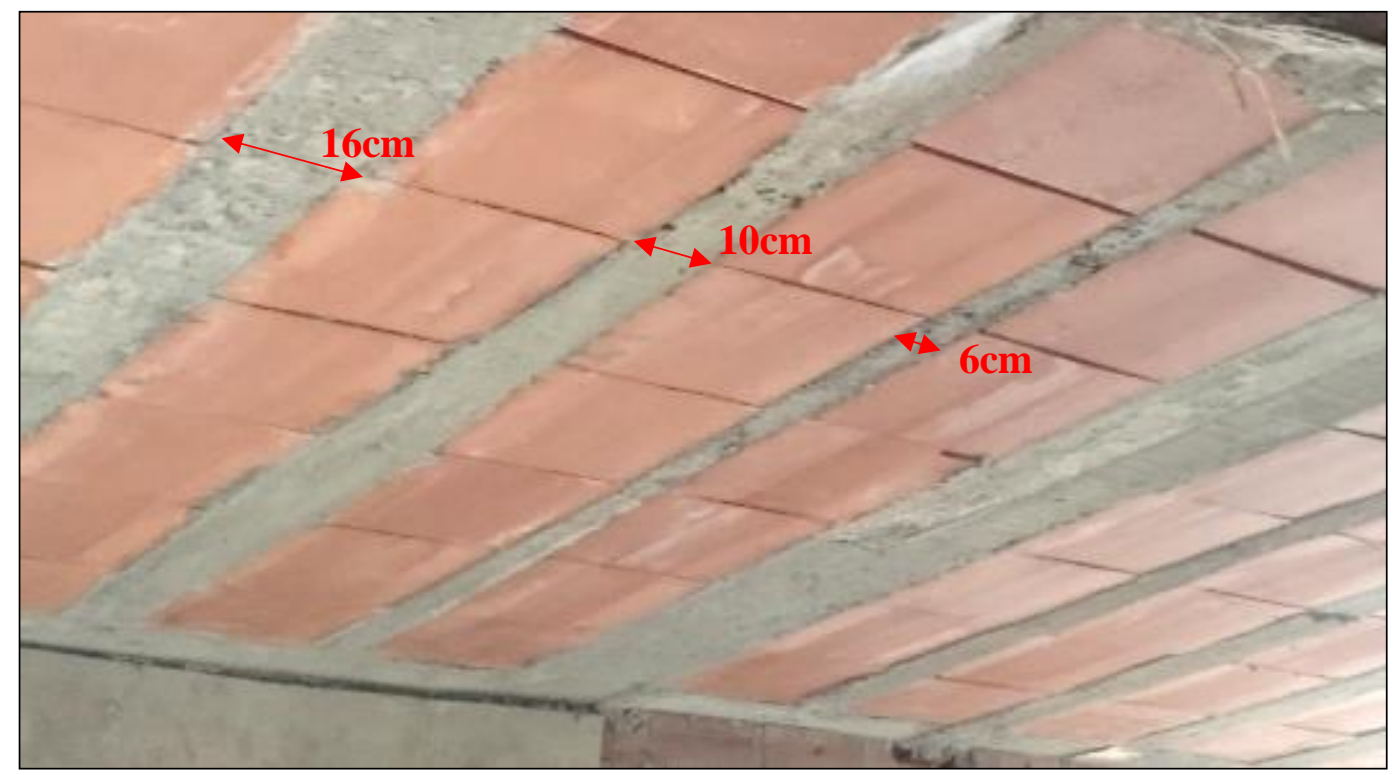

Fuente propia (2016) 


\subsection{Sistema de Losa aligerada con Vigueta Pretensada}

Las etapas del proceso constructivo para este sistema están resumidos en el Figura 60.

Figura 60: Proceso constructivo sistema de losa aligerada con vigueta pretensada

- Almacen de viguetas en obra

- Apuntalamiento

- Colocación de viguetas, bovedillas e instalaciones

- Vaciado de concreto en losa y curado

- Desencofrado

Fuente propia (2016)

A continuación se va a detallar todas las etapas constructivas que se muestran en la figura anterior para la construcción de una losa aligerada con viguetas pretensadas.

\subsubsection{Proceso constructivo:}

Almacenamiento de viguetas en obra

Es recomendable que las viguetas se coloquen sobre suelo firme y sean colocadas formando varias planchas de viguetas, las planchas deben estar separadas por listones de madera, estos deben estar correctamente alineados como se puede observar en la Figura 61. 
Figura 61: Correcto almacén de viguetas

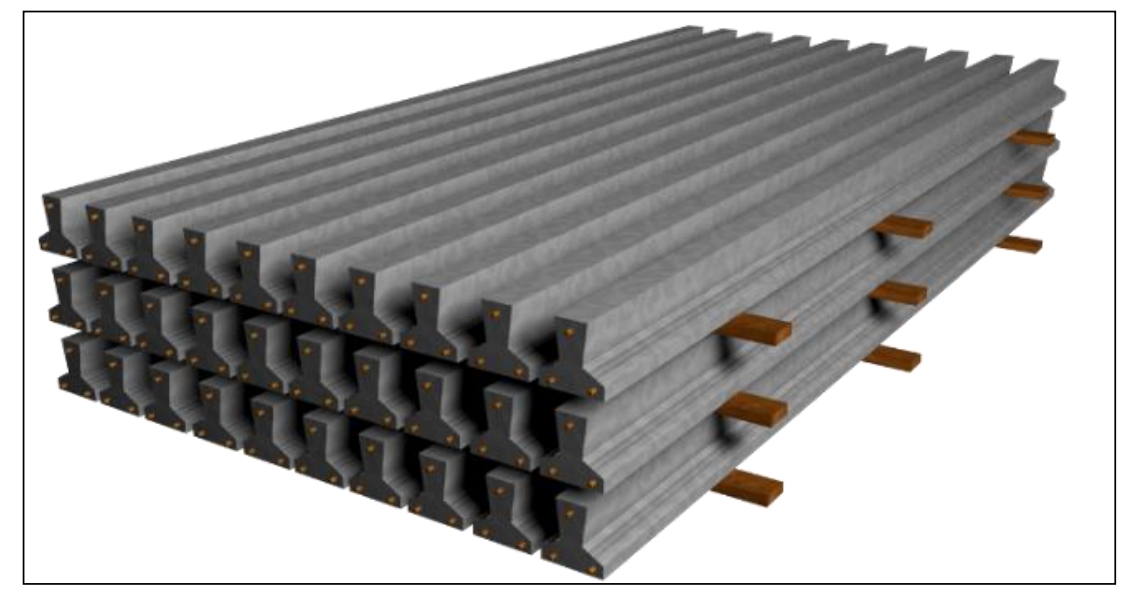

Adaptado de Pretensa (s.f.)

Apuntalamiento: Colocación de soleras y pies derechos (apuntalamiento)

El apuntalamiento es la etapa más relevante de todo el montaje de viguetas, ya que un error en esta etapa puede impedir el correcto funcionamiento de la losa y poner en riesgo la ejecución de la obra, el encofrado que se recomienda debe ser de madera para permitir que la contraflecha se la vigueta seda con el peso de la losa vaciada.

La separación entre soleras es de $1.50 \mathrm{~m}$ y los puntales de estas soleras deben estar separados a $1.50 \mathrm{~m}$; las soleras deben respetar la contra fecha de las viguetas, no se debe reducir la contra flecha por ningún motivo para que esta quede horizontalmente en el momento del vaciado del concreto de losa. En el caso de que los puntales o pies derechos estén apoyados sobre terreno natural se deben colocar sobre tablas para asegurar los trabajos a realizarse sobre la losa. El espaciado de soleras y puntales deben quedar como muestra la Figura 62. 
Figura 62: Colocación de soleras y puntales

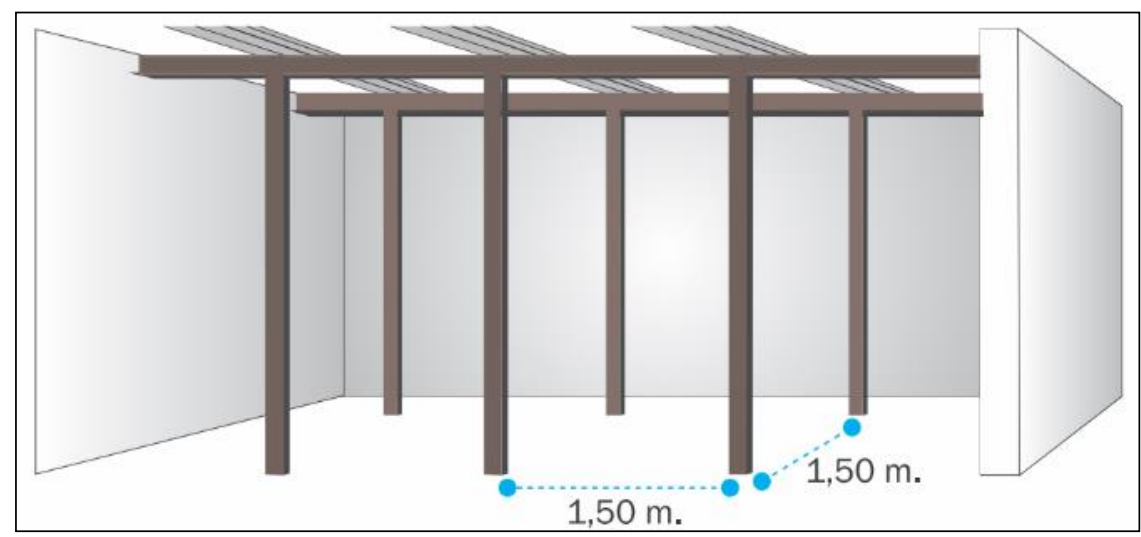

Adaptado de Pretensa (s.f.)

Montaje de viguetas

Esta etapa comienza con la distribución de viguetas, por lo general el vendedor en obra proporciona los planos de distribución de las viguetas; las viguetas empiezan a ser colocadas al lado de la viga (VIGA-VIGUETA-LADRILLO O BOVEDILLA) como se aprecia en la Figura 63. La rapidez de ejecución de esta actividad, permite ahorro en mano de obra.

Figura 63: Montaje de vigueta pretensada

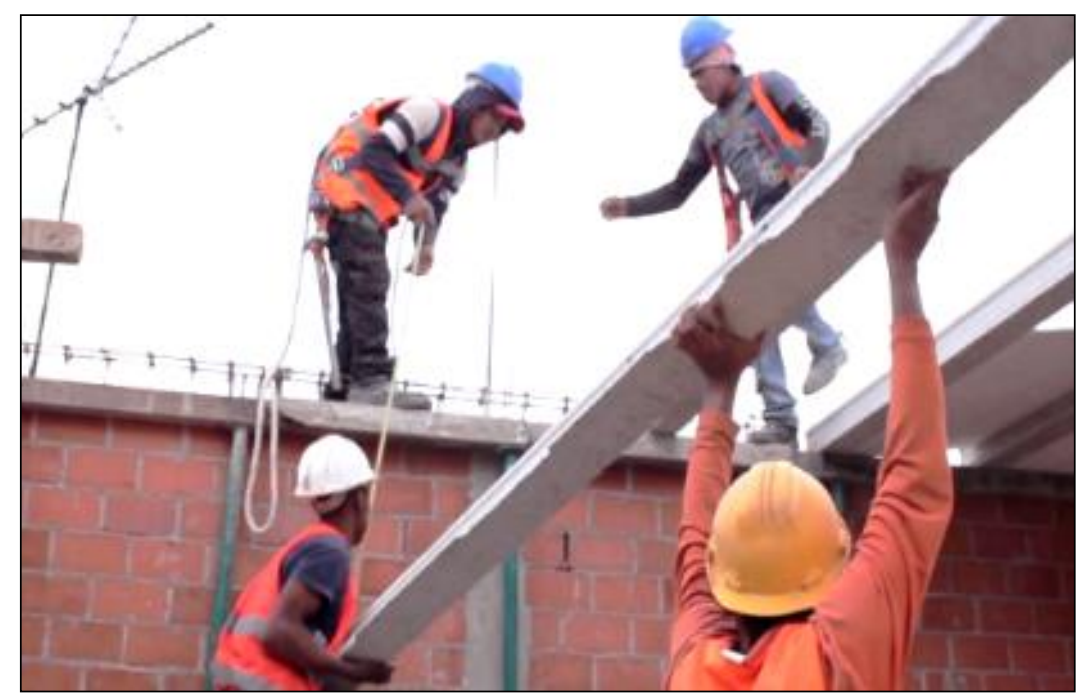

Adaptado de Premex (2015) 
Las viguetas son empotradas $10 \mathrm{~cm}$ para luces menores a $5.50 \mathrm{~m}$ y $15 \mathrm{~cm}$ para luces mayores a $15 \mathrm{~cm}$ como se aprecia en la Figura 64 (Concremax, s.f.). En el caso de coincidir con los estribos de la viga, estos se desplazan no más de $5 \mathrm{~cm}$; en algunos casos se despunta la vigueta, pero es más práctico correr un poco los estribos y si es necesario, adicionar otro estribo.

Figura 64: Conexión viga peraltada - vigueta

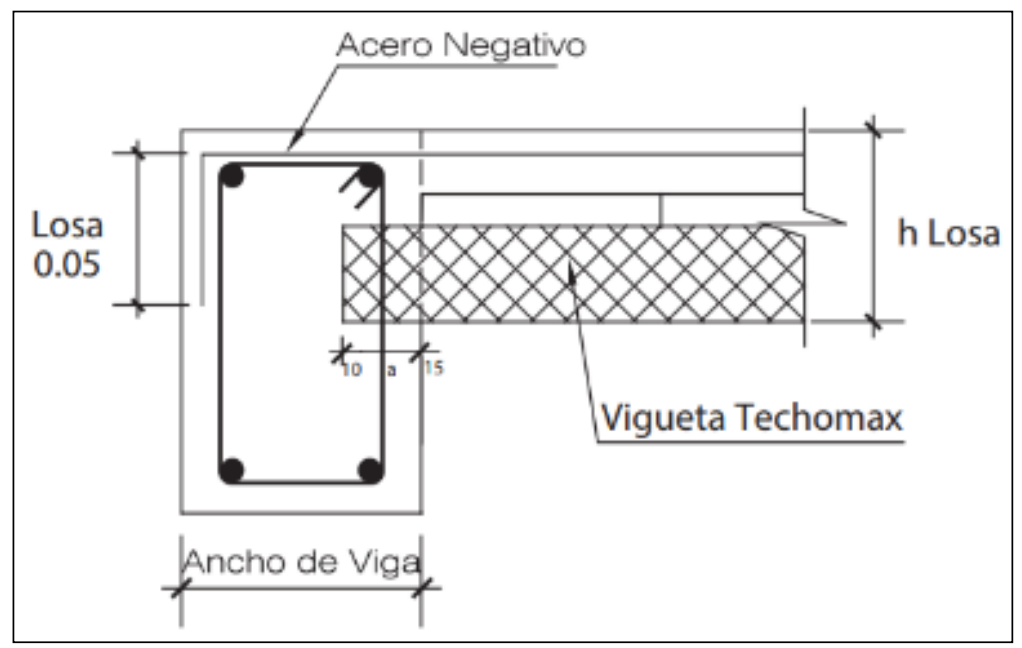

Adaptado de Concremax (s.f.)

Para el caso de viguetas empotradas en vigas chatas y para longitudes menores a $4.40 \mathrm{~m}$, Concremax (s.f.) indica que la vigueta debe ingresar por lo menos $2 \mathrm{~cm}$ y el acero de la vigueta entre $10 \mathrm{~cm}$ y $15 \mathrm{~cm}$ como se aprecia en la Figura 65. Para luces mayores a 4.40m se debe dejar un ensanche alternado de la bovedilla (Concremax, s.f.) 
Figura 65: Conexión viga chata - vigueta

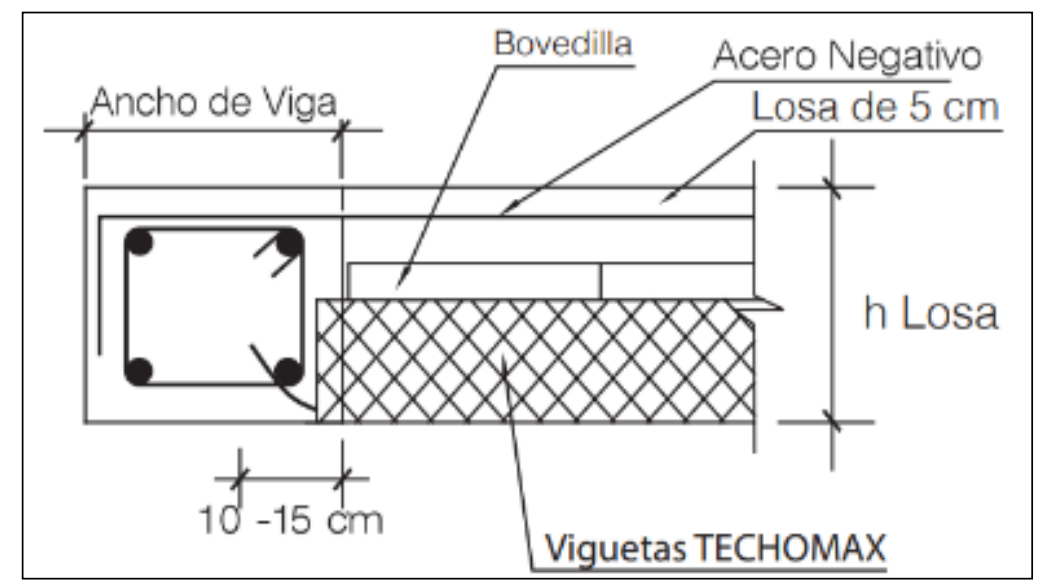

Adaptado de Concremax (s.f.)

Para el caso de los voladizos la vigueta pretensada ya no va a trabajar, solamente se debe adicionar el acero negativo requerido para el paño según el cálculo estructural.

Colocado de ladrillos, bovedillas o poli estireno expandido

Se colocan los ladrillos bovedilla empezando desde los extremos como se aprecia en la Figura 66, ya que esto marcará la pauta para las siguientes bovedillas del techo.

Figura 66: Colocación de bovedillas desde los extremos

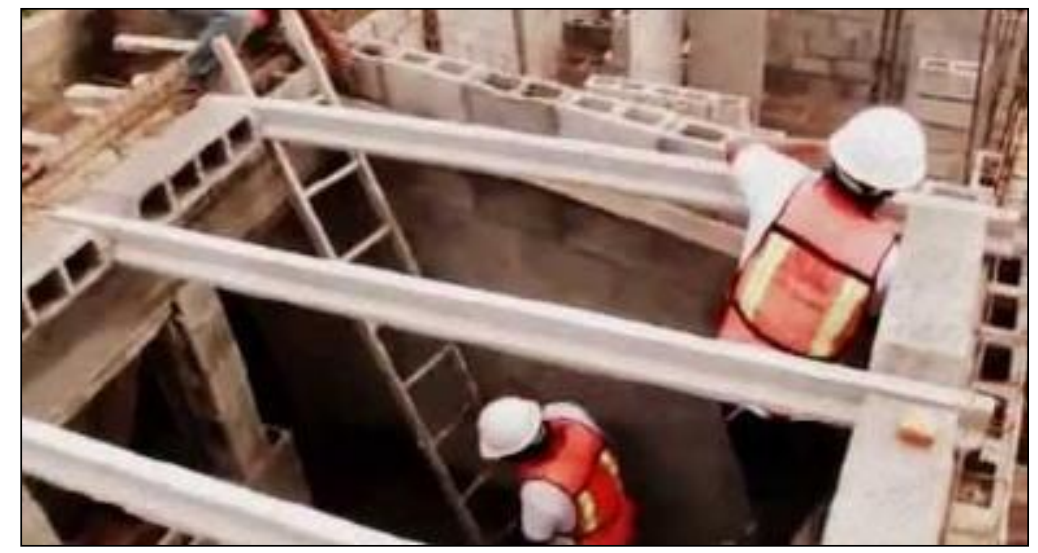

Adaptado de Concremax (s.f.) 
En la figura anterior se puede ver una bovedilla de concreto que tiene $20 \mathrm{~cm}$ de largo, en este sistema también se puede emplear la bovedilla de arcilla que tiene $25 \mathrm{~cm}$ de largo o también casetones de poliestireno expandido que miden $1 \mathrm{~m}$ de longitud, la elección del tipo de bovedilla va depender muchas veces del sistema que maneje el fabricante o ante solicitaciones estructurales requeridas por el diseño del aligerado.

Colocación de bastones, balancín y acero negativo

Se trata de bastones que se colocan en la parte superior de la vigueta, enganchados a la viga y que deberán respetar las dimensiones indicadas en los planos.

Colocación de instalaciones eléctricas y sanitarias

En esta etapa se van a colocar las instalaciones tanto eléctricas como sanitarias, en algunos casos se puede contar con bandejas o bovedillas hechas en fábrica en las que encajan las instalaciones, en caso de que no se cuente con estas bandejas, se debe hacer un espacio adecuado para colocar las instalaciones. Es importante tener en cuenta que ninguna de las instalaciones se debe colocar en las viguetas. En la mayoría de casos, las instalaciones sanitarias se van colocando de forma paralela a la colocación de la bovedilla y viguetas como se aprecia en las Figura 67 y 68.

Figura 67: Instalaciones eléctricas con viguetas pretensadas

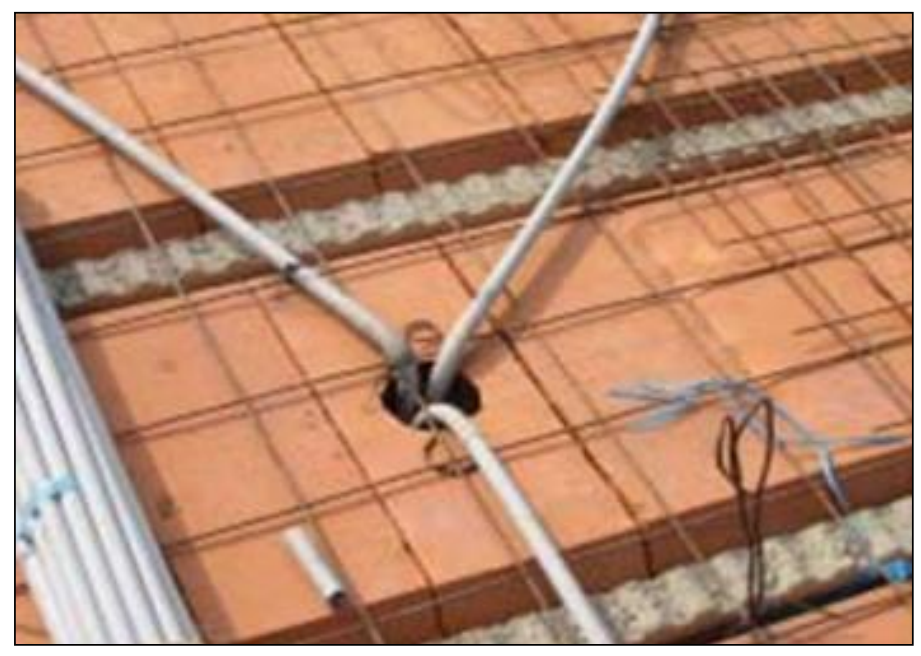

Adaptado de Firth (2012) 
Figura 68: Instalaciones sanitarias con viguetas pretensadas

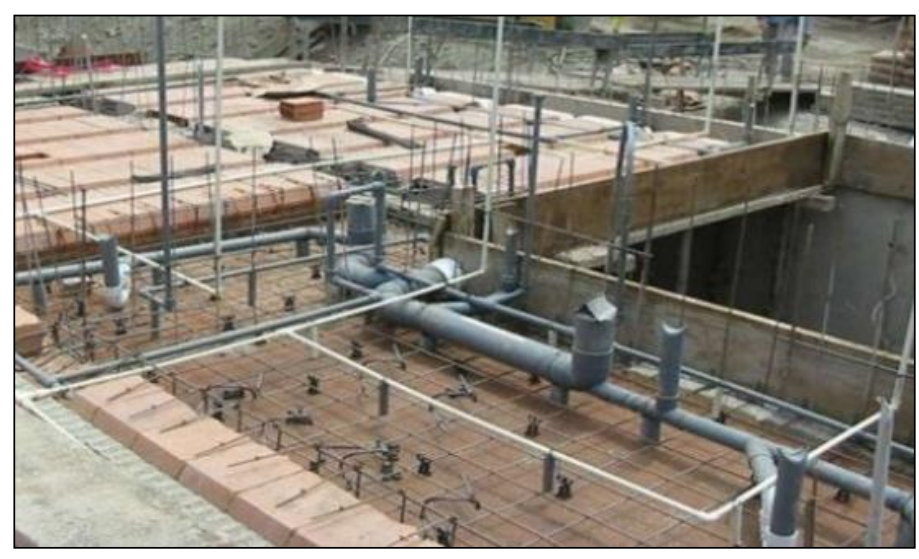

Adaptado de Firth (2012)

Colocado de malla de temperatura

Se coloca la malla de temperatura de acero de 1/4" o $6 \mathrm{~mm}$ como se muestra en la Figura 69, la ubicación de esta malla es sobre la bovedilla. Asimismo, se deben colocar dados o separadores de concreto, para evitar levantar la malla durante el vaciado del concreto, ya que la malla no puede quedar pegada a la bovedilla y de esta forma permita el ingreso del concreto de forma uniforme.

Figura 69: Malla de temperatura en losa con viguetas pretensadas

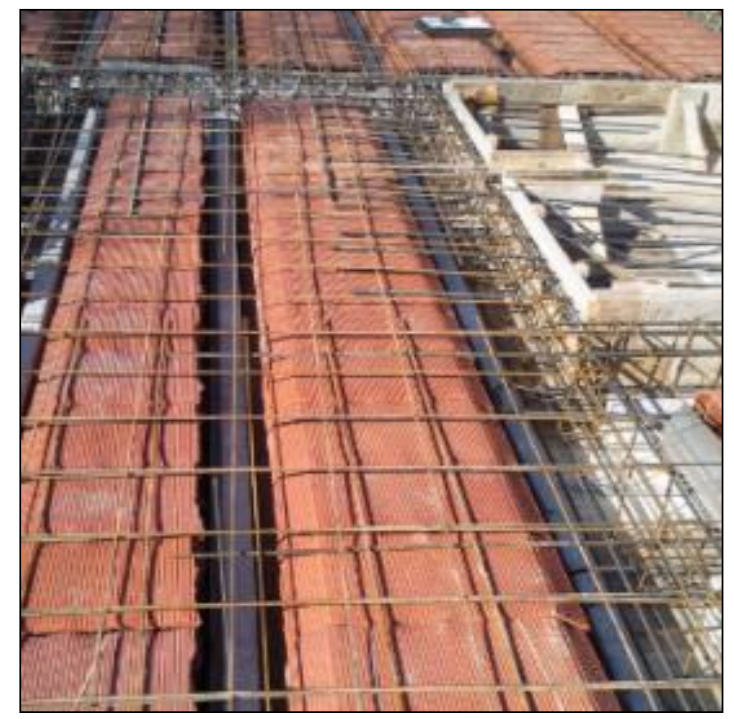

Adaptado de Firth (2012) 
Limpieza y mojado

Con el objetivo de mejorar la adherencia del concreto, se debe limpiar la superficie de las viguetas mediante un riego antes del vaciado de la capa de compresión como se muestra en la Figura 70.

Figura 70: Limpieza y mojado de losa

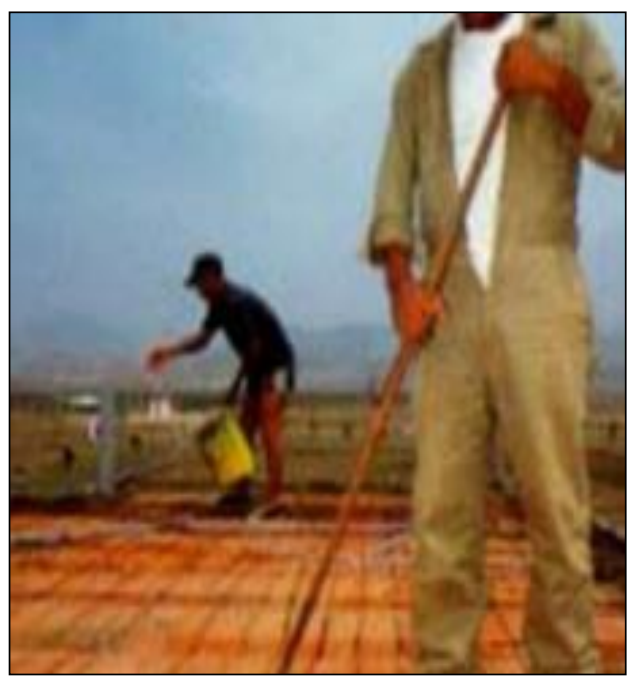

Adaptado de Firth (2012)

Vaciado de la capa de compresión

La mezcla, vibrado y curado del concreto de la capa de compresión seguirá las normas convencionales de construcción. El vaciado debe ser de forma paralela a las viguetas como se aprecia en la Figura 71, con la finalidad de evitar movimientos al pisar las viguetas que faltan vaciar.

Existen diferentes prácticas de vaciado, una de ellas es vaciar primero las viguetas y luego empezar a vaciar la losa; sin embargo, lo recomendable es vaciar la capa de compresión y las viguetas en conjunto, ya que de no hacerlo puede generar que el fraguado no sea homogéneo muchas veces por las grandes dimensiones de la losa (Viguetas pretensadas S.A.C. \& Avall contratistas, 2011) 
Figura 71: Vaciado de concreto sobre losa

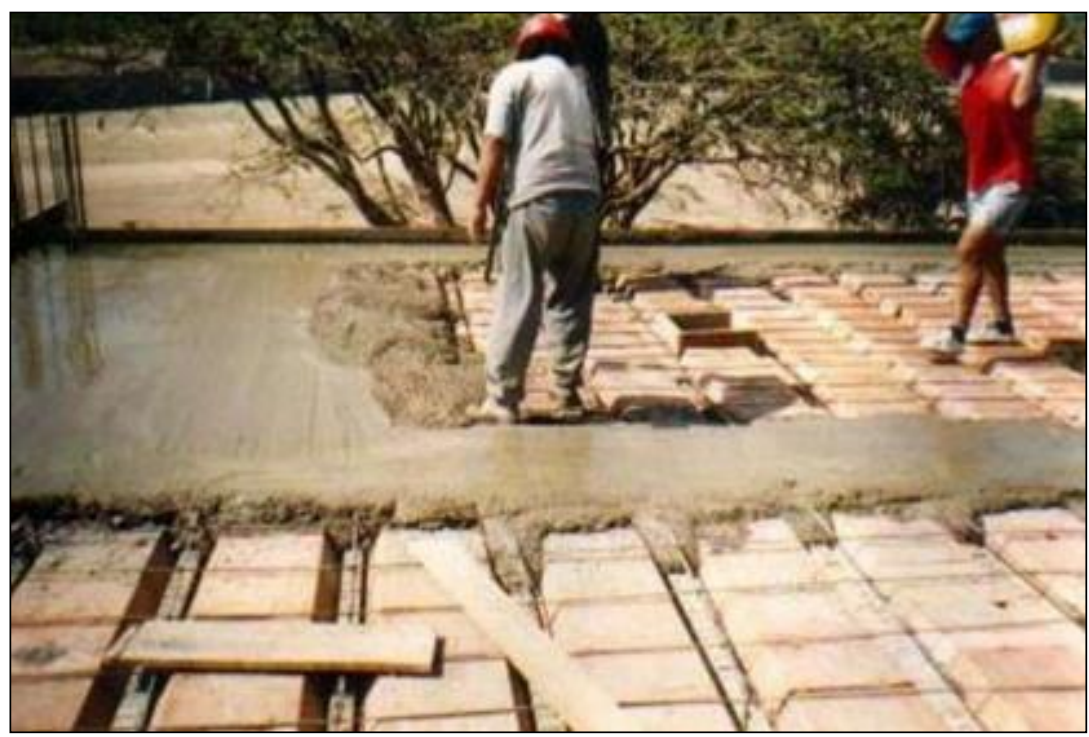

Adaptado de Firth (2012)

Desencofrado

Se empieza a desencofrar desde los extremos y primero se van a quitar los puntales de la losa para luego seguir con los puntales de la viga. Los días que debe permanecer la losa sin desencofrar van a depender de la luz del paño y del tipo de concreto empleado, pero se maneja un estimado de 10 días para una construcción convencional de vivienda.

\subsubsection{Evaluación Técnica por tiempo de ejecución}

Para explicar esta evaluación se ha buscado un proyecto con las mismas características que se tuvo en el sistema anterior, de este modo es más fácil hacer una comparación entre estos sistemas. Las características que tiene este proyecto son las siguientes:

\section{Ubicación:}

Jr. Lloque Yupanqui Mz. R, Lote 7

Urb. El Trébol - Los Olivos

Nombre del maestro a cargo: Yohel Montalvo

Área de losa:

$120 \mathrm{~m}^{2}$

Dentro de todo el proceso constructivo que se tiene para la ejecución se han identificado 3 etapas principales que son: Armado de losa, Vaciado de concreto de losa y 
Desencofrado de losa. A continuación, se va a explicar el tiempo que ha llevado cada una de estas etapas con el sistema de viguetas pretensadas VIPRET.

Armado de la losa (7 días)

Esta actividad se ha realizado con una cuadrilla de 2 carpinteros, 2 fierreros y un maestro de obra. Esta etapa comienza con el encofrado de las vigas principales y vigas soleras. Las vigas principales van a servir de apoyo para las viguetas pretensadas, estas se van a colocar respetando el espaciamiento de $50 \mathrm{~cm}$ de eje a eje. Mientras se estén colocando las viguetas se debe ir apuntalando para asegurar su posición y evitar accidentes (3 días de duración).

En el cuarto día de trabajo se realiza el colocado de las bovedillas y también se inician los trabajos de acero, en este caso el armado de la malla de temperatura y acero negativo, ya que la vigueta incluye el acero positivo (2 día de duración).

En el sexto día se terminan los trabajos de acero y se comienzan con los trabajos de instalaciones. En esta etapa el sistema de viguetas presenta algunas desventajas cuando las tuberías de desagüe las cruzan, en este caso la solución en obra que se hace es optar por una losa maciza. (2 días de duración)

Vaciado de concreto de losa (1 días)

Esta segunda etapa se realizó con una cuadrilla de 5 peones, un operario y el maestro. En el caso del proyecto que se ha visitado se utilizó un mixer de concreto para la losa. Este día se realizaron correcciones antes del vaciado, a diferencia del sistema anterior, el desperdicio de concreto que se tiene debido al encofrado es mínimo, ya que la vigueta en unión con la bovedilla forma un sello que retiene el concreto y no deja que pase al nivel inferior, cosa que si sucede con el sistema convencional en algunas zonas del encofrado.

Desencofrado de la losa (10 días) 
La tercera etapa se realizó con una cuadrilla de 3 peones. Para comenzar con el desencofrado de la losa el concreto debe haber adquirido una resistencia de por lo menos $160 \mathrm{~kg} / \mathrm{cm}^{2}$, lo que ocurre mayormente en el décimo día que es cuando se desencofra. En todos los casos el desencofrado toma un día de trabajo.

\subsubsection{Análisis Técnico por Calidad de acabo}

En esta evaluación se evidencia, mediante fotografías de un proyecto real, el resultado que ofrece el sistema de losa aligerada con viguetas prefabricadas en cuanto al acabado de fondo de losa luego del desencofrado. Este es un aspecto que se ha considerado importante mencionar en vista de que el acabado del fondo de losa representa un gasto adicional para el propietario y si este logra reducirse o eliminarse mediante el uso de este sistema lo vuelve una opción más llamativa para utilizarse.

Como ya se ha mostrado en el Capítulo 3, las viguetas y las bovedillas son fabricadas de manera industrial, garantizándose muchos estándares de calidad que el mercado actual exige. La Figura 72 muestra el fondo de losa luego del desencofrado en el proyecto que se está evaluando.

Figura 72: Fondo de losa luego del desencofrado - vigueta pretensada

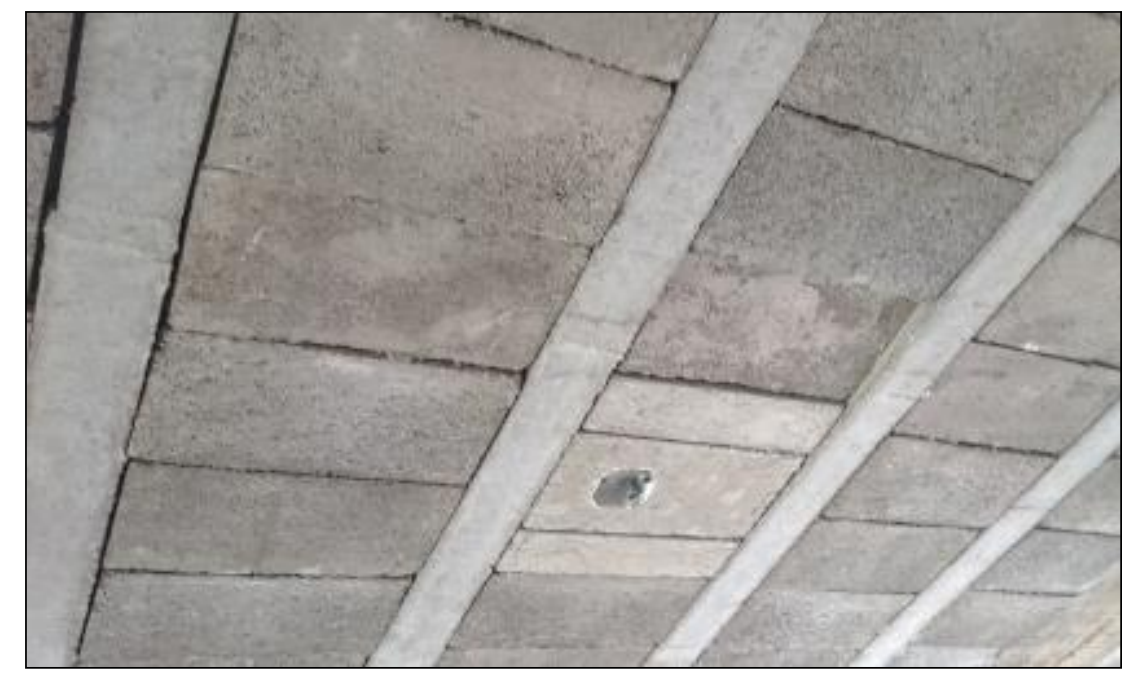

Fuente propia (2016) 
Se aprecia que, a diferencia del sistema convencional, este sistema presenta un mínimo de imperfecciones que es invisible a primera vista, lo cual puede permitir eliminar el tarrajeo de cielorraso y simplemente culminar el acabado con una pintura en las viguetas y bovedillas reduciéndose al 100\% el costo de tarrajeo por acabado. La Figura 73 muestra un área mucho mayor de losa que tampoco presenta defectos en su acabado.

Figura 73: Fondo de losa con vigueta, columna y muro - vigueta prefabricada

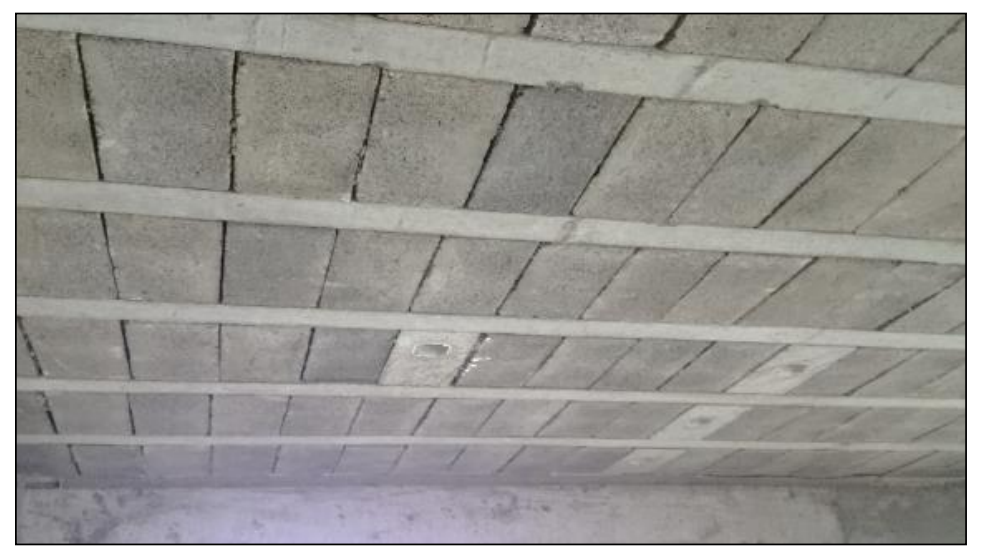

Fuente propia (2016)

Además, debido a que este sistema elimina el uso de tablas para el encofrado y cuyo sistema de cerramiento entre vigueta y bovedillas es tan eficaz, se elimina casi al 100\% los desperdicios de concreto que ensucian el nivel inferior y las columnas, esta limpieza también se refleja en el piso utilizado para el encofrado de la losa.

\subsubsection{Evaluación Técnica por Calidad del Concreto}

La empresa VIPRET realizó un comparativo estructural de los sistemas de losa aligerada convencional frente al de vigueta pretensada para un artículo de la revista CONSTRUCTIVO (enero, 2015) con la finalidad de comparar ambos sistemas y mostrar su desempeño en situaciones iguales.

En el artículo se explica detalladamente la elaboración de dos losas de 1 metro de ancho por 20 centímetros de alto para ambos sistemas de losa aligerada. Ambos ejemplares están sujetos a la situación más crítica, un apoyo simple en sus extremos de 10 
centímetros. El objetivo de este ensayo es evaluar el comportamiento de ambos sistemas ante la situación más desfavorable (Constructivo, enero 2015)

La luz de estos ejemplares es de 4.10 metros y el ensayo se ha realizado cuando el concreto alcanzó una resistencia de $210 \mathrm{~kg} / \mathrm{cm}^{2}$ a los 28 días. El Parámetro L/360 tomado como flecha máxima para este ensayo muestra un descenso máximo de $1.14 \mathrm{~cm}$ según lo establecido en el Reglamento Nacional de Edificaciones.

Se han considerado 2 casos de carga, el primero con $425 \mathrm{~kg} / \mathrm{m}^{2}+$ peso propio como se muestra en la Figura 74 y el segundo con $680 \mathrm{~kg} / \mathrm{m}^{2}+$ peso propio como se muestra en la Figura 75.

Figura 74: Caso de carga $\mathrm{N}^{\circ} 1$ vigueta pretensada - 425kg/m2 + Peso propio

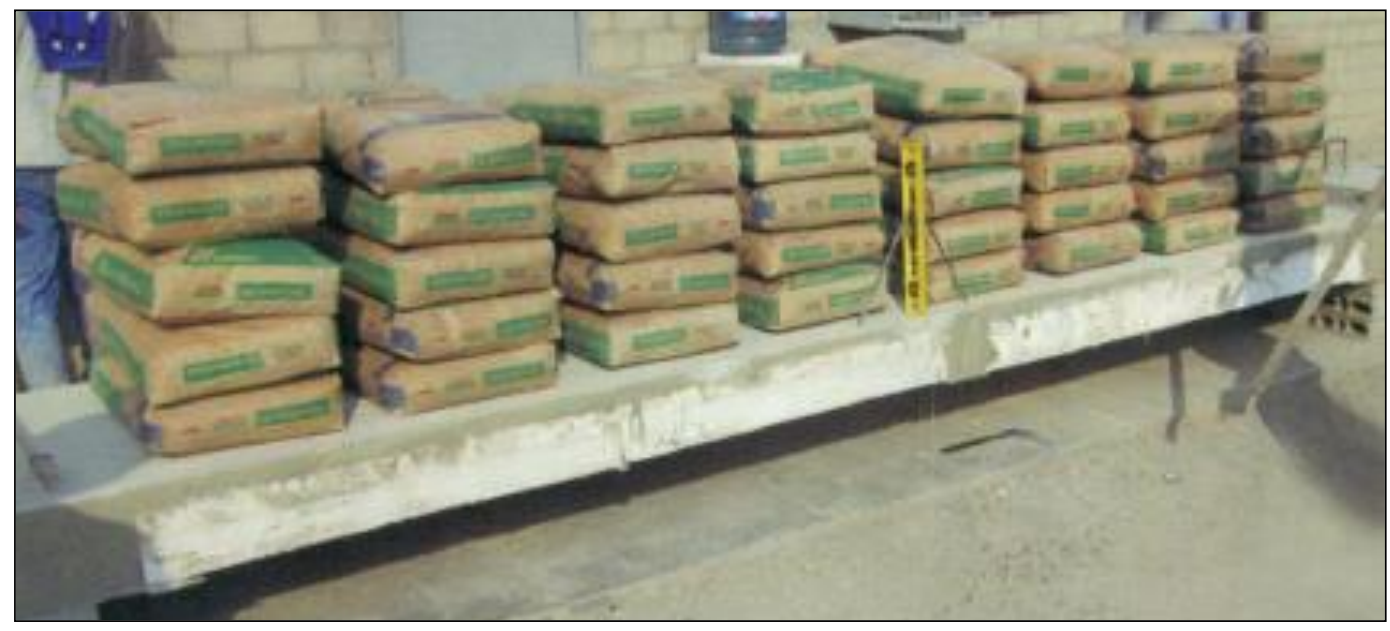

Adaptado de Constructivo (enero, 2015) 
Figura 75: Caso de carga $\mathrm{N}^{\circ} 2$ vigueta pretensada - 680kg/m2 + Peso propio

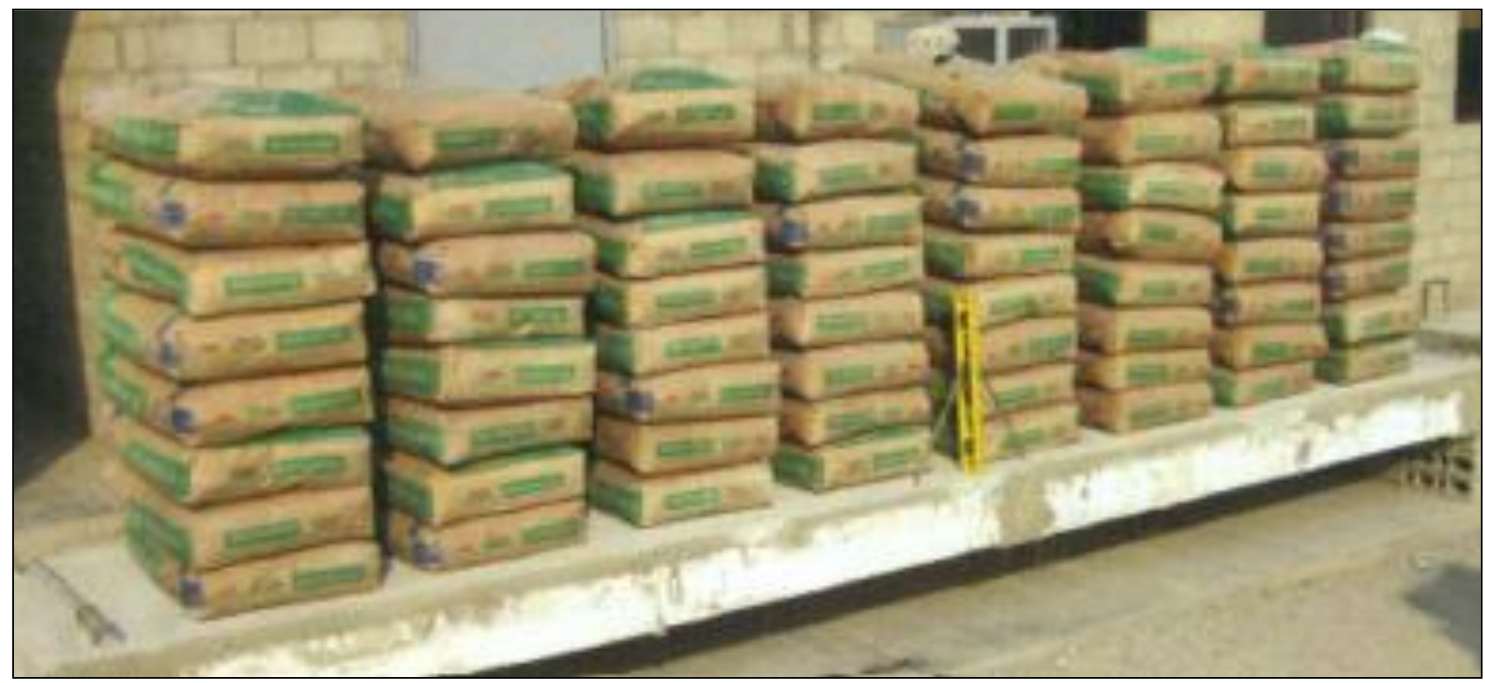

Adaptado de Constructivo (enero, 2015)

En el caso de carga $\mathrm{N}^{\circ} 1$ el descenso fue de $3 \mathrm{~mm}$ y en el caso de carga $\mathrm{N}^{\circ} 2$ fue de $12 \mathrm{~mm}$. En ambos casos, la losa aligerada con vigueta pretensada VIPRET recupera su flecha original cumpliendo con lo establecido en el R.N.E. Los ensayos para la losa con el sistema convencional se muestran en las Figura 76 y 77 con los 2 casos al igual que para el sistema de vigueta pretensada.

Figura 76: Caso de carga $\mathrm{N}^{\circ} 1$ losa convencional $-680 \mathrm{~kg} / \mathrm{m} 2+$ Peso propio

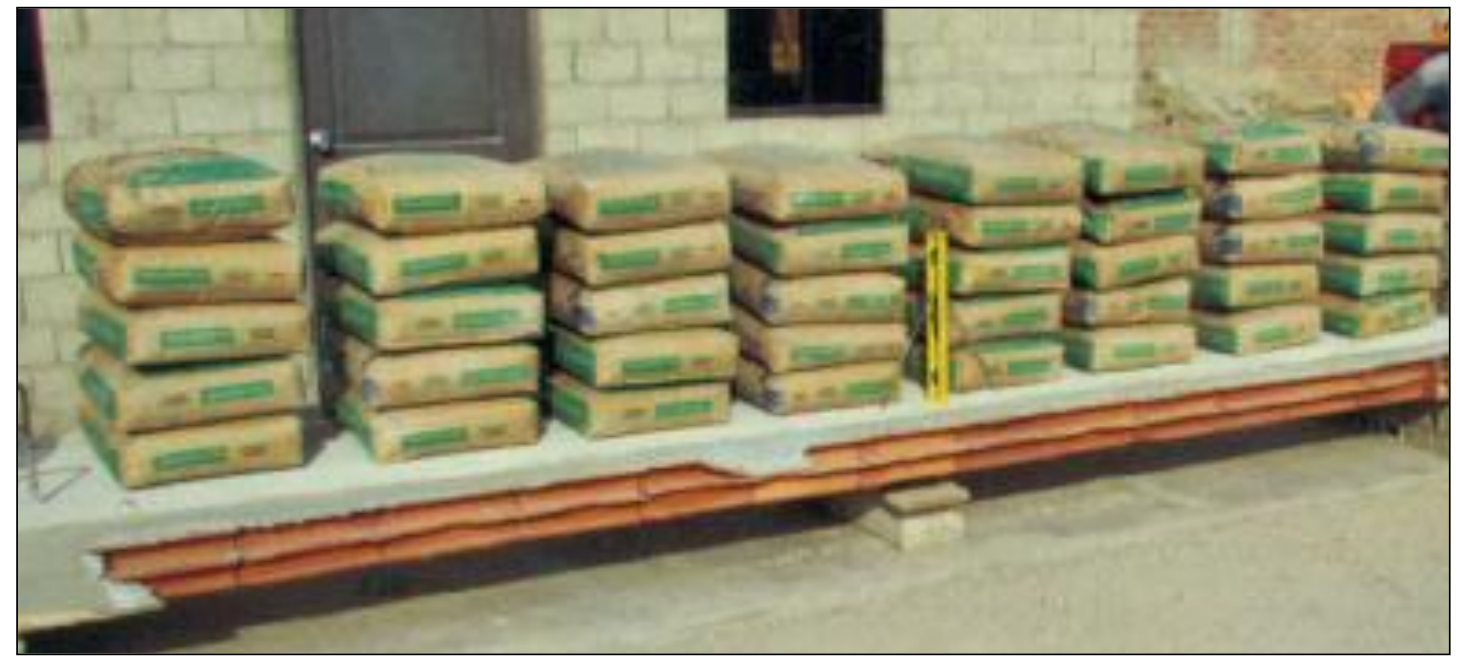

Adaptado de Constructivo (enero, 2015) 
Figura 77: Caso de carga $\mathrm{N}^{\circ} 1$ losa convencional - 425kg/m2 + Peso propio

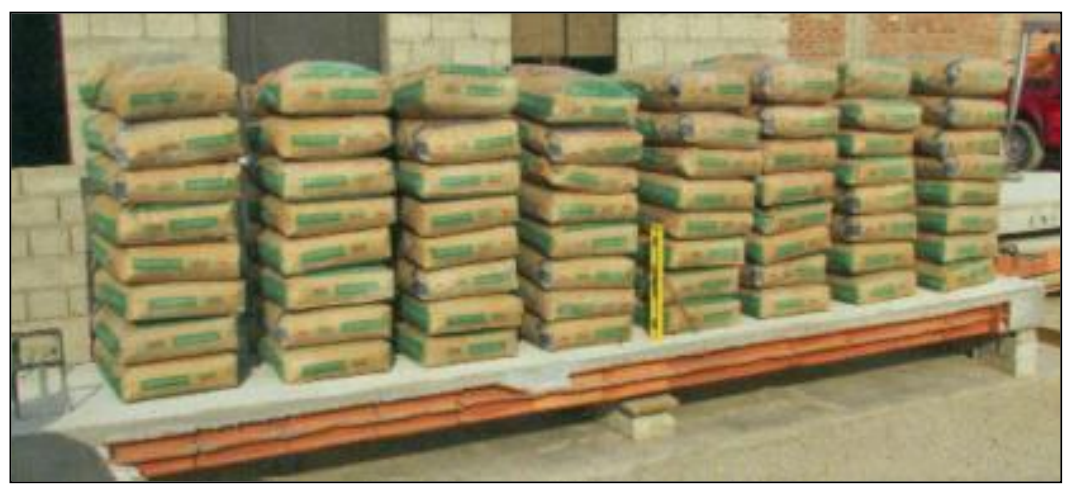

Adaptado de Constructivo (enero, 2015)

En el caso de carga $\mathrm{N}^{\circ} 1$ el descenso fue de $17 \mathrm{~mm}$ y en el caso de carga $\mathrm{N}^{\circ} 2$ fue de $47 \mathrm{~mm}$. En este sistema se sobrepasa el descenso máximo para ambos casos de carga, además, en el segundo caso la deformación en la losa es permanente luego de retirar la carga. Es claro apreciar la diferencia entre ambos sistemas, además de esto, la empresa VIPRET otorga los resultados de sus ensayos a compresión del concreto utilizado en sus viguetas garantizando la resistencia estructural del elemento. La Figura 78 muestra un certificado que entrega la empresa con sus resultados de compresión. 
Figura 78: Resultado de ensayo resistencia a la compresión para vigueta pretensada

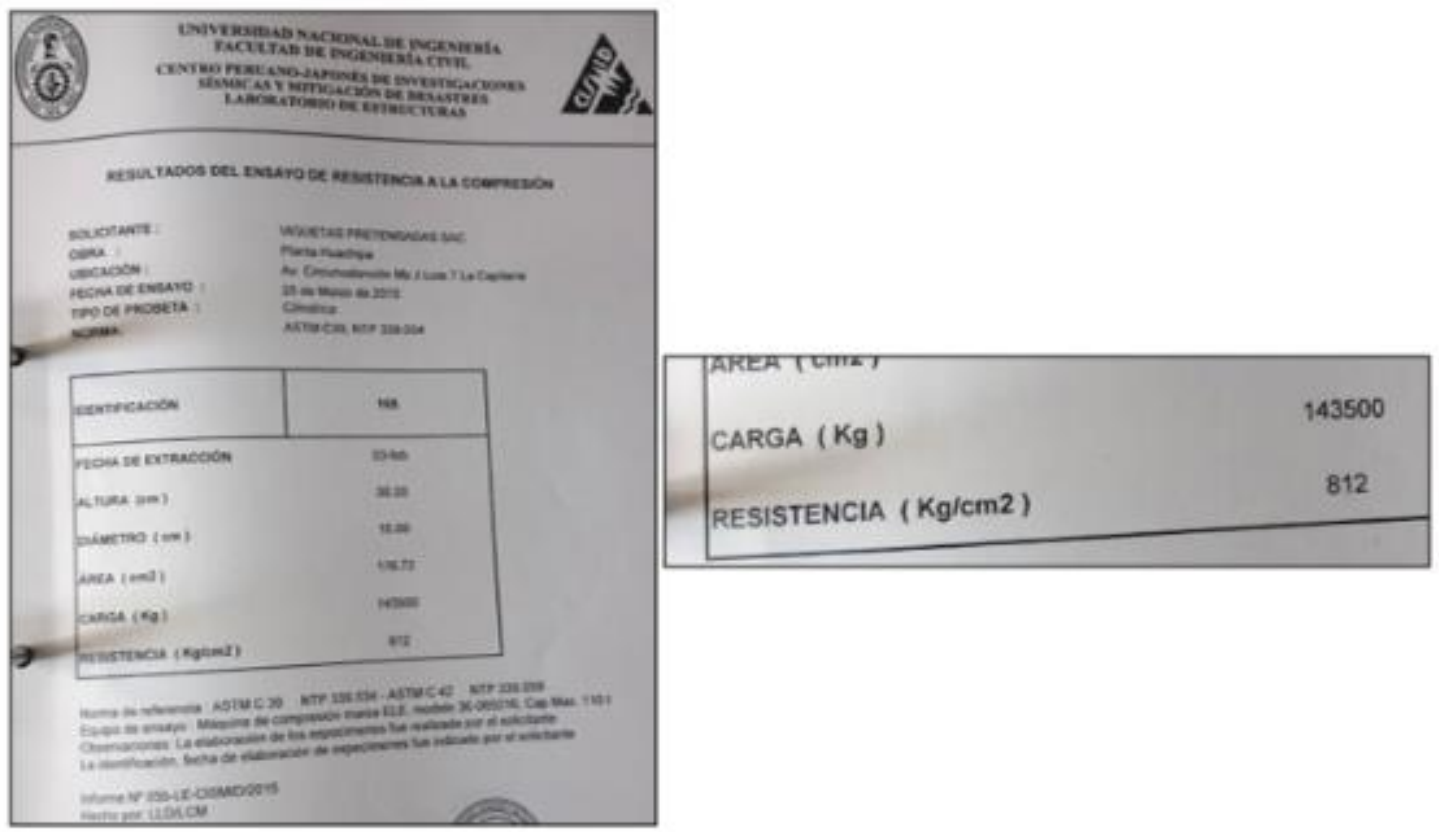

Adaptado de Vipret (s.f.)

Las resistencias que ofrece la empresa VIPRET varía desde $350 \mathrm{~kg} / \mathrm{cm}^{2}$ a $500 \mathrm{~kg} / \mathrm{cm}^{2}$, sin embargo los ensayos han demostrado que esta resistencia puede llegar incluso a $800 \mathrm{~kg} / \mathrm{cm}^{2}$, con lo cual la empresa no solo garantiza la resistencia de servicio que ofrece sino que garantiza la resistencia frente a otras cargas durante la etapa constructiva como maquinarias o materiales apilados.

\subsection{Sistema de Losa aligerada con Vigueta TRALICHO}

Las etapas del proceso constructivo para este sistema están resumidos en la Figura 79. 
Figura 79: Proceso constructivo sistema de losa aligerada con vigueta Tralicho

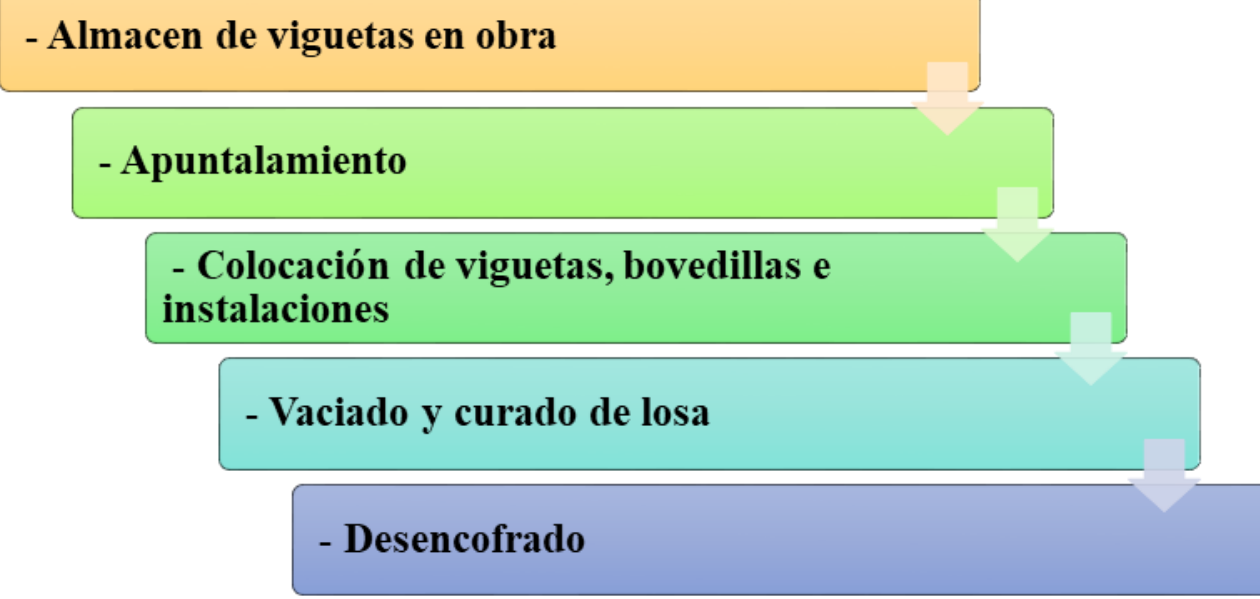

Fuente propia (2018)

\subsubsection{Proceso Constructivo:}

El proceso constructivo de losa aligerada con vigueta tralicho es similar al proceso constructivo de una losa aligerada con viguetas pretensadas, la diferencia se encuentra en el montaje de las viguetas y el tipo de bovedilla que se utiliza.

Las etapas como el almacenaje de viguetas y el armado de vigas no se van a detallar ya que su procedimiento constructivo es el mismo que el del sistema anterior, esto se encuentra explicado en la página 73 de esta investigación.

- Almacenamiento de viguetas en obra

- Armado de las vigas externas

- Apuntalamiento provisional

De la misma forma que para el proceso constructivo anterior, la separación entre puntales y soleras es de $1.50 \mathrm{~m}$, todas las viguetas deben estar apoyadas firmemente; los puntales o pies derechos deben apoyarse en suelo firme y plano, en caso de no ser así, se deben colocar tablones para ayudar a tener una base firme. También, se tienen los mismos beneficios en cuanto a espacio y limpieza que en el sistema anterior. 
- Colocación de viguetas

El proceso es similar al de las viguetas pretensadas. Las viguetas prefabricadas Tralicho se colocan manualmente cada 50 o $60 \mathrm{~cm}$ de eje a eje de vigueta, estas deben apoyarse en muros o vigas. En caso la vigueta coincida con los estribos es posible mover el estribo $5 \mathrm{~cm}$. Las viguetas deben ingresar $5 \mathrm{~cm}$ en la viga, en el caso de los muros y vigas chatas, las mechas de acero de la viga deben ingresar no menos de 10 $\mathrm{cm}$, pues en este caso las viguetas trabajarán simplemente apoyadas.

- Colocación de bovedillas de arcilla, concreto o poli estireno

Como se muestra en la Figura 80, el montaje se realiza de forma manual, se empieza por los extremos para dar la separación adecuada entre viguetas.

Figura 80: Colocación de bovedilla

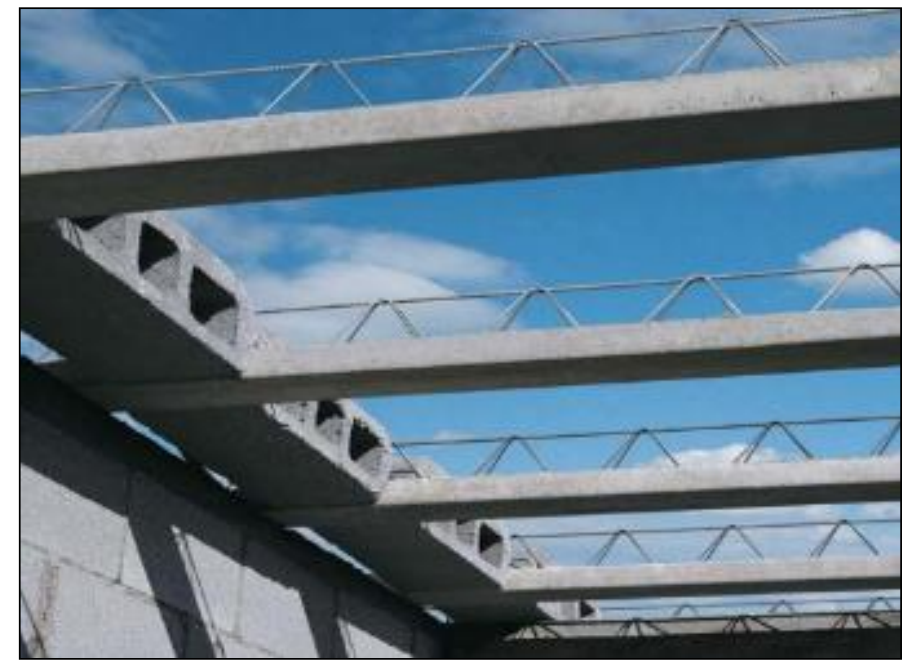

Adaptado de Deacero (s.f.)

- Colocación de instalaciones eléctricas y sanitarias

Como se aprecia en la Figura 81, esta etapa consiste en colocar las instalaciones tanto eléctricas y sanitarias, en algunos casos se puede contar con bandejas hechas en fábrica en las que encajan las instalaciones, en caso de que no se cuente con estas bandejas, se debe hacer un espacio adecuado para colocar las instalaciones. Es importante tener en cuenta que ninguna de las instalaciones se debe colocar en las viguetas. 
Figura 81: Colocado de Instalaciones en sistema Tralicho

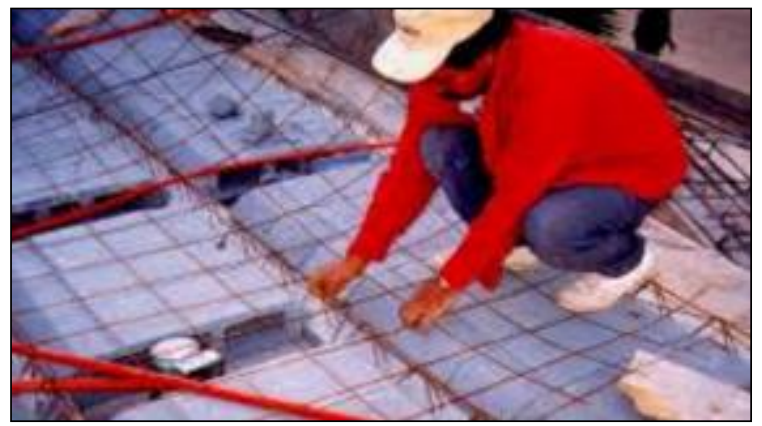

Adaptado de Deacero (s.f.)

- Colocación de malla de temperatura

Esta esta del proceso constructivo es igual a la etapa del proceso constructivo de losas aligeradas con viguetas Firth. Se coloca la malla de temperatura de acero de 1/4"o 6mm, la ubicación de esta malla es sobre la bovedilla. También, se deben colocar dados o separadores de concreto, para evitar levantar la malla durante el vaciado del concreto, ya que la malla no puede quedar pegada a la bovedilla y permita el ingreso del concreto de forma uniforme como se aprecia en la Figura 82.

Figura 82: Malla de temperatura en armado de losa con viguetas Tralicho

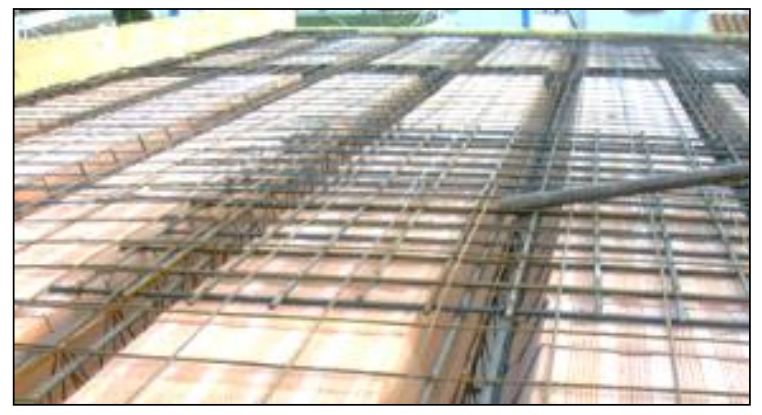

Adaptado de Deacero (s.f.)

- Limpieza y mojado

Esta esta del proceso constructivo es igual para los tres sistemas constructivos de losas aligeradas (convencional, vigueta Firth y vigueta Tralicho). 
- Vaciado de la capa de compresión

Esta esta del proceso constructivo es igual para los tres sistemas constructivos de losas aligeradas (convencional, vigueta Firth y vigueta Tralicho).

- Desencofrado

Esta esta del proceso constructivo es igual para los tres sistemas constructivos de losas aligeradas (convencional, vigueta Firth y vigueta Tralicho).

\subsubsection{Análisis Técnico por tiempo de ejecución}

Igualmente que en los sistemas anteriores, esta evaluación se ha realizado en un proyecto real con características similares, misma área y condiciones iguales. Los datos de este proyecto se encuentran a continuación:

\section{Ubicación: $\quad$ Jr. Lloque Yupanqui Mz. R, Lote 7} Surquillo

Nombre del maestro a cargo: Luis Aquinando

Área de losa: $\quad 120 \mathrm{~m}^{2}$

Se han identificado 3 etapas principales que son: Armado de losa, Vaciado de concreto de losa y Desencofrado de losa. A continuación, se va a explicar el tiempo que ha llevado cada una de estas etapas con el sistema de viguetas prefabricadas TRALICHO:

- Armado de la losa (7 días)

Estas actividades se realizaron con una cuadrilla de 2 carpinteros, 2 fierreros, y un maestro de obra. Esta etapa comienza con el encofrado de las vigas principales y soleras. Las vigas principales van a servir de apoyo para las viguetas prefabricadas, estas se van a colocar respetando el espaciamiento de $50 \mathrm{~cm}$ de eje a eje. Mientras se estén colocando las viguetas se debe ir apuntalando para asegurar su posición y evitar accidentes (3 días de duración). En paralelo se realiza el colocado de las bovedillas y también se inician los trabajos de acero, en este caso el armado de la malla de temperatura y acero negativo, ya que la vigueta incluye el acero positivo (2 día de duración). 
El sexto día se terminan los trabajos de acero y se comienzan con los trabajos de instalaciones. En esta etapa el sistema de viguetas presenta algunas desventajas cuando las tuberías de desagüe las cruzan, en este caso la solución en obra que se hace es optar por una losa maciza. (2 días de duración).

- Vaciado de la losa (1 días)

En esta segunda etapa se realiza con una cuadrilla de 3 peones, un operario y el maestro. En el caso del proyecto que se ha visitado, se utilizó un mixer de concreto para la losa. Este día se realizaban correcciones antes del vaciado, al igual sistema anterior, el desperdicio que se tiene debido al encofrado es mínimo, ya que las viguetas en unión con las bovedillas forman un sello que retiene el concreto y no deja que pase al nivel inferior, cosa que si sucede con el sistema convencional en algunas zonas del encofrado.

- Desencofrado de la losa (7 días)

Esta tercera etapa se realizó con una cuadrilla de 3 peones. Para comenzar con el desencofrado de la losa el concreto debe haber adquirido una resistencia de por lo menos $160 \mathrm{~kg} / \mathrm{cm}^{2}$, lo que ocurre mayormente en el décimo día que es cuando se desencofra. Esta labor toma un día de duración.

\subsubsection{Análisis Técnico por Calidad de acabo}

Al igual que en el sistema anterior, a través de fotos se ha evidenciado el resultado que tiene el uso de viguetas prefabricadas TRALICHO en la calidad del acabado de fondo de losa. Como ya se ha mostrado en el Capítulo 3, las viguetas y las bovedillas de arcilla son fabricadas de manera industrial, garantizándose muchos estándares de calidad que el mercado actual exige. La Figura 83 muestra el fondo de losa luego del desencofrado en el proyecto que se está evaluando. 
Figura 83: Fondo de losa luego del desencofrado con vigueta Tralicho

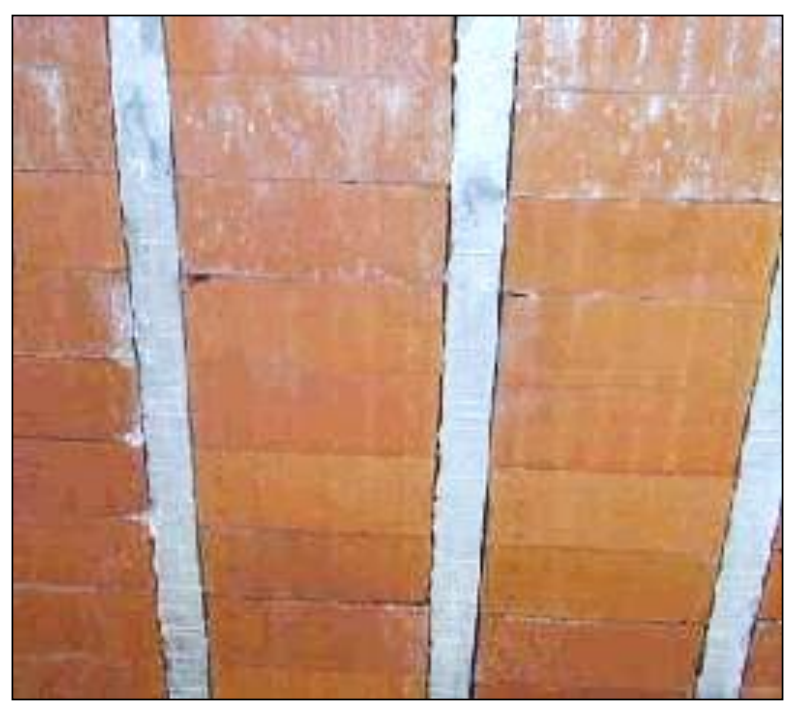

Fuente propia (2018)

Se aprecia que, a diferencia del sistema anterior, este sistema presenta un mínimo de imperfecciones, pero en este caso si son más notorias a simple vista, esto puede aceptar eliminar el tarrajeo, pero si se opta por tarrajear el cielo raso las imperfecciones son mínimas y facilitan los trabajos de acabado.

Además, debido a que este sistema elimina el uso de tablas para el encofrado y cuyo sistema de cerramiento entre vigueta y bovedillas es tan eficaz, se elimina casi al $100 \%$ los desperdicios de concreto que ensucian el nivel inferior y las columnas.

\subsubsection{Evaluación Técnica por Calidad del Concreto}

La resistencia a la compresión mínima que garantiza la vigueta tralicho es de $280 \mathrm{~kg} / \mathrm{cm} 2$ y según Italconcreto (s.f.), las viguetas del sistema Alitec se encuentran sometidos a un estricto control de calidad durante todo el proceso de fabricación de sus viguetas y que cumplen con la NTP 339.114, Concreto premezclado. 


\subsection{Comparación Técnica de los 3 Sistemas de Losa}

Para finalizar este capítulo se van a presentar los resultados de las evaluaciones realizadas para los 3 sistemas de losa aligerada de manera sencilla para poder realizar una comparación objetiva.

\subsubsection{Comparación Técnica por tiempo de Ejecución}

En la Figura 84 se resume de manera gráfica las duraciones de cada etapa constructiva para cada sistema.

Figura 84: Duración en días por etapas para cada sistema de losa aligerada

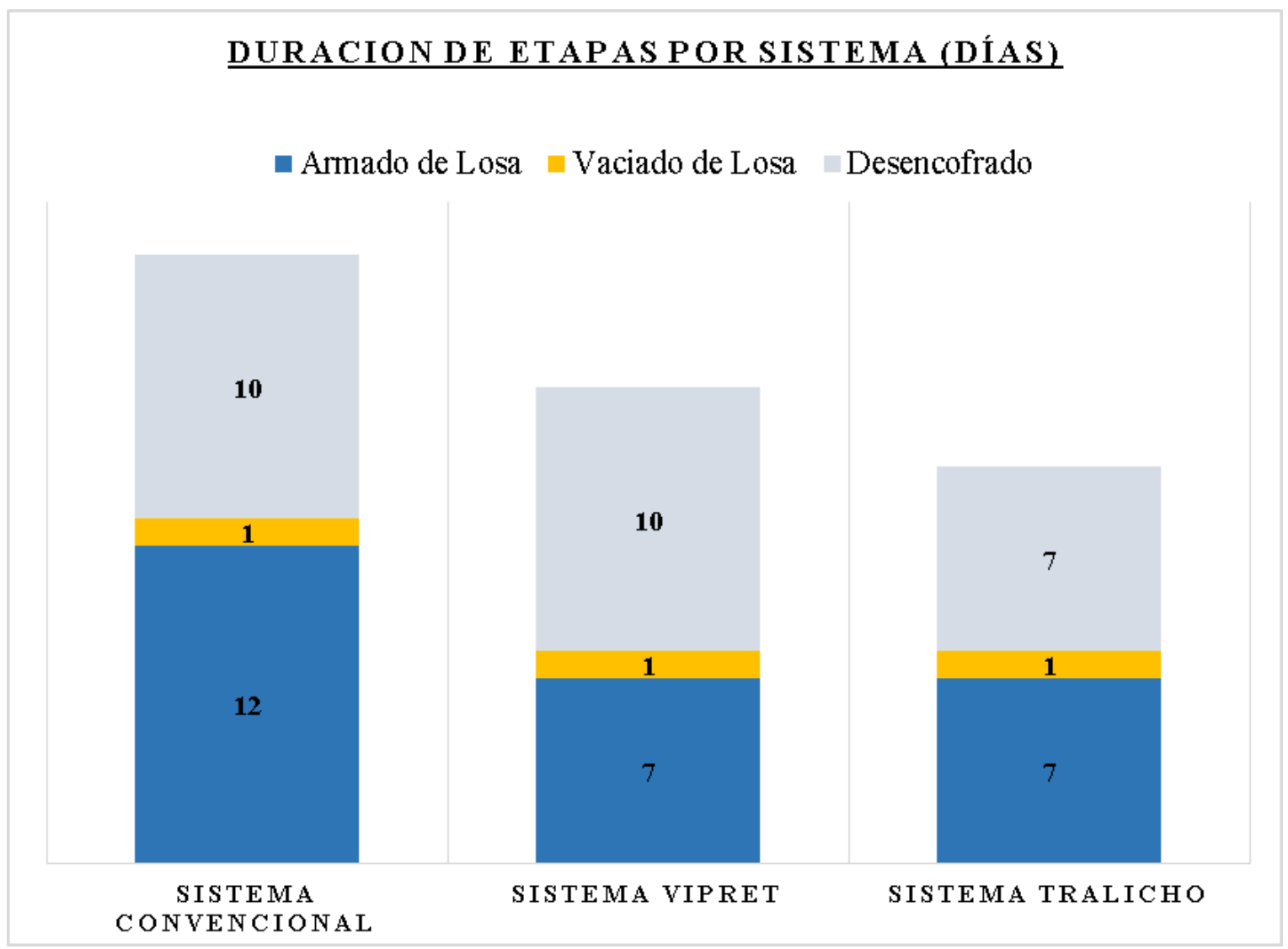

Fuente propia (2018)

La figura anterior muestra que el sistema de vigueta pretensada representa el 78\% del tiempo del sistema convencional, y el sistema de vigueta Tralicho un 65\% debido al 
menor tiempo para el desapuntalamiento. Ambos sistemas de prefabricado aportan un ahorro de tiempo de $40 \%$ en la etapa de encofrado frente al sistema convencional.

La diferencia en duraciones tiene mucho que ver con las actividades que han quedado suprimidas con los sistemas de losa prefabricadas, ya que se eliminó el uso de tablas para el encofrado, se redujo el número de puntales y soleras y se eliminó el habilitado del acero positivo en toda la losa.

\subsubsection{Comparación Técnica por Calidad de acabado}

En cuanto a esta comparación, la Tabla 6 resume los resultados que se han obtenido.

Tabla 6: Comparación fotográfica del acabado de fondo de losa por sistema

\begin{tabular}{|c|c|c|}
\hline Tipo de Sistema & Fotografia & Comentario \\
\hline Convencional & & $\begin{array}{l}\text { El sistema convencional presentó } \\
\text { mayor segregación en el concreto, } \\
\text { lo que se evidenció al desencofrar } \\
\text { la losa como se aprecia en la foto. }\end{array}$ \\
\hline Vipret & & $\begin{array}{l}\text { E1 sistema VIPRET resultó ser más } \\
\text { limpio en el acabado de fondo de } \\
\text { losa y se eliminaron los trabajos de } \\
\text { limpieza posterior al desencofrado. }\end{array}$ \\
\hline Todocemento & & $\begin{array}{l}\text { E1 sistema TRALICHO tuvo } \\
\text { algunos problemas con las } \\
\text { bovedillas, pues se rompían en las } \\
\text { esquinas como se observa en la } \\
\text { foto, esto causó suciedad e } \\
\text { imperfecciones en el fondo de losa. }\end{array}$ \\
\hline
\end{tabular}

Nota: Fuente propia (2018) 
De estos tres sistemas, el que mejor acabado presenta es el de vigueta pretensada VIPRET, tanto las viguetas como las bovedillas presentan un mínimo de imperfecciones imperceptibles a simple vista.

El sistema convencional presenta el peor acabado con presencia de segregado del concreto de las viguetas y pedazos de madera pegados al fondo de losa. El sistema Tralicho presenta un poco más de imperfecciones que el sistema VIPRET.

\subsubsection{Comparación Técnica por Calidad del Concreto}

En cuanto a esta comparación, la Figura 85 muestra los resultados mostrando la máxima resistencia que se utiliza en el concreto de las viguetas para cada sistema.

Figura 85: Máxima resistencia del concreto (f’c) por sistema de losa aligerada

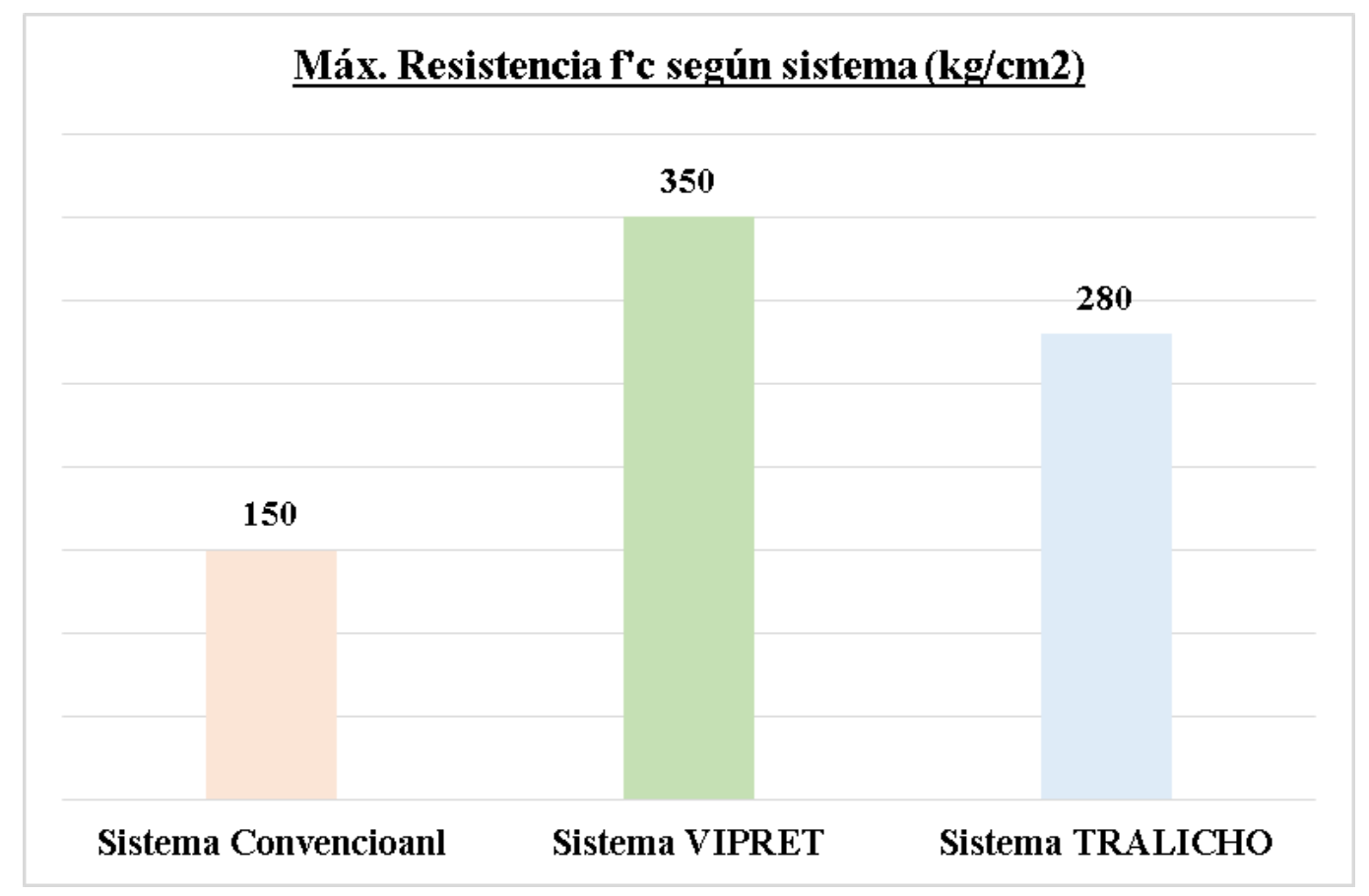

Fuente propia (2018)

Según estos resultados es fácil darse cuenta que el sistema VIPRET ofrece mejor calidad en el concreto, seguido del sistema Tralicho, ya que estos elementos son hechos en fábrica y el control de los materiales utilizados para el concreto es mejor. A esto se le suma que en el sistema convencional los agregados presentan deficiencias, debido a 
la cantera de procedencia y, en la mayoría de viviendas visitadas, el acero utilizado presenta oxidación parcial en su superficie que reduce el tiempo de vida de la estructura. 


\section{CAPÍTULO V: EVALUACIÓN ECONÓMICA DE LOS SISTEMAS DE LOSAS ALIGERADA: CONVENCIONAL, CON VIGUETA PREFABRICADA VIPRET Y CON VIGUETA PREFABRICADA TRALICHO}

Para la evaluación económica que se desarrolla en el presente capítulo se realizó un análisis de precio unitario y un presupuesto para una planta típica de losa aligerada de vivienda unifamiliar empleando los 3 sistemas de losa aligerada estudiados en esta investigación y son los que se indican en el título de este capítulo. La arquitectura del proyecto que se está evaluando se puede ver en la Figura 86. 
Figura 86: Arquitectura de vivienda

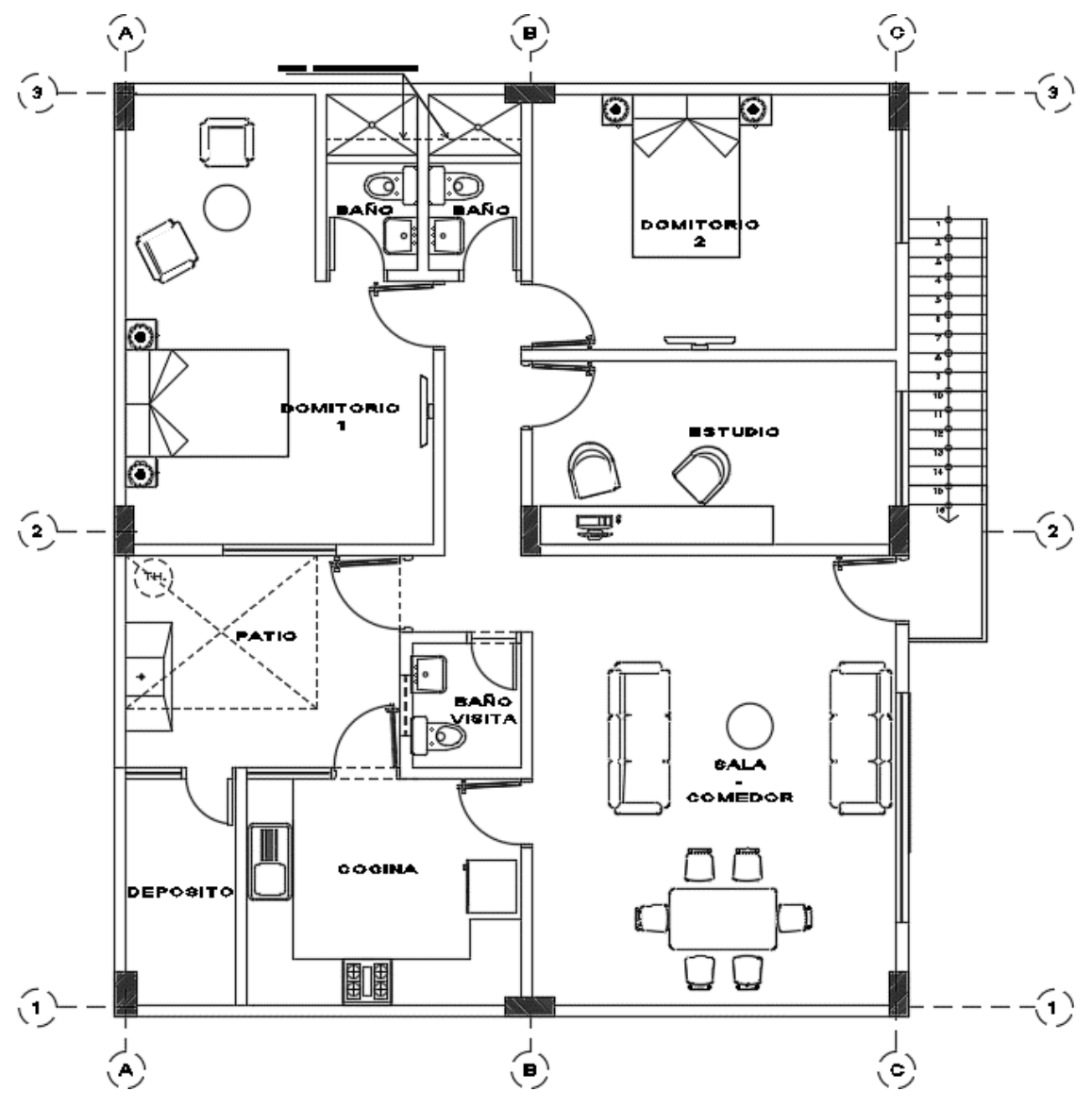

Fuente propia (2018)

En la figura anterior se puede observar una distribución típica para una vivienda unifamiliar, con dos dormitorios, una cocina, comedor, un patio y un estudio. A partir de esta arquitectura se ha planteado una estructuración para el techo que se observa en la Figura 87 y es la que se va a utilizar para los cálculos de materiales de este capítulo. 
Figura 87: Encofrado de techo para la arquitectura planteada

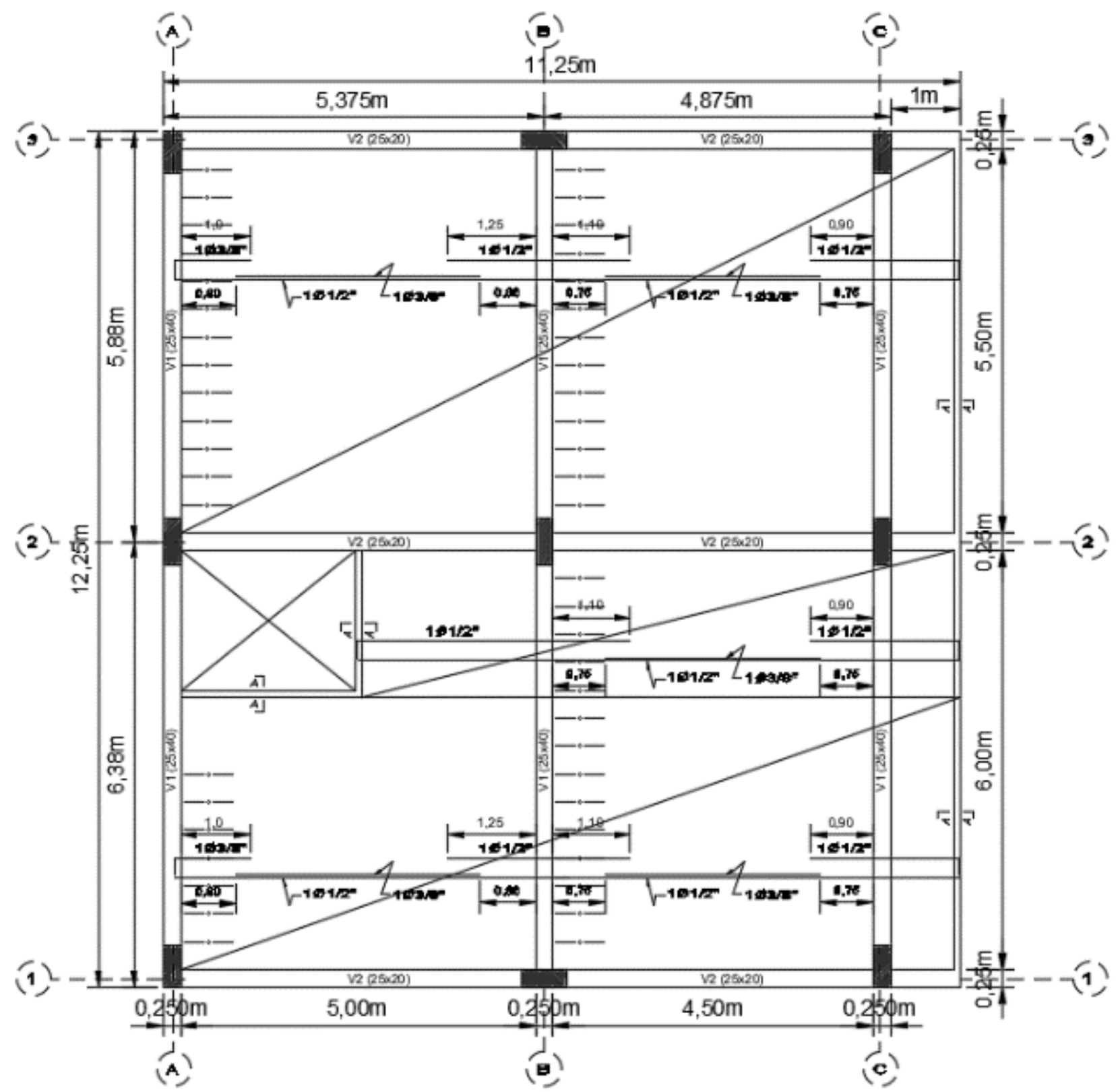

Fuente propia (2016)

Al finalizar este capítulo se obtendrán 3 presupuestos por cada sistema y un costo por metro cuadrado que servirá para hacer una comparación objetiva de los sistemas evaluados. Es importante aclarar que la alternativa con menor costo no necesariamente será la más adecuada, se debe considerar la evaluación vista en el capítulo anterior antes de tomar una decisión. 
El presupuesto resultante de esta evaluación económica va a contemplar todos los costos que conlleva construir una losa aligerada. Se considerarán los costos de mano obra, materiales y equipos utilizados, además, cualquier costo adicional va a ser indicado en el presupuesto final. Los pasos a seguir para llegar al presupuesto final de cada sistema se muestran en la Figura 88:

Figura 88: Pasos para elaborar el presupuesto

\section{Definir peralte de losa aligerada}

2. Definir sentido de las viguetas

3. Calcular la cantidad de materiales

\section{Elaborar APU's de las partidas}

\section{Elaborar el presupuesto}

Fuente propia (2018)

Los pasos número 1 y 2 del Gráfico anterior requieren conocimientos estructurales para poder ejecutarlos. El paso número 3 se refiere el metrado de las cantidades que se van a emplear durante la construcción de la losa, para lo cual se han empleado algunos ratios ya comprobados para su cálculo.

\subsection{Sistema de Losa aligerada convencional}

Como primer paso, hallar el peralte de la losa, se recurre a la Norma de concreto Armado, E.060, del Reglamento Nacional de Edificaciones (RNE), que establece el peralte (h) de una losa aligerada según la siguiente expresión:

$$
h \geq \frac{L}{25}, \text { Les la luz menor }
$$


Para este caso la luz menor es de $4.50 \mathrm{~m}$ y con esto se tiene un peralte mayor o igual a $0.18 \mathrm{~m}$, con lo que se va a trabajar un peralte de losa de $20 \mathrm{~cm}$.

En el segundo paso, elegir el sentido de las viguetas de la losa, se va a elegir en el sentido de la luz menor de la losa. Una vez que se tiene esto se debe definir la distribución del acero por vigueta como se muestra en la Figura 89.

Figura 89: Distribución del acero por vigueta

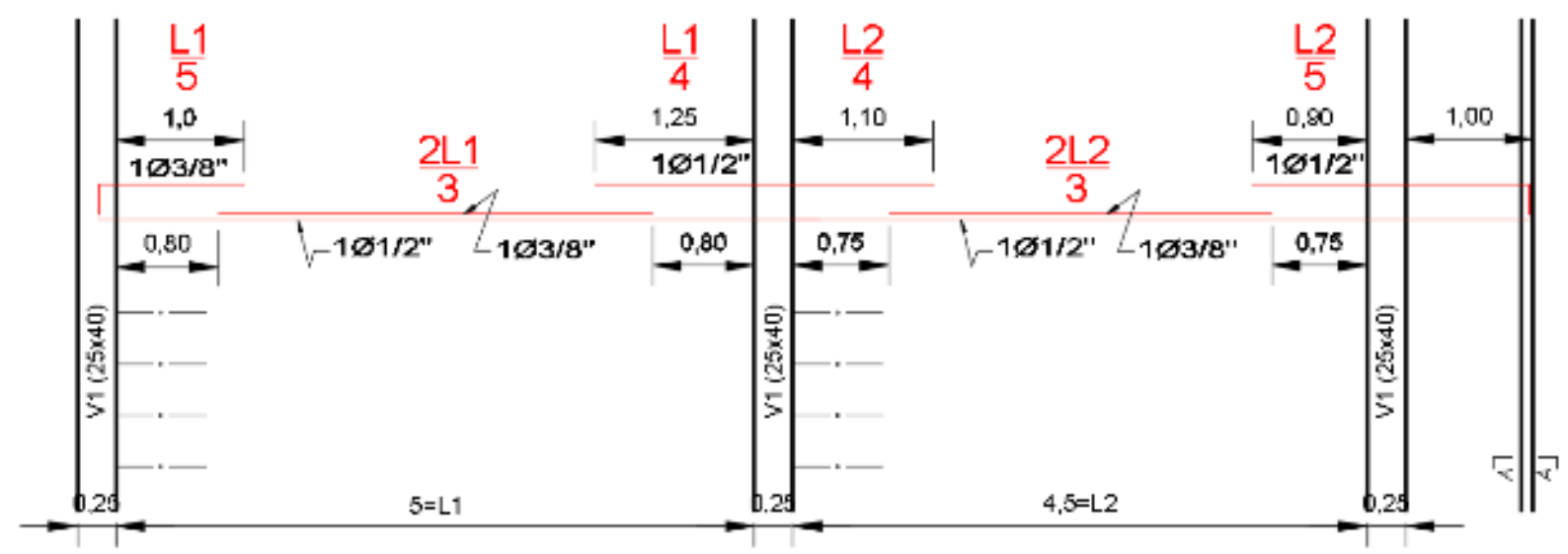

Fuente propia (2018)

Como tercer paso, calcular las cantidades de los materiales, se ha considerado el cálculo para los 3 insumos principales dentro de una losa: acero corrugado, concreto y ladrillo.

Para calcular la cantidad de acero que es necesario para cada vigueta se ha calculado las longitudes empleadas para cada varilla de la figura anterior. El resultado de este cálculo se encuentra mejor explicado en la Tabla 7. 
Tabla 7: Cálculo de la cantidad de acero por vigueta

\begin{tabular}{|c|c|c|c|c|c|}
\hline \multirow{2}{*}{ Tipo } & \multirow{2}{*}{ Diseño } & \multicolumn{2}{|l|}{ Metrado } & \multicolumn{2}{|c|}{$\varnothing$} \\
\hline & & Cálculo & Total & 3/8" & $1 / 2^{\prime \prime}$ \\
\hline \multirow{3}{*}{ As (-) } & $\Gamma$ & $0.10 \mathrm{~m}+0.25 \mathrm{~m}+1.00 \mathrm{~m}$ & $1.35 \mathrm{~m}$ & $0.76 \mathrm{~kg}$ & \\
\hline & & $1.25 \mathrm{~m}+0.25 \mathrm{~m}+1.10 \mathrm{~m}$ & $2.65 \mathrm{~m}$ & & $2.58 \mathrm{~kg}$ \\
\hline & & $0.90 \mathrm{~m}+0.25 \mathrm{~m}+1.00 \mathrm{~m}+0.10 \mathrm{~m}$ & $\begin{array}{c}2.25 \mathrm{~m} \\
\text { Sub-Total }\end{array}$ & $0.76 \mathrm{~kg}$ & $2.24 \mathrm{~kg}$ \\
\hline \multirow{5}{*}{$\operatorname{As}(+)$} & & $3.40 \mathrm{~m}$ & $3.40 \mathrm{~m}$ & $1.90 \mathrm{~kg}$ & \\
\hline & & $3.00 \mathrm{~m}$ & $3.00 \mathrm{~m}$ & $1.68 \mathrm{~kg}$ & \\
\hline & & $3 * 0.25 \mathrm{~m}+5.00 \mathrm{~m}+4.50 \mathrm{~m}+1.00 \mathrm{~m}$ & $11.25 \mathrm{~m}$ & & $11.18 \mathrm{~kg}$ \\
\hline & & & Sub-Total & $3.58 \mathrm{~kg}$ & $11.18 \mathrm{~kg}$ \\
\hline & TOTAL & \multicolumn{4}{|c|}{$\operatorname{As}(-)+\operatorname{As}(+)=0.76 \mathrm{~kg}+4.82 \mathrm{~kg}+3.58 \mathrm{~kg}+11.18 \mathrm{~kg}=20.34 \mathrm{~kg}$} \\
\hline
\end{tabular}

Nota: Fuente propia (2018)

Las viguetas van a ir transversalmente a lo largo de los $5.50 \mathrm{~m}$ y $6.00 \mathrm{~m}$ que tiene la losa, por lo que en estas longitudes van a entrar 2.5 viguetas por cada metro, se tiene:

$$
(2.5 \text { viguetas } / \mathrm{m}) \times(5.50 \mathrm{~m}+6.00 \mathrm{~m})=29 \text { viguetas }
$$

Por cada vigueta se ha calculado $20.34 \mathrm{~kg}$ de acero, entonces:

$$
29 \text { viguetas } \mathrm{x} 20.34 \mathrm{~kg} / \text { vigueta }=589.86 \mathrm{~kg}
$$

A este cálculo se le debe añadir el acero de temperatura cuyo diámetro es $6 \mathrm{~mm}$ :

$$
(33 \emptyset 6 \mathrm{~mm}) \times(5.50 \mathrm{~m}+6.00 \mathrm{~m}) \times(0.22 \mathrm{~kg} / \mathrm{m})=83.49 \mathrm{~kg}
$$

Si sumamos todo se va a tener el siguiente resultado para el cálculo de acero:

$$
\text { As }(-)+\mathrm{As}(+)+\mathrm{AsT}=589.86 \mathrm{~kg}+83.49 \mathrm{~kg}=\mathbf{6 7 3 . 3 5} \mathbf{~ k g} \text { de acero }
$$

A partir de este resultado y el área de $120 \mathrm{~m} 2$ de losa del proyecto se obtiene un consumo de acero $5.61 \mathrm{~kg} / \mathrm{m} 2$ para el sistema de losa aligerada convencional, esto incluye acero positivo, acero negativo y de temperatura, de los cuales, el $63.57 \%$ es acero positivo, $24.03 \%$ es acero negativo y $12.40 \%$ es acero de temperatura. 
Para calcular la cantidad de concreto se hizo uso de un ratio, por cada $\mathrm{m}^{2}$ de losa se tiene $0.0875 \mathrm{~m}^{3}$ de concreto, el origen de este ratio se explicó en el capítulo anterior, página 53 de esta investigación. Al multiplicar el ratio por el área de losa se obtiene el cosnumo de concreto que se tendrá.

$$
0.0875 \mathrm{~m}^{3} / \mathrm{m}^{2} \times 120 \mathrm{~m}^{2}=10.50 \mathrm{~m}^{3} \text { de concreto }
$$

Para el cálculo de la cantidad de ladrillo se va a utilizar un ratio de consumo que indica que por cada $\mathrm{m}^{2}$ de losa se tienen 8.33 und de ladrillo de techo de $15 \times 30 \times 30 \mathrm{~cm}$, multiplicando por el área de losa del proyecto se obtiene la cantidad de ladrillo a utilizar.

\section{$8.33 \mathrm{lad} / \mathrm{m} 2 \times 120 \mathrm{~m} 2=1000$ und de ladrillo de techo}

En el caso de las vigas, la Figura 90 muestra la distribución de acero que tienen:

Figura 90: Distribución del acero en vigas

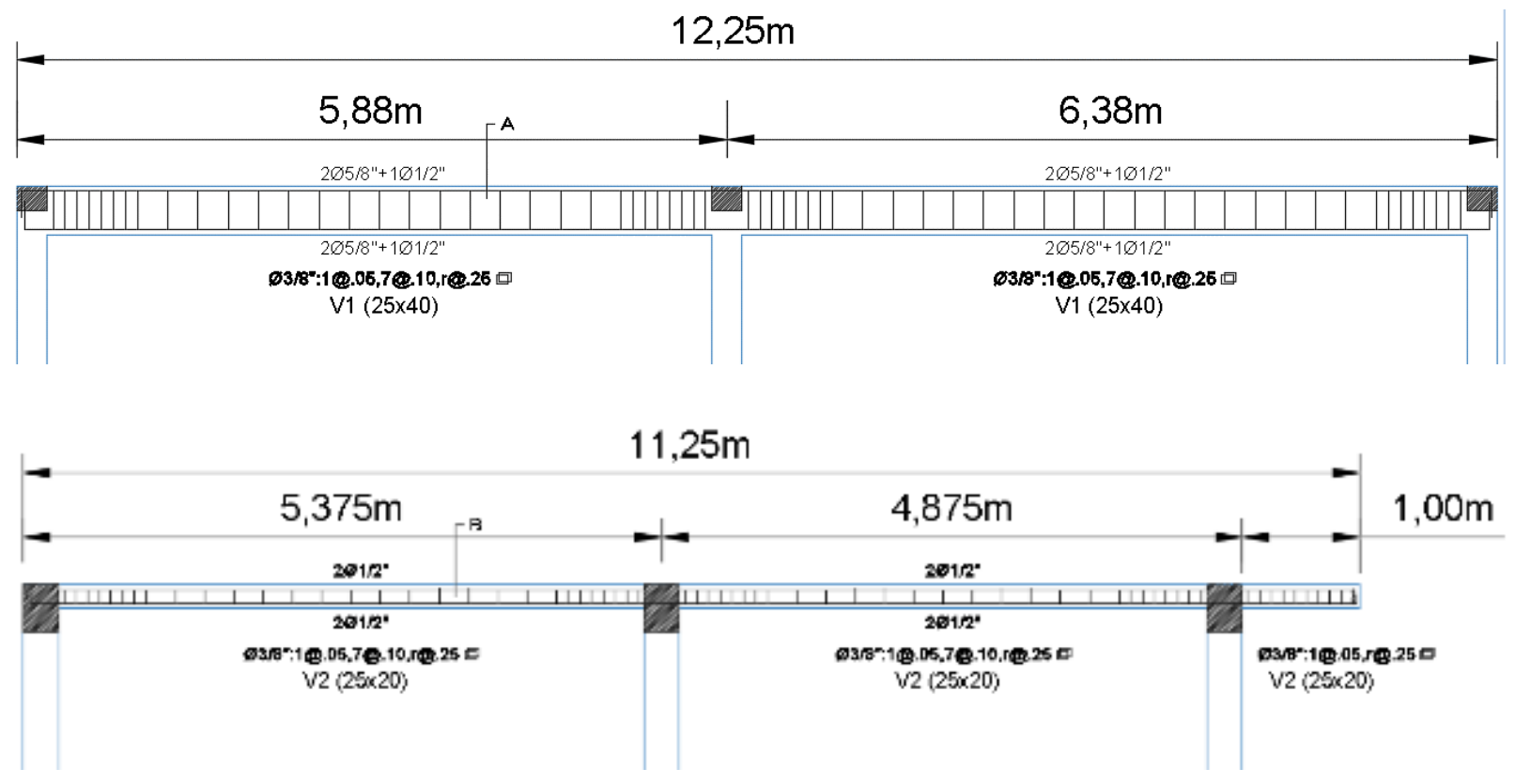

Fuente propia (2018)

Con estas características se procede a calcular la cantidad de concreto y acero que se va a necesitar para las vigas. 
Viga $1(25 \times 40)$ :

Se tiene 3 vigas de estas características, con 12.25 m y la sección de 0.25 m x 0.40 m se tiene:

Vol. Concreto $=3 \times(12.25 \times 0.25 \times 0.40)=3.675 \mathrm{~m}^{3}$ de concreto de viga

Referente al acero, la Tabla 8 presenta el cálculo del acero longitudinal, se está considerando un empalme de $40 \mathrm{~cm}$ en el refuerzo inferior y $50 \mathrm{~cm}$ en el refuerzo superior.

Tabla 8: Cálculo de acero longitudinal - Viga 1

\begin{tabular}{|c|c|c|c|c|c|}
\hline \multirow{2}{*}{ Tipo } & \multirow{2}{*}{ Diseño } & \multicolumn{2}{|l|}{ Metrado } & \multicolumn{2}{|c|}{$\emptyset$} \\
\hline & & Cálculo & Total & $1 / 2^{\prime \prime}$ & $5 / 8^{\prime \prime}$ \\
\hline \multirow{4}{*}{ As (-) } & $\longrightarrow$ & $12.25 \mathrm{~m}+0.20 \mathrm{~m}+0.50 \mathrm{~m}$ & $12.95 \mathrm{~m}$ & $12.87 \mathrm{~kg}$ & \\
\hline & $\longrightarrow$ & $12.25 \mathrm{~m}+0.20 \mathrm{~m}+0.50 \mathrm{~m}$ & $12.95 \mathrm{~m}$ & & $20.10 \mathrm{~kg}$ \\
\hline & $\Gamma$ & $12.25 \mathrm{~m}+0.20 \mathrm{~m}+0.50 \mathrm{~m}$ & $12.95 \mathrm{~m}$ & & $20.10 \mathrm{~kg}$ \\
\hline & & & Sub-Total & $12.87 \mathrm{~kg}$ & $40.20 \mathrm{~kg}$ \\
\hline \multirow{5}{*}{$\mathbf{A s}(+)$} & $ـ$ & $12.25 \mathrm{~m}+0.20 \mathrm{~m}+0.40 \mathrm{~m}$ & $12.85 \mathrm{~m}$ & $12.77 \mathrm{~kg}$ & \\
\hline & 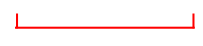 & $12.25 \mathrm{~m}+0.20 \mathrm{~m}+0.40 \mathrm{~m}$ & $12.85 \mathrm{~m}$ & & $19.94 \mathrm{~kg}$ \\
\hline & 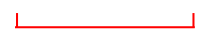 & $12.25 \mathrm{~m}+0.20 \mathrm{~m}+0.40 \mathrm{~m}$ & $12.85 \mathrm{~m}$ & & $19.94 \mathrm{~kg}$ \\
\hline & & & Sub-Total & $12.77 \mathrm{~kg}$ & $19.89 \mathrm{~kg}$ \\
\hline & TOTAL & \multicolumn{4}{|c|}{$A s(-)+A s(+)=12.87 \mathrm{~kg}+40.20 \mathrm{~kg}+12.77 \mathrm{~kg}+39.89 \mathrm{~kg}=105.73 \mathrm{~kg}$} \\
\hline
\end{tabular}

Nota: Fuente propia (2018)

Como se tiene 3 vigas de estas mismas características, el resultado se multiplica por 3:

$$
\text { Acero longitudinal }=3 \times 105.73 \mathrm{~kg}=317.19 \mathrm{~kg}
$$

En el cálculo de los estribos tenemos:

$$
\text { Longitud de estribo de } 2(0.30+0.40+0.10)=1.60 \mathrm{~m}
$$

Se tiene 31 estribos distribuidos en la luz de $5.50 \mathrm{~m}$ y 33 estribos en la luz de $6.00 \mathrm{~m}$, los estribos son de diámetro de $3 / 8$ ". Se debe considerar que se tienen 3 vigas: 
64 estribos x $1.60 \mathrm{~m} / \mathrm{estribo}=3 \times 102.4 \mathrm{~m} \times 0.56 \mathrm{~kg} / \mathrm{m}=172.03 \mathrm{~kg}$

Viga $2(25 \times 20)$ :

Se tiene 3 vigas de estas características, con 11.25 m y la sección de 0.25 m x 0.20 m:

Vol. Concreto $=3 \times(11.25 \times 0.25 \times 0.20)=1.71 \mathrm{~m}^{3}$ de concreto de viga

Vol. Concreto $=1.69 \mathrm{~m}^{3}$ de concreto de viga

Referente al acero, la Tabla 9 presenta el cálculo del acero longitudinal para esta viga.

Tabla 9: Cálculo de acero longitudinal - Viga 2

\begin{tabular}{|c|c|c|c|c|c|}
\hline \multirow{2}{*}{ Tipo } & \multirow{2}{*}{ Diseño } & \multicolumn{2}{|l|}{ Metrado } & \multicolumn{2}{|c|}{$\varnothing$} \\
\hline & & Cálculo & Total & $1 / 2^{\prime \prime}$ & $5 / 8^{\prime \prime}$ \\
\hline \multirow{3}{*}{ As (-) } & $\Gamma$ & $11.25 \mathrm{~m}+0.20 \mathrm{~m}+0.50 \mathrm{~m}$ & $11.95 \mathrm{~m}$ & $11.88 \mathrm{~kg}$ & \\
\hline & $\Gamma$ & $11.25 \mathrm{~m}+0.20 \mathrm{~m}+0.50 \mathrm{~m}$ & $11.95 \mathrm{~m}$ & $11.88 \mathrm{~kg}$ & \\
\hline & & & Sub-Total & $23.76 \mathrm{~kg}$ & \\
\hline \multirow{4}{*}{$\operatorname{As}(+)$} & $\longleftarrow$ & $11.25 \mathrm{~m}+0.20 \mathrm{~m}+0.40 \mathrm{~m}$ & $11.85 \mathrm{~m}$ & $11.78 \mathrm{~kg}$ & \\
\hline & $\longleftarrow$ & $11.25 \mathrm{~m}+0.20 \mathrm{~m}+0.40 \mathrm{~m}$ & $11.85 \mathrm{~m}$ & $11.78 \mathrm{~kg}$ & \\
\hline & & & Sub-Total & $22.22 \mathrm{~kg}$ & \\
\hline & TOTAL & \multicolumn{4}{|c|}{$\operatorname{As}(-)+\operatorname{As}(+)=23.76 \mathrm{~kg}+22.22 \mathrm{~kg}=45.98 \mathrm{~kg}$} \\
\hline
\end{tabular}

Nota: Fuente propia (2018)

Como se tiene 3 vigas de estas mismas características, el resultado se multiplica por 3:

$$
\text { Acero longitudinal }=3 \times 45.98 \mathrm{~kg}=137.94 \mathrm{~kg}
$$

En el cálculo de los estribos tenemos:

$$
\text { Longitud de estribo de } 2(0.25+0.20+0.10)=1.10 \mathrm{~m}
$$

Se tiene 29 estribos distribuidos en la luz de 5.00 m, 27 estribos en la luz de $4.50 \mathrm{~m}$ y 9 estribos en la luz de $1.00 \mathrm{~m}$, los estribos son de diámetro de 3/8". Se debe considerar que se tienen 3 vigas: 


$$
65 \text { estribos x } 1.10 \mathrm{~m} / \mathrm{estribo}=3 \times 71.50 \mathrm{~m} \times 0.56 \mathrm{~kg} / \mathrm{m}=120.12 \mathrm{~kg}
$$

De todos estos resultados se obtiene un total de $747.28 \mathrm{~kg}$ de acero para las vigas $\mathrm{y}$ $5.37 \mathrm{~m} 3$ de concreto para los mismos elementos del proyecto.

La incidencia de encofrado por metro cuadrado para el sistema de losa aligerada convencional se obtuvo del libro de costos y presupuestos de CAPECO (Ramos, 2017) y se detalla mejor en la Tabla 10.

Tabla 10: Consumo de encofrado por $\mathrm{m} 2$ para una losa convencional

\begin{tabular}{|c|c|c|c|c|c|c|c|c|c|c|}
\hline \multirow{2}{*}{$\begin{array}{c}\text { Elemento } \\
\mathbf{N}^{\circ}\end{array}$} & \multirow[b]{2}{*}{ Descripción } & \multirow{2}{*}{$\begin{array}{c}\text { Sección } \\
\text { (A) }\end{array}$} & \multicolumn{2}{|c|}{ LONGITUD } & \multirow{2}{*}{$\begin{array}{c}\text { Cantidad de } \\
\text { Elementos } \\
\text { (C) }\end{array}$} & \multirow{2}{*}{$\begin{array}{c}\text { Pies2 } \\
\text { AxBxC/12 =D }\end{array}$} & \multirow{2}{*}{$\begin{array}{l}\text { Desperdicios } \\
\text { Madera 10\% } \\
(\text { Dx1.10)=E }\end{array}$} & \multirow{2}{*}{$\begin{array}{c}\mathbf{N}^{\circ} \text { Usos } \\
\text { (G) }\end{array}$} & \multirow{2}{*}{$\begin{array}{c}\text { Pies } 2 / \mathrm{N}^{\circ} \\
\text { Usos } \\
\mathbf{E} / \mathbf{G}=\mathbf{H}\end{array}$} & \multirow{2}{*}{$\begin{array}{r}\text { H/U.M. } \\
\text { (Pie 2) }\end{array}$} \\
\hline & & & M.L. & PIES (B) & & & & & & \\
\hline 1 & Tablones & $11 / 2 " x 8 "$ & 0.90 & 2.95 & 3 & 8.85 & 9.74 & 7 & 1.39 & 1.93 \\
\hline \multirow{2}{*}{$\begin{array}{l}2 \\
3\end{array}$} & \multirow{2}{*}{$\begin{array}{l}\text { Soleras } \\
\text { Pies Derecho }\end{array}$} & 2"x4" & 0.80 & 2.62 & 1 & 1.75 & 1.93 & 7 & 0.28 & 0.39 \\
\hline & & 2"x3" & 2.35 & 7.71 & 2 & 7.71 & 8.48 & 7 & 1.21 & 1.68 \\
\hline 4 & Arriostres & 1 1/2"x4" & 0.80 & 2.62 & 1 & 1.31 & 1.44 & 7 & 0.21 & 0.29 \\
\hline 5 & Cuñas & 2"x4" & 0.30 & 0.98 & 2 & 1.31 & 1.44 & 4 & 0.36 & 0.50 \\
\hline 6 & $\begin{array}{l}\text { Uniones } \\
\text { Solera - Pie }\end{array}$ & 1"x3" & 0.30 & 0.98 & 2 & 0.49 & 0.54 & 4 & 0.14 & 0.19 \\
\hline 7 & $\begin{array}{l}\text { Refuerzo } \\
\text { Lateral }\end{array}$ & 1"x3" & 0.90 & 2.95 & 1 & 0.74 & 0.81 & 7 & 0.12 & 0.17 \\
\hline \multicolumn{5}{|c|}{ UNIDAD DE MEDIDA (U.M.): Losa: 0.80 x 0.90} & \multicolumn{2}{|c|}{$0.72 \mathrm{~m} 2$ (Losa) } & & Total & & 5.15 \\
\hline
\end{tabular}

Nota: Adaptado de Ramos (2017)

La cantidad de elementos de la losa se ha obtenido para una losa con unidad de medida de $0.80 \times 0.90 \mathrm{~m}$, es decir una losa de $0.72 \mathrm{~m} 2$.

A continuación se muestran los Análisis de Precio Unitario (APU's) para las partidas que intervienen en nuestro presupuesto final, estas se muestran detalladas en las Tablas $11,12,13,14,15,16$ у 17. 
Tabla 11: APU de acero en losa - Sistema convencional

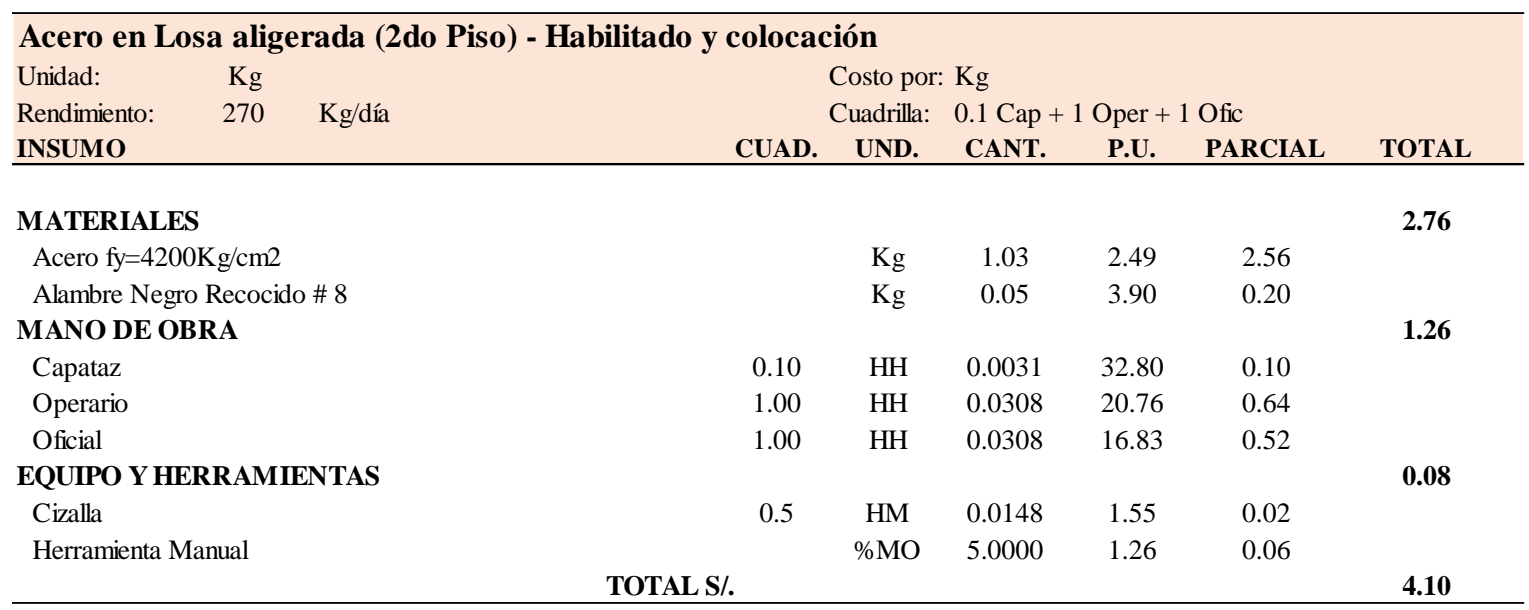

Nota: Rendimiento y cuadrilla adaptado de Constructivo (abril, 2018)

Tabla 12: APU de ladrillo de techo en losa - Sistema convencional

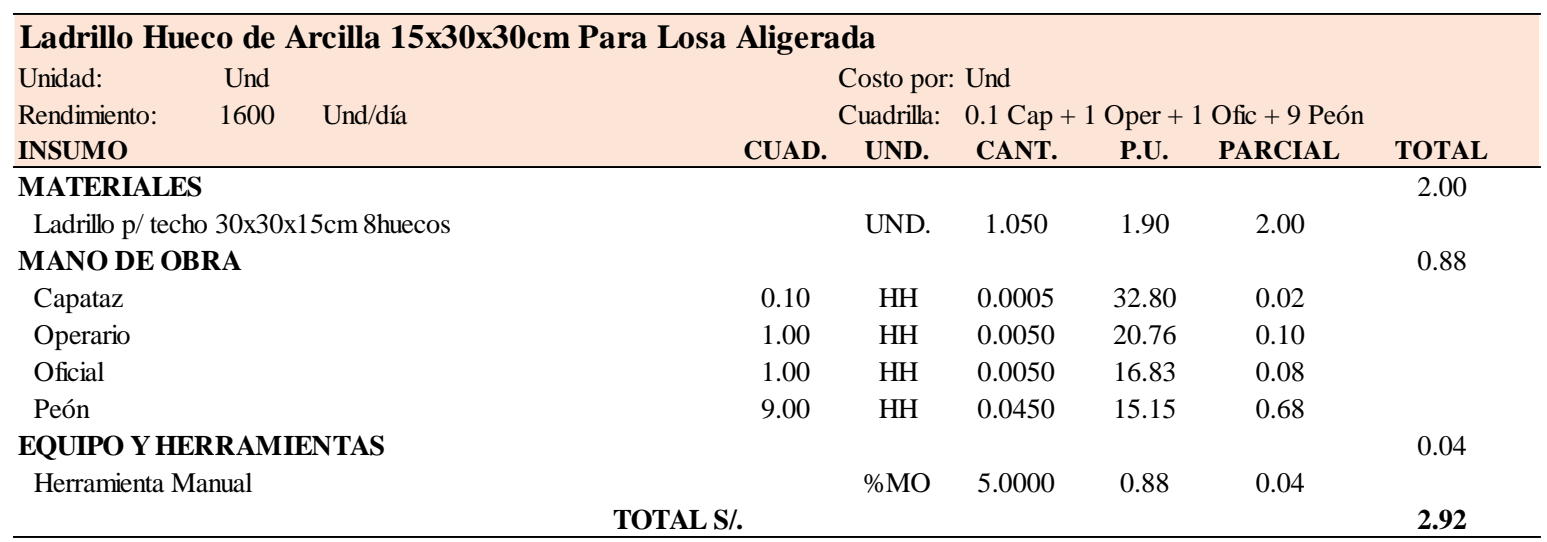

Nota: Rendimiento y cuadrilla adaptado de Constructivo (abril, 2018) 
Tabla 13: APU de concreto en losa - Sistema convencional

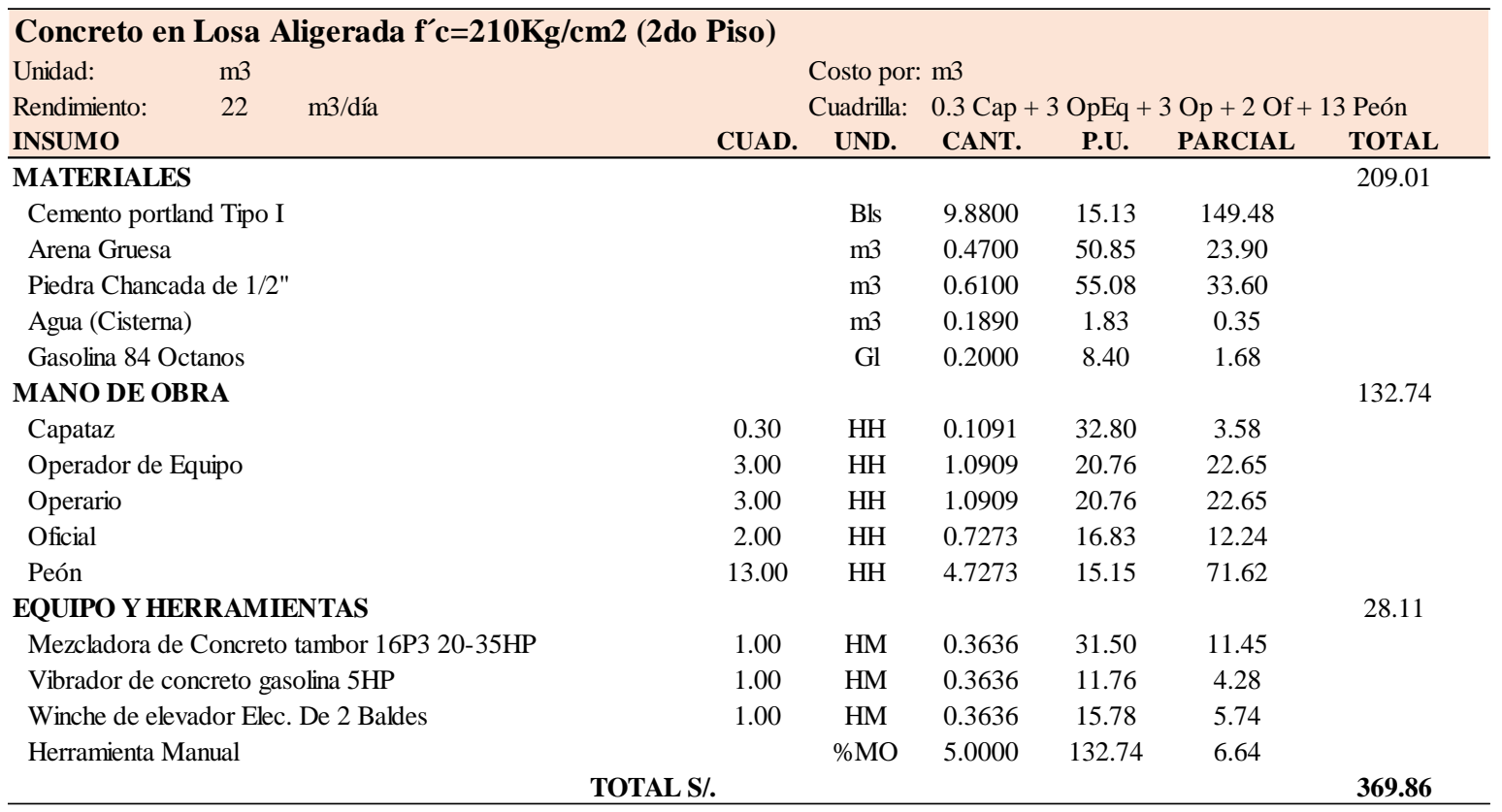

Nota: Rendimiento y cuadrilla adaptado de Constructivo (abril, 2018)

Tabla 14: APU de encofrado en losa - Sistema convencional

\begin{tabular}{|c|c|c|c|c|c|c|c|}
\hline \multicolumn{8}{|c|}{ Encofrado en Losa Aligerada (2do Piso) } \\
\hline \multirow{3}{*}{$\begin{array}{l}\text { Unidad: } \\
\text { Rendimiento: } \\
\text { INSUMO } \\
\end{array}$} & \multirow{3}{*}{$\begin{array}{l}\mathrm{m} 2 \\
12 \quad \mathrm{~m} 2 / \mathrm{dí} a\end{array}$} & \multicolumn{5}{|c|}{ Costo por: $\mathrm{m} 2$} & \multirow[b]{3}{*}{ TOTAL } \\
\hline & & & uadrilla: & 0.1 Cap - & Oper + & Ofic & \\
\hline & & CUAD. & UND. & CANT. & P.U. & PARCIAL & \\
\hline \multicolumn{3}{|c|}{ MATERIALES } & & & & & 21.42 \\
\hline \multicolumn{3}{|c|}{ Alambre Negro Recocido \# 8} & $\mathrm{Kg}$ & 0.100 & 3.90 & 0.39 & \\
\hline \multicolumn{3}{|c|}{ Clavos para madera de $2 "$ a $4 "$} & $\mathrm{Kg}$ & 0.110 & 3.90 & 0.43 & \\
\hline \multicolumn{3}{|c|}{ Madera Tornillo larga } & $\mathrm{p} 2$ & 5.150 & 4.00 & 20.60 & \\
\hline \multicolumn{3}{|c|}{ MANO DE OBRA } & & & & & 27.25 \\
\hline \multicolumn{2}{|l|}{ Capataz } & 0.10 & $\mathrm{HH}$ & 0.0667 & 32.80 & 2.19 & \\
\hline \multicolumn{2}{|l|}{ Operario } & 1.00 & $\mathrm{HH}$ & 0.6667 & 20.76 & 13.84 & \\
\hline \multicolumn{2}{|l|}{ Oficial } & 1.00 & $\mathrm{HH}$ & 0.6667 & 16.83 & 11.22 & \\
\hline \multicolumn{3}{|c|}{ EQUIPO Y HERRAMIENTAS } & & & & & 1.36 \\
\hline \multirow{2}{*}{\multicolumn{2}{|c|}{ Herramienta Manual }} & & $\% \mathrm{MO}$ & 5.000 & 27.25 & 1.36 & \\
\hline & & & & & & & 50.03 \\
\hline
\end{tabular}

Nota: Rendimiento y cuadrilla adaptado de Ramos (2017) 
Tabla 15: APU de acero en viga - Sistema convencional

\begin{tabular}{|c|c|c|c|c|c|c|c|}
\hline \multicolumn{8}{|c|}{ Acero en Vigas (2do Piso) } \\
\hline \multirow{3}{*}{$\begin{array}{l}\text { Unidad: } \\
\text { Rendimiento: } \\
\text { INSUMO }\end{array}$} & \multirow{3}{*}{$\begin{array}{l}\mathrm{kg} \\
250 \quad \mathrm{~kg} / \mathrm{dí} a\end{array}$} & \multicolumn{5}{|c|}{ Costo por: $\mathrm{Kg}$} & \multirow[b]{3}{*}{ TOTAL } \\
\hline & & \multicolumn{5}{|c|}{ Cuadrilla: $\quad 0.1$ Cap +1 Oper +1 Ofic } & \\
\hline & & CUAD. & UND. & CANT. & P.U. & PARCIAL & \\
\hline \multicolumn{3}{|l|}{ MATERIALES } & & & & & 2.97 \\
\hline \multicolumn{2}{|c|}{ Alambre Negro Recocido \# 8} & & $\mathrm{Kg}$ & 0.080 & 3.90 & 0.31 & \\
\hline \multicolumn{2}{|c|}{ Acero fy $=4200 \mathrm{Kg} / \mathrm{cm} 2$} & & $\mathrm{Kg}$ & 1.070 & 2.49 & 2.66 & \\
\hline \multicolumn{2}{|c|}{ MANO DE OBRA } & & & & & & 1.30 \\
\hline \multicolumn{2}{|l|}{ Capataz } & 0.10 & $\mathrm{HH}$ & 0.0032 & 32.80 & 0.10 & \\
\hline \multicolumn{2}{|l|}{ Operario } & 1.00 & $\mathrm{HH}$ & 0.0320 & 20.76 & 0.66 & \\
\hline \multicolumn{2}{|l|}{ Oficial } & 1.00 & $\mathrm{HH}$ & 0.0320 & 16.83 & 0.54 & \\
\hline \multicolumn{2}{|c|}{ EQUIPO Y HERRAMIENTAS } & & & & & & 0.17 \\
\hline \multicolumn{2}{|l|}{ Cizalla } & & HM & 0.0320 & 1.55 & 0.05 & \\
\hline \multicolumn{2}{|c|}{ Andamios Metalicos } & & HM & 0.0320 & 1.50 & 0.05 & \\
\hline \multirow{2}{*}{\multicolumn{2}{|c|}{ Herramienta Manual }} & & $\% \mathrm{MO}$ & 5.0000 & 1.30 & 0.07 & \\
\hline & & & & & & & 4.44 \\
\hline
\end{tabular}

Nota: Rendimiento y cuadrilla adaptado de Constructivo (abril, 2018)

Tabla 16: APU de concreto en vigas - Sistema convencional

\begin{tabular}{|c|c|c|c|c|c|c|c|}
\hline \multicolumn{8}{|c|}{ Concreto en Vigas f'c $=210 \mathrm{~kg} / \mathrm{cm} 2(2 \mathrm{do}$ Piso $)$} \\
\hline \multirow{3}{*}{$\begin{array}{l}\text { Unidad: } \\
\text { Rendimiento: } \\
\text { INSUMO }\end{array}$} & \multirow{3}{*}{$\begin{array}{c}\mathrm{m} 3 \\
17.5 \quad \mathrm{~m} 3 / \text { día }\end{array}$} & \multicolumn{5}{|c|}{ Costo por: $\mathrm{m} 3$} & \multirow[b]{3}{*}{ TOTAL } \\
\hline & & & Cuadrilla: & 0.2 Cap + & Oper + & Ofic + 10 Peón & \\
\hline & & CUAD. & UND. & CANT. & P.U. & PARCIAL & \\
\hline \multicolumn{3}{|c|}{ MATERIALES } & & & & & 209.00 \\
\hline \multicolumn{3}{|c|}{ Cemento portland Tipo I } & Bls & 9.7300 & 15.13 & 147.21 & \\
\hline \multicolumn{3}{|c|}{ Arena Gruesa } & $\mathrm{m} 3$ & 0.4700 & 50.85 & 23.90 & \\
\hline \multicolumn{3}{|c|}{ Piedra Chancada de $1 / 2 "$} & $\mathrm{~m} 3$ & 0.6100 & 55.08 & 33.60 & \\
\hline \multicolumn{3}{|c|}{ Agua (Cisterna) } & $\mathrm{m} 3$ & 0.1840 & 1.83 & 0.34 & \\
\hline \multicolumn{3}{|c|}{ Gasolina 84 Octanos } & $\mathrm{Gl}$ & 0.2000 & 8.40 & 1.68 & \\
\hline \multicolumn{3}{|c|}{ MANO DE OBRA } & & & & & 127.40 \\
\hline \multicolumn{2}{|l|}{ Capataz } & 0.20 & $\mathrm{HH}$ & 0.0914 & 32.80 & 3.00 & \\
\hline \multicolumn{2}{|c|}{ Operador de Equipo } & 3.00 & $\mathrm{HH}$ & 1.3714 & 20.76 & 28.47 & \\
\hline \multicolumn{2}{|c|}{ Operario } & 2.00 & $\mathrm{HH}$ & 0.9143 & 20.76 & 18.98 & \\
\hline \multicolumn{2}{|l|}{ Oficial } & 1.00 & $\mathrm{HH}$ & 0.4571 & 16.83 & 7.69 & \\
\hline \multicolumn{2}{|l|}{ Peón } & 10.00 & $\mathrm{HH}$ & 4.5714 & 15.15 & 69.26 & \\
\hline \multicolumn{3}{|c|}{ EQUIPO Y HERRAMIENTAS 0.03} & & & & & 27.84 \\
\hline \multicolumn{2}{|c|}{ Mezcladora de Concreto tambor 16P3 20-35HP } & 1.00 & HM & 0.3636 & 31.50 & 11.45 & \\
\hline \multicolumn{2}{|c|}{ Vibrador de concreto gasolina 5HP } & 1.00 & $\mathrm{HM}$ & 0.3636 & 11.76 & 4.28 & \\
\hline \multicolumn{2}{|c|}{ Winche de elevador Elec. De 2 Baldes } & 1.00 & $\mathrm{HM}$ & 0.3636 & 15.78 & 5.74 & \\
\hline \multirow{2}{*}{\multicolumn{2}{|c|}{ Herramienta Manual }} & & $\% \mathrm{MO}$ & 5.0000 & 127.40 & 6.37 & \\
\hline & & & & & & & 364.24 \\
\hline
\end{tabular}

Nota: Rendimiento y cuadrilla adaptado de Constructivo (abril, 2018) 
Tabla 17: APU de desencofrado en losa - Sistema convencional

\begin{tabular}{|c|c|c|c|c|c|c|c|c|}
\hline \multicolumn{9}{|c|}{ Desencofeado en Losa Aligerada (2do Piso) } \\
\hline \multirow{3}{*}{$\begin{array}{l}\text { Unidad: } \\
\text { Rendimiento: } \\
\text { INSUMO }\end{array}$} & \multirow{3}{*}{$\begin{array}{l}\mathrm{m} 2 \\
36\end{array}$} & \multirow{3}{*}{ m2/día } & & \multirow[b]{3}{*}{ PARCIAL } & \multirow[b]{3}{*}{ TOTAL } \\
\hline & & & $\begin{array}{l}\text { Costo por: } \mathrm{m} 2 \\
\text { Cudrilla: } 1 \text { Ofic }+2 \text { Peón }\end{array}$ & Cuadrilla: & $1 \mathrm{Ofic}+$ & eón & & \\
\hline & & & CUAD. & UND. & CANT. & P.U. & & \\
\hline \multicolumn{3}{|c|}{ MANO DE OBRA } & & & & & & 31.42 \\
\hline \multicolumn{3}{|l|}{ Oficial } & 1.00 & $\mathrm{HH}$ & 0.6667 & 16.83 & 11.22 & \\
\hline \multicolumn{3}{|l|}{ Peón } & 2.00 & $\mathrm{HH}$ & 1.3333 & 15.15 & 20.20 & \\
\hline \multirow{2}{*}{\multicolumn{4}{|c|}{ EQUIPO Y HERRAMIENTAS }} & & & & & 1.57 \\
\hline \multirow{2}{*}{\multicolumn{3}{|c|}{ Herramienta Manual }} & & $\% \mathrm{MO}$ & 5.000 & 31.42 & 1.57 & \\
\hline & & & & & & & & 32.99 \\
\hline
\end{tabular}

Nota: Rendimiento y cuadrilla adaptado de Ramos (2017)

Una vez que se tienen los APU's desarrollados se procede a realizar el presupuesto para el sistema de losa aligerada convencional que se muestra en la Tabla 18.

Tabla 18: Presupuesto final - Sistema convencional

\begin{tabular}{|c|c|c|c|c|c|c|}
\hline \multicolumn{7}{|c|}{ PRESUPUESTO $\mathbf{N}^{\circ} \mathbf{1}$} \\
\hline Descripción & Und. & Metrado & Precio (S/.) & Parcial & & Total (S/) \\
\hline LOSA ALIGERADA $\mathrm{e}=0.20$ & & & & & & 24798.74 \\
\hline Concreto en Losa Aligerada $f^{\prime} c=210 \mathrm{Kg} / \mathrm{cm} 2$ & m3 & 10.50 & 369.86 & 3883.53 & & \\
\hline Encofrado de Losa Aligerada & $\mathrm{m} 2$ & 120.00 & 50.03 & 6003.60 & & \\
\hline Desencofrado de Losa Aligerada & $\mathrm{m} 3$ & 120.00 & 32.99 & 3958.80 & & \\
\hline Acero Corrugado fy $=4200 \mathrm{Kg} / \mathrm{cm} 2$ ASTM A615 Grado 60 & $\mathrm{Kg}$ & 673.35 & 4.10 & 2760.74 & & \\
\hline Ladrillo Hueco de Arcilla $15 \times 30 \times 30 \mathrm{~cm}$ Para Losa Aligerada & Und. & 1000.00 & 2.92 & 2920.00 & & \\
\hline Acero en Vigas (2do Piso) & $\mathrm{Kg}$ & 747.28 & 4.44 & 3317.92 & & \\
\hline \multirow[t]{4}{*}{ Concreto en Vigas $\mathrm{f}^{\prime} \mathrm{c}=210 \mathrm{~kg} / \mathrm{cm} 2(2 \mathrm{do}$ Piso $)$} & $\mathrm{m} 3$ & 5.37 & 364.24 & 1954.15 & & \\
\hline & \multicolumn{4}{|c|}{ COSTO DIRECTO } & $\mathrm{S} / \mathrm{s}$ & $24,798.74$ \\
\hline & \multicolumn{4}{|c|}{ 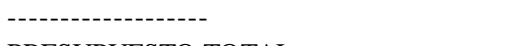 } & & \\
\hline & \multicolumn{4}{|c|}{$\begin{array}{l}\text { PRESUPUESTO TOTAL } \\
\text { Valor de m2 de Losa Aligerada convencional }\end{array}$} & & $\begin{array}{r}24,798.74 \\
206.66\end{array}$ \\
\hline
\end{tabular}

Nota: Fuente propia (2018)

\subsection{Sistema de Losa aligerada con Vigueta VIPRET}

Los pasos número 1 y 2 van a ser los mismos que el sistema anterior, y también lo será para el sistema de vigueta Tralicho. El paso número 3 sería calcular la cantidad de acero requerido. En este caso, solo se tiene que calcular la cantidad de acero negativo y de 33temperatura que se tiene que colocar en obra, ya que acero positivo viene embebido 
en la vigueta. El cálculo es el mismo que en el sistema anterior y los resultados se muestran en la Tabla 19.

Tabla 19: Cálculo de cantidad de acero por vigueta - Sistema VIPRET

\begin{tabular}{|c|c|c|c|c|c|}
\hline \multirow{2}{*}{ Tipo } & \multirow{2}{*}{ Diseño } & \multicolumn{2}{|l|}{ Metrado } & \multicolumn{2}{|c|}{$\varnothing$} \\
\hline & & Cálculo & Total & 3/8" & $1 / 2^{\prime \prime}$ \\
\hline \multirow{4}{*}{ As (-) } & & $0.10 m+0.25 m+1.00 m$ & $1.35 \mathrm{~m}$ & $0.76 \mathrm{~kg}$ & \\
\hline & & $1.25 \mathrm{~m}+0.25 \mathrm{~m}+1.10 \mathrm{~m}$ & $2.60 \mathrm{~m}$ & & $2.58 \mathrm{~kg}$ \\
\hline & & $0.90 \mathrm{~m}+0.25 \mathrm{~m}+1.00 \mathrm{~m}+0.10 \mathrm{~m}$ & $\begin{array}{c}2.25 \mathrm{~m} \\
\text { Sub-Total }\end{array}$ & $0.76 \mathrm{~kg}$ & $\begin{array}{r}2.24 \mathrm{~kg} \\
4.82 \mathrm{~kg}\end{array}$ \\
\hline & TOTAL & \multicolumn{4}{|c|}{$\operatorname{As}(-)=0.76 \mathrm{~kg}+4.82 \mathrm{~kg}=5.58 \mathrm{~kg}$} \\
\hline
\end{tabular}

Nota: Fuente propia (2018)

Las viguetas van a ir transversalmente a lo largo de los $5.50 \mathrm{~m}$ y $6.00 \mathrm{~m}$ que tiene la losa, por lo que en estas longitudes van a entrar 2 viguetas por cada metro, se tiene:

$$
(2 \text { viguetas } / m) \times(5.50 m+6.00 m)=23 \text { viguetas }
$$

Por cada vigueta se ha calculado $5.58 \mathrm{~kg}$ de acero, entonces:

$$
23 \text { viguetas } \times 5.58 \mathrm{~kg} / \text { vigueta }=128.34 \mathrm{~kg}
$$

A este cálculo se le debe añadir el acero de temperatura cuyo diámetro es 6 mm:

$$
(33 \varnothing 6 \mathrm{~mm}) \times(5.50 \mathrm{~m}+6.00 \mathrm{~m}) \times(0.22 \mathrm{~kg} / \mathrm{m})=83.49 \mathrm{~kg}
$$

Si sumamos todo se va a tener el siguiente resultado para el cálculo de acero:

$$
\text { As }(-)+\text { AsT }=128.34 \mathrm{~kg}+83.49 \mathrm{~kg}=211.83 \mathrm{~kg} \text { de acero }
$$

Para este sistema se obtiene un consumo de acero $1.77 \mathrm{~kg} / \mathrm{m} 2$, considerando un área de losa de $120 \mathrm{~m} 2$. Para calcular la cantidad de concreto se usó un ratio, por cada $\mathrm{m}^{2}$ de losa se tiene $0.0700 \mathrm{~m}^{3}$ de concreto, en esta evaluación se tiene:

$$
0.0700 \mathrm{~m}^{3} / \mathrm{m}^{2} \times 120 \mathrm{~m}^{2}=8.40 \mathrm{~m}^{3} \text { de concreto }
$$


Para el cálculo de la cantidad de ladrillo se utiliza el siguiente ratio: por cada $\mathrm{m}^{2} \mathrm{de}$ losa se tienen 8 und de ladrillo bovedilla para techo.

$8 \mathrm{lad} / \mathrm{m} 2 \times 120 \mathrm{~m} 2=960$ und de ladrillo bovedilla

En el caso de las vigas, se tiene la misma distribución de acero que en el sistema anterior, con estas características vamos a calcular la cantidad de concreto y acero que se va a necesitar para las vigas.

Viga $1(25 \times 40)$ :

Se tiene 3 vigas de estas características, con 12.25 m y la sección de 0.25 m x 0.40 m se tiene:

Vol. Concreto $=3 \times(12.25 \times 0.25 \times 0.40)=3.675 \mathrm{~m}^{3}$ de concreto de viga

Referente al acero, se van a utilizar los resultados ya calculados con el sistema anterior, ya que esto no varía nada entre un sistema y otro. Como se tiene 3 vigas de estas mismas características, el resultado se multiplica por 3:

$$
\text { Acero longitudinal }=3 \times 105.73 \mathrm{~kg}=317.19 \mathrm{~kg}
$$

En el cálculo de los estribos tenemos

$$
\text { Longitud de estribo de } 2(0.30+0.40+0.10)=1.60 \mathrm{~m}
$$

Se tiene 31 estribos distribuidos en la luz de 5.50 m y 33 estribos en la luz de $6.00 \mathrm{~m}$, los estribos son de diámetro de 3/8". Se debe considerar que se tienen 3 vigas:

64 estribos x $1.60 \mathrm{~m} / \mathrm{estribo}=3 \times 102.4 \mathrm{~m} \times 0.56 \mathrm{~kg} / \mathrm{m}=172.03 \mathrm{~kg}$

Viga $2(25 \times 20)$ :

Se tiene 3 vigas de estas características, con 11.14 m y la sección de 0.25 mx0.20 m:

Vol. Concreto $=3 \times(11.25 \times 0.25 \times 0.20)=1.69 \mathrm{~m}^{3}$ de concreto de viga 
Vol. Concreto $=1.69 \mathrm{~m}^{3}$ de concreto de viga

Como se tiene 3 vigas de estas mismas características, el resultado se multiplica por 3:

$$
\text { Acero longitudinal }=3 \times 45.98 \mathrm{~kg}=137.94 \mathrm{~kg}
$$

En el cálculo de los estribos tenemos

$$
\text { Longitud de estribo de } 2(0.25+0.20+0.10)=1.10 \mathrm{~m}
$$

Se tiene 29 estribos distribuidos en la luz de $5.00 \mathrm{~m}, 27$ estribos en la luz de $4.50 \mathrm{~m}$ y 9 estribos en la luz de $1.00 \mathrm{~m}$, los estribos son de diámetro de $3 / 8$ ". Se debe considerar que se tienen 3 vigas:

$$
65 \text { estribos } \times 1.10 \mathrm{~m} / \mathrm{estribo}=3 \times 71.50 \mathrm{~m} \times 0.56 \mathrm{~kg} / \mathrm{m}=120.12 \mathrm{~kg}
$$

Para calcular la incidencia de encofrado por metro cuadrado para el sistema de losa aligerada con vigueta pretensada se utilizó el mismo método que en el sistema anterior,

\begin{tabular}{|c|c|c|c|c|c|c|c|c|c|c|}
\hline \multirow{2}{*}{$\begin{array}{c}\text { Elemento } \\
\mathbf{N}^{\circ}\end{array}$} & \multirow[b]{2}{*}{ Descripción } & \multirow{2}{*}{$\begin{array}{l}\text { Sección } \\
\text { (A) }\end{array}$} & \multicolumn{2}{|c|}{ LONGITUD } & \multirow{2}{*}{$\begin{array}{c}\text { Cantidad de } \\
\text { Elementos } \\
\text { (C) }\end{array}$} & \multirow{2}{*}{$\begin{array}{c}\text { Pies2 } \\
\text { AxBxC/12 =D }\end{array}$} & \multirow{2}{*}{$\begin{array}{l}\text { Desperdicios } \\
\text { Madera 10\% } \\
(\text { Dx1.10)=E }\end{array}$} & \multirow{2}{*}{$\begin{array}{c}\mathbf{N}^{\circ} \text { Usos } \\
\text { (G) }\end{array}$} & \multirow{2}{*}{$\begin{array}{c}\text { Pies } 2 / \mathrm{N}^{\circ} \\
\text { Usos } \\
\mathbf{E} / \mathbf{G}=\mathbf{H}\end{array}$} & \multirow[b]{2}{*}{ H/U.M. } \\
\hline & & & M.L. & PIES (B) & & & & & & \\
\hline 1 & Tablones & 1 1/2"x8" & 0.90 & 2.95 & 0 & 0 & 0 & 7 & 0.00 & 0.00 \\
\hline \multirow{2}{*}{$\begin{array}{l}2 \\
3\end{array}$} & Soleras & 2"x4" & 0.80 & 2.62 & 0.3 & 0.56 & 0.62 & 7 & 0.09 & 0.13 \\
\hline & Pies Derecho & 2"x3" & 2.35 & 7.71 & 0.6 & 2.31 & 2.54 & 7 & 0.36 & 0.50 \\
\hline 4 & Arriostres & 1 1/2"x4" & 0.80 & 2.62 & 0.3 & 0.39 & 0.43 & 7 & 0.06 & 0.08 \\
\hline 5 & Cuñas & 2"x4" & 0.30 & 0.98 & 0.6 & 0.39 & 0.43 & 4 & 0.11 & 0.15 \\
\hline 6 & $\begin{array}{l}\text { Uniones } \\
\text { Solera - Pie }\end{array}$ & 1"x3" & 0.30 & 0.98 & 0.3 & 0.08 & 0.09 & 4 & 0.02 & 0.03 \\
\hline 7 & $\begin{array}{l}\text { Refuerzo } \\
\text { Lateral }\end{array}$ & 1"x3" & 0.90 & 2.95 & 1 & 0.74 & 0.81 & 7 & 0.12 & 0.17 \\
\hline \multicolumn{5}{|c|}{ UNIDAD DE MEDIDA (U.M.): Losa: 0.80 x 0.90} & \multicolumn{2}{|c|}{$0.72 \mathrm{~m} 2$ (Losa) } & & Total & & 1.06 \\
\hline
\end{tabular}
y el resultado se detalla en la Tabla 20:

Tabla 20: Consumo de encofrado por $\mathrm{m} 2$ para una losa con vigueta pretensada

Nota: Fuente propia (2018)

La unidad de medida es la misma que en el sistema convencioanl, pero la cantidad de elementos se modificó debido a que en el sistema de vigueta pretensada se utilizan 
puntales y soleras especiadas hasta $1.50 \mathrm{~m}$, esto se indicó en el capítulo anterior, página 57. Este mismo ratio será utilizada para el sistema de vigueta tralicho.

En cuanto a los elementos propios del sistema, la vigueta pretensada y la bovedilla, se contactó a la empresa VIPRET, fabricante de viguetas pretensadas, quienes cotizaron la losa que se muestra a inicios de este capítulo en 4’354.64 soles, precio que incluye las viguetas y las bovedillas, además del transporte. Los datos que se manejaron en esta cotización se muestran a continuación

\section{EMPRESA: $\quad$ VIPRET S.A.C.}

AREA DE LOSA: $120 \mathrm{~m}^{2}$

DIRECCIÓN: Av. Pan. Norte con Alisos

PRECIO TOTAL: $\quad$ 4'833.94 soles

PRECIO POR M2: 36.41 soles $/ \mathrm{m}^{2}$

Para una distribución por metro cuadrado se tienen 2 viguetas pretensadas y 8 bovedillas. El costo de una vigueta pretensada es de 9.00 soles el metro lineal, mientras que el costo de la bovedilla sería de 2.30 soles la unidad.

Todos estos componentes van a entrar en unos Análisis de Precio Unitario (APU’s) para obtener los costos unitarios de cada partida por separado. A continuación, se van a mostrar las Tablas 21, 22, 23 y 24 donde se han desarrollado cada uno de los APU's, solo se muestran los análisis referentes al sistema de pretensado, ya que el resto de partidas son las mismas que el sistema anterior. 
Tabla 21: APU de apuntalamiento y desencofrado - Sistema Vigueta pretensada

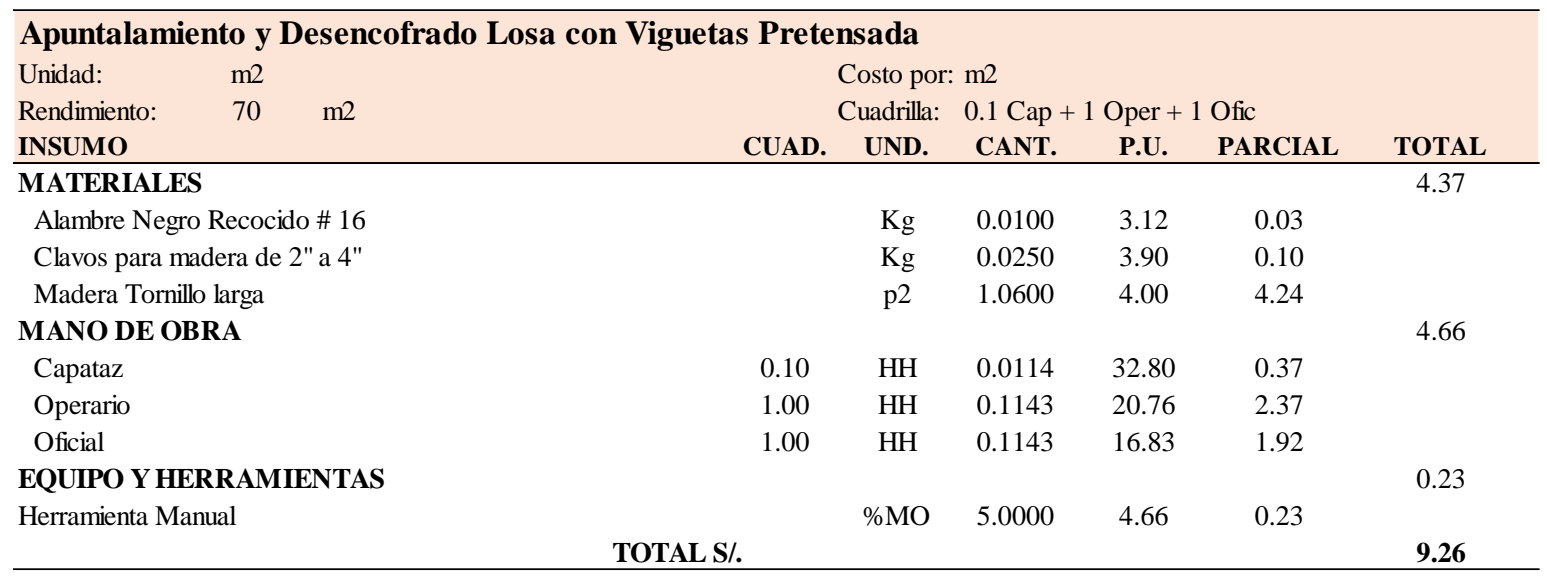

Nota: Rendimiento y cuadrilla adaptado de Morán (2016)

Tabla 22: APU de viguetas pretensadas - Sistema VIPRET

\begin{tabular}{|c|c|c|c|c|c|c|c|}
\hline \multicolumn{8}{|c|}{ Vigueta Pretensada VIPRET - Incluye colocación en forma manual } \\
\hline \multirow{3}{*}{$\begin{array}{l}\text { Unidad: } \\
\text { Rendimiento: } \\
\text { INSUMO }\end{array}$} & \multirow{3}{*}{$\begin{array}{c}\mathrm{m} 2 \\
140\end{array}$} & \multicolumn{6}{|c|}{ Costo por: $\mathrm{m} 2$} \\
\hline & & \multicolumn{2}{|c|}{ Cuadrilla: } & \multicolumn{3}{|c|}{0.1 Cap + 1 Oper + 5 Peón } & \multirow[b]{2}{*}{ TOTAL } \\
\hline & & CUAD. & UND. & CANT. & P.U. & PARCIAL & \\
\hline \multicolumn{7}{|c|}{ MATERIALES } & 18.9 \\
\hline \multicolumn{2}{|c|}{ Vigueta Pretensada } & & $\mathrm{m}$ & 2.1 & 9.00 & 18.90 & \\
\hline \multicolumn{2}{|c|}{ MANO DE OBRA } & & & & & & 5.71 \\
\hline \multicolumn{2}{|l|}{ Capataz } & 0.1 & $\mathrm{HH}$ & 0.0057 & 32.80 & 0.19 & \\
\hline \multicolumn{2}{|l|}{ Operario } & 1.00 & $\mathrm{HH}$ & 0.0571 & 20.76 & 1.19 & \\
\hline \multicolumn{2}{|l|}{ Peón } & 5.00 & $\mathrm{HH}$ & 0.2857 & 15.15 & 4.33 & \\
\hline \multicolumn{3}{|c|}{ EQUIPO Y HERRAMIENTAS } & & & & & 0.17 \\
\hline \multirow{2}{*}{\multicolumn{2}{|c|}{ Herramienta Manual }} & & $\% \mathrm{MO}$ & 3.0000 & 5.71 & 0.17 & \\
\hline & & & & & & & 24.78 \\
\hline
\end{tabular}

Nota: Rendimiento y cuadrilla adaptado de Morán (2016) 
Tabla 23: APU de bovedilla - Sistema VIPRET

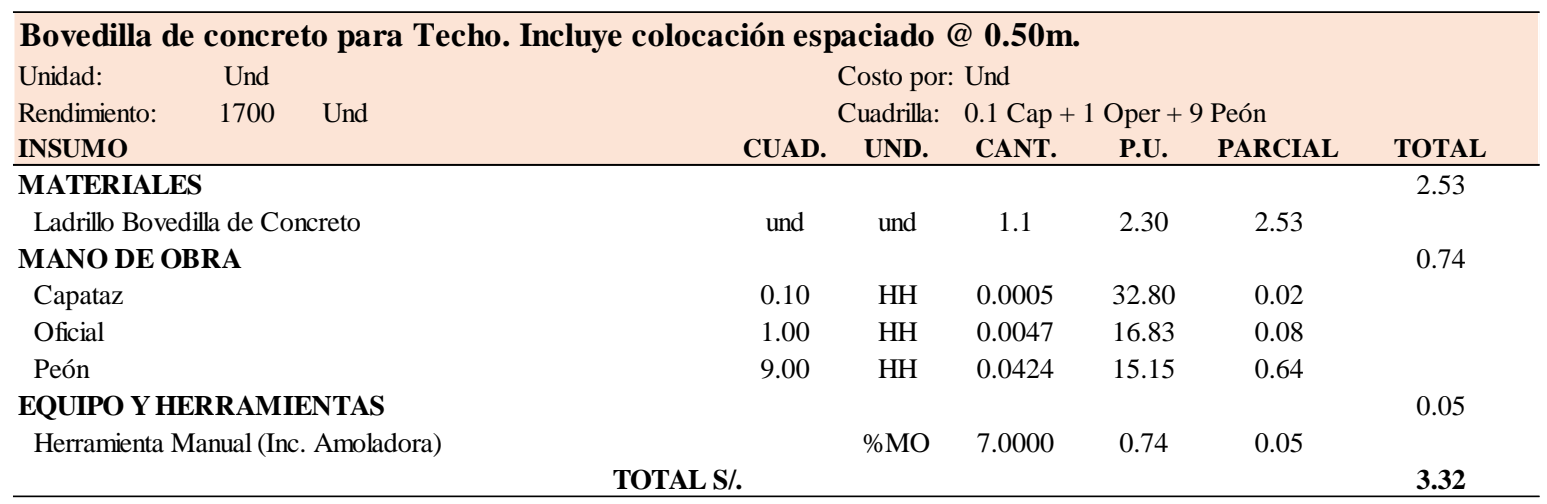

Nota: Rendimiento y cuadrilla adaptado de Morán (2016)

Tabla 24: APU de izaje de viguetas pretensadas - Sistema VIPRET

\begin{tabular}{|c|c|c|c|c|c|c|c|}
\hline \multicolumn{8}{|c|}{ Izaje de Viguetas (al 2do Piso) } \\
\hline \multirow{3}{*}{$\begin{array}{l}\text { Unidad: } \\
\text { Rendimiento: } \\
\text { INSUMO }\end{array}$} & \multirow{3}{*}{$\begin{array}{c}\mathrm{m} 2 \\
180\end{array}$} & \multicolumn{4}{|c|}{ Costo por: $\mathrm{m} 2$} & \multirow[b]{3}{*}{ PARCIAL } & \multirow[b]{3}{*}{ TOTAL } \\
\hline & & & Cuadrilla: & 0.1 Cap & Oper & & \\
\hline & & CUAD. & UND. & CANT. & P.U. & & \\
\hline \multicolumn{2}{|c|}{ MANO DE OBRA } & & & & & & 4.19 \\
\hline \multicolumn{2}{|l|}{ Capataz } & 0.1 & $\mathrm{HH}$ & 0.0044 & 32.80 & 0.15 & \\
\hline \multicolumn{2}{|l|}{ Peón } & 6 & $\mathrm{HH}$ & 0.2667 & 15.15 & 4.04 & \\
\hline \multirow{2}{*}{\multicolumn{2}{|c|}{ EQUIPO Y HERRAMIENTAS }} & & & & & & 0.13 \\
\hline & & & $\% \mathrm{MO}$ & 3.0000 & 4.19 & 0.13 & \\
\hline \multicolumn{2}{|c|}{ Herramienta Manual } & & & & & & 4.32 \\
\hline
\end{tabular}

Nota: Rendimiento y cuadrilla adaptado de Morán (2016)

Una vez que se tienen los APU's desarrollados se procede a realizar el presupuesto para el sistema de losa aligerada convencional se muestra en la Tabla 25. 
Tabla 25: Presupuesto final - Sistema VIPRET

\begin{tabular}{|c|c|c|c|c|c|c|}
\hline \multicolumn{7}{|c|}{$\begin{array}{l}\text { PRESUPUESTO } \mathrm{N}^{\circ} 2 \\
\end{array}$} \\
\hline Descripción & Und. & Metrado & Precio $(\mathrm{S} /)$. & $\operatorname{Parcial}(\mathrm{S} /)$. & & Total $(\mathrm{S} /)$ \\
\hline LOSA ALIGERADA $\mathrm{e}=0.20$ & & & & & & 17037.79 \\
\hline Izaje de Viguetas (al 2do Piso) & $\mathrm{m} 2$ & 120.00 & 4.32 & 518.40 & & \\
\hline Vigueta Pretensada VIPRET - Incluye colocación en forma manual & $\mathrm{m} 2$ & 120.00 & 24.78 & 2973.60 & & \\
\hline Bovedilla de concreto para Techo. Incluye colocación espaciado @ 0.50m. & Und. & 960.00 & 3.32 & 3187.20 & & \\
\hline Apuntalamiento y Desencof rado Losa con Viguetas Firth c/ladrillo - Madera & $\mathrm{m} 2$ & 120.00 & 9.26 & 1111.20 & & \\
\hline Acero Corrugado fy $=4200 \mathrm{Kg} / \mathrm{cm} 2$ ASTM A615 Grado 60 & $\mathrm{Kg}$ & 211.83 & 4.10 & 868.50 & & \\
\hline Concreto en Losa Aligerada $f^{\prime} c=210 \mathrm{Kg} / \mathrm{cm} 2$ & $\mathrm{~m} 3$ & 8.40 & 369.86 & 3106.82 & & \\
\hline Acero en Vigas (2do Piso) & $\mathrm{Kg}$ & 747.28 & 4.44 & 3317.92 & & \\
\hline \multirow[t]{5}{*}{ Concreto en Vigas $\mathrm{fc}=210 \mathrm{~kg} / \mathrm{cm} 2$ (2do Piso) } & $\mathrm{m} 3$ & 5.37 & 364.24 & 1954.15 & & \\
\hline & \multicolumn{4}{|c|}{ COSTO DIRECTO } & $\mathrm{S} /$. & $17,037.79$ \\
\hline & \multicolumn{4}{|c|}{------------------ } & & \\
\hline & \multicolumn{4}{|c|}{ PRESUPUESTO TOTAL } & & $17,037.79$ \\
\hline & \multicolumn{4}{|c|}{ Valor de $\mathrm{m} 2$ de Losa Aligerada convencional } & $\mathrm{S} /$. & 141.98 \\
\hline
\end{tabular}

Nota: Fuente propia (2018)

\subsection{Sistema de Losa aligerada con Vigueta Tralicho}

Los pasos número 1 y 2 del Sistema con Vigueta Tralicho serán los mismos que los sistemas anteriores. El paso número 3 sería calcular la cantidad de acero que será necesario. En este caso, la vigueta no necesita acero positivo, ya que este viene embebido en la vigueta; por ello, solo será necesario calcular la cantidad de acero negativo y de temperatura necesaria. El cálculo va ser el mismo que para el sistema anterior, tal y como se mostró en la Tabla 18, la cantidad de acero por vigueta que se va a considerar será de $5.58 \mathrm{~kg}$ por vigueta.

Las viguetas van a ir transversalmente a lo largo de los $5.50 \mathrm{~m}$ y $6.00 \mathrm{~m}$ que tiene la losa, por lo que en estas longitudes van a entrar 2 viguetas por cada metro, se tiene:

$$
(2 \text { viguetas } / \mathrm{m}) \times(5.50 \mathrm{~m}+6.00 \mathrm{~m})=23 \text { viguetas }
$$

Por cada vigueta se ha calculado $5.58 \mathrm{~kg}$ de acero, entonces:

$$
23 \text { viguetas } \times 5.58 \mathrm{~kg} / \text { vigueta }=128.34 \mathrm{~kg}
$$

A este cálculo se le debe añadir el acero de temperatura cuyo diámetro es $6 \mathrm{~mm}$ : 


$$
(33 \varnothing 6 \mathrm{~mm}) \times(5.50 \mathrm{~m}+6.00 \mathrm{~m}) \times(0.22 \mathrm{~kg} / \mathrm{m})=83.49 \mathrm{~kg}
$$

Si sumamos todo se va a tener el siguiente resultado para el cálculo de acero:

$$
\text { As }(-)+\text { As }(+)+\text { AsT }=131.10 \mathrm{~kg}+83.49 \mathrm{~kg}=211.83 \mathrm{~kg} \text { de acero }
$$

Para calcular la cantidad de concreto se utilizó un ratio que indica que por cada $\mathrm{m}^{2} \mathrm{de}$ losa se tiene $0.0750 \mathrm{~m}^{3}$ de concreto, para esta evaluación se tiene:

$$
0.0750 \mathrm{~m}^{3} / \mathrm{m}^{2} \times 120 \mathrm{~m}^{2}=9.00 \mathrm{~m}^{3} \text { de concreto }
$$

Para el cálculo de la cantidad de ladrillo se utilizó un ratio que indica que por cada $\mathrm{m}^{2}$ de losa se tienen 8 unid de ladrillo bovedilla para techo.

$$
8 \mathrm{lad} / \mathrm{m} 2 \times 120 \mathrm{~m} 2=960 \text { unid de ladrillo bovedilla }
$$

En el caso de las vigas, se tiene la misma distribución de acero que en el sistema anterior, con estas características vamos a calcular la cantidad de concreto y acero que se va a necesitar para las vigas.

Viga $1(25 \times 40)$ :

Se tiene 3 vigas de estas características, con $12.25 \mathrm{~m}$ y la sección de $0.25 \mathrm{mx} 0.40 \mathrm{~m}$ se tiene:

Vol. Concreto $=3 \times(12.25 \times 0.25 \times 0.40)=3.675 \mathrm{~m}^{3}$ de concreto de viga

Referente al acero, se van a utilizar los resultados ya calculados con el sistema anterior, ya que esto no varía nada entre un sistema y otro. Como se tiene 3 vigas de estas mismas características, el resultado se multiplica por 3:

$$
\text { Acero longitudinal }=3 \times 105.73 \mathrm{~kg}=317.19 \mathrm{~kg}
$$

En el cálculo de los estribos tenemos

Longitud de estribo de $2(0.30+0.40+0.10)=1.60 \mathrm{~m}$ 
Se tiene 31 estribos distribuidos en la luz de $5.50 \mathrm{~m}$ y 33 estribos en la luz de $6.00 \mathrm{~m}$, los estribos son de diámetro de 3/8". Se debe considerar que se tienen 3 vigas:

64 estribos x $1.60 \mathrm{~m} /$ estribo $=3 \times 102.4 \mathrm{~m} \times 0.56 \mathrm{~kg} / \mathrm{m}=172.03 \mathrm{~kg}$

Viga $2(25 \times 20)$ :

Se tiene 3 vigas de estas características, con 11.25 m y la sección de 0.25 m x 0.20 m:

Vol. Concreto $=3 \times(11.25 \times 0.25 \times 0.20)=1.69 \mathrm{~m}^{3}$ de concreto de viga

Vol. Concreto $=1.69 \mathrm{~m}^{3}$ de concreto de viga

Como se tiene 3 vigas de estas mismas características, el resultado se multiplica por 3:

Acero longitudinal $=3 \times 45.98 \mathrm{~kg}=137.94 \mathrm{~kg}$

En el cálculo de los estribos tenemos

Longitud de estribo de $2(0.25+0.20+0.10)=1.10 \mathrm{~m}$

Se tiene 29 estribos distribuidos en la luz de 5.00 m, 27 estribos en la luz de $4.50 \mathrm{~m}$ y 9 estribos en la luz de $1.00 \mathrm{~m}$, los estribos son de diámetro de $3 / 8$ ”. Se debe considerar que se tienen 3 vigas:

65 estribos x $1.10 \mathrm{~m} /$ estribo $=3 \times 71.50 \mathrm{~m} \times 0.56 \mathrm{~kg} / \mathrm{m}=120.12 \mathrm{~kg}$

En cuanto a los elementos propios del sistema, la vigueta Tralicho y la bovedilla, se contactó a la empresa TODOCEMENTO, fabricante de viguetas pretensadas, quienes cotizaron la losa que se muestra a inicios de este capítulo en 6'700 soles, precio que incluye las viguetas y las bovedillas, además del transporte. Los datos que se manejaron en esta cotización se muestran a continuación 
EMPRESA:

AREA DE LOSA:

DIRECCIÓN:

PRECIO TOTAL: 6'700 soles

PRECIO POR M2: 56 soles $/ \mathrm{m}^{2}$

Según una distribución por metro cuadrado, en esta área entran 2 viguetas pretensadas y 8 bovedillas, si distribuimos el costo por metro cuadrado mitad para la vigueta y mitad para la bovedilla entonces una vigueta pretensada sale costando a 14.0 soles el metro lineal, mientras que una bovedilla estaría costando 3.50 soles por unidad.

Todos estos componentes van a entrar en unos Análisis de Precio Unitario (APU's) para obtener los costos unitarios de cada partida por separado. A continuación, se van a mostrar las Tablas 26, 27, 28 y 29 donde se han desarrollado cada uno de los APU's, solo se muestran los análisis referentes al sistema de pretensado, ya que el resto de partidas son las mismas que el sistema anterior.

Tabla 26: APU de apuntalamiento y desencofrado - Sistema TRALICHO

\begin{tabular}{|c|c|c|c|c|c|c|c|}
\hline \multicolumn{8}{|c|}{ Apuntalamiento y Desencofrado Losa con Viguetas Tralicho } \\
\hline \multirow{3}{*}{$\begin{array}{l}\text { Unidad: } \\
\text { Rendimiento: } \\
\text { INSUMO }\end{array}$} & $\mathrm{m} 2$ & \multicolumn{3}{|c|}{ Costo por: $\mathrm{m} 2$} & & \multirow[b]{3}{*}{ TOTAL } \\
\hline & $\mathrm{m} 2$ & \multicolumn{2}{|c|}{ Cuadrilla: } & $0.1 \mathrm{Cap}+$ & Oper + & Ofic & \\
\hline & & CUAD. & UND. & CANT. & P.U. & PARCIAL & \\
\hline \multicolumn{3}{|c|}{ MATERIALES } & & & & & 4.37 \\
\hline \multicolumn{2}{|c|}{ Alambre Negro Recocido \# 16} & & $\mathrm{Kg}$ & 0.0100 & 3.12 & 0.03 & \\
\hline \multicolumn{2}{|c|}{ Clavos para madera de $2 "$ a $4 "$} & & $\mathrm{Kg}$ & 0.0250 & 3.90 & 0.10 & \\
\hline \multicolumn{2}{|c|}{ Madera Tornillo larga } & & $\mathrm{p} 2$ & 1.0600 & 4.00 & 4.24 & \\
\hline \multicolumn{2}{|c|}{ MANO DE OBRA } & & & & & & 4.66 \\
\hline \multicolumn{2}{|l|}{ Capataz } & 0.10 & $\mathrm{HH}$ & 0.0114 & 32.80 & 0.37 & \\
\hline \multicolumn{2}{|l|}{ Operario } & 1.00 & $\mathrm{HH}$ & 0.1143 & 20.76 & 2.37 & \\
\hline \multicolumn{2}{|l|}{ Oficial } & 1.00 & $\mathrm{HH}$ & 0.1143 & 16.83 & 1.92 & \\
\hline \multicolumn{3}{|c|}{ EQUIPO Y HERRAMIENTAS } & & & & & 0.23 \\
\hline \multirow{2}{*}{\multicolumn{2}{|c|}{ Herramienta Manual }} & & $\% \mathrm{MO}$ & 5.0000 & 4.66 & 0.23 & \\
\hline & & & & & & & 9.26 \\
\hline
\end{tabular}

Nota: Rendimiento y cuadrilla adaptado de Morán (2016) 
Tabla 27: APU de vigueta - Sistema TRALICHO

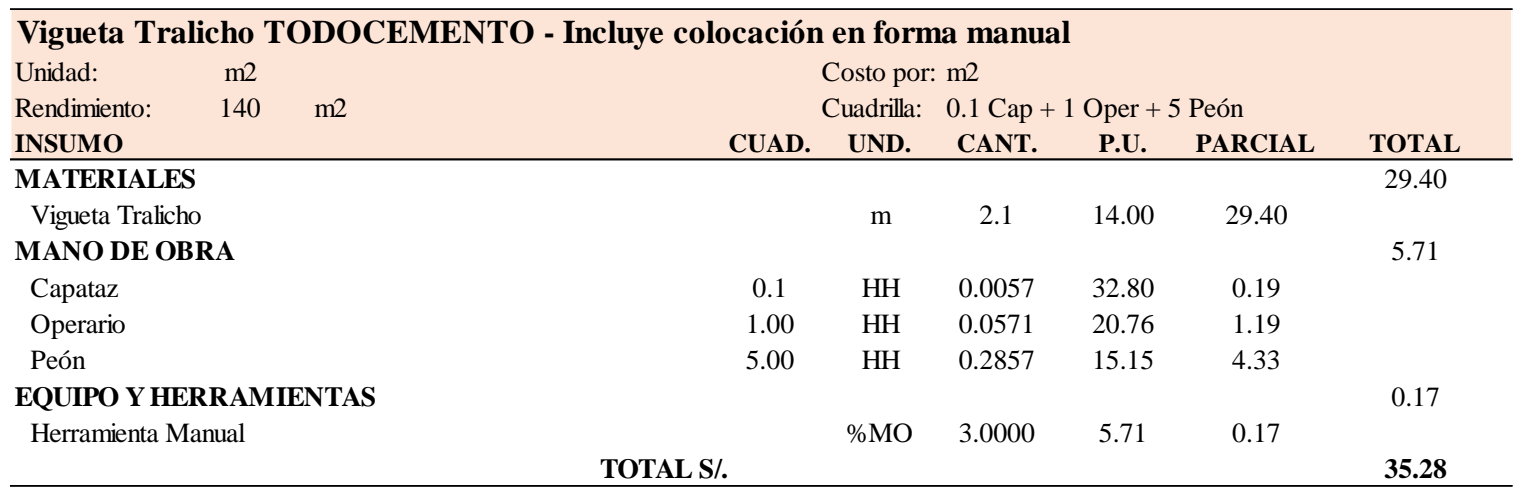

Nota: Rendimiento y cuadrilla adaptado de Morán (2016)

Tabla 28: APU de bovedilla - Sistema TRALICHO

\begin{tabular}{|c|c|c|c|c|c|c|c|c|}
\hline \multicolumn{9}{|c|}{ Bovedilla de arcilla para Techo. Incluye colocación espaciado@ 0.50m. } \\
\hline \multirow{3}{*}{$\begin{array}{l}\text { Unidad: } \\
\text { Rendimiento: } \\
\text { INSUMO }\end{array}$} & \multirow{3}{*}{\multicolumn{2}{|c|}{$\begin{array}{c}\text { Und } \\
1700\end{array}$}} & \multicolumn{5}{|c|}{ Costo por: Und } & \multirow[b]{3}{*}{ TOTAL } \\
\hline & & & & Cuadrilla & 0.1 Cap - & Oper + & Peón & \\
\hline & & & CUAD. & UND. & CANT. & P.U. & PARCIAL & \\
\hline \multicolumn{8}{|c|}{ MATERIALES } & 3.85 \\
\hline \multicolumn{3}{|c|}{ Ladrillo Bovedilla p. tralicho } & und & und & 1.1 & 3.50 & 3.85 & \\
\hline \multicolumn{3}{|c|}{ MANO DE OBRA } & & & & & & 0.74 \\
\hline \multicolumn{3}{|c|}{ Capataz } & 0.10 & $\mathrm{HH}$ & 0.0005 & 32.80 & 0.02 & \\
\hline \multicolumn{3}{|l|}{ Oficial } & 1.00 & $\mathrm{HH}$ & 0.0047 & 16.83 & 0.08 & \\
\hline \multicolumn{3}{|l|}{ Peón } & 9.00 & $\mathrm{HH}$ & 0.0424 & 15.15 & 0.64 & \\
\hline \multicolumn{4}{|c|}{ EQUIPO Y HERRAMIENTAS } & & & & & 0.05 \\
\hline \multirow{2}{*}{\multicolumn{3}{|c|}{ Herramienta Manual (Inc. Amoladora) }} & & $\% \mathrm{MO}$ & 7.0000 & 0.74 & 0.05 & \\
\hline & & & & & & & & 4.64 \\
\hline
\end{tabular}

Nota: Rendimiento y cuadrilla adaptado de Morán (2016)

Tabla 29: APU de izaje de viguetas - Sistema TRALICHO

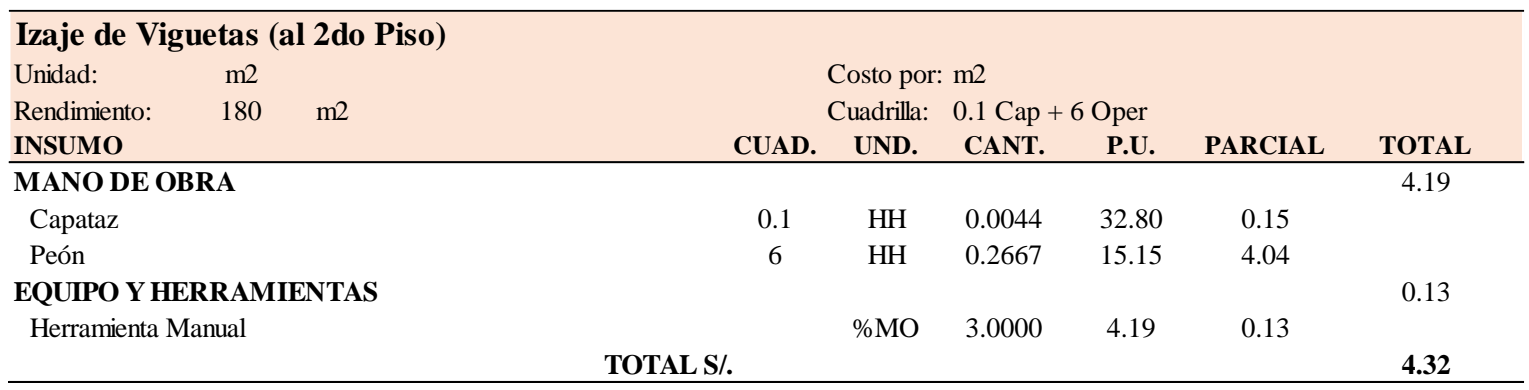

Nota: Rendimiento y cuadrilla adaptado de Morán (2016) 
Una vez que se tienen los APU's desarrollados se procede a realizar el presupuesto para el Sistema de losa aligerada con Vigueta Tralicho se muestra en la Tabla 30.

Tabla 30: Presupuesto final - Sistema TRALICHO

\begin{tabular}{|c|c|c|c|c|c|c|}
\hline \multicolumn{7}{|c|}{$\begin{array}{l}\text { PRESUPUESTO } \mathrm{N}^{\circ} 3 \\
\end{array}$} \\
\hline Descripción & Und. & Metrado & Precio (S/.) & Parcial (S/.) & & Total (S/) \\
\hline LOSA ALIGERADA $\mathrm{e}=0.20$ & & & & & & 19786.91 \\
\hline Izaje de Viguetas (al 2do Piso) & $\mathrm{m} 2$ & 120.00 & 4.32 & 518.40 & & \\
\hline Vigueta Tralicho TODOCEMENTO - Incluye colocación en forma manual & $\mathrm{m} 2$ & 120.00 & 35.28 & 4233.60 & & \\
\hline Bovedilla de arcilla para Techo. Incluye colocación espaciado @ 0.50m. & Und. & 960 & 4.64 & 4454.40 & & \\
\hline Apuntalamiento y Desencof rado Losa con Viguetas Firth c/ladrillo - Madera & $\mathrm{m} 2$ & 120.00 & 9.26 & 1111.20 & & \\
\hline Acero Corrugado fy $=4200 \mathrm{Kg} / \mathrm{cm} 2$ ASTM A615 Grado 60 & $\mathrm{Kg}$ & 211.83 & 4.10 & 868.50 & & \\
\hline Concreto en Losa Aligerada $\mathrm{f}^{\prime} \mathrm{c}=210 \mathrm{Kg} / \mathrm{cm} 2$ & $\mathrm{~m} 3$ & 9.00 & 369.86 & 3328.74 & & \\
\hline Acero en Vigas (2do Piso) & $\mathrm{Kg}$ & 747.28 & 4.44 & 3317.92 & & \\
\hline Concreto en Vigas $\mathrm{f}^{\prime} \mathrm{c}=210 \mathrm{~kg} / \mathrm{cm} 2$ (2do Piso) & $\mathrm{m} 3$ & 5.37 & 364.24 & 1954.15 & & \\
\hline \multicolumn{5}{|c|}{ COSTO DIRECTO } & $\mathrm{S} / \mathrm{s}$ & $19,786.91$ \\
\hline & \multicolumn{4}{|c|}{ 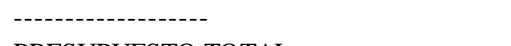 } & & \\
\hline & \multirow{2}{*}{\multicolumn{4}{|c|}{$\begin{array}{l}\text { PRESUPUESTO TOTAL } \\
\text { Valor de m2 de Losa Aligerada convencional }\end{array}$}} & S/. & 19,786.91 \\
\hline & & & & & S/. & 164.89 \\
\hline
\end{tabular}

Nota: Fuente propia (2018)

\subsection{Comparación Económica de los sistemas evaluados}

Para finalizar, se muestran los resultados obtenidos de manera resumida a fin de tener una comparación más clara, en el aspecto económico, de los tres sistemas. Es necesario aclarar que los tres presupuestos antes vistos no incluyen partidas para los acabados.

Según los resultados mostrados en la Figura 91, el sistema de losa aligerada más costoso, para un área de $120 \mathrm{~m}^{2}$, es el sistema convencional, con 24'798.74 soles, seguido del sistema TRALICHO con 19’786.91 soles y finalmente, el sistema más económico es el de vigueta pretensada VIPRET con tan solo 17'037.79 soles, lo cual representa un ahorro de $30 \%$ frente al sistema convencional y de $14 \%$ frente al sistema de vigueta Tralicho, esto referente al costo directo. 
Figura 91: Presupuesto final por sistema de losa aligerada

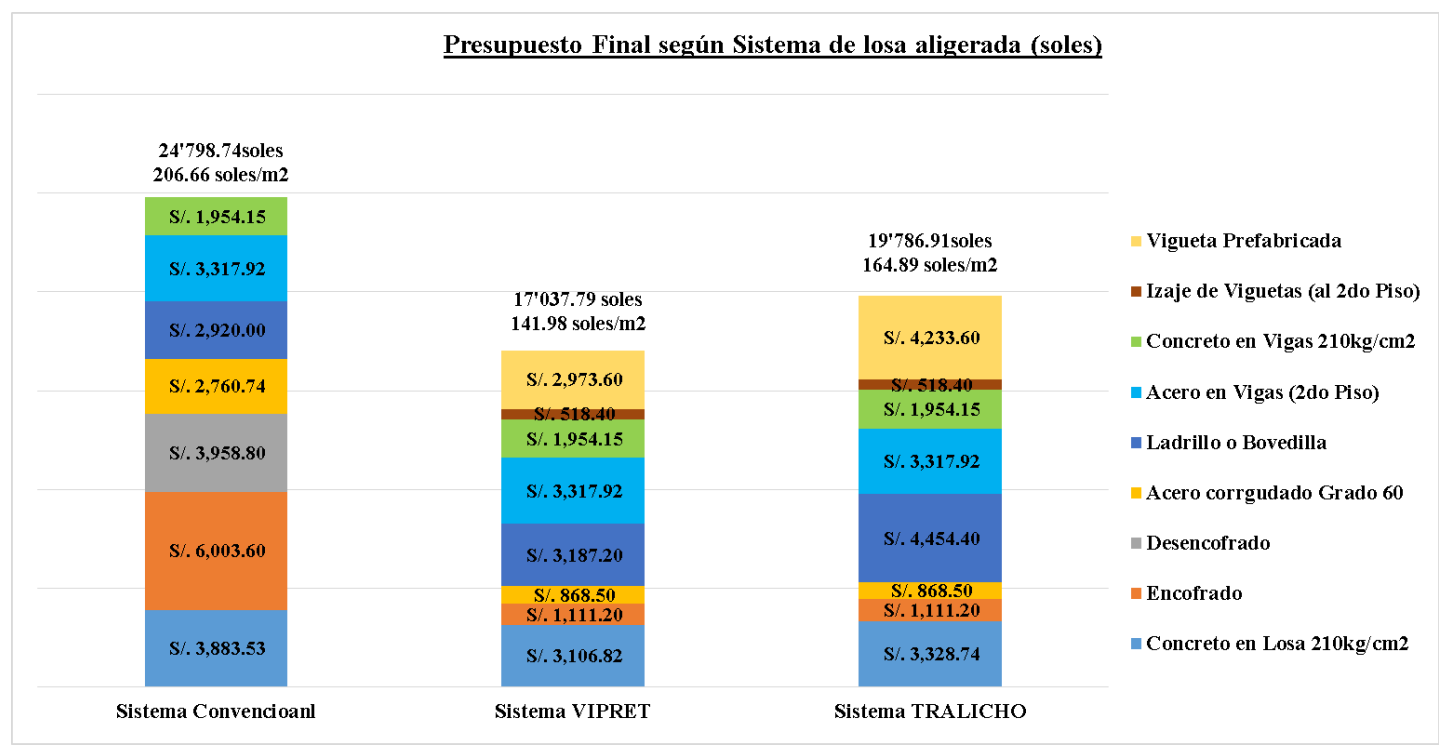

Fuente propia (2018)

Para este proyecto, el costo de concreto para el sistema de vigueta pretensada representa un $80 \%$ del costo de concreto de el sistema convencional y el de vigueta tralicho un $86 \%$, esto se debe al menor consumo de concreto que se tiene en los sistemas de losa con vigueta prefabricada frente al sistema convencional como se detalló en el capítulo IV de esta investigación. En esta partida y para este proyecto se tuvo un ahorro en el costo de concreto de 776.71 soles con el sistema de vigueta pretensada y 554.79 soles con el sistema de vigueta tralicho, esto equivale un ahorro de concreto de 5 soles $/ \mathrm{m} 2$ aproximadamente entre ambos sistemas.

El costo de encofrado es uno de los ítems con mayor diferencia de costo entre el sistema convencional y los dos sistemas de vigueta prefabricada, ya que el consumo de madera para los sistemas de vigueta prefabricada representa el $21 \%$ del consumo de madera en el sistema convencional, lo que se evidencia en el costo de encofrado, el cual equivale a un ahorro del $80 \%$ utilizando un sistema de vigueta prefabricada, esto es evidente en el gráfico anterior, ya que se tiene un ahorro de 4892.40 soles al utilizar uno de los sistemas de vigueta prefabricada, esto equivale un ahorro de encofrado de 40.77 soles/m2. 
Por último, el costo de acero corrugado se reduce en una tercera parte al utilizar un sistema de vigueta prefabricada, esto debido al ahorro de acero positivo que representa un $64 \%$ de todo el acero de la losa convencional en este proyecto, se tiene un ahorro de 1892.24 soles en el costo de acero al utilizar un sistema de vigueta prefabricada, esto equivale un ahorro de acero de 15 soles $/ \mathrm{m} 2$.

Es necesario indicar que los beneficios económicos al utilizar un sistema de vigueta prefabricada van más allá del ahorro de materiales, ya que hay actividades que se están suprimiento al utilizar estos sistemas como acarreo de materiales, transporte de encofrado, habilitado de acero, con lo que los beneficios son todavía mayores que al de emplear el sistema convencional. 


\section{CAPÍTULO VI: GUIA PRÁCTICA PARA LA CORRECTA APLICACIÓN DE LA VIGUETA PRETENSADA EN UNA VIVIENDA UNIFAMILIAR Y DIFUSIÓN DE UN MANUAL PARA MAESTROS DE OBRA}

En este último capítulo se presenta la estructura de un Manual Didáctico dirigido hacia los maestros de obra y autoconstructores donde se muestran los beneficios de utilizar las viguetas pretensadas y la correcta aplicación de este sistema en la construcción de una vivienda unifamiliar de los sectores $\mathrm{C}$ y D de Lima. Luego se muestra una investigación de las principales causas que tienen los maestros de obra y autoconstructores para no utilizar las viguetas pretensadas en la construcción de sus viviendas, para lo cual se han aplicado encuestas en obras autoconstruidas que se visitaron en el cono norte de Lima, específicamente San Martín de Porres y los Olivos.

En los siguientes subcapítulos se van a detallar los puntos más importantes para la elaboración de este manual, estos puntos son el fundamento, la estructura y el desarrollo final.6.1. Fundamento

Como fundamento se entiende a las fuentes que se han utilizado para la elaboración de este manual, ya que el objetivo principal es dar a conocer a los maestros de obra y autoconstructores los beneficios y la correcta aplicación de la vigueta pretensada en una vivienda unifamiliar, se han buscado manuales que tengan el mismo objetivo.

El primer documento que se empleó como fuente fue el "Manual de Construcción para Maestros de Obra" de Aceros Arequipa (s.f.) ya que el contenido de este manual se transmite de forma sencilla y con ayuda de figuras que motivan a continuar con la lectura del mismo. 
La segunda fuente fue el manual técnico de viguetas pretensadas del sistema TECHOMAX de la empresa Concremax (s.f.), de este documento se obtuvo información sobre el encofrado con viguetas pretensadas, el almacenaje de las mismas en obra y las características de los elementos de participan en una losa aligerada con viguetas pretensadas.

La tercera fuente fue la página web de Vipret (s.f.), específicamente la pestaña de procesos constructivos, en la cual se muestra algunos casos de vigueta pretensada apoyada sobre vigas y muros, estos casos se ilustraron y usaron en el manual elaborado de esta investigación para explicarlos mejor y de forma más didáctica.

Finalmente, se utilizaron los resultados obtenidos en el capítulo 4 de esta investigación como fuente de información técnica para el manual, se utilizó el calculó el consumo de encofrado y de materiales para una losa aligerada convencional y para una losa con el sistema de viguetas pretensadas. Esta información se presentó con ayuda de gráficos y cuadros que ayudan a comparar de manera simple ambos sistemas de losa aligerada.

\subsection{Estructura}

La estructura que se ha elaborado en este manual busca explicar, en primer lugar, lo que es una vigueta pretensada y los tipos de bovedilla que se pueden emplear en este sistema según los requerimientos que se tengan en la estructura. En segundo lugar, se ha buscado mostrar los beneficios de usar la vigueta pretensada en cuanto al ahorro de encofrado, ahorro de concreto y el mejor acabado del fondo de losa. Como tercer punto se ha mostrado las correctas prácticas al momento de utilizar el sistema de vigueta pretensada en una obra, desde el momento en que se tenga que apilar en obra hasta el vaciado del concreto de la losa. Para finalizar se ha mostrado unas recomendaciones para los autoconstructores al momento de ejecutar una losa aligerada. A continuación se muestra el contenido general de este manual.

\section{Presentación}

2. Objetivo

3. La vigueta pretensada y la bovedilla 
4. Beneficios de la vigueta pretensada

5. Vigueta pretensada

6. Formas correctas de trabajar con la vigueta

7. Recomendaciones para los autoconstructores

\subsection{Desarrollo}

El desarrollo se encuentra en el manual elaborado que es el entregable de esta investigación, la estructura que contiene ha sido explicado en el punto anterior, la estructura.

Para finalizar con este capítulo y ya identificado el público objetivo, maestro de obra y autoconstructores, se ha planteado un plan de difusión que tiene los siguientes objetivos, tanto del plan de difusión y del manual didáctico.Objetivos del Plan de Difusión:

- Identificar establecimientos para vender las viguetas prefabricadas.

- Dar a conocer la existencia de las viguetas pretensadas en el sector de la autoconstrucción.

Objetivos del Manual Didáctico:

- Difundir el uso correcto de las viguetas pretensadas exponiendo diversos casos que se pueden presentar durante la ejecución de una losa aligerada con viguetas pretensadas.

- Mostrar de forma sencilla y resumida los beneficios en cuanto a costos, tiempo y calidad de utilizar viguetas pretensadas en la construcción de losas aligeradas.

Para cumplir con los objetivos planteados, tanto para el plan de difusión y del manual didáctico, se realizaron 30 encuestas a maestros de obra y autoconstructores en las mismas obras donde se encontraban trabajando y también en algunos locales ferreteros como Maestro de Los Olivos y Surquillo, esta encuesta se encuentra en los anexos de esta investigación. 
En la primera parte se consulta sobre datos de los maestros de obra, la edad y los años trabajando en la construcción con la finalidad separarlos por grupos y evaluar el grado de apertura a utilizar nuevos métodos constructivos.

En la Figura 92 se muestran los resultados para esta primera evaluación.

Figura 92: Edad de los maestros de obra encuestados

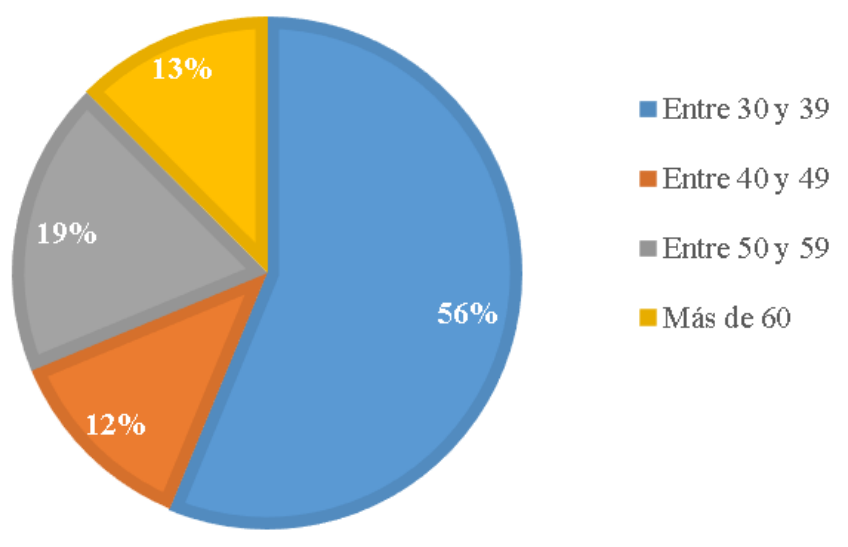

Fuente propia (2018)

De los 30 maestros encuestados, el 56\% se encuentran entre los 30 y 39 años de edad, esto fue necesario de identificar, ya que más adelante se mostrará que son los maestros jóvenes quienes están dispuestos a conocer y utilizar nuevos productos y métodos constructivos. Este dato es un indicador importante sobre el potencial mercado al que estaría dirigida la vigueta pretensada en la autoconstrucción. De estos primeros resultados también se identificó la edad del maestro de obra en la autoconstrucción, el cual tiene una edad máxima de 71 años, edad mínima de 30 años y la edad promedio de 45 años.

En la Figura 93 se muestra los años de experiencia de los maestros de obra encuestados.

Figura 93: Años de experiencia de los maestros de obra encuestados 


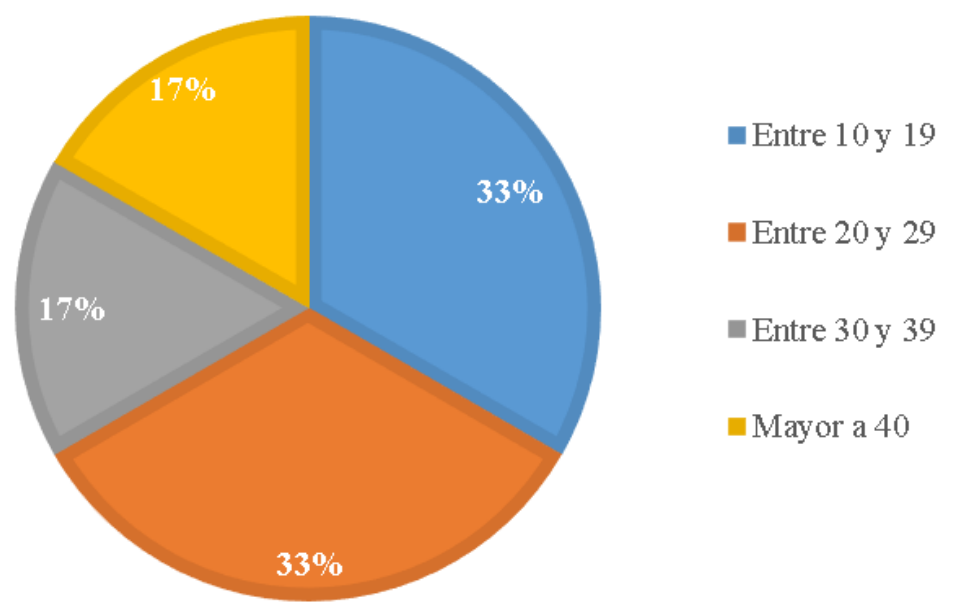

Fuente propia (2018)

Según la figura anterior, el 33\% cuenta una experiencia entre 10 y 19 años trabajando en la construcción, otro 33\% cuenta con una experiencia de 20 a 29 años, el 17\% cuenta con una experiencia entre 30 y 39 años y el 17\% restante cuenta con una experiencia mayor a 40 años. Estos resultados evidencian que la mayoría de los maestros de obra encuestados son jóvenes y tienen pocos años de experiencia. De esta información se comprobó que la población joven de los maestros de obra suele recurrir a puntos de venta de materiales de construcción como Maestro, Sodimac y ferias constructivas como Excon y YoConstructor.

En tercer lugar se consultó sobre los principales problemas o inconvenientes al ejecutar una losa convencional, ello con la finalidad de identificar estos problemas y resaltar las soluciones que la vigueta pretensada ofrece ante estas dificultades.

En seguida se consultó sobre el conocimiento que tenían los maestros de obra de la vigueta pretensada con el objetivo de saber que tan difundido es el sistema de losas aligeradas con viguetas pretensadas en el sector autoconstrucción de los niveles socioeconómicos C y D de Lima.

Posteriormente, a los encuestados que conocía el sistema de losa aligerada con viguetas pretensadas se le consultó la razón por la que no utilizaban este sistema para la construcción de viviendas unifamiliares, estos resultados se muestran en la Figura 94. 
Figura 94: Razones por las que no usa el sistema de vigueta pretensada en la construcción de viviendas unifamiliares

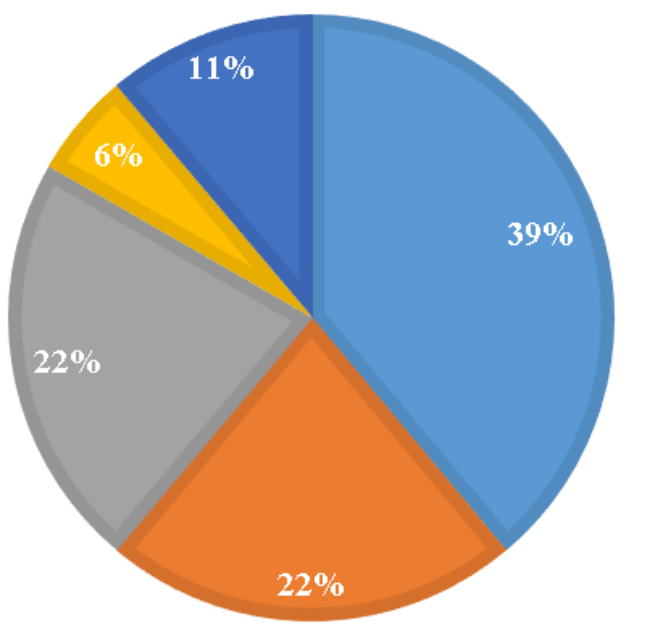

- El propietario no conoce o no quiere

El precio es muy caro

- No lo venden cerca

- No confio en el sistema

- No conozco cómo usarlo

Fuente propia (2018)

Según la encuesta, la razón principal por la que los maestros de obra no utilizan este sistema es porque el propietario del predio no desea o no conoce la aplicación de este sistema (39\% de encuestados), con ello se evidencia la importancia del propietario del predio en la elección de los materiales de construcción o del sistema a utilizar; por ello, el propietario del predio será parte de la población a la cual esté dirigido el Manual Didáctico que se ha elaborado. Con respecto a los otros motivos y razones, el $22 \%$ de encuestados comentaron que el precio era muy elevado, otro $22 \%$ contestó que las viguetas no se vendían lo suficientemente cerca para poder ser utilizadas y el $11 \%$ restante respondió no saber cómo utilizar las viguetas y solo una persona dijo que el sistema era malo y no confiaba lo suficiente como para utilizarlo.

Los datos sobre la elección de los lugares estratégicos para difundir los Manuales Didácticos y vender las viguetas pretensadas se desprenden de las respuestas de los maestros de obra a la pregunta “¿en qué lugar le gustaría comprar la vigueta pretensada en el caso de tener que utilizarla en la construcción de una losa aligerada?", estos resultados se observan en la Figura 95.

Figura 95: Lugares donde compraría la vigueta pretensada 


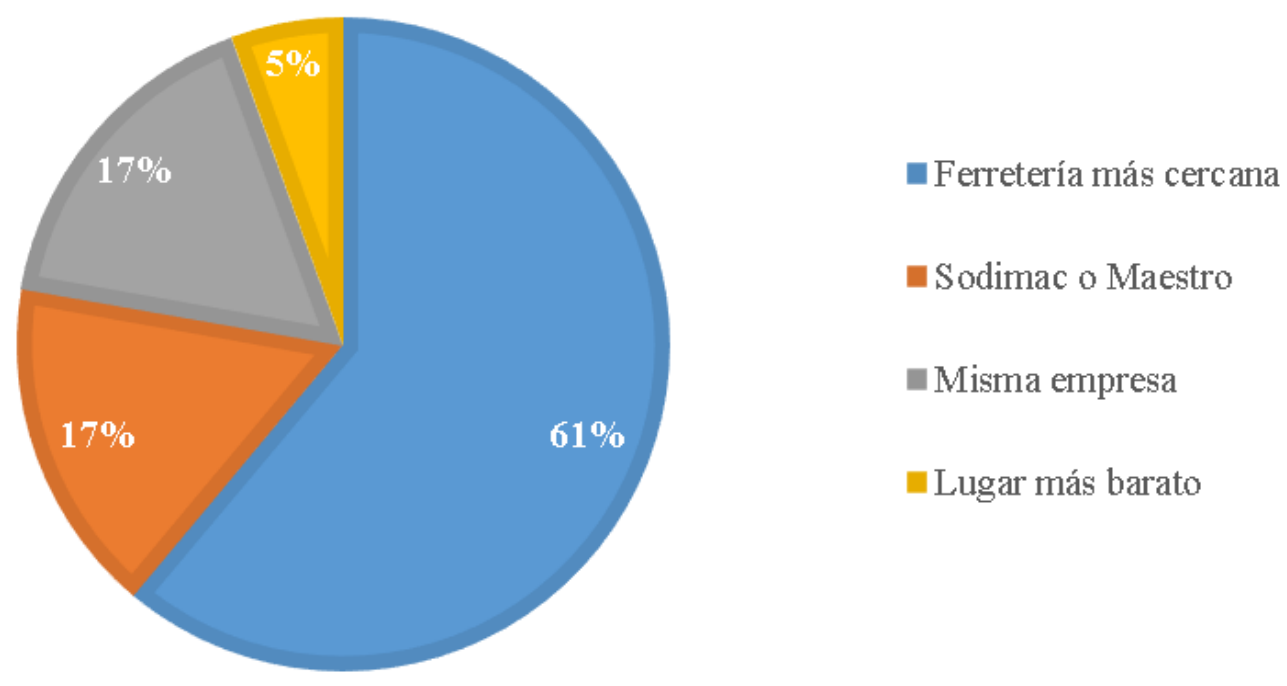

Fuente propia (2018)

El 61\% de encuestados respondió que la mejor opción de adquirir la vigueta pretensada sería en la ferretería más cercana; el 17\% respondió que la empresa fabricante es la mejor alternativa para adquirir este producto, otro $17 \%$ respondió que en Sodimac o Maestros sería el lugar conveniente para comprar la vigueta y dos personas respondieron que el lugar óptimo es en donde el costo sea el menor del mercado ya sea en cualquier establecimiento de las 3 opciones antes mencionadas. Con estos resultados es evidente que los nexos entre las empresas fabricantes de viguetas y el maestro y propietario para vender las viguetas pretensadas son las ferreterías medianas ubicadas cerca a estas viviendas autoconstruidas.

Frente a este último dato, surge una oportunidad de negocio como distribuidor de las viguetas pretensadas en el sector autoconstrucción de Lima; pues se trata de un mercado absolutamente nuevo. Esta opción resulta muy atractiva debido a que existe un porcentaje importante del sector autoconstrucción que puede empezar a utilizar este novedoso sistema de losa aligerada, a un precio competitivo comparado con el sistema convencional. Asimismo, con esta difusión de uso se garantiza viviendas autoconstruidas más seguras, de mejor calidad y en un menor tiempo de ejecución. 
Entonces sería interesante realizar un análisis más profundo sobre esta oportunidad de ser un distribuir o nexo entre el fabricante y el usuario final adicionando en el análisis los gastos de almacén, trabajadores y transporte.

Del mismo modo, se consultó sobre los lugares en los cuales los maestros se informan sobre novedades en la construcción y nuevos productos para utilizar, estos resultados se encuentran resumidos en la Figura 96.

Figura 96: Lugares donde se informa sobre nuevos productos constructivos

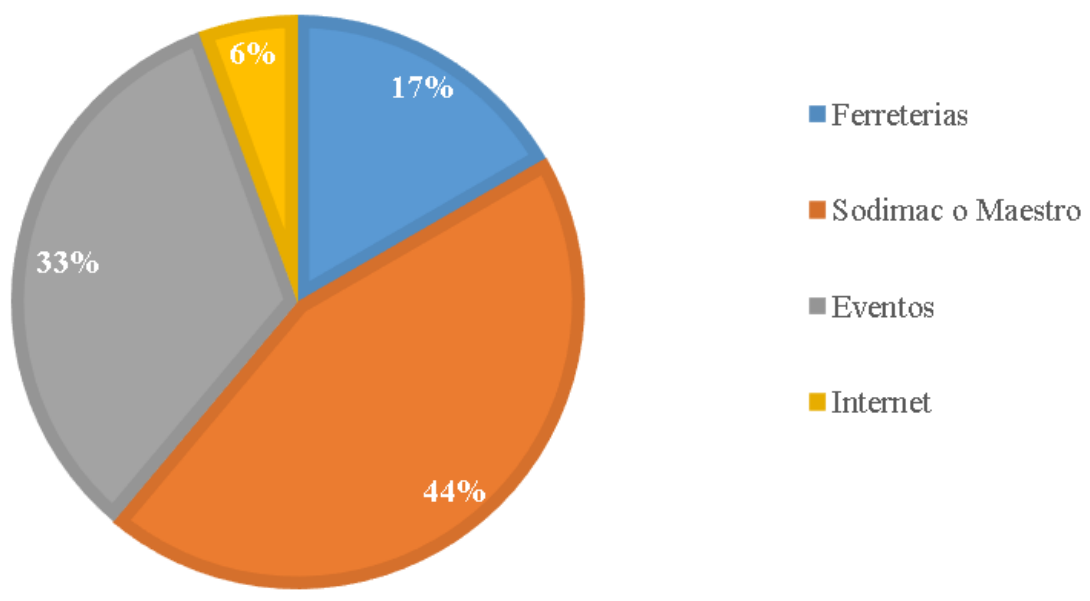

Fuente propia (2018)

Un 44\% de los encuestados respondió que se informa en "ferreterías grandes" como Sodimac o Maestro, en estos centros reciben información de empresas sobre nuevos productos o novedades, un 33\% respondió que asistía a eventos para conocer las novedades constructivas, un $17 \%$ dijo que en ferreterías y solo una persona dijo que mediante internet el recibía información a su correo de las empresas sobre novedades del sector construcción. Esta información es esencial, pues se ha identificado los lugares idóneos para difundir la información sobre las viguetas pretensadas, en este caso, las charlas o capacitaciones de Sodimac o Maestro son los lugares perfectos para difundir la información planteada, además que estos lugares también son visitados por propietarios que piensan autoconstruir su vivienda. En la Figura 98 se observa la portada que tiene este manual. 
Figura 97: Portada y contenido del manual elaborado

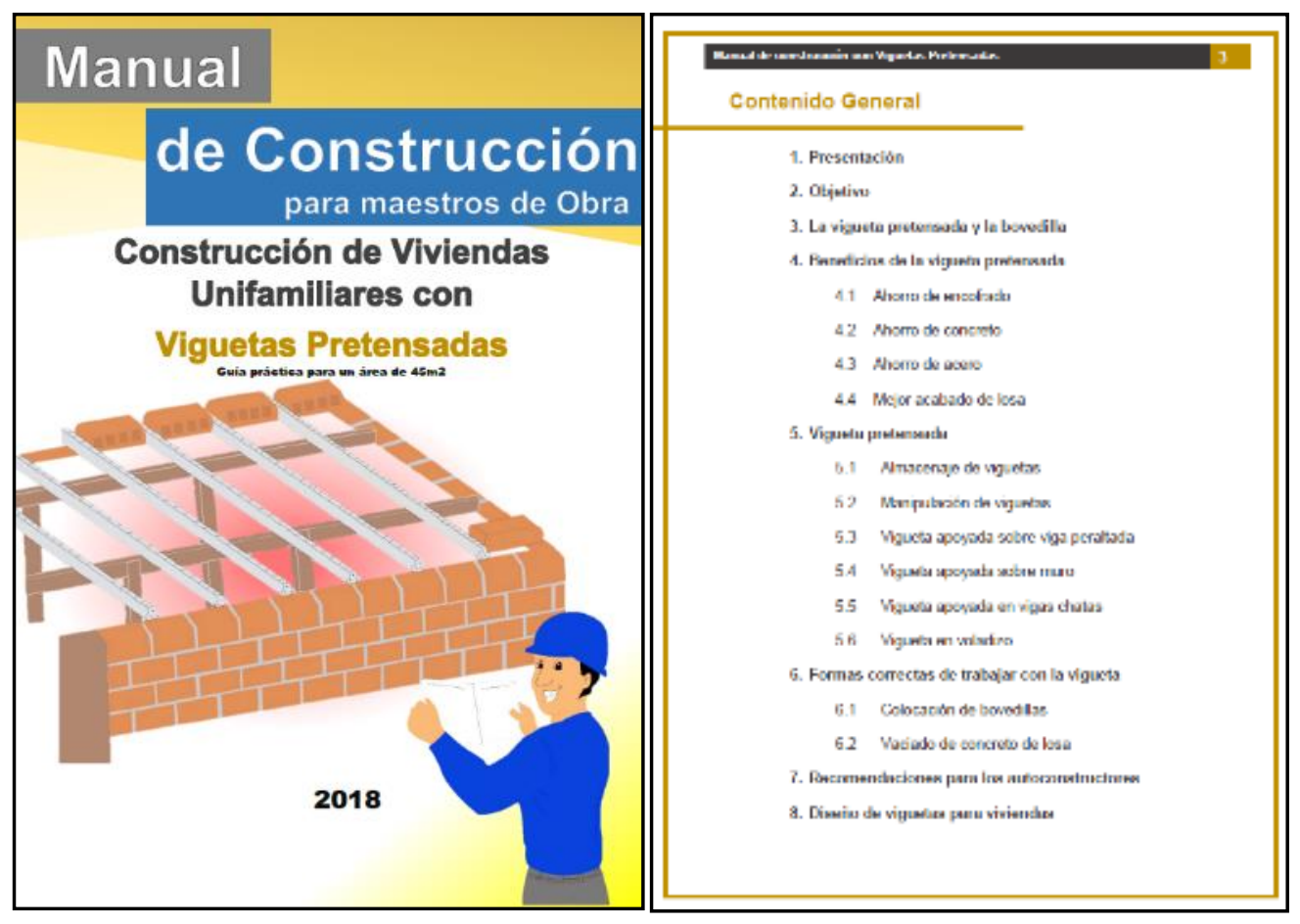

Fuente propia (2018)

De esta forma se quiere difundir los beneficios del empleo de la vigueta pretensada en la autoconstrucción de una vivienda unifamiliar que se han encontrado en esta investigación y de esta forma contribuir a mejorar la construcción con la ayuda de sistemas industrializados. 


\section{CAPÍTULO VII: CONCLUSIONES}

El principal problema que se ha llegado a identificar en la autoconstrucción de una losa aligerada tiene que ver con el tiempo de armado que conlleva la losa aligerada, esta etapa representa más del 50\% de todo el tiempo que toma ejecutar el techo, esto tiene que ver por el encofrado que requiere este sistema y por el escaso personal que utilizan los maestros de obra en este tipo de construcciones.

En el aspecto técnico desarrollado en el capítulo 4, el ahorro del encofrado es un factor muy importante para utilizar el sistema de vigueta pretensada o tralicho, ya que permite un ahorro de $80 \%$ de madera frente al sistema convencional, además que acelera el proceso de encofrado de losa en un $40 \%$ y mejora la calidad de la losa, tanto en el aspecto estructural como de acabado final de cielo razo.

En el aspecto económico desarrollado en el capítulo 5, para una losa aligerada de $120 \mathrm{~m}^{2}$, el sistema de convencional resultó ser el más caro de los tres sistemas evaluados con un precio total de 24'798.74 soles, seguido del sistema TRALICHO que obtuvo un costo de 19'786.91 soles, finalmente el sistema de vigueta pretensada VIPRET resultó ser el más económico con un precio total de 17’037.79 soles. El sistema de vigueta pretensada VIPRET representa un ahorro de $30 \%$ frente al sistema convencional y de $14 \%$ frente al sistema de vigueta Tralicho, esto referente al costo directo.

El sistema de vigueta pretensada, como sistema constructivo industrializado, resulta una mejor opción para construir losas aligeradas de viviendas unifamiliares frente al sistema convencional y vigueta Tralicho, tanto en aspectos técnicos (mejor productividad), económica (más barato) y calidad del concreto (resistencia adecuada del concreto). 


\section{CAPÍTULO VIII: RECOMENDACIONES}

La autoconstrucción en el Perú, específicamente en Lima, es un sector con un gran potencial para la economía actual, sin embargo no tiene una adecuada atención por parte de entidades públicas y privadas para su adecuado aprovechamiento.

Tener en cuenta los nuevos procesos constructivos, ya que generan beneficios económicos y técnicos para las viviendas unifamiliares.

Seguir un proceso adecuado para las diferentes etapas del proceso constructivo de la losa aligerada con los sistemas de losa prefabricada, para maximizar la productividad y mantener la calidad de los acabados.

Las empresas fabricantes de estos elementos, tanto de la vigueta pretensada como de la vigueta tralicho, pueden con un mejor proceso de concientización y difusión hacia la población sobre este producto, ya que su empleo mejora la construcción de viviendas unifamiliares y existe una cantidad considerable de viviendas autoconstruidas. 


\section{CAPÍTULO IX: BIBLIOGRAFÍA}

Aceros Arequipa. (s.f.). Manual de Construcción para Maestros de Obra. Recuperado de

http://www.acerosarequipa.com/fileadmin/templates/AcerosCorporacion/PDF/manual _MAESTRO_OBRA.pdf [Consulta: 10 de abril de 2018]

Arellano Marketing. (09 de septiembre de 2017). Estudio Multiclientes Autoconstrucción. Arellano Marketing. Recuperado de http://www.arellanomarketing.com/inicio/el-75-de-limenos-que-autoconstruye-tieneclaro-que-marcas-compraran/ [Consulta: 10 de abril de 2018] Asociación Peruana de Empresas de Investigación de Mercados (APEIM). (2017). Niveles Socioeconómicos 2017. Recuperado de http://www.apeim.com.pe/wpcontent/themes/apeim/docs/nse/APEIM-NSE-2017.pdf [Consulta: 09 de octubre de 2016]

Chang, M. (2014). Propuesta y evaluación de la aplicación del sistema de construcción industrializada modular. (Tesis para optar el título de Ingeniero Civil, Facultad de Ciencias e Ingeniería, Pontificia Universidad Católica del Perú. Lima, Perú). Recuperado de file:///C:/Users/OSCAR/Downloads/MARCO_ANTONIO_CHANG_BRE\%C3\%91A _PROPUESTA_EVALUACION_SISTEMA_CONSTRUCCION.pdf [Consulta: 16 de abril de 2018]

Compañía Peruana de Estudios de Mercados y Opinión Pública S.A.C. (CPI) (2017) Perú: Población 2017 (Market Report N7). Recuperado de http://cpi.pe/images/upload/paginaweb/archivo/26/mr_poblacion_peru_2017.pdf Concremax. (s.f.) Sistema de losas aligeradas con viguetas pretensadas TECHOMAX. Recuperado de http://www.firth.com.pe/repositorioaps/data/1/1/1/jer/techomax-losasaligeradas-

pretensadas/files/Manual\%20de\%20Viguetas\%20TECHOMAX\%202017.pdf

[Consulta: 10 de abril de 2018] 
Constructivo. (enero, 2015). Losas aligeradas pretensadas vs losas aligeradas tradicionales. Revista CONSTRUCTIVO, (104), 216-217.

Constructivo. (abril, 2018). Partidas desagregadas. Revista CONSTRUCTIVO, (127), 188-195.

Corcuera, M. (2009). Estudio de Investigación para el desarrollo de viviendas sociales de bajo coste en la ciudad de Lima - Perú. (Trabajo fin de Máster, Universidad Politécnica de Cataluña. Madrid, España). Recuperado de http://doczz.es/doc/320464/estudio-de-investigaci\%C3\%B3n-para-el-desarrollo-deviviendas-... [Consulta: 10 de abril de 2018]

Custodio, L. (2014). Manual de instalación de techo aligerado con viguetas prefabricadas de acero. Recuperado de http://www.sencico.gob.pe/descargar.php?id=71 [Consulta: 10 de abril de 2018] Deacero. (s.f.). Manual técnico armadura y losas de vigueta y bovedilla. Recuperado de http://cablesdeacero.info/Content/Products/Files/ArmaduraMAnualTecnico.PDF [Consulta: 10 de abril de 2018]

Dominguez, S. (23 de octubre de 2017). La construcción será nuevamente motor del crecimiento económico. El Peruano. Recuperado de http://www.elperuano.pe/noticiala-construccion-sera-nuevamente-motor-del-crecimiento-economico-60463.aspx [Consulta: 06 de abril de 2018]

Estructuras de concreto S.A. (ECONSA). (s.f.). Productos. Recuperado de http://econsa.org/ [Consulta: 10 de abril de 2018]

Firth. (2012). Losa aligerada con viguetas pretensadas. [Presentación explicativa del proceso constructivo] Recuperado de https://es.slideshare.net/DavidEscobedo2/aligerado-expo-constru-1608 [Consulta: 10 de abril de 2018]

Flores, R. (2002). Diagnostico preliminar de la vulnerabilidad sísmica de las autoconstrucciones en Lima (Tesis para optar el título de Ingeniero Civil, Facultad de Ciencias e Ingeniería, Pontificia Universidad Católica del Perú. Lima, Perú). Recuperado de http://tesis.pucp.edu.pe/repositorio/bitstream/handle/123456789/5668/FLORES_ROB 
ERTO_VULNERABILIDAD_SISMICA_AUTOCONSTRUCCIONES_LIMA.pdf?s equence $=1$ [Consulta: 10 de abril de 2018]

Gestión. (07 de agosto de 2013). Sencico: Un 60\% de viviendas en el Perú es autoconstruida. Gestión. Recuperado de https://gestion.pe/tudinero/inmobiliarias/sencico-60-viviendas-peru-autoconstruida-45051 [Consulta: 09 de octubre de 2016]

Instituto Nacional de Estadística e Informática (INEI). (2018). Producción Nacional Noviembre 2017 (Informe Técnico Nº ${ }^{\circ}$ ). Recuperado de https://www.inei.gob.pe/media/MenuRecursivo/boletines/01-informe-tecnicon01_produccion-nacional-nov2017.pdf [Consulta: 10 de abril de 2018] Instituto Nacional de Estadística e Informática (INEI) (s.f.). Estimaciones y Proyecciones de Población (Población estimada y proyectada por sexo y tasa de crecimiento, según años calendarios). Recuperado de https://www.inei.gob.pe/estadisticas/indice-tematico/population-estimates-andprojections/ [Consulta: 06 de abril de 2018] Ipsos Perú. (5 de febrero de 2018). Estadística Poblacional 2018. [Estado de Facebook]. Recuperado de https://www.facebook.com/ipsosPE/posts/2000563059959110 [Consulta: 10 de abril de 2018]

Italconcreto (s.f.). El sistema Alitec. Recuperado de https://gerardoor.wordpress.com/ [Consulta: 10 de abril de 2018]

Laucata, J. (2013). Análisis de la vulnerabilidad sísmica de las viviendas informales en la ciudad de Trujillo (Tesis para optar el Título de Ingeniero Civil, Facultad de Ciencias e Ingeniería, Pontificia Universidad Católica del Perú. Lima, Perú). Recuperado de http:/tesis.pucp.edu.pe/repositorio/bitstream/handle/123456789/4967/LAUCATA_J OHAN_ANALISIS_VULNERABILIDAD_SISMICA_VIVIENDAS_INFORMALE S_CIUDAD_TRUJILLO.pdf?sequence=1 [Consulta: 10 de abril de 2018]

Lozano, M. (2011). Gestión de viviendas autoconstruidas en asentamientos humanos de Lima. (Trabajo de fin de Máster, Escuela Universitaria de Arquitectura Técnica, Universidad Politécnica de Madrid. Madrid, España). Recuperado de 
http://oa.upm.es/9319/2/TESIS_MASTER_MARGARITA_LOZANO_R.pdf

[Consulta: 10 de abril de 2018]

Ministerio del Trabajo y Promoción del Empleo (MTPE). (2010). Norma G.050

Seguridad durante la Construcción. Recuperado de file://C:/Users/User/Downloads/G.050SegConstruc\%20(1).pdf [Consulta: 10 de abril de 2018]

Ministerio del Trabajo y Promoción del Empleo (MTPE). (2014). Identificación de las ocupaciones demandadas a nivel nacional (Estudio del Sector Construcción).

Recuperado

de http://www.mintra.gob.pe/archivos/file/publicaciones_dnpefp/2014/IDENTIFICACI ON_OCUPACIONES_DEMANDADAS_NIVELNACIONAL_SC_1E-2014.pdf

[Consulta: 10 de abril de 2018]

Ministerio de Vivienda, Construcción y Saneamiento (MVCS). (2017). Diagnóstico y perspectivas del sector vivienda. Recuperado de http://www.adiperu.pe/wpcontent/uploads/04-CARLOS-BRUCE-DIAGN\%C3\%93STICO-Y-

PERSPECTIVAS-DEL-SECTOR-VIVIENDA.pdf [Consulta: 10 de abril de 2018] Morán, E. (2016). Problema aplicativo. [Ejemplo de un presupuesto para viguetas pretensadas como parte del curso Construcción]. Lima. Universidad Peruana de Ciencias Aplicadas.

Mosqueira, M. \& Tarque, S. (2005). Recomendaciones técnicas para mejorar la seguridad sísmica de viviendas de albañilería confinada de la costa peruana. (Tesis para optar el grado académico de Magíster en Ingeniería Civil, Escuela de Graduados, Pontificia Universidad Católica del Perú. Lima, Perú). Recuperado de http://tesis.pucp.edu.pe/repositorio/bitstream/handle/123456789/850/MOSQUEIRA_ MORENO_MIGUEL_SEGURIDAD_SISMICA_COSTA_PERUANA.pdf

[Consulta: 10 de abril de 2018]

Novas, J. (2010). Sistemas constructivos prefabricados aplicables a la construcción de edificaciones en países en desarrollo. (Proyecto de fin de Máster, Escuela Técnica Superior de Ingenieros de Caminos, Canales y Puertos, Universidad Politécnica de Madrid. Madrid, España). Recuperado de 
http://oa.upm.es/4514/1/TESIS_MASTER_JOEL_NOVAS_CABRERA.pdf

[Consulta: 16 de abril de 2018]

Preansa. (s.f.). Productos. Recuperado de http://www.preansa.com.pe/ [Consulta: 10 de abril de 2018]

Prefabricados de Concreto para la Construcción (PRECON). (s.f.). Productos. Recuperado de http://www.precon.com.pe/ [Consulta: 10 de abril de 2018]

Premex. (2015). Construcción a base de vigueta y bovedilla - PREMEX. [Video publicitario]. Recuperado de https://www.youtube.com/watch?v=0jM29EZbuFY [Consulta: 10 de abril de 2018]

Pretensa. (s.f.). Viguetas. Recuperado de https://pretensa.com/ [Consulta: 10 de abril de 2018]

Ramos, J. (2017). Costos y presupuestos en edificación. $13^{\circ}$ ed. Lima: Fondo Editorial Capeco.

Rivera, C. (2014). Manual técnico vigueta pretensada DEACERO. Recuperado de http://imcyc.com/biblioteca/ArchivosPDF/Bovedillas/Manual\%20Tecnico\%20Viguet a\%20presentada\%202004.pdf [Consulta: 10 de abril de 2018]

Servicio Nacional de Capacitación para la Industria de la Construcción (SENCICO). (2010). Curso modular de encofrado - fierreria. Recuperado de https://civilgeeks.com/wp-content/uploads/2015/11/MODULO-2-FASCICULO-6-

ENCOFRAR-LOSA-ALIGERADA-HACER-ARMADURA-PARA-LOSA-

ALIGERADA.pdf [Consulta: 10 de abril de 2018]

Supermix. (s.f.). Productos. Recuperado de https://www.supermix.com.pe/ [Consulta:

10 de abril de 2018]

Tensolite. (s.f.). Manual para la construcción de losas alivianadas de viguetas pretensadas. Recuperado de http://www.tensolite.com.ar/Sis/Contenidos/29.pdf [Consulta: 10 de abril de 2018]

VARGAS, B. (2007). Industrialización de la construcción para la vivienda social. (Estudio de casos: España - Colombia, Madrid: Revista Nodo N`3 - Volumen 2) Recuperado de file:///C:/Users/OSCAR/Downloads/DialnetIndustrializacionDeLaConstruccionParaLaViviendaSoc-3396693.pdf [Consulta: 16 de abril de 2018] 
Viguetas pretensadas S.A.C. \& Avall contratistas (2011). Techos aligerados con viguetas pretensadas VIPRET. Recuperado de https://issuu.com/viguetaspretensadasvipret/docs/boletin_tecnico_de_techos_aligerad o [Consulta: 10 de abril de 2018]

Vipret. (s.f.). Proceso Constructivo. Recuperado de https://www.vipret.org/colocacionde-viguetas [Consulta: 10 de abril de 2018] 